LBNL-51707

\title{
Air Pollutant Monitoring for The East Bay Children's Respiratory Health Study
}

\author{
Final Project Report \\ OEHHA Agreement No. 00-E0018
Brett C. Singer, Toshifumi Hotchi, and Alfred T. Hodgson
Indoor Environment Department
Environmental Energy Technologies Division
E.O. Lawrence Berkeley National Laboratory
1 Cyclotron Road
Berkeley, CA 94720

November 2002

\author{
Submitted To: \\ Janice Kim \\ Project Manager \\ Air Toxicology \& Epidemiology Section \\ Office of Environmental Health Hazard Assessment \\ 1515 Clay Street, $16^{\text {th }}$ Floor \\ Oakland, CA 94612
}

This study was sponsored by the California Environmental Protection Agency, Office of Environmental Health Hazard Assessment through Agreement Number 00-E0018, Exposure to Traffic Pollution/Children's Respiratory Health Study," with E.O. Lawrence Berkeley National Laboratory. Additional support was provided, in part, by the Assistant Secretary for Energy Efficiency and Renewable Energy, Building Technology Program of the U.S. Department of Energy under Contract Number DE-AC03-76SF00098. 


\section{DISCLAIMER}

The statements and conclusions in this report are those of the contractor and not necessarily those of the Office of Environmental Health Hazard Assessment. The mention of commercial products, their source or their use in connection with material reported herein is not to be construed as actual or implied endorsement of such products. 


\section{Table of Contents}

1.0 Introduction

Page No.

2.0 Pollutant Measurements ...................................................................................... 2

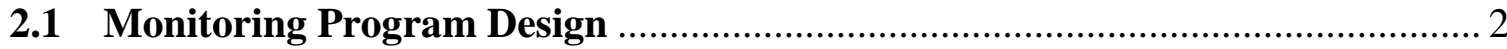

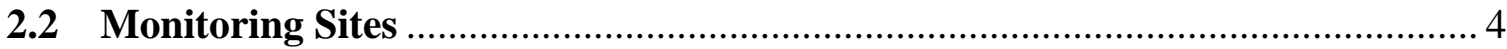

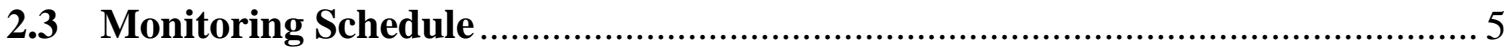

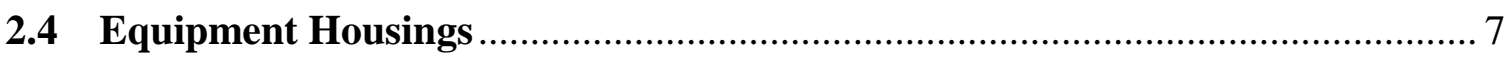

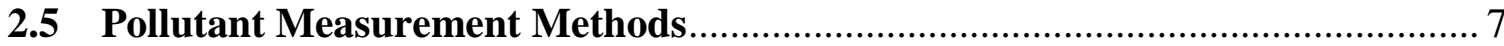

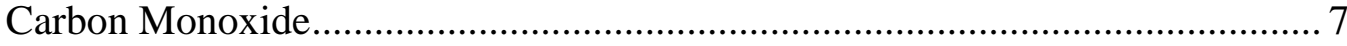

Fine Particle Mass and Black Carbon .......................................................... 9

Temperature and Relative Humidity ............................................................... 14

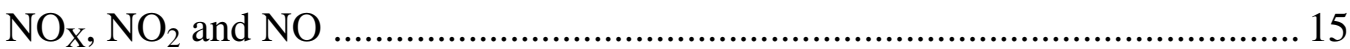

Volatile Organic Compounds.................................................................... 18

Wind Speed and Direction ...................................................................... 21

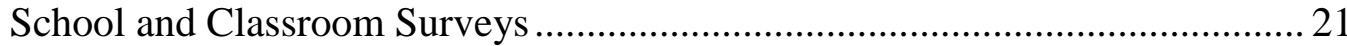

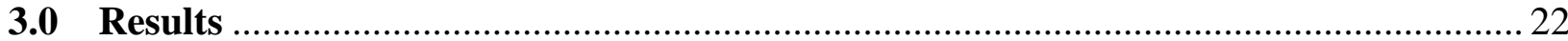

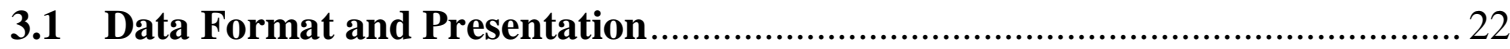

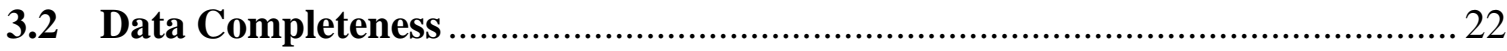

3.3 Comparisons with Ambient Air Quality Standards .................................... 23

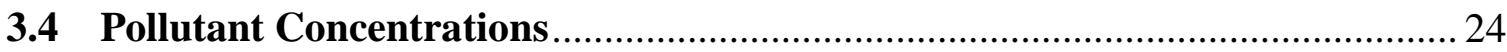

Carbon Monoxide ................................................................................... 24

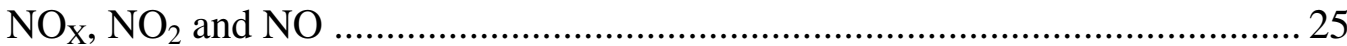

Fine Particle Mass .......................................................................................... 27

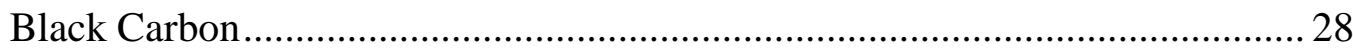

Volatile Organic Compounds............................................................. 28

Indoor versus Outdoor Pollutant Concentrations .......................................... 30

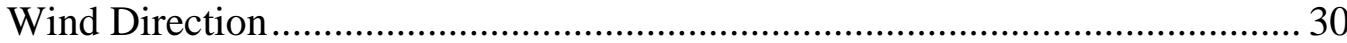

3.5 Correlations among Pollutant Concentrations ............................................ 31

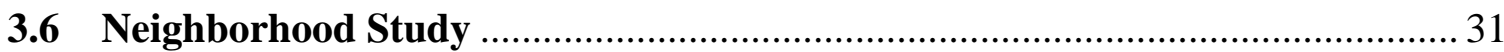

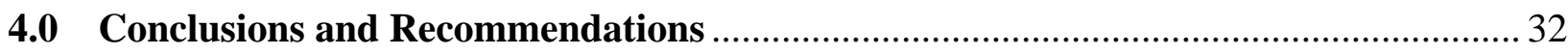

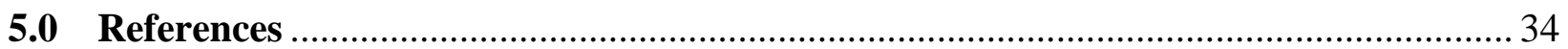




\section{Abstract}

This report describes the methodology and presents the summary results of the air pollutant monitoring program conducted by Lawrence Berkeley National Laboratory in support of the East Bay Children's Respiratory Health Study. The full study is examining the effects of chronic exposure to traffic-related pollutants on respiratory health among $3^{\text {rd }}$ and $4^{\text {th }}$ grade children attending ten neighborhood elementary schools in the San Francisco East Bay Area (Hayward, San Leandro and Oakland, CA). The demographically similar schools are located at varying distances from the I-880 and CA92 freeways. Several schools were selected because they are located within $300 \mathrm{~m}$ in the predominant downwind direction (east) from either of the freeways. Measurements of multiple pollutants were made outdoors at the schools over 1-2 week intervals for 14 weeks in spring and eight weeks in fall 2001 using a custom-designed and validated package of commercially available monitoring equipment.

Particulate matter was sampled over all hours ( $24 \mathrm{~h}$ per day) or during schools hours only with battery-operated programmable pumps and inlet devices for $\mathrm{PM}_{10}$ and $\mathrm{PM}_{2.5}$. These pumps were modified to allow for up to 10 days of continuous operation. Fine particle mass and black carbon (BC) were determined from the collected filters. Nitrogen oxides $\left(\mathrm{NO}_{\mathrm{X}}\right.$ and $\left.\mathrm{NO}_{2}\right)$ were measured with passive samplers. Carbon monoxide (CO) was measured continuously with an electrochemical sensor. Gasoline-related volatile organic compounds (VOCs) were measured with passive samplers during three 4-week intervals in spring 2001 and two 4-week periods in early 2002. All samplers were deployed in a metal cabinet located outside at each school.

Ranges of study average pollutant concentrations (all-hours) at the ten individual schools were: $\mathrm{NO}_{\mathrm{X}}, 33-68 \mathrm{ppb} ; \mathrm{NO}_{2}, 19-31 \mathrm{ppb} ; \mathrm{PM}_{10}$ mass, $27-32 \mu \mathrm{g} / \mathrm{m}^{3} ; \mathrm{PM}_{2.5}$ mass, $12-15 \mu \mathrm{g} / \mathrm{m}^{3}$; and $\mathrm{BC}$ associated with $\mathrm{PM}_{2.5}, 0.6-1.0 \mu \mathrm{g} / \mathrm{m}^{3}$. Although statistical analysis of the data is yet to be performed, some general observations can be made. Absolute pollutant levels varied by season and week, but the simultaneous sampling design allowed for comparisons of concentrations among schools during each interval. Pollutant concentrations at each school were normalized to the sampling period averages among all schools. The normalized concentrations were generally consistent at each school 
throughout the entire study, suggesting that measured differences represent ongoing conditions and chronic exposures in the vicinities of the schools. Substantially elevated concentrations of $\mathrm{NO}_{\mathrm{X}}, \mathrm{NO}_{2}$, and $\mathrm{BC}$, and somewhat elevated concentrations of $\mathrm{PM}_{2.5}$ were observed at one school located less than 100 meters to the east of I-880. Normalized concentrations of $\mathrm{NO}_{\mathrm{X}}, \mathrm{NO}_{2}$, and $\mathrm{BC}$ were also higher at the three other "nearby and downwind" schools relative to those located far from any freeway or other major traffic source.

An ancillary monitoring program was implemented to examine the correlation between school-based pollutant measurements and measurements throughout the neighborhoods adjacent to three of the schools. Volunteer households were obtained from among the families of participating schoolchildren. Concentrations of $\mathrm{NO}_{\mathrm{X}}$ and $\mathrm{NO}_{2}$ were measured with passive samplers outside the homes of these volunteers during one of two 1-week periods in spring 2002. Simultaneous measurements were conducted at all ten of the schools and a central monitoring station during each week. The neighborhoods surrounding two schools were predominantly upwind of the I-880 freeway, while the neighborhood surrounding the other school was downwind from I-880. The overall distribution of concentrations observed for the residences near the downwind school appeared to be substantially higher than the regional background concentrations. The variability observed within the neighborhoods appeared to be, at least in part, explained by the proximity of individual residences to the freeway or other local traffic sources. Results from the neighborhood study generally support the use of school-based concentration measurements to characterize differences among outdoor exposures in different neighborhoods. 


\section{List of Tables}

Page No.

Table 2.1. Summary of target air pollutants and measurement methods ..................................... 35

Table 2.2. Summary of important traffic-related sources nearby to monitoring sites.................... 36

Table 2.3. Spring 2001 sampling schedule for $\mathrm{CO}, \mathrm{PM}$ mass, $\mathrm{BC}, \mathrm{NO}_{\mathrm{X}}$ and $\mathrm{NO}_{2} \ldots \ldots \ldots \ldots \ldots \ldots . . . . . . . . .36$

Table 2.3a. Spring 2001 pollutant monitoring ......................................................................... 37

Table 2.4. Fall 2001 sampling schedule for $\mathrm{PM}$ mass, $\mathrm{BC}, \mathrm{NO}_{\mathrm{X}}$ and $\mathrm{NO}_{2} \ldots \ldots \ldots \ldots \ldots \ldots \ldots \ldots \ldots \ldots \ldots . . . . . . . . . . . . . . . . .37$

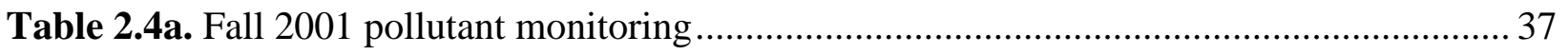

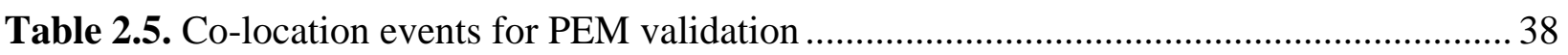

Table 2.6. Response of each PEM relative to event averages ........................................................ 38

Table 2.7. Co-located field samples of $\mathrm{NO}_{\mathrm{X}}$ and $\mathrm{NO}_{2}$ during spring monitoring period.............. 39

Table 2.8. Co-located field samples for $\mathrm{NO}_{\mathrm{X}}$ and $\mathrm{NO}_{2}$ during fall monitoring period ................. 39

Table 2.9. Target VOCs associated with gasoline (group 1) and diesel (group 2) vehicle use.....

Table 2.10. Summary statistics comparing inside versus outside equipment housing deployment of passive VOC samplers, based on analysis of samples from eight schools 40

Table 3.1. Data completeness for spring monitoring period ……………………....................... 42

Table 3.2. Data completeness for fall monitoring period .......................................................... 43

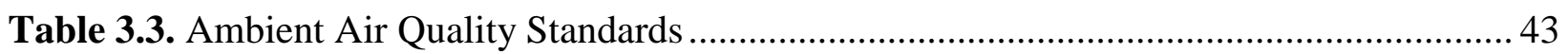

Table 3.4. $\mathrm{NO}_{\mathrm{X}}$ concentrations (ppb) during fall, spring and both periods ................................. 44

Table 3.5. $\mathrm{NO}_{2}$ concentrations (ppb) during fall, spring and both periods .................................. 45

Table 3.6. Normalized $\mathrm{NO}_{\mathrm{X}}$ concentrations during fall, spring and both periods......................... 45

Table 3.7. Normalized $\mathrm{NO}_{2}$ concentrations during fall, spring and both periods ........................ 46

Table 3.8. $\mathrm{PM}_{2.5}$ mass $\left(\mu \mathrm{g} \mathrm{m}^{-3}\right.$ ) for all-hours sampling during fall, spring and

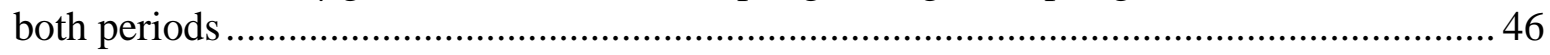

Table 3.9. $\mathrm{PM}_{10}$ mass $\left(\mu \mathrm{g} \mathrm{m}^{-3}\right)$ for all-hours sampling during fall, spring and both periods ....... 47

Table 3.10. Normalized $\mathrm{PM}_{2.5}$ for all-hours sampling during fall, spring and both periods ........ 47

Table 3.11. Normalized $\mathrm{PM}_{10}$ for all-hours sampling during fall, spring and both periods ......... 48

Table 3.12. $\mathrm{PM}_{2.5}$ mass $\left(\mu \mathrm{g} \mathrm{m}^{-3}\right)$ for school-hours sampling during fall, spring and both periods

Table 3.13. $\mathrm{PM}_{10}$ mass $\left(\mu \mathrm{g} \mathrm{m}^{-3}\right)$ for school-hours sampling during fall, spring and both periods

Table 3.14. Normalized $\mathrm{PM}_{2.5}$ for school-hours sampling during fall, spring and both periods 


\section{List of Tables, Continued}

Page No.

Table 3.15. Normalized $\mathrm{PM}_{10}$ for school-hours sampling during fall, spring and both periods.

Table 3.16. $\mathrm{BC}\left(\mu \mathrm{g} \mathrm{m}^{-3}\right)$ from $\mathrm{PM}_{2.5}$ all-hours sampling during fall, spring and both periods....

Table 3.17. $\mathrm{BC}\left(\mu \mathrm{g} \mathrm{m}^{-3}\right)$ from $\mathrm{PM}_{10}$ all-hours sampling during fall, spring and both periods

Table 3.18. Normalized $\mathrm{BC}$ concentrations from $\mathrm{PM}_{2.5}$ for all-hours sampling during fall, spring and both periods

Table 3.19. Normalized $\mathrm{BC}$ concentrations from $\mathrm{PM}_{10}$ for all-hours sampling during fall, spring and both periods

Table 3.20. $\mathrm{BC}\left(\mu \mathrm{g} \mathrm{m}^{-3}\right)$ from $\mathrm{PM}_{2.5}$ school-hours sampling during fall, spring and both periods.

Table 3.21. $\mathrm{BC}\left(\mu \mathrm{g} \mathrm{m}^{-3}\right)$ from $\mathrm{PM}_{10}$ school-hours sampling during fall, spring and both periods.

Table 3.22. Normalized BC concentrations for school-hours sampling during fall, spring and both monitoring periods

Table 3.23. Mean VOC concentrations $\left(\mu \mathrm{g} \mathrm{m}^{-3}\right)$ measured at each school (S1-S10) during 8-12 weeks of passive sampling during spring monitoring period

Table 3.24. Mean VOC concentrations $\left(\mu \mathrm{g} \mathrm{m}^{-3}\right)$ measured at each school (S1-S10) during 8 weeks of passive sampling during winter monitoring (Jan-Feb 2002)

Table 3.25. Correlation coefficients for pair-wise linear relationships for combined spring and fall monitoring data at all schools

Table 3.26. Number of data pairs used to calculate correlation coefficients in Table 3.25 .........57

Table 3.27. Results from neighborhood study at school 6 ................................................ 58

Table 3.28. Results from neighborhood study at schools 3 and 5 


\section{List of Figures}

Page No.

Figure 2.1a. Co-located CO measurements prior to start of spring period ........................................... 61

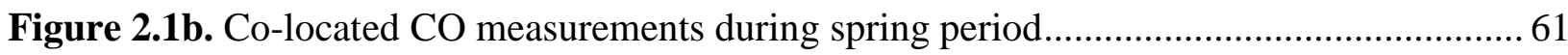

Figure 2.2a. Co-located $\mathrm{CO}$ measurements after completion of spring period; units that agree

Figure 2.2b. Co-located $\mathrm{CO}$ measurements after completion of spring period;

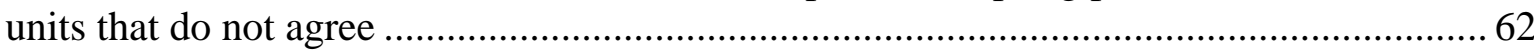

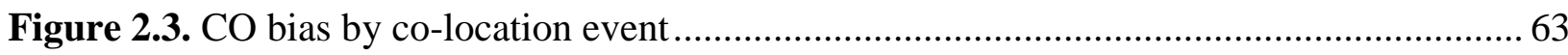

Figure 2.4. Comparison of black carbon quantiation on fiberfilm versus quartz filters ............... 63

Figure 2.5. 2.5- $\mu \mathrm{m}$ Black carbon mass measured in co-location experiments; each unit was normalized to event-average of all units

Figure 2.6. $\mathrm{PM}_{10}$ mass measured in co-location experiments; each unit was normalized to event-average of all units

Figure 2.7. 10- $\mu \mathrm{m}$ Black carbon mass measured in co-location experiments; each unit normalized to event-average of all units.

Figure 2.8a. Effect of inside versus outside equipment housing deployment on $\mathrm{NO}_{\mathrm{X}}$ concentrations during week 1

Figure 2.8b. Effect of inside versus outside equipment housing deployment on $\mathrm{NO}_{2}$ concentrations during week 1

Figure 2.9a. Co-located $\mathrm{NO}_{\mathrm{X}}$ samples analyzed by Ogawa and LBNL laboratories (Week 17)

Figure 2.9b. Co-located $\mathrm{NO}_{2}$ samples analyzed by Ogawa and LBNL laboratories (Week 17)

Figure 2.10. $\mathrm{NO}_{\mathrm{X}}$ concentrations measured by Ogawa passive samplers, deployed in a PVC protective cap and a metal cabinet, and a chemilumiscent analyzer at the BAAQMD Fremont monitoring station in Feb-Apr 2002.

Figure 2.11. $\mathrm{NO}_{2}$ concentrations measured by Ogawa passive samplers, deployed in a PVC protective cap and a metal cabinet, and a chemilumiscent analyzer at the BAAQMD Fremont monitoring station in Feb-Apr 2002

Figure 2.12. $\mathrm{NO}_{\mathrm{X}}$ concentrations measured by Ogawa passive samplers and a chemiluminescent analyzer at the BAAQMD Fremont station in Feb-Apr 2002.

Figure 2.13. $\mathrm{NO}_{2}$ concentrations measured by Ogawa passive samplers and a chemiluminescent analyzer at the BAAQMD Fremont station in Feb-Apr 2002 ................ 70

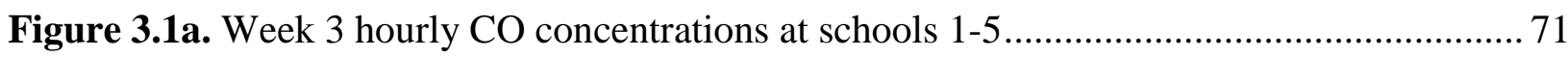

Figure 3.1b. Week 3 hourly $\mathrm{CO}$ concentrations at schools 6-10 ............................................... 71

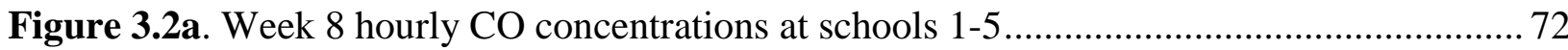




\section{List of Figures, Continued}

Page No.

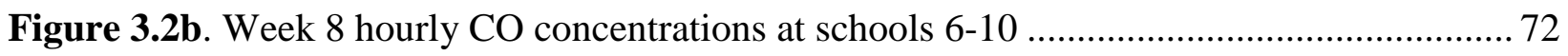

Figure 3.3. Mean CO concentrations averaged over all hours of each week ............................... 73

Figure 3.4. Mean CO concentrations averaged over school-hours of each week ......................... 73

Figure 3.5. Deviations (ppm) between individual school and weekly mean $\mathrm{CO}$ concentrations during all-hours sampling............................................................... 74

Figure 3.6. Deviations (ppm) between individual school and weekly mean

CO concentrations during school-hours sampling ............................................................ 74

Figure 3.7. Weekly average $\mathrm{NO}_{\mathrm{X}}$ concentrations during spring period ....................................... 75

Figure 3.8. Weekly average $\mathrm{NO}_{2}$ concentrations during spring period .......................................... 75

Figure 3.9. Weekly average NO concentrations during spring period ........................................ 76

Figure 3.10. $\mathrm{NO}_{\mathrm{X}}$ normalized to weekly mean at all schools during spring period ........................ 76

Figure 3.11. $\mathrm{NO}_{2}$ normalized to weekly mean at all schools during spring period....................... 77

Figure 3.12. NO normalized to weekly mean at all schools during spring period........................ 77

Figure 3.13. Weekly average $\mathrm{NO}_{\mathrm{X}}$ concentrations during fall period............................................ 78

Figure 3.14. Weekly average $\mathrm{NO}_{2}$ concentrations during fall period ........................................ 78

Figure 3.15. Weekly average NO concentrations during fall period........................................... 79

Figure 3.16. $\mathrm{NO}_{\mathrm{X}}$ normalized to weekly mean at all schools during fall period............................ 79

Figure 3.17. $\mathrm{NO}_{2}$ normalized to weekly mean at all schools during fall period ........................... 80

Figure 3.18. NO normalized to weekly mean at all schools during fall period............................. 80

Figure 3.19. $\mathrm{PM}_{2.5}$ mass concentrations for all-hours sampling during spring period .................. 81

Figure 3.20. $\mathrm{PM}_{10}$ mass concentrations for all-hours sampling during spring period................... 81

Figure 3.21. $\mathrm{PM}_{2.5}$ for all-hours sampling normalized to weekly mean at all schools

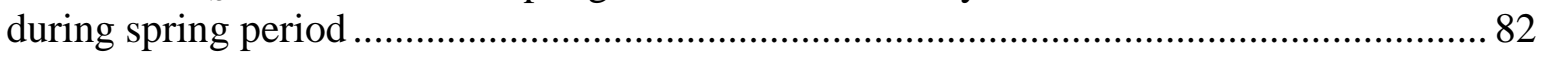

Figure 3.22. $\mathrm{PM}_{10}$ for all-hours sampling normalized to weekly mean at all schools

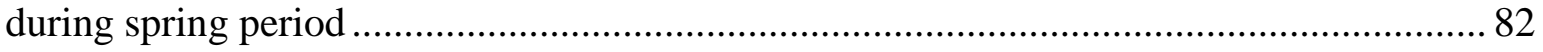

Figure 3.23. $\mathrm{PM}_{2.5}$ mass concentrations for school-hours sampling during spring period ........... 83

Figure 3.24. $\mathrm{PM}_{10}$ mass concentrations for school-hours sampling during spring period ............ 83

Figure 3.25. $\mathrm{PM}_{2.5}$ for school-hours sampling normalized to weekly mean at all schools

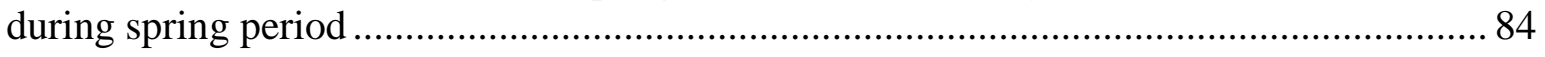

Figure 3.26. $\mathrm{PM}_{10}$ for school-hours sampling normalized to weekly mean at all schools

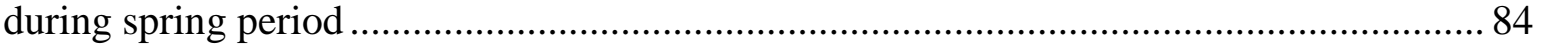

Figure 3.27. $\mathrm{PM}_{2.5}$ mass concentrations for all-hours sampling during fall period....................... 85

Figure 3.28. $\mathrm{PM}_{10}$ mass concentrations for all-hours sampling during fall period ...................... 85 


\section{List of Figures, Continued}

Page No.

Figure 3.29. $\mathrm{PM}_{2.5}$ for all-hours sampling normalized to weekly mean at all schools

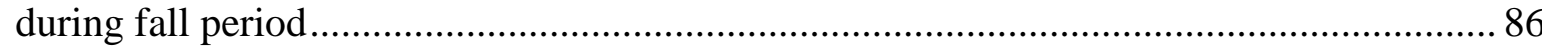

Figure 3.30. $\mathrm{PM}_{10}$ for all-hours sampling normalized to weekly mean at all schools during fall period

Figure 3.31. 2.5- $\mu \mathrm{m} \mathrm{BC}$ for all-hours sampling normalized to weekly mean at all schools during spring period

Figure 3.32. 10- $\mu \mathrm{m} \mathrm{BC}$ for all-hours sampling normalized to weekly mean at all schools during spring period

Figure 3.33. 10- $\mu \mathrm{m} \mathrm{BC}$ for school-hours sampling normalized to weekly mean at all schools during spring period

Figure 3.34. 2.5- $\mu \mathrm{m} \mathrm{BC}$ for all-hours sampling normalized to weekly mean at all schools during fall period

Figure 3.35. 10- $\mu \mathrm{m} \mathrm{BC}$ for all-hours sampling normalized to weekly mean at all schools during fall period.

Figure 3.36. $2.5-\mu \mathrm{m}$ and $10-\mu \mathrm{m} \mathrm{BC}$ for school-hours sampling normalized to weekly mean at all schools during fall period.

Figure 3.37. 2.5- $\mu \mathrm{m}$ and $10-\mu \mathrm{m}$ Black carbon concentrations during week 1 ............................. 90

Figure 3.38. $2.5-\mu \mathrm{m}$ and $10-\mu \mathrm{m}$ Black carbon concentrations during week 2 ............................ 90

Figure 3.39. Mean ( \pm Stdev.) relative concentrations for 12 gasoline-related VOCs during spring period …………………...................................................................... 91

Figure 3.40. Methylcyclopentane concentrations during spring period ...................................... 92

Figure 3.41. 2,2,4-Trimethylpentane concentrations during spring period ................................. 92

Figure 3.42. Benzene concentrations during spring period....................................................... 93

Figure 3.43. $m$,p-Xylene concentrations during spring period................................................. 93

Figure 3.44. 1,2,4-Trimethylbenzene concentrations during spring period ................................. 94

Figure 3.45. n-Undecane concentrations during spring period .................................................... 94

Figure 3.46. Mean ( \pm Stdev.) relative concentrations for 13 gasoline-related VOCs in

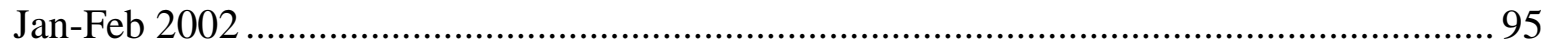

Figure 3.47. $\mathrm{NO}_{\mathrm{X}}$ concentrations measured in one classroom and outdoors at each school........ 96

Figure 3.48. $\mathrm{NO}_{2}$ concentrations measured in one classroom and outdoors at each school ........ 96

Figure 3.49. $\mathrm{PM}_{2.5}$ mass concentrations measured in one classroom and outdoors at each school

Figure 3.50. $\mathrm{PM}_{10}$ mass concentrations measured in one classroom and outdoors at each school 


\section{List of Figures, Continued}

Page No.

Figure 3.51. 10- $\mu \mathrm{m} B C$ concentrations measured in one classroom and outdoors at each school

Figure 3.52. Mean wind direction during all-hours or school-hours for each one- or two-week sampling period

Figure 3.53. Hourly mean wind direction by month for June through December 2000; months are listed by number

Figure 3.54. Hourly mean wind direction by month for January through June 2001; months are listed by number

Figure 3.55. Hourly mean wind direction by month for July through December 2001; months are listed by number 100

Figure 3.56. Hourly mean wind direction by month for January through May 2002; months are listed by number

\section{List of Appendices}

Page No.

Appendix A. Photographs of School Monitoring Sites and Equipment Housing and Diagrams of PEM Impactor and $\mathrm{NO}_{\mathrm{X}}$ Sampler.

Appendix B. Deployment Records for Carbon Monoxide Instruments and PEM Impactors

Appendix C. Plots of Hourly Average Carbon Monoxide (CO) Concentrations at All Schools Over Spring Monitoring Period.

Appendix D. Plots of Hourly Average Carbon Monoxide (CO) Concentrations at All Schools Over Fall Monitoring Period 


\section{Acknowledgements}

This study was sponsored by the California Environmental Protection Agency, Office of Environmental Health Hazard Assessment through Contract Number 00-E0018, "Exposure to Traffic Pollution/Children's Respiratory Health Study," with E.O.

Lawrence Berkeley National Laboratory. This work additionally was supported, in part, by the U.S. Department of Energy under Agreement Number DE-AC03-76SF00098. The authors thank Derek Shendell of LBNL for conducting the classroom surveys, David Behnken and Marion Russell, also of LBNL, for assistance with laboratory analyses, and Gary Zoppo of the Bay Area Air Quality Management District for assistance with the $\mathrm{NO}_{\mathrm{X}} / \mathrm{NO}_{2}$ method intercomparison study. The study could not have been completed successfully without the generous assistance of numerous school personnel and the residential volunteers. 


\subsection{Introduction}

As part of the larger "Clean Air for California Communities" initiative, the Office of Environmental Health Hazard Assessment (OEHHA), a division of California's Environmental Protection Agency (Cal EPA), is studying the effects of chronic exposure to traffic-related pollutants on the respiratory health of California's children. In support of this objective, OEHHA contracted with the Environmental Energy Technologies Division of Lawrence Berkeley National Laboratory (LBNL) to lead in the planning and implementation of a comprehensive air monitoring program. The overall objective was to assess the absolute and relative exposure levels for a population of $3^{\text {rd }}$ and $4^{\text {th }}$ grade children including sub-populations chronically exposed to lower and higher traffic-related pollutant levels. LBNL specifically was asked to measure pollutant concentrations to study the following research questions (abridged):

1. Within a geographic area with approximately uniform levels of regional air pollution, are there significant differences in ambient concentrations of traffic-related air pollutants adjacent to major roadways compared with sites further away?

2. Are children with increased exposure to traffic-related emissions at increased risk of adverse respiratory health effects?

3. Is exposure to diesel-related emissions, as measured by elemental carbon and nitrogen oxides or by local truck traffic density, a stronger predictor of adverse respiratory health outcomes than overall traffic-related emissions?

The respiratory health study is focused on student populations at ten neighborhood elementary schools in Hayward (6), San Leandro (3), and Oakland (1). The schools were selected by OEHHA in consultation with LBNL. They are located at varying (predominant) downwind distances from freeways and other major roadways. Previous studies have shown traffic-related pollutant concentrations and, therefore, exposures are often higher at schools and neighborhoods adjacent to, and downwind from freeways and high-traffic roadways.

The monitoring program focused on pollutants that are primarily or substantially produced from motor vehicle use, i.e. traffic. These pollutants were carbon monoxide (CO), nitrogen oxides ( $\mathrm{NO}_{\mathrm{X}}$ and $\mathrm{NO}_{2}$ ), individual volatile organic compounds (VOCs) associated with gasoline and diesel vehicles, fine particulate matter (PM) and black carbon (BC), which is the carbonaceous, light absorbing portion of PM commonly referred to as soot. Carbon monoxide 
and nitrogen oxides are formed during both gasoline and diesel fuel combustion. These pollutants are largely removed by emission control systems of 1980s and later-model gasolinepowered vehicles, but are emitted in large amounts from older and malfunctioning gasoline vehicles. Diesel vehicles produce $\mathrm{CO}$ at relatively low levels, but are a major source of $\mathrm{NO}_{\mathrm{X}}$ and the major source of urban ambient black carbon, even though BC can be produced from oil burned in malfunctioning gasoline engines. VOCs are emitted as the result of incomplete fuel combustion in gasoline and diesel vehicles and by fuel evaporation from in-use and stationary vehicles and during fuel distribution. While gasoline vehicles contribute more to the total mass of traffic-related VOCs in urban areas, the specific compounds emitted (speciation) differ for gasoline and diesel vehicles. As a result, exposure to emissions from each type of vehicle may be evaluated by quantifying compounds that are specific to each. Direct PM emissions associated with vehicle operation are believed to be responsible for only a fraction of ambient PM mass concentrations. Yet, there is some evidence that particle concentrations may be elevated directly downwind from busy freeways and roadways. Fine PM mass was measured also because of the established association between mass concentrations and respiratory health effects.

The extent to which local pollutant concentrations correlate to traffic proximity will depend on regional background pollutant levels, overall mass emission levels at the roadway (a function of traffic density and vehicle emission rates), dilution (the amount of clean air into which the roadway emissions mix), and the presence of other local sources.

\subsection{Pollutant Measurements}

\subsection{Monitoring program design}

The measurement program included two multi-month periods during which most of the pollutants were measured at all ten schools simultaneously in spring and fall, 2002; a supplemental two-month period of VOC monitoring at all schools during Jan-Feb, 2002; and a spring 2002 effort to characterize $\mathrm{NO}_{2}$ and $\mathrm{NO}_{\mathrm{X}}$ concentrations in the neighborhoods surrounding several of the schools. Pollutant concentrations were measured primarily using fixed-site monitors located outside at the schools. A combination of passive and active sampling methods were used to measure time-resolved concentrations of $\mathrm{CO}$, and time integrated concentrations of fine particle mass, black carbon, nitrogen oxides $\left(\mathrm{NO}_{\mathrm{X}}\right)$, nitrogen dioxide 
$\left(\mathrm{NO}_{2}\right)$, and volatile organic compounds (VOCs). Particulate matter was sampled with programmable pumps using inlet devices that limited collection to particles with aerodynamic diameters smaller than $10 \mu \mathrm{m}\left(\mathrm{PM}_{10}\right)$ and $2.5 \mu \mathrm{m}\left(\mathrm{PM}_{2.5}\right)$. Fine particle mass and black carbon (BC) were determined from the collected filter samples. The pumps were set to sample either during "all hours" (24 hours a day for the duration of the sampling period) or during "school hours" only (08:00-13:00 on Wednesday and 08:00-15:00 of the other weekdays). Air temperature and relative humidity $(\mathrm{RH})$ were measured and recorded at each site. Measurement methods are summarized in Table 2.1 and described below. Company and product names are provided for identification purposes only.

The monitoring program was designed to best satisfy several competing objectives and limitations. Monitoring conducted over a relatively long time period is required to accurately characterize chronic exposures to pollutants generated outdoors because daily or weekly concentrations at a given site are determined largely by meteorology. For example, pollutant concentrations may be considerably higher at a "lower-exposed" school on a day with poor atmospheric mixing (i.e. less dilution of emitted pollutants) compared with a "higher-exposed" school on a day with better atmospheric mixing, as shown in the Results section. Likewise, a short-term shift in wind direction may result in lower pollutant levels at sites that experience higher long-term average pollutant concentrations. Personal sampling over relatively long periods to determine chronic exposures of individual children and long-term measurements of pollutants in many microenvironments were deemed infeasible. Schools were selected as the best monitoring locations since elementary school children typically are present at their schools for seven or more hours per day and most live nearby to the schools. By focusing on a single monitoring location per school/neighborhood, we were able to collect more samples over a longer time period; allowing for a more accurate assessment of absolute pollutant concentrations at one central neighborhood site and relative pollutant levels among the schools/neighborhoods. Monitoring for $\mathrm{NO}_{\mathrm{X}}$ and $\mathrm{NO}_{2}$ was conducted in neighborhoods surrounding three of the schools to investigate how concentrations throughout the neighborhoods correlate with those measured at the schools.

Concentrations of some of the pollutants sampled are likely to be different indoors versus outdoors, due to indoor loss mechanisms and potential sources. We conducted one-week of 
simultaneous indoor-outdoor sampling in one classroom at each school and surveyed some of the important physical and operational characteristics of all classrooms occupied by the students involved in the study. More extensive indoor sampling was not achievable with the available resources.

\subsection{Monitoring Sites}

Ten public elementary schools were selected within the cities of Oakland, San Leandro and Hayward, CA. They are coded as schools 1-10 in this report. Their identities have been provided to OEHHA under separate cover. By design, the schools are located at varying downwind distances from freeways and major roadways so that the group is likely to contain "higherexposed" and lower-exposed" schools. The predominant wind direction in this region is from the Pacific Ocean and San Francisco Bay, which lie to the west. Selected schools include three that are "downwind" within $300 \mathrm{~m}$ of Interstate-880, the East Bay freeway with the highest traffic density and a fourth that is within $300 \mathrm{~m}$ and generally downwind of California 92, which feeds a cross-bay bridge and experiences heavy commute traffic (this school is also within $300 \mathrm{~m}$ and generally upwind of I-880). Table 2.2 summarizes the proximity of the sampling site at each school to large freeways. OEHHA staff is analyzing the potential importance of other nearby roadways.

Sampling sites at the schools were selected based on a number of criteria. Not all of these were achieved at all of the schools. Criteria for an ideal site were:

1. Centrally located in relation to classrooms and play areas;

2. >50 m away from large parking lots, bus stops, student pickup areas, and loading docks;

3. Good air circulation, i.e. not placed in nooks and corners of buildings;

4. Preferably under a building overhang for best weather protection;

5. Availability of structure/fence to attach cabinet for seismic and theft security;

6. Unobtrusive to students and school staff; and

7. Preferably out of sight to passers-by.

Photographs of the specific locations selected at the schools are presented in Appendix A. 


\subsection{Monitoring Schedule}

Spring monitoring occurred over 14 weeks in March-June 2001. The strategy focused on longterm monitoring outside at all schools simultaneously. Except for problems at individual schools, there were 7 weeks in which all pollutants were measured during all hours at all schools. Table 2.3 summarizes the schedule for $\mathrm{CO}, \mathrm{PM}$ mass, $\mathrm{BC}, \mathrm{NO}_{\mathrm{X}}$ and $\mathrm{NO}_{2}$. Fine particles were sampled simultaneously at all schools during school hours for five weeks, divided into two 2-week and one 1-week sampling periods. Passive $\mathrm{NO}_{\mathrm{X}}$ and $\mathrm{NO}_{2}$ samplers were exposed during all hours of these weeks. Hourly-average CO measurements were calculated for both school-hours and allhours for all sampling periods. Simultaneous indoor-outdoor measurements were made over two 1-week periods in the spring. Indoor-outdoor sampling occurred at schools 2, 3, 4, 7, and 8 during week 7 and at the remaining five schools during week 9. Outdoor VOC samples were collected over three 4-week periods, starting on weeks 1, 5 and 9. Sampling periods routinely started and ended on Wednesday afternoon, taking advantage of early student dismissal on that day. Two groups of five schools were visited in parallel by two field technicians. Schools were usually visited in the same order each week to maximize the uniformity of sampling periods among the schools. Visits occurred over a 3-6 hour window, starting at approximately 13:00. Sampling periods were ended one day early before each of the indoor-outdoor sampling events. During these weeks, each site was visited on Tuesday afternoon to retrieve samples and sampling equipment. Equipment and new samplers were then re-deployed at indoor and outdoor locations on Wednesday afternoon.

The fall monitoring period occurred over eight consecutive weeks, between September 26 and November 21, 2001 as summarized in Table 2.4. The eight sampling weeks are numbered 15-22 to distinguish them from the spring sample weeks. Sampling periods again started and ended on Wednesday afternoon, corresponding to early class dismissal. Concentrations of nitrogen oxides $\left(\mathrm{NO}_{\mathrm{X}}\right)$ and nitrogen dioxide $\left(\mathrm{NO}_{2}\right)$ were measured over all hours during each of the eight weeks. Fine particle samples were collected over all hours or over school hours. Allhours samples were collected over one-week periods while school-hours samples were collected over two-week periods. In contrast to the spring schedule, $\mathrm{PM}_{10}$ and $\mathrm{PM}_{2.5}$ sampling periods were alternated such that one size cut was used for all-hours sampling while the other was used for school-hours sampling (see Table 2.4). This allowed for all-hours particle mass and black carbon measurements during each week of sampling. But as a result, the fall data do not include 
simultaneous measurements of $\mathrm{PM}_{10}$ and $\mathrm{PM}_{2.5}$. The decision to place more emphasis on the measurement of black carbon was made based on a preliminary analysis of the spring data. This analysis indicated that black carbon associated with $\mathrm{PM}_{10}$ and $\mathrm{PM}_{2.5}\left(\mathrm{BC}_{10}\right.$ and $\left.\mathrm{BC}_{2.5}\right)$ was correlated with the traffic-related pollutants $\mathrm{NO}_{2}$ and $\mathrm{NO}_{\mathrm{X}}$. Carbon monoxide was measured continuously during weeks 16-22, but the monitors were not calibrated each week as they were in the spring. $\mathrm{CO}$ data for the fall monitoring period were collected primarily to serve as an indicator of major nearby combustion-related air pollution events (e.g., fires). The data also provide information about temporal CO patterns at each location, but cannot be used for site-tosite comparisons due to the lack of periodic calibration. VOCs were measured during two 4week periods using a modified deployment protocol as described below. This protocol, which was aimed at improving our ability to quantify diesel-related VOCs, was found to be problematic when the samples were analyzed. In response, we initiated a supplemental two-month period of VOC monitoring during Jan-Feb 2002 in which VOC samplers were deployed with the original spring protocol; results were obtained for gasoline-related VOCs only.

A third monitoring effort was conducted in Mar-Apr 2002 in the neighborhoods surrounding three of the schools. The objective of this study component was to investigate the degree to which concentrations measured at the schools are predictive of concentrations throughout the surrounding neighborhoods where the study population lives. Passive monitors for $\mathrm{NO}_{\mathrm{X}}$ and $\mathrm{NO}_{2}$ were deployed outside at the residences of selected families of study participants. During the first week, monitors were deployed at 16 households in the neighborhood of school 6, at all ten of the study schools, and at the BAAQMD Fremont monitoring station. During the second week, monitors were deployed at 25 households and one additional school in the adjoining neighborhoods of schools 3 and 5, and again at all study schools and the Fremont monitoring site. The neighborhoods monitored during the second week are on opposite sides of I-880. On the deployment day, samplers were first deployed at the Fremont station, then at the schools, then at the residences over a total period of approximately six hours. Duplicate samplers were deployed at the Fremont station and at each school in the neighborhood(s) being studied. The school duplicates were offset in time with one deployed before and the other after the neighborhood samples. Samplers were left in the field for one full week and were collected in the same general order (Fremont station, schools, and 
neighborhoods), except that the neighborhood samplers were collected in parallel by two technicians. Total collection time was approximately four hours.

\subsection{Equipment Housings}

Monitoring equipment and instruments were housed in metal cabinets purchased from a used office furniture supplier. The cabinets were 90-cm wide, $45-\mathrm{cm}$ deep, and 180-cm high (36" $\times$ 18 " $\times 72$ "). Cabinets were modified to increase the air exchange with the outside environment. 18 by $30-\mathrm{cm}$ sections were cut from the upper portion of the two cabinets sides over which we fastened louvered heating vent covers. The $\mathrm{CO}$ monitor, filter sampling pumps, and T/RH sensor were placed on a shelf just below the louvered vent covers. Two circular holes were cut in the middle of the cabinet top. The short, cylindrical particle size-selective inlets (PEMs) were inserted through these holes so they sampled from the outside environment. Each PEM impactor unit was supported underneath with a small plate that could be lowered and raised with wing nuts. A small plate was mounted $\sim 5 \mathrm{~cm}$ above the cabinet top, just to the side of the PEM holes, to which passive $\mathrm{NO}_{\mathrm{X}}, \mathrm{NO}_{2}$ and VOC samplers were attached for sampling outside of the cabinet. Passive samplers were clipped on or adjacent to the louvered vent covers when deployed inside the cabinets. A 100 by $55-\mathrm{cm}$ plate of aluminum was mounted on four posts $10 \mathrm{~cm}$ above the top of the cabinet to protect impactor inlets and passive samplers from sun and rain. An equipment housing cabinet with monitors and pumps is shown in Appendix A.

For neighborhood monitoring, passive $\mathrm{NO}_{\mathrm{X}}-\mathrm{NO}_{2}$ samplers were housed within small specially constructed housings. Each housing consisted of a 3-inch diameter PVC plumbing cap with an L-bracket attached inside to hold a passive sampler body. Three I-hooks were mounted on the sides and the top to allow for the housing to be attached to a wide variety of structures using plastic tie wraps. Housings were tied to tree limbs, fences, railings, or freestanding wooden stakes at heights of 1-2 m from the ground. Detailed information about placement was collected for each sampler; a digital photograph was also recorded for each.

\subsection{Pollutant Measurement Methods}

Carbon Monoxide. $\mathrm{CO}$ was measured in real time at each site using the Langan Products, Inc. Model T15d CO Enhanced Personal Exposure Measurer. The T15d device combines a Citicell@

electrochemical sensor with a Databear ${ }^{\mathrm{TM}}$ datalogger, which can measure and record temperature 
and $\mathrm{CO}$ at two resolution levels; the higher range is $0-120 \mathrm{ppm}$ at $1 \mathrm{ppm}$ resolution, the lower range is $0-12 \mathrm{ppm}$ at $0.05 \mathrm{ppm}$ resolution. The T15d device continuously monitors the voltage that results from the reaction of diffusing $\mathrm{CO}$ with the electrochemical sensor, recording one measurement each second or at less frequent intervals specified with software provided by the manufacturer. Time-response is on the order of 30-60 seconds. Data were recorded every 60 seconds for temperature and $\mathrm{CO}$ on the $0-12 \mathrm{ppm}$ scale, allowing ten days of data storage. Data were downloaded as 60-min averages or as Databear files for later analysis. CO monitors numbered 1-10 were generally deployed at schools 1-10, respectively, except for the 2 weeks of indoor-outdoor measurements.

Instrument calibrations were set at the beginning of the spring sampling program and adjusted each week as needed, using software to change the linear parameters relating voltage to CO. Zero and span values were initially set and checked using small, pressurized cylinders that contained $\sim 0.3$ and 5.0 ppm CO (Scott Specialty Gases, Inc.). Since this procedure was too timeconsuming given the tight schedule of field visits, we instead brought the instruments back to LBNL each week to zero them in batch mode using a glass tank supplied with "ultrapure" air $(\mathrm{CO}<0.03 \mathrm{ppm})$. The instruments were returned to the field sites before the afternoon commute on Thursday. As a result, CO data for the spring generally covers a period of six days for each 1-week period. Zero calibrations generally drifted by less than 0.2 ppm over a 1-2 week period. Raw data were adjusted using the average of zero offsets measured before and after each sampling period. Span values were checked at the end of the sampling program. Unit 2 was $14 \%$ high, unit 8 was $16 \%$ high and all other units reported within $8 \%$ of the calibration standard.

Quantitative CO data are available for all sample periods listed in Table 2.3 with a few exceptions. No data were collected at school 10 during weeks 1-2. Unit 9 was destroyed in act of vandalism at school 9, during week 9; a spare unit (0) was deployed at school 9 for weeks 11-14. Also, CO was sampled at the schools for only 1 week of the two-week period starting on week 5. All but one of the CO units was co-located in a Berkeley household for the second week of that period to check the intercomparability of the instruments. Appendix B, Table B-1 provides a record of the $\mathrm{CO}$ units used each week at each school during the spring period.

Figures 2.1a, 2.1b, 2.2a and 2.2b show one-hour average CO concentrations reported by co-located units for approximate 1-week periods before, during, and after the spring monitoring 
program. Excellent agreement was observed during the first two events, except unit 5 showed a higher threshold and did not register very low CO concentrations (Figure 2.1b). Co-located measurements after the completion of the spring monitoring program reveal that most units continued to track one another, albeit with a wider deviation (Figure 2.2a), but units 4, 6, and 7 deviated substantially from the others (Figure 2.2b). Close examination of hourly CO plots for each week of spring sampling (Appendix C) and the CO deployment schedule suggests inconsistent behavior of some of the instruments. For example, school 7 appear to have different trends than the other schools during weeks 1-4 and 11-14, when measured with unit 7, but similar trend to the other schools during weeks 5, 7, 8, 10 with unit 0 . However, as shown below, unit 7 behaved consistently to other units in co-location events 1-2 (before field deployment) and event 3 during week 6 of the field deployment. The overall bias of each unit relative to the event average $\mathrm{CO}$ concentrations is presented in Figure 2.3.

Fine Particle Mass and Black Carbon. Fine particle samples were collected on Pallflex fiberfilm $37 \mathrm{~mm}$ filters (Pall/Gelman), using Airchek 2000 personal sampling pumps (SKC Inc.) and Personal Environmental Monitor (PEM) impactors for size selection at 2.5 and $10 \mu \mathrm{m}$ (MSP Corp.). A schematic of the PEMs is shown in Appendix A. Pumps and PEMs were numbered and the same pump/PEM combinations were generally used throughout the study.

It was necessary to modify the Airchek 2000 pumps for battery-powered operation over 1-week sample periods because the stock 4.8-V, $2.0 \mathrm{amp}-\mathrm{hr}$ rechargeable NiCd battery is designed to run for only 8 hours on a single charge. We used commercially available 12-V, 33 amp-hr lead-acid batteries together with custom-fabricated $12 \mathrm{~V}$-to-5V converters to supply power to the pumps. Samples were drawn at a nominal $2000 \mathrm{cc} \mathrm{min}^{-1}$ as required for the PEMs. Pumps were calibrated at the beginning of each sample period using a BIOS International Drycal DC-Lite with CalCheck Communicator adapter (SKC Inc.) that provides direct communication between the calibrator and a pump. The pumps were calibrated with the filter-loaded PEMs inline using a special calibration cap that fits over the face of the impactor (MSP Corp.). The pumps include temperature and pressure correction for constant volume sampling. Flows were checked and recorded at the end of each sampling period. For all hours sampling, pumps ran continuously between site visits (approximately 168 hours). The pumps' internal scheduler was used to start and stop the pumps during school hours sampling. The history feature of the pump 
software was checked at the end of each period to confirm sampling occurred as scheduled. When set for school-hours sampling, the pumps were turned on for a few minutes to check the flow at the end of the sampling period.

Filters were pre-weighed before sampling then weighed again after sampling using a Cahn 21 Automatic Electrobalance. Each filter used for mass analysis was weighed on two separate occasions both before deployment and after recovery from field sampling. The purpose of this procedure was to confirm accurate weighing and reporting. Pre-sampling filter masses differed by more than $5 \mu \mathrm{g}$ for only six of the 135 filters used (120 samples plus 15 field blanks) during the fall monitoring period. Post-sampling filter masses determined from the two weighing events differed by more than $5 \mu \mathrm{g}$ for only one filter (fall data). All differences were less than 10 $\mu \mathrm{g}$ in the fall. Overall, the pre-sampling masses differed by $0.3 \pm 3.3 \mu \mathrm{g}$, and the post-sampling masses differed by $0.5 \pm 2.1 \mu \mathrm{g}$ (mean \pm 1 stdev) for all fall samples.

The net mass on each filter, calculated as the difference between pre- and post-sample masses, was divided by the sample air volume to calculate the mass concentration for each sample. Since they do not readily absorb water, fiberfilm filters are generally much less sensitive than quartz filters to variations in ambient relative humidity. Nevertheless, filters were equilibrated for a minimum of three hours at $\mathrm{T}=21 \pm 3 \mathrm{C}$ and $\mathrm{RH}=30-40 \%$ for at least one weighing. A subset of ten laboratory standard filters was checked at each weighing to confirm consistent operation of the balance. Measurement uncertainty was approximately 5-10 $\mu \mathrm{g}$, based on repeat weighing of lab standards and sample filters. The calibration of the scale appears to have shifted by $6 \mu \mathrm{g}$ at one point in the middle of the spring sampling program, based on very consistent standard filter weights before and after this point. The cause of this shift is not known, but it should have a minimal effect on our results for three reasons: (a) all filters from a given sample period were always weighed together; (b) the shift is within the measurement uncertainty of the instrument; and (c) collected mass on most filter samples was more than 10x this value. Filters were stored and transported in labeled, 50-mm diameter petri dishes (Pall/Gelman). Sample filters were removed from the PEMs on-site, using the cabinet as protection from wind and contamination, and the shelf as a working surface. After flows were checked, each PEM was disconnected from the pump, removed from the top of the cabinet, and placed on a clean Kimwipe napkin. One at a time, each PEM was opened and the sample filter replaced directly 
into the labeled petri dish. A clean, pre-weighted filter was then loaded for the next sample, and the filter number was recorded on a log sheet.

The contamination associated with filter handling was evaluated by collecting two field blanks during each week of the fall monitoring period (two field technicians each collected one blank each week). Field blanks were handled identically to sample filters except that no air was pumped through them. Each field blank filter was taken to the field and inserted into a PEM sizeselective inlet at a sampling site. The PEM inlet was closed fully with the filter inside. The filter was then removed from the PEM, stored in its designated case, and transported with other samples back to the laboratory. A total of 15 field blanks were recovered. One intended field blank was used to collect a sample when a planned sample filter was dropped at one of the sites. The mass differences measured before and after deployment of the 15 field blanks ranged from 0 to $8 \mu \mathrm{g}(4.1 \pm 2.8 \mu \mathrm{g})$. For comparison, the collected fine particle masses were in the range of 242-339 and 87-229 $\mu \mathrm{g}$ for $\mathrm{PM}_{10}$ and $\mathrm{PM}_{2.5}$, respectively during school-hours sampling, and 521799 and 153-389 $\mu \mathrm{g}$ for $\mathrm{PM}_{10}$ and $\mathrm{PM}_{2.5}$, respectively during all-hours sampling in the fall.

Black carbon was quantified with a light attenuation method developed at LBNL. The technique as outlined by Gundel et al. (1984) measures the attenuation of light as it passes through a filter containing sample particles. Specifically, we measured the intensity of light passing through a defined area of a sample filter (I) and the intensity of light passing through a same-sized clean section of the same filter or similar filters (Io). Light attenuation (ATN) was calculated using Equation 1:

$$
\mathrm{ATN}=-100 * \ln (\mathrm{I} / \mathrm{Io})
$$

Gundel et al. showed that the attenuation measurement is proportional to black carbon as determined by evolved gas analysis (EGA) in which the particle sample is gradually heated in oxygen to first liberate organic carbon then later the more refractory material referred to as black carbon. EGA is one of several similar methods used to measure the carbonaceous fraction of ambient particulate matter that are referred to as either elemental or black carbon. In our study, a standard GE soft white $15 \mathrm{~W}$ incandescent bulb was used as a light source and a photodiode connected to a voltmeter was used to measure light intensity. A typical incandescent bulb with 
tungsten filament emits over a broad spectrum with peak wavelength about $900 \mathrm{~nm}$ (blackbody T $=3000 \mathrm{~K}$ ). Attenuation of the light generated by the incandescent bulb agrees closely with the attenuation measured at single wavelengths of 800-1000 nm. Black carbon is the only major particle component that absorbs in this spectral region (Tom Kirchstetter, LBNL, personal communication). Reflectance of $\mathrm{PM}_{2.5}$ filters (i.e., black smoke) also has been shown to correlate with elemental carbon measurements (Jaansen et al., 2001).

Black carbon mass concentration was calculated with Equation 2 below, where A is the collection area of the sample filter $\left(\mathrm{cm}^{2}\right), \sigma$ is the mass absorption coefficient or cross section $\left(\mathrm{cm}^{2} \mu \mathrm{g}^{-1}\right)$, and $\mathrm{V}$ is the volume of air passing through the filter $\left(\mathrm{m}^{3}\right)$, calculated from the measured flow rate and sampling time.

$$
\mathrm{BC}\left[\mu \mathrm{g} \mathrm{m}^{-3}\right]=(\mathrm{ATN} * \mathrm{~A}) /(\sigma * \mathrm{~V})
$$

We used the cross-section of $25 \mathrm{~cm}^{2} \mu \mathrm{g}^{-1}$ determined by Gundel et al. This value results from the light absorbing properties of the carbonaceous material and an enhancement factor of about two associated with the filter.

The use of fiberfilm filters with this method was validated by collecting samples on colocated quartz and fiberfilm filters over a range of ambient particle concentrations and mass loadings encountered during the study. Comparison of the paired samples indicates a correlation relationship of $\mathrm{ATN}_{\text {fiberfilm }}=1.13 * \mathrm{ATN}_{\text {quartz }}-13.8\left(\mathrm{r}^{2}=0.99\right)$, as shown in Figure 2.4. This relationship is important only to the quantitation of absolute BC concentrations, and does not affect the relative $\mathrm{BC}$ levels measured at the ten schools. The negative intercept indicates we may be understating absolute BC concentrations for 1-week, school-hour only samples with attenuations of 20-50.

Plate-aluminum (0.26 mm thickness) rings or "masks" were used to reduce and clearly define the area over which a sample was collected. Without the masks, particles sampled using the PEM are not distributed evenly over the entire collection area (diameter =33 $\mathrm{mm}$ ); the sample is visibly less concentrated around the edges. The masks have a $20-\mathrm{mm}$ diameter hole. Two masks were used in each PEM, placed directly above and below the filter. This ensured that all sample air flowed only through the 20 -mm diameter hole and no sample was lost on the mask. 
Particle samples were much more evenly distributed over the collection area when masks were used. The use of masks also allows for the sample and reference intensities (I, Io) to be measured from the same filter. This improves sensitivity at low concentrations of black carbon because the reference intensity varies somewhat from filter to filter.

Masks were used successfully with both $\mathrm{PM}_{10}$ and $\mathrm{PM}_{2.5}$ samples during the preliminary validation experiments. However, during the first two weeks of the spring sampling period, filters stuck to the masks in several instances, invalidating the mass measurement. Masks were not used during week 3 and were used for $\mathrm{PM}_{10}$ samples only during subsequent weeks of the spring measurement period to ensure the validity of the $\mathrm{PM}_{2.5}$ mass measurement. Black carbon measurements were made from the $\mathrm{PM}_{2.5}$ samples (collected without masks) by taking punched disks from the middle of the collection area and using the average reference intensity measured from three clean filters. Since particle collection without a mask was more concentrated in the middle of the filter, black carbon concentrations estimated from $\mathrm{PM}_{2.5}$ samples collected without masks were higher than co-located $\mathrm{PM}_{10}$ samples collected with masks. Masks were used for all particle sampling during the fall measurement period.

We now believe filter sticking was caused by over tightening of PEM assembly screws (see schematic in Appendix A). Starting in week 3, special care was taken to not over tighten these screws, and the incidences of filter sticking decreased substantially. A pre-calibration flow rate measurement enabled us to determine if the screws were not sufficiently tight. If the flow was $<90 \%$ of the set point (i.e., $<1800 \mathrm{cc} / \mathrm{min}$ ) following re-assembly of the PEM, screws were tightened and the flow was rechecked to ensure a proper seal.

To validate the equivalence of all PEM units, co-location experiments were conducted before and after the monitoring program. The seven co-location events covered a range of mass and $\mathrm{BC}$ concentrations, as shown in Table 2.5. Results are summarized in Figures 2.5-2.7, which show the concentrations of mass and BC measured with each PEM, normalized to the average values for all PEMs during each event. The 2.5- $\mu \mathrm{m}$ PEMs were numbered 0-10 and deployed consecutively at schools 1-10. The 10- $\mu$ m PEMs were numbered 11-20 and deployed consecutively at schools 1-10. Two PEMs (original numbers 10 and 20) yielded inconsistent results during the first two validation experiments. The reason for this was uncertain, but as a courtesy, the manufacturer sent two replacement units. The results shown in Figures 2.5-2.7 
include only the replacement units used after event 2. Units 21 and 22 are spares that were obtained after the first four validation experiments; they were used for some of the fiberfilm to quartz correlation experiments and deployed at school 9 during weeks 11-14. A record of the PEMs used each week at each school during the spring is included in Appendix B.

Black carbon concentrations (Figure 2.7) varied little among all the units, with relative standard deviations of 2-6\% for each size cut. Averaged over all events, the relative response of individual units ranged from 0.95-1.03 for $\mathrm{BC}_{2.5}$ and 0.95-1.04 for $\mathrm{BC}_{10}$, indicating the potential systematic bias was $<10 \%$ between the highest and lowest responding units. For $\mathrm{BC}_{2.5}$, eight of the ten most-used units (1-10) had relative responses within $\pm 2 \%$ of unity. For $\mathrm{BC}_{10}$, six of ten units fell within this narrow range.

The mass measurements were less precise and more variable among units, with relative standard deviations of 3-18\% for individual co-location experiments (Figures 2.5-2.6). The largest single deviation in $\mathrm{PM}_{10}$ mass of $40 \%$ for PEM19 in event 4 may have resulted from sample contamination. Excluding this value, the relative standard deviation in $\mathrm{PM}_{10}$ mass for this event was 9\%. Individual PEM results for $\mathrm{PM}_{10}$ mass were always within $\pm 25 \%$ of the event average (excluding PEM19 in event 4), and within $\pm 10 \%$ of the average for 43 of the 50 cases. $\mathrm{PM}_{2.5}$ mass measurements for individual PEMs were within $\pm 25 \%$ of the event average for 46 of the 47 cases, and within $\pm 10 \%$ for 33 cases. Overall average responses for all PEM units are listed in Table 2.6. Most units showed a small or negligible bias (i.e. <5\%) for $\mathrm{PM}_{2.5}$ mass, but units 8 and 10 were about $10 \%$ high and unit 3 was $7 \%$ below unity. For $\mathrm{PM}_{10}$ mass, units 17 and 20 were $7 \%$ and $9 \%$ low, respectively, and unit 14 was $8 \%$ high. These results indicate a worstcase systematic bias of $\pm 14-17 \%$ for mass measurement between specific PEM pairs (e.g., PEM8 or PEM10 versus PEM3 and PEM14 versus PEM17 or PEM20) with biases of less than 10\% for all other paired comparisons.

Temperature and Relative Humidity. Site-specific temperature and humidity were measured with temperature/relative humidity data loggers (HOBO H8 Pro RH/Temperature Logger, Onset Computer Corp.) placed inside the equipment housings. These were programmed to record data continuously for two weeks and were downloaded weekly. Temperatures and relative humidities were averaged over $\mathrm{NO}_{\mathrm{X}}$ and $\mathrm{NO}_{2}$ sampler deployment periods and were used to adjust the 
effective sampling rate for calculation of $\mathrm{NO}_{\mathrm{X}}$ and $\mathrm{NO}_{2}$ concentrations following the equations provided by Ogawa \& Co. USA.

$\underline{\mathrm{NO}_{\underline{X}}}, \mathrm{NO}_{2}$ and $\mathrm{NO} . \mathrm{NO}_{\mathrm{X}}$ and $\mathrm{NO}_{2}$ were sampled using commercially available passive monitors (Ogawa \& Company USA, Inc.). The monitors consist of re-usable bodies that are displayed schematically in Appendix A. Sampling occurs by diffusion through the small cylindrical tubes in the diffusion end cap. Dimensions of a single tube are diameter $=1.86 \mathrm{~mm}$ and length $=6$ $\mathrm{mm}$. Consistent with manufacturer instructions, sampler bodies were washed with DI water prior to each use. Pads were stored in the freezer or refrigerator and loaded into samplers a few hours prior to deployment. Once loaded, the numbered samplers were placed into sealed screw-top cups bearing the same numbers for transport to the field sites. On site, samplers were removed from the cups and clipped onto the equipment housings. At the end of each period, samplers were transported back to LBNL in the same, numbered screw-top cups and placed into a refrigerator for short-term storage.

Initially in the spring, the sampler bodies were attached to the aluminum perch outside of the cabinets. Starting with week 8, samplers were always attached inside of the cabinet to reduce the possibility of tampering. However, samplers were attached inside at school 10 during weeks 3-7 and inside at schools 6-9 during week 7. In the fall, samplers were always attached inside the cabinets.

For the spring period, sample pads were sent to outside laboratories for analysis. Within a few days of sample collection, sample pads were removed from their samplers and placed into numbered, smaller screw top vials, and again stored in the refrigerator. Sample pads were transferred one-by-one to reduce the possibility of mixing up the unmarked pads. A number of duplicate samples were collected to check the precision of the measurement technique. Field blanks were handled in the same manner as samples except, once opened in the field, they were returned immediately to the screw-top cups. At least one unused pad for both $\mathrm{NO}_{\mathrm{X}}$ and $\mathrm{NO}_{2}$ were included as lab blanks in each batch of samples sent for analysis. Samples were sent by overnight airfreight without refrigeration to an outside laboratory for analysis in batches of 1-3 sampling periods. Samples from week 1 were sent to Research Triangle Institute in North Carolina. Samples from all subsequent periods were sent to Ogawa \& Co. USA in Florida. Ogawa \& Co. USA subsequently forwarded the samples to the Ogawa laboratory in Japan for analysis. The 
method used for this shipment is unknown. The laboratories reported analyte mass for each $\mathrm{NO}_{\mathrm{X}}$ and $\mathrm{NO}_{2}$ pad. The identities of the samples and blanks were not provided to the laboratories. Similar background levels of $\mathrm{NO}_{\mathrm{X}}$ and $\mathrm{NO}_{2}$ were reported for most laboratory and field blanks. These were $<10 \%$ of the lowest sample values. A sample level mass was reported for one laboratory blank included with the samples from weeks 5 and 7, indicating possible contamination or a laboratory error. Reported mass levels for all other samples from these weeks were consistent with the prevailing trends observed during the entire study. Several inconsistencies appeared in the reported $\mathrm{NO}_{\mathrm{X}}$ masses from week 2, suggesting a possible mix-up of samples and vials or pads. As a result, $\mathrm{NO}_{\mathrm{X}}$ data from week 2 are not presented or included in any analyses.

Fall samples were analyzed for $\mathrm{NO}_{\mathrm{X}}$ and $\mathrm{NO}_{2}$ at $\mathrm{LBNL}$ according to the method published by Ogawa (www.Ogawausa.com).

Duplicate samples were collected during both spring and fall to evaluate measurement precision. Results shown in Table 2.7 (spring samples analyzed by Ogawa) and Table 2.8 (fall samples analyzed by LBNL) indicate a high level of precision for analysis by each lab. In the spring, co-located samples agreed within $5 \%$ for 8 of 12 pairs and within $15 \%$ for all but two. In the fall, co-located samples agreed with $10 \%$ for all but one of 28 pairs and within $5 \%$ for 20 of 28 pairs.

To inter-compare results from the two laboratories, we placed at least two samplers at each school during week 17. One set of samples, including one additional duplicate and laboratory blanks, were sent to Ogawa for analysis while the other set, also including a duplicate and blanks, was analyzed at LBNL. Results from these co-located samples analyzed by LBNL and by Ogawa are shown in Figures 2.9a-b. Measured concentrations of $\mathrm{NO}_{2}$ were almost identical while $\mathrm{NO}_{\mathrm{X}}$ results reported by Ogawa were slightly higher on average than those determined at LBNL. The mean difference was $3.5 \mathrm{ppb}$. This difference may be related to the lower laboratory blank value for $\mathrm{NO}_{\mathrm{X}}$ reported by Ogawa, although the reason for the difference in blank values is currently unknown. The $\mathrm{NO}_{\mathrm{X}}$ laboratory blank value reported by Ogawa for the fall samples is consistent with the blank value reported by Ogawa for the spring sample sets. Our own laboratory blank value for $\mathrm{NO}_{\mathrm{X}}$ was obtained consistently during every analysis performed at LBNL, which included several different batches of sampling pads, reagents and 
standard mixtures. With the possible exception of the $\mathrm{NO}_{\mathrm{X}}$ blank, differences in sample storage, shipment, time elapsed between collection and analysis, and analytical details were shown not to be important factors. Excellent correlation was observed between results from the two laboratories $\left(\mathrm{r}=0.997\right.$ for $\mathrm{NO}_{\mathrm{X}}$ and $\mathrm{r}=0.937$ for $\mathrm{NO}_{2}$ ). Thus, despite the small offset for $\mathrm{NO}_{\mathrm{X}}$, the good measurement precision demonstrated by both laboratories allowed us to detect small differences among the schools in both the spring and fall periods.

Ogawa samplers have been shown by Spicer et al. (2001) to agree closely with indoor $\mathrm{NO}_{2}$ concentrations measured by chemiluminescent detection (mean $\mathrm{RSD}=4.9 \%, \mathrm{n}=10$ ) when $\mathrm{HONO}$ concentrations are low compared to $\mathrm{NO}_{2}$. $\mathrm{HONO}$ can interfere at higher concentrations because it is collected on the Ogawa and other passive samplers (including Palmes tubes). HONO is likely to be less of a problem for outdoor samples because it rapidly dissociates by photolysis (i.e., in sunlight).

At the request of OEHHA staff, LBNL conducted an inter-comparison study between Ogawa samplers and chemiluminescent instrument monitoring, which is the primary method used to measure $\mathrm{NO}_{\mathrm{X}}$ and $\mathrm{NO}_{2}$ in ambient air. Ogawa samplers were deployed at the Bay Area Air Quality Management District's (BAAQMD) Fremont monitoring station for several oneweek periods in Mar-May 2002. The primary objective was to compare one-week integrated $\mathrm{NO}_{\mathrm{X}}$ and $\mathrm{NO}_{2}$ concentrations measured by Ogawa samplers to those reported by the chemiluminescent instrument at the site. Ogawa samplers were placed outside, approximately 1.5-2 $\mathrm{m}$ above the roof and adjacent to the air intake manifold for the instruments at the site. Samplers were deployed in two configurations: (1) in a metal locker that is similar to, but narrower than the cabinets located at the ten schools, and (2) clipped inside inverted 3-inch diameter PVC caps that were affixed to a pole on the roof. This deployment arrangement was to validate that samplers deployed in the PVC caps for the neighborhood study produce results consistent with samplers placed in a metal cabinet.

Results from this study are presented in Figures 2.10-2.11. The $\mathrm{NO}_{\mathrm{X}}$ and $\mathrm{NO}_{2}$ concentrations reported for the Fremont station chemiluminescent instrument are averages calculated from one-hour measurements during each period over which the passive samplers were deployed. The Fremont station results are unofficial until reviewed by the BAAQMD for quality assurance; they have been provided so that the inter-comparison may be included in this 
report. Fremont station data were unavailable for the hours of 02:00, 03:00 and 04:00 each day because instruments were automatically calibrated during this period. Since $\mathrm{NO}_{\mathrm{X}}$ concentrations are generally lower at night, we interpolated concentrations for these three hour-long periods using data from 01:00 and 05:00 each morning. Each bar of passive sampler results represents the average of duplicate or in some cases triplicate measurements. Results obtained with the passive samplers correlated well with the chemiluminescent instrument, with an overall $\mathrm{r}=0.989$ for $\mathrm{NO}_{\mathrm{X}}$ and $\mathrm{r}=0.987$ for $\mathrm{NO}_{2}$ (average of passive samplers deployed in PVC caps correlated to Fremont station results), as shown in Figures 2.12-2.13. These results indicate that accurate data can be obtained when the passive samplers are deployed using only the inverted PVC caps for protection.

The equivalence of inside cabinet versus. outside placement was investigated by placing one sampler in each location at schools 1-9 during the first week of sampling. Figures 2.8a and $2.8 \mathrm{~b}$ show the results from this test. The samplers placed inside of the cabinet yielded results that were higher by $8 \pm 5 \%$ (mean \pm standard deviation) for $\mathrm{NO}_{\mathrm{X}}$ and $5 \pm 6 \%$ for $\mathrm{NO}_{2}$. By contrast, higher values were obtained for co-located samplers deployed under PVC caps versus those placed inside of the cabinet at the Fremont station; the outside (PVC) versus inside cabinet ratio for five co-location events was $0.94 \pm 0.05$ for $\mathrm{NO}_{\mathrm{X}}$ and $0.97 \pm 0.03$ for $\mathrm{NO}_{2}$.

Volatile Organic Compounds. Samples for volatile organic compounds (VOCs) were passively collected with 3M Organic Vapor Monitors (OVMs) Model 3520 (3M Corp.) that contain a primary charcoal sorbent wafer. This OVM model contains a second, backup section with a charcoal wafer that is intended to quantify sample breakthrough for high concentration, industrial hygiene applications. A porous film serving as a windscreen sits above the primary charcoal wafer to reduce the possibility of advective airflow into the sampler. In the spring, samplers were deployed at each school for three 4-week periods, starting on weeks 1, 5, and 9. During the first two of these periods, samplers were deployed both inside and outside of the equipment housings. In the fall and early 2002, samplers were deployed inside the equipment housings.

OVMs are packaged by the manufacturer in individual, sealed aluminum cans. A can was opened on site at the time of deployment and the OVM was clipped either to the platform on top of the cabinet (but under the extended plate aluminum canopy) or on one of the screws inside the cabinet. Four weeks later when sampling was complete, the wind-screen was removed and the 
OVM body was sealed with an airtight plastic cap provided by the manufacturer. The OVM was then replaced in its original can, which was covered with a snap-on plastic lid. Sealed OVMs were transported back to LBNL and placed in a freezer until analysis. On week 5, one OVM was opened and then immediately sealed and returned to LBNL with the collected samples to serve as a field blank for the spring sampling period. Duplicate samples were collected inside the equipment housing at school 10 during weeks 9-12. Of 29 targeted period/school combinations, 26 valid samples were recovered and analyzed. No sample was collected at school 10 during the first 4-week period, and two additional samplers were lost (stolen or vandalized) from schools 3 and 9 during the third sampling period.

OVMs from the spring sampling period were analyzed in batch mode at LBNL after the completion of all spring field sampling. Each OVM was analyzed for both gasoline- and dieselrelated VOCs as follows. An OVM was first removed from the freezer and allowed to equilibrate to room temperature. It was taken from the can, and the airtight cap was removed. The top charcoal wafer was separated from the body. The wafer was inserted into a clean 2-ml conical glass vial containing $1.5 \mathrm{~mL}$ of carbon disulfide $\left(\mathrm{CS}_{2}, 99.9+\%\right.$ redistilled, low benzene, Aldrich Chemical Co., Inc.) spiked with an internal standard mixture to yield extract concentrations of $34.2 \mathrm{ng} \mu \mathrm{L}^{-1}$ 1-bromo-4-fluorobenzene, $2.35 \mathrm{ng} \mu \mathrm{L}^{-1}$ 2-bromotoluene, and $1.76 \mathrm{ng}_{\mu} \mathrm{L}^{-1}$ 1-bromoundecane. The first internal standard was applied to the measurement of gasoline-related compounds; the latter two were applied to the measurement of diesel components from a concentrated portion of the extract. It was necessary to roll/fold the wafer several times to make it fit into the vial. The vial was sealed with a screw-top cap lined with clean aluminum foil and placed into the rack of a sample agitator for 40 minutes. Following agitation, the wafer was removed from the vial with clean forceps and discarded. The primary extract was quantitatively analyzed for gasoline-related target compounds (group 1 in Table 2.9) by manually injecting a $1.4 \mu \mathrm{L}$ aliquot (subsequently reduced to $1.0 \mu \mathrm{L}$ ) into an HP 6890 Series gas chromatograph (GC) equipped with a 5973 mass selective (MS) detector (Hewlett-Packard Corp.). The GC was operated in the split-less injection mode. The analytical column was a DB-1701, 30-m x 0.25mm I.D. x 1- $\mu \mathrm{m}$ film, Model 122-0733 (J\&W Scientific). The oven temperature program was $25^{\circ} \mathrm{C}$ for $3 \mathrm{~min}, 10 \mathrm{C}^{\circ} \mathrm{min}^{-1}$ ramp rate, $225 \mathrm{C}^{\circ}$ for $2 \mathrm{~min}$. Five hundred micoliters of the sample extract was then transferred to a second $2-\mathrm{mL}$ vial. This vial was placed beneath a nitrogen flow for about 10-15 min to achieve a 20-50x concentration by solvent blow down. A 1.4- $\mu \mathrm{L}$ aliquot 
of the concentrated extract was injected into the GC/MS and analyzed as described above to quantify the diesel-related target compounds (group 2 in Table 2.9). The concentration factor was determined by dividing the mass of internal standard measured in the concentrated extract by the mass expected in $1.4 \mu \mathrm{L}$ of unconcentrated extract.

The GC/MS output was processed and analyzed using HP Chemstation software to determine the mass of each compound in the injection, and by extension in the original extract, based on calibrations referenced to the internal standards: bromofluorobenzene for the gasolinerelated VOCs and bromoundecane (or bromotoluene) for the diesel-related VOCs. The field blank and several lab blanks were analyzed from two of the three OVM production lots used in the spring study. All blanks yielded consistently low concentrations of gasoline-related VOCs and consistently elevated concentrations of many diesel-related VOCs. The blank results for selected compounds are shown in Table 2.9. Background (i.e., blank) levels of $\mathrm{C}_{13}-\mathrm{C}_{17}$ normal alkane hydrocarbons were as high as the measured sample levels. $n$-Undecane $\left(\mathrm{C}_{11}\right)$ and ndodecane $\left(\mathrm{C}_{12}\right)$ were also present in field and laboratory blanks, at approximately $15-50 \%$ of the sample levels. For these two compounds, the average background mass was subtracted from each sample measurement to estimate the mass contributed from ambient VOCs. The concentrations of the target VOCs in air were derived using the compound-specific "effective" sampling rates shown in Table 2.9. In many cases, the sampling rates were obtained from the OVM manufacturer's Technical Data Bulletin (3M, 1999). For some compounds not listed in the technical bulletin, theoretical rates calculated based on Fick's First Law of Diffusion by Shields and Weschler (1987) were utilized. For seven compounds, the sampling rate was inferred from the rate for a chemically related compound with similar volatility. Efficiencies for extraction of the target VOCs from the charcoal wafers were not measured. Thus, the concentrations are uncorrected for any incomplete recovery during extraction.

Results from the inside versus the outside of the equipment housing location of samplers during the first deployment period (Table 2.10) show there is a small, statistically significant difference between deployment locations for many compounds. However, the differences are within $7 \%$ for all compounds. These results also indicate a high-level of reproducibility of results since the two samplers at each school also may be considered to be duplicates. Similar results were obtained for sampler pairs that were placed inside and outside of the housings during later periods. 
During the fall monitoring period, OVM deployment was modified in an attempt to reduce contamination of the higher molecular weight normal alkane hydrocarbons (n-tridecane through n-heptadecane) associated with diesel exhaust. The source of this contamination was determined to be the porous film used as a windscreen. The samplers were deployed in the fall with the windscreen and the front charcoal wafer removed. The intent was to use only the backup section of the OVM, which is isolated from the windscreen and was shown to be free of contamination. The windscreen was thought to be unnecessary when the samplers were deployed inside of the cabinets. The samplers were deployed for two consecutive four-week exposure periods, corresponding to weeks 15-18 and 19-22. Upon recovery, they were analyzed for gasoline and diesel VOCs as previously described. The masses of individual gasoline VOCs collected on these samplers were as much as six times higher than results from the spring period. Additionally, the fall samples showed greater inter-school variability. We suspect that a substantial increase in mass collection was caused by a reduction in the effective diffusion distance when the windscreens were removed. The higher variability with location possibly results from differing air velocities in the cabinets. As a result, the fall VOC data were deemed to be questionable, and were not reported.

A third deployment of OVM samplers occurred during two four-week periods in Jan-Feb 2002. OVMs were deployed with windscreens and analyzed only for gasoline VOCs.

Wind Speed and Direction. Meteorological data files from Oakland International Airport and Hayward Executive Airport were purchased and downloaded from the Western Region Climate Center in Reno, NV. Hourly data were obtained in two installments, together covering the period beginning June 1, 2000 and ending May 10, 2002. The data include the following parameters: station, date, time, air temperature, dew point temperature, wind direction, wind speed, peak gust, altimeter setting, barometric pressure, and relative humidity.

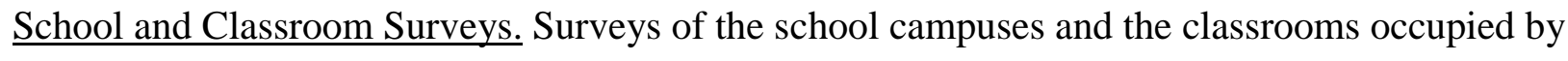
the students participating in the respiratory health study were conducted during the weeks in which the indoor/outdoor pollutant measurements were made. Two survey instruments were utilized. The Classroom Description - Source Information checklist was completed once for each school. It assessed the presence of potential indoor and outdoor sources of contamination. The 
outdoor observations included proximity to traffic, garbage dumpsters, exposed soil and construction activities. Indoor observations were made in all of the participating classrooms and janitorial staff was interviewed. The indoor assessments included evidence of water damage, cleaning procedures and frequency, presence of carpets and rugs, and presence of cleaning and other solvent-containing products. The Classroom Checklist was completed for all of the participating classrooms. Each classroom was visited once and the classrooms in which the indoor pollutant measurements were made were visited two additional times in conjunction with placement and removal of monitoring equipment. This checklist characterized operational parameters for the classrooms. Observations were recorded with respect to type, lighting fixtures on, doors and windows open, HVAC system on, indoor temperature, computers on and odors. The data were entered into Microsoft Access. The database was provided to OEHHA under separate cover and are not discussed or analyzed as part of this report.

\subsection{Results}

\subsection{Data Format and Presentation}

The monitoring program described in this report has produced a database (provided separately) that may be used to evaluate the research questions of the children's respiratory health study. The sponsoring agency, OEHHA intends to analyze the data to address these questions. The results presented in this report are descriptive only and are intended for illustrative purposes. Although, there are apparent differences among the schools for some pollutant parameters, these differences have not been tested statistically. Thus, all statements contained in this report regarding such differences must be considered tentative at this time.

\subsection{Data Completeness}

The monitoring program produced a record of pollutant concentrations spanning two seasons at the ten schools. Critical to the goals of the project, the data provide extensive information about relative traffic-related pollutant concentrations and thus potential exposures at the schools. Tables 3.1 and 3.2 summarize the numbers of samples that were deployed and the number of valid measurements obtained in the spring and fall monitoring periods. Many fewer problems were encountered in the fall than in the spring. 
Major problems in the spring included the sticking of some filters to masks during the first 2 weeks, late approval to start sampling at school 10 (week 3), several acts of vandalism in which samples were either stolen or destroyed, and the loss of two weeks of $\mathrm{NO}_{\mathrm{X}}$ (weeks 2 and 10) and one week of $\mathrm{NO}_{2}$ (week 10) data resulting from uncertain matching of laboratory results to sample identities.

In the fall, all attempted $\mathrm{NO}_{\mathrm{X}}$ and $\mathrm{NO}_{2}$ samples were obtained without incident and there were only three minor problems with filter samples, all related to pump operation. On two occasions, planned two-week school-hours samples were actually collected for one week only. The $\mathrm{PM}_{10}$ school-hours sample intended for weeks 15-16 at school 6 was collected during week 16 only. The two 1-week $\mathrm{PM}_{2.5}$ all-hours samples during weeks 15-16 yielded $\mathrm{BC}$ concentrations that differed by a factor of two. Consistent with this, the $\mathrm{BC}$ concentration determined from the week 16 school hours sample at school 6 was much lower than those obtained at the other schools for weeks 15 and 16 combined. The BC value for school 6 during this period is therefore not included in the calculation of average relative values. The $\mathrm{PM}_{2.5}$ school-hours sample intended for weeks 21-22 at school 6 was successfully collected during week 22 only, but the black carbon values were similar for the individual weeks (determined again by the all-hours measurements); the relative concentration was thus retained in the data set. A third sample, the $\mathrm{PM}_{2.5}$ all-hours sample at school 8 during week 20 was not included in the final summary data because of a potential leak.

\subsection{Comparisons with Ambient Air Quality Standards}

Pollutant concentrations were lower than national and state Ambient Air Quality Standards (AAQS) for most pollutants at most schools. The standards and their associated averaging times are shown in Table 3.3. Direct comparisons between measurements at the schools and the air quality standards are generally not appropriate when averaging times differ. For example, the one-week measurements of fine particulate matter $\left(\mathrm{PM}_{2.5}\right)$ generally are anticipated to be lower than the 24-hr standard; but lower values do not mean that the standard was never violated during the one- or two- week sampling intervals. The overall average concentrations at each site (using only all-hours PM data) can be compared to annual average standards. In making such comparisons, it is important to consider that the measurements in this study were not made with 
standard reference methods that are accepted for establishing compliance with the various AAQS.

\subsection{Pollutant Concentrations}

The following paragraphs present and discuss the main results of this study, i.e., the absolute pollutant concentrations measured at the schools throughout the spring and fall 2001 study periods. To facilitate an analysis of the central question of whether children attending schools and living in neighborhoods located closer to major freeways are exposed to higher levels of air pollutants, we also present normalized, relative pollutant concentration data. Relative concentrations were calculated as the pollutant concentration measured at a given school divided by (i.e., normalized to) the average concentration measured at all schools with valid data during the specified measurement period (generally one week). Relative concentrations were calculated for all pollutants during each measurement period in which at least six schools had valid data. This normalization procedure allows for a straightforward assessment of which schools experience pollutant concentrations that are consistently higher or lower than at the other schools.

Carbon Monoxide. CO concentrations were uniformly low at the ten schools throughout the spring study period. CO did not exceed 9 ppm (an 8-hr standard) during any single hour at any school during this period (hourly CO data were available for approximately 14 weeks, six days per week). The data generally indicate CO concentrations at all of the schools followed the same temporal trends with substantial deviations likely resulting from instrument problems. For example, schools 6 and 7 appear to deviate somewhat from the prevailing temporal pattern of $\mathrm{CO}$ during many weeks as shown in Figures 3.1a and 3.1b for week 3. However, when units other than 6 and 7 were used at schools 6 and 7, CO concentrations at these locations appeared to be consistent with the overall temporal trend. Figures $3.2 \mathrm{a}$ and $3.2 \mathrm{~b}$ provide examples from week 8 , during which unit 0 was deployed at school 7 and unit 3 was deployed at school 6 . Hourly CO concentrations for all schools during the spring period are shown in Appendix C.

The highest $\mathrm{CO}$ concentrations were typically observed in the morning and at night, while the lowest concentrations occurred mid-day. We hypothesize that this results from a combination of temporal meteorology and emissions patterns. The atmospheric mixing height, which determines the volume of air into which ground-level emissions mix typically rises during 
the day and drops in the evening. The morning peak results from emissions of early commute traffic mixing into a still smaller volume of air near the ground. Concentrations then decrease during midday corresponding to increased mixing volume. Emissions from the evening commute then lead to higher concentrations as the atmospheric mixing volume decreases in the evening. Concentrations fall or remain steady through the night as traffic emissions drop to the lowest levels of the daily cycle. The mixing height typically rises quickly in the morning as solar radiation (sunshine) warms the air close to the ground, which then rises and mixes with the air above.

Weekly mean all hours and school hours CO concentrations at each school are shown in Figures 3.3 and 3.4 (spring period only). These plots include questionable data for individual units on individual weeks, i.e., from unit 5 on weeks 4-13 (potentiometer problems as described previously) and from unit 0 at school 9 during weeks 11-14 (zero offset problem apparent in time-resolved plots presented in Appendix C). Deviations of individual school averages from weekly averages at all schools are shown in Figures 3.5 and 3.6. Weekly averages for both all hours and school hours sampling varied widely at each school. The relative or normalized concentrations (i.e., individual schools relative to the weekly average for all schools; data not shown) varied by about a factor of two. Weekly average concentrations were highest at school 10 and lowest at school 5.

CO concentration profiles are shown for the fall, weeks 16-22 in Appendix D. As noted above, the units were not calibrated after they were deployed to the field. Consequently, the zero offsets may have drifted or wandered. Thus, the reported concentrations for any individual unit may be offset in either direction by as much as a few parts per ten million during a given week or over the entire deployment period. Nevertheless, the time-concentration profiles of $\mathrm{CO}$ at the ten schools should be valid.

$\underline{\mathrm{NO}}_{\underline{x}}, \mathrm{NO}_{2} \underline{\text { and NO}}$. Integrated average concentrations of nitrogen oxides measured at all schools during all spring sampling weeks are shown in Figures 3.7-3.9. The difference between $\mathrm{NO}_{\mathrm{X}}$ and $\mathrm{NO}_{2}$ concentrations is described as $\mathrm{NO}$, but other compounds, including HONO, may contribute to the difference between measured $\mathrm{NO}_{\mathrm{X}}$ and $\mathrm{NO}_{2}$. Week-to-week concentrations at each school ranged over a factor of two-three for $\mathrm{NO}_{\mathrm{X}}$, factor of two for $\mathrm{NO}_{2}$, and up to a factor of four for NO. Concentrations of all species were generally highest at schools 5 and 10. 
Figures 3.10-3.12 show the normalized nitrogen oxide concentrations for the spring period in which the concentrations measured at each school are related to the period averages for all schools. This normalization process allows for an aggregation of data for all sampling periods, including those with an incomplete set for the ten schools. In this presentation, the ranges of values at each school are tighter, with the exception of $\mathrm{NO}_{\mathrm{X}}$ and $\mathrm{NO}$ at school 5, indicating consistent relative concentrations at the schools. School-to-school differences were largest for NO followed by $\mathrm{NO}_{\mathrm{X}}$.

Absolute $\mathrm{NO}_{\mathrm{X}}, \mathrm{NO}_{2}$ and $\mathrm{NO}$ concentrations measured during the fall monitoring period are shown in Figures 3.13-3.15. Concentrations at individual schools varied over the period by $25-50 \%$ of the maximum value per school for $\mathrm{NO}_{2}$, by a factor of two to three for $\mathrm{NO}_{\mathrm{X}}$ (i.e., 50$67 \%$ of maximum value per school), and by even a wider margin for NO. These results generally are consistent with the spring results and reinforce the importance of simultaneous sampling at all locations. The overall range of $\mathrm{NO}_{2}$ concentrations in the fall was similar to that observed in the spring. By contrast, the upper end of the $\mathrm{NO}_{\mathrm{X}}$ concentration range was higher in the fall versus the spring, with 11 measurements above $80 \mathrm{ppb}$ in the fall versus none at this level in the spring.

Summary data for $\mathrm{NO}_{\mathrm{X}}$ and $\mathrm{NO}_{2}$ concentrations measured throughout the entire study are shown in Tables 3.4 and 3.5. Average $\mathrm{NO}_{\mathrm{X}}$ and $\mathrm{NO}_{2}$ concentrations were higher at each school during the fall versus the spring. For $\mathrm{NO}_{\mathrm{X}}$, the differences between the fall and spring were about $20 \mathrm{ppb}$ at each school. For $\mathrm{NO}_{2}$, the differences between fall and spring were about 8 to $2.5 \mathrm{ppb}$ with the smallest difference occurring at school 10. Average $\mathrm{NO}_{2}$ concentrations at the schools for both study periods were well below the Federal annual average arithmetic mean AAQS of 53 ppb.

Normalized $\mathrm{NO}_{\mathrm{X}}, \mathrm{NO}_{2}$ and $\mathrm{NO}$ values at each school in the fall are shown in Figures 3.16-3.18. Summary data for $\mathrm{NO}_{\mathrm{X}}$ and $\mathrm{NO}_{2}$ concentrations measured throughout are shown in Tables 3.6 and 3.7. Overall, the fall data show a pattern consistent with that observed in the spring. Normalized concentrations at each school are very similar from week to week for both pollutants. Among schools, $\mathrm{NO}_{2}$ shows less variability than $\mathrm{NO}_{\mathrm{X}}$ or $\mathrm{NO}$. Schools 2, 5, 9 and 10 generally had higher $\mathrm{NO}_{\mathrm{X}}, \mathrm{NO}_{2}$ and $\mathrm{NO}$ concentrations relative to schools $1,4,6$ and 7 . 
Fine Particle Mass. Figures 3.19-3.22 show all-hours results for $\mathrm{PM}_{2.5}$ and $\mathrm{PM}_{10}$ as absolute and relative mass concentrations at the ten schools during the spring period. Relative differences among schools were higher for $\mathrm{PM}_{2.5}$ than for $\mathrm{PM}_{10}$. Figures 3.23-3.26 show school-hours results for $\mathrm{PM}_{2.5}$ and $\mathrm{PM}_{10}$ as absolute and relative mass concentrations at the ten schools during the spring period. The relative results indicate show somewhat elevated school-hours $\mathrm{PM}_{2.5}$ mass concentrations at school 10. School hours $\mathrm{PM}_{10}$ mass concentrations were highest (even with the outlying value removed) at school 1, which is not located close to any major traffic sources.

Figures 3.27-3.30 show all-hours results for Mass concentrations of $\mathrm{PM}_{2.5}$ and $\mathrm{PM}_{10}$ as absolute and relative mass concentrations at the ten schools during the fall period. The absolute mass concentrations for both the spring and fall are summarized in Tables 3.8 and 3.9. All-hours $\mathrm{PM}_{2.5}$ mass concentrations were comparable or slightly higher during the fall versus the spring period. All-hours $\mathrm{PM}_{10}$ mass concentrations were somewhat higher in the fall than in spring at all schools, with the smallest difference observed at school 10. Normalized mass concentrations for the spring and fall are summarized in Tables 3.10 and 3.11. Normalized values for both metrics were within $\pm 15 \%$ of unity at all schools, with the exception of $\mathrm{PM}_{2.5}$ at schools 10 (all periods) and 7 (spring period).

The mean all-hours $\mathrm{PM}_{2.5}$ value at school 10 was at the Federal annual arithmetic mean AASQ of $15 \mu \mathrm{g} \mathrm{m}^{-3}$. The mean all-hours $\mathrm{PM}_{10}$ values for all the schools approached or slightly exceeded the California annual geometric mean AAQS of $30 \mu \mathrm{g} \mathrm{m}^{-3}$.

$\mathrm{PM}_{2.5}$ and $\mathrm{PM}_{10}$ mass concentrations measured during school hours appeared not to be strongly affected by close proximity of the freeways, as shown in Tables 3.12-3.15. During school-hours sampling, both $\mathrm{PM}_{2.5}$ and $\mathrm{PM}_{10}$ concentrations were generally higher in the fall compared to the spring period; this is consistent with the results for $\mathrm{NO}_{\mathrm{X}}, \mathrm{NO}_{2}$, and all-hours $\mathrm{PM}_{2.5}$ and $\mathrm{PM}_{10}$. Relative particle concentrations during school hours are near unity for all schools except for $\mathrm{PM}_{2.5}$ concentrations at school 10. $\mathrm{PM}_{2.5}$ and $\mathrm{PM}_{10}$ concentrations were higher during school-hours than during all-hours sampling for both spring and fall.

Although the statistical analysis has yet to be performed, the results suggest that 24-hr average particle mass concentrations did not vary strongly among the ten schools. 
Black Carbon. In the spring period, both all-hours and school-hours black carbon concentrations associated with $\mathrm{PM}_{2.5}$ and $\mathrm{PM}_{10}$ appeared to be somewhat related to the proximity of nearby freeways, as shown in Figures 3.31-3.33. The highest relative concentrations for all-hours sampling generally occurred at schools 5,9 and 10, while the lowest relative concentrations occurred at schools 6, 7 and 8. For school-hours sampling, concentrations also were relatively low at schools 2, 3 and 4. In the fall period, both all-hours and school-hours black carbon concentrations associated with $\mathrm{PM}_{2.5}$ and $\mathrm{PM}_{10}$ were highest at school 10 and lowest at schools 6 and 7. The absolute and normalized black carbon concentrations for the spring and fall periods are compared in Tables 3.16-3.22. These tables show that both all-hours and school-hours black carbon concentrations associated with $\mathrm{PM}_{2.5}$ and $\mathrm{PM}_{10}$ were uniformly higher in the fall versus the spring period. However, the absolute concentrations of $\mathrm{BC}$ associated with $\mathrm{PM}_{2.5}$ during the fall and spring periods may not be directly comparable because many of the spring $\mathrm{PM}_{2.5}$ samples were collected without the use of masks. These samples are subject to greater uncertainty because reference intensity was measured from three blank filters rather than directly from the sample filters. There is also an apparent positive bias (i.e., towards higher concentration) resulting from the non-uniform collection area of unmasked samples.

Black carbon is associated with very small particles that should be collected equally with and $\mathrm{PM}_{2.5}$ and $\mathrm{PM}_{10}$. However, during the two weeks of spring monitoring (weeks 1 and 2) when $\mathrm{PM}_{2.5}$ and $\mathrm{PM}_{10}$ were simultaneously collected with masks, black carbon concentrations were slightly higher on the $\mathrm{PM}_{10}$ versus the $\mathrm{PM}_{2.5}$ samples (Figures 3.37-3.38). During the fall period, $\mathrm{PM}_{2.5}$ and $\mathrm{PM}_{10}$ were not simultaneously collected, so a direct comparison cannot be made. Black carbon was higher during the four weeks when $\mathrm{PM}_{10}$ was sampled during all hours (weeks $17,18,21,22$ ) than during the four weeks when $\mathrm{PM}_{2.5}$ was sampled during all hours (weeks 15 , 16, 19, 20). Consistent with this, the school-hours measurements of black carbon were higher on the $\mathrm{PM}_{2.5}$ samples (collected during weeks 17, 18, 21, 22) than on the $\mathrm{PM}_{10}$ samples, as shown in Tables 3.20-3.21.

Volatile Organic Compounds. Concentrations of individual VOCs measured over 8-12 weeks at each school in the spring are presented in Table 3.23, which also indicates the deployment/sampling periods (A, B and C) with available data. The data were generally consistent for all the VOCs, with occasional outlying values for individual compounds. With the 
apparent outlying values excluded concentrations of individual VOCs generally ranged over a factor of approximately two among the schools. All of the data for the 12 gasoline-related VOCs (i.e., the first 12 compounds in Table 3.23) from the spring period are presented in summarized form in Figure 3.39, which shows normalized VOC concentrations (i.e., the concentration at each site was normalized to the respective period average for all sites with data). In this figure, the relative concentrations of the 12 VOCs were averaged together for each study period. This averaging technique reduces the influence of the few outlying values for individual compounds at individual schools. The result indicates that the concentrations of gasoline-related VOCs were generally highest at schools 5 and 10. The uncertainty bars in Figure 3.39 represent the standard deviations for the relative concentrations of the individual compounds. Thus, the larger bars are associated with schools that had outlying values for individual VOCs. The concentrations of selected individual VOCs (methylcyclopentane, 2,2,4-trimethylpentane, benzene, m,p-xylene, 1,2,4-trimethylbenzene and n-undecane) are presented in Figures 3.40-3.45. For schools with data available from all three spring deployment periods (schools 1, 2, 4, 5, 6, 7 and 8) the concentrations at each school were generally similar over time. Generally, the largest temporal differences were observed at schools 1 and 4.

Concentrations of the 13 gasoline-related VOCs (includes 3-methylhexane, an isomer not measured in the spring period) measured at each school over the winter 2002 deployment period are presented Table 3.24. Concentrations measured during winter 2002 were uniformly higher than concentrations measured during the spring 2001 period. The VOC data for the winter period are summarized in Figure 3.46 in the same manner used for presentation of the spring data in Figure 3.39. Concentrations during the two winter periods were similar to one another. Similar to the spring, and consistent with observed trends for other pollutants, relative VOC concentrations were highest at school 10 and lowest at schools 6 and 7. The relative results for VOCs in the spring and winter periods do not appear to be entirely consistent with the relative results for the pollutants, $\mathrm{NO}_{\mathrm{X}}$ and black carbon, that are most strongly related to vehicle activity. This suggests that factors other than downwind proximity to the major freeways may be important in determining local traffic-related VOC concentrations. A possible explanation is that evaporative emissions from resting vehicles and gasoline storage and distribution may be important at the local level. Overall in urban areas of California, evaporative processes are estimated to contribute on the order of a quarter to half (a highly uncertain number) of total VOC emissions. 
Indoor versus Outdoor Pollutant Concentrations. The limited set of time-correlated indooroutdoor pollutant concentration measurements is insufficient to provide conclusive information regarding pollutant entry into the individual school classrooms. However, taken as a whole, the data indicate several important trends. When making comparisons, overall indoor levels should be inter-compared only for the schools measured together, i.e. schools $2,3,4$, 7, and 8 (week 7) and schools 1, 5, 6, 9, and 10 (week 9).

Indoor-outdoor data for $\mathrm{NO}_{\mathrm{X}}$ and $\mathrm{NO}_{2}$ are compared in Figures 3.47-3.48. Indoor concentrations for both $\mathrm{NO}_{\mathrm{X}}$ and $\mathrm{NO}_{2}$ were about one-half to nearly equal the corresponding outdoor concentrations. At schools 5 and 10 (i.e., two of the three schools with relatively high $\mathrm{NO}_{\mathrm{X}}$ concentrations), indoor levels of $\mathrm{NO}_{\mathrm{X}}$ were approximately $80-90 \%$ of outdoor levels and were higher than indoor levels at the other schools. The outdoor sample for this comparison is unavailable for school 9 , the other school with consistently elevated outdoor $\mathrm{NO}_{\mathrm{X}}$ levels.

Indoor versus outdoor comparisons of fine particle mass and black carbon concentrations are shown in Figures 3.49-3.51. Indoor and outdoor $\mathrm{PM}_{2.5}$ mass concentrations were nearly the same at some schools (1, 2, 7, 8 and 10). At other schools (4 and 6), indoor $\mathrm{PM}_{2.5}$ concentrations were higher. Indoor $\mathrm{PM}_{10}$ mass concentrations were higher than outdoors concentrations at all schools with complete data. For a number of these schools, the differences were substantial. Clearly higher indoor versus outdoor concentrations of black carbon associated with $\mathrm{PM}_{10}$ were measured for two schools ( 3 and 4) with the high indoor versus outdoor ratios of $\mathrm{PM}_{10}$ mass concentration. There are several possible explanations for this finding. It is possible, but we think unlikely that there are indoor sources of $\mathrm{PM}_{10}$ with significant light-absorbing properties because black carbon was a smaller fraction of total mass on the indoor versus the outdoor samples. A more reasonable explanation derives from the probable source of the elevated PM10, i.e. resuspension of particles caused by student activity. To the extent that these deposited particles are of outside origin, they will contain black carbon. Therefore, both $\mathrm{PM}_{10}$ and black carbon may be higher indoors than outdoors, even at schools having lower outdoor concentrations of black carbon.

Wind Direction. Summary wind data for spring, fall and neighborhood monitoring periods are presented in Figure 3.52. This figure shows mean wind direction for all-hour and school-hour 
periods associated with each start week (weeks 5 and 11 extended over two-weeks each). Winds were uniformly from approximately the west (270 degrees) throughout the spring 2001 period (weeks 1-14) and the neighborhood study during spring 2002 (weeks 23-34). During the fall 2001 period (weeks 15-22), winds were initially from the west and over time shifted to the southwest (225 degrees) then to the south (180 degrees). Typical daily wind patterns are illustrated in Figures 3.54-3.57, which show hourly mean values for each month of over a twoyear period encompassing the study activities. During spring and summer, winds were from the west throughout the day, with only a slight shift to the southwest during early morning hours. In the winter, winds shifted from the southeast during the overnight and early morning hours and to the southwest during the mid-day and evening hours. A progression from summertime to wintertime patterns was seen during the fall each year.

\subsection{Correlations among Pollutant Concentrations}

Correlation coefficients for all relevant pollutant pairs for both the spring and fall periods are presented in Table 3.25. The numbers of data pairs used to calculate the coefficients are shown in Table 3.26. Comparisons between all-hours and school-hours measurements are always for the same weeks. For example, data for school-hours samples extending over two weeks in the fall period are compared to the average of sample data for other parameters collected over the two individual weeks. The highest levels of correlation were observed among $\mathrm{NO}_{\mathrm{X}}, \mathrm{NO}$ and black carbon concentrations associated with all-hours samples of $\mathrm{PM}_{2.5}$ and $\mathrm{PM}_{10}$. These quantities also correlated fairly highly with $\mathrm{NO}_{2} . \mathrm{PM}_{2.5}$ mass concentration was highly correlated with $\mathrm{PM}_{10}$ mass concentration for all-hours samples and these quantities correlated somewhat to $\mathrm{NO}_{2}$. Correlation coefficients of 0.59 and 0.73 were observed for comparisons between particle mass and black carbon concentrations on $\mathrm{PM}_{2.5}$ and $\mathrm{PM}_{10}$. Analysis of the statistical uncertainties associated with these correlations is beyond the scope of this report, but is recommended.

\subsection{Neighborhood Study}

$\mathrm{NO}_{\mathrm{X}}$ and $\mathrm{NO}_{2}$ results are shown in Tables 3.27 and 3.28 for the two weeks of the neighborhood study. These results include measurements at the ten schools and at the BAAQMD Fremont monitoring station. The pattern of concentrations at the ten schools during each of these weeks was similar to the overall trend observed for the spring and fall monitoring periods.

Concentrations measured at the Fremont station were within about $10 \%$ of those observed at 
schools 3, 4, 6, and 7. This result suggests that these sites may be representative of background levels for the study region, at least during typical wind conditions that prevail during the spring, summer and fall. Since winds were blowing from the west during these two weeks, the neighborhoods surrounding schools 3 and 6 were predominantly upwind of the I-880 freeway, while the neighborhood surrounding school 5 was downwind from I-880. $\mathrm{NO}_{\mathrm{X}}$ and $\mathrm{NO}_{2}$ concentrations at most of the residential sampling locations at schools 3 and 6 were within 20\% of the values measured at the corresponding schools. The highest concentration outlier for school 6 was far from the school and less than $50 \mathrm{~m}$ downwind from I-880. Outliers from school 3 included one residence on a major throughway that was also part of a boat and trailer yard and several residences within about $100 \mathrm{~m}$ of ramps linking I-880 to another major throughway. Much more variability was observed among the residential sampling locations at school 5; however, the concentrations appeared to be approximately inversely related to distance from I-880. School 5 residences that were far from the freeway (less than one half of those sampled) had $\mathrm{NO}_{\mathrm{X}}$ and $\mathrm{NO}_{2}$ concentrations that approached the regional background levels. The overall distribution of concentrations observed for school 5 residences appears to be substantially higher than the regional background, as measured at the Fremont site.

\subsection{Conclusions and Recommendations}

Although statistical analysis of the data is yet to be performed, a few general observations can be made. Overall, trends were observed for some pollutants that are apparently related to distance downwind of local freeways. The most prominent trends were observed for $\mathrm{NO}_{\mathrm{X}}, \mathrm{NO}_{2}$ and black carbon, which were highly correlated to one another and elevated at schools near to and downwind from the I-880 freeway. Elevated concentrations of CO, $\mathrm{PM}_{2.5}$ mass, and VOCs were also observed at the school closest to I-880 and adjacent to a shopping center (\#10). Otherwise, fine particle mass concentrations were nearly uniform among the schools, suggesting little correlation with freeway proximity. Gasoline-related VOCs exhibited a somewhat different pattern between the spring and fall monitoring periods. Additionally, the pattern of VOC concentrations at the schools was somewhat different than the pattern exhibited by other trafficrelated pollutants. Possible explanations include shifting wind patterns during winter versus spring, different patterns of gasoline versus diesel vehicle traffic near the schools, and the possible influence of stationary emission sources at some schools. Black carbon and $\mathrm{NO}_{\mathrm{X}}$ are 
both associated with diesel traffic so proximity to the freeway is expected to be an important factor in determining exposure to these pollutants. Since gasoline vehicle use is more ubiquitous, exposure to these pollutants may only be weakly linked to freeway proximity, and possibly more strongly linked to local vehicle density, activity and fleet characteristics. These questions should be investigated to the extent possible, perhaps through the use of travel-demand or other transportation activity modeling.

Results from the neighborhood study generally support the use of school-based concentration measurements to characterize differences among outdoor exposures in different neighborhoods. The variability observed within the neighborhoods studied appeared to be, at least in part, explained by proximity of individual residences to the freeway or other local traffic sources. One potential outcome of a more detailed analysis of these results is a model to estimate individual student exposure as a combination of school-based exposures and residential exposures adjusted for residence proximity to major traffic sources compared to the school location.

Since this was a pilot study, one of the goals of this work was to evaluate the most efficient and relevant pollutants and sampling technologies for a wider assessment of children's exposure to traffic-related pollutants. Of all methods tested, the Ogawa passive $\mathrm{NO}_{\mathrm{X}}-\mathrm{NO}_{2}$ samplers were by far the least expensive, most versatile, and most robust method for measuring integrated concentrations of a traffic-related pollutant. We demonstrated that these samplers yield results that are consistent with chemiluminescent analyzers for ambient sampling, and that they may be deployed outdoors using inexpensive and easy-to-build weather protection devices. Based on the very high degree of correlation, it appears that $\mathrm{NO}_{\mathrm{X}}$ may serve as a reasonable surrogate for black carbon in urban ambient air. If particle measurements are desired, we have shown that relatively inexpensive commercially available equipment may be used with slight modification to sample for both particle mass and black carbon over programmable time intervals of more than 168 hours of cumulative sampling time. The OVM passive monitor was shown to be valuable for measuring gasoline-related VOCs. We believe additional method development may extend their usefulness of the device to the measurement of diesel-related VOCs. CO is theoretically an excellent tracer for motor vehicle emissions, but differentiation among locations at the sub-ppm levels observed in this study requires instrumentation with a stable precision of $<0.1 \mathrm{ppm}(<100 \mathrm{ppb})$ over a minimum period of one week. The Langan 
Products, Inc. CO monitors used here have nominally sufficient precision, but their calibrations were observed to drift by up to several hundred ppb, possibly as a result of variable temperature sensitivity among instruments. Thus, the utility of $\mathrm{CO}$ as an indicator of differential vehiclerelated pollutant exposure in this study is limited.

A significant finding of this study is that simultaneous sampling at one or more reference locations is necessary to assure the reliability of comparisons between study locations or individual exposures. Reference station sampling is needed because temporal variations in pollutant concentrations at any single site were almost always larger than differences among sites. Thus is especially important when a limited number of samplers are employed in a monitoring scheme that doesn't allow for all sites/individuals to be sampled simultaneously.

\subsection{References}

3M Company. Organic vapor monitor sampling and analysis guide. Technical Data Bulletin 1028, October 1, 1999, $11 \mathrm{p}$.

Gundel, L.A., R.L. Dod, H. Rosen, and T. Novakov (1984). The relationship between optical attenuation and black carbon concentration for ambient and source particles. The Science of the Total Environment 36: 197-202.

Jaansen, N.A.H., P.H.N. van Vliet, F. Aarts, H. Harssema, and B. Brunekreef (2001). Assessment of exposure to traffic related air pollution of children attending schools near motorways. Atmospheric Environment 35: 3875-3884.

Shields, H.C. and C.J. Weschler (1987). Analysis of ambient concentrations of organic vapors with a passive sampler. Journal of the Air Pollution Control Association 37: 1039-1045.

Spicer, C.W., I.H. Billick, and Y. Yanigasawa (2001). Nitrous acid interference with passive NO2 measurement methods and the impact on indoor NO2 data. Indoor Air 11: 156-161. 
Table 2.1. Summary of target air pollutants and measurement methods.

\begin{tabular}{|c|c|c|c|}
\hline Pollutant & Collection method & Analysis method & Time resolution \\
\hline $\mathrm{CO}$ & $\begin{array}{l}\text { Continuous diffusive } \\
\text { sampling with } \\
\text { electrochemical } \\
\text { sensor; one } \\
\text { measurement per } \\
\text { second. }\end{array}$ & $\begin{array}{l}\text { Voltage output from } \\
\text { electrochemical } \\
\text { sensor. }\end{array}$ & $\begin{array}{l}\text { Recorded one } \\
\text { measurement per minute; } \\
\text { data averaged \& stored } \\
\text { in } 10 \text { - and } 60 \text {-minute } \\
\text { increments. }\end{array}$ \\
\hline $\begin{array}{l}\mathrm{PM}_{10} \& \\
\mathrm{PM}_{2.5} \text { mass }\end{array}$ & $\begin{array}{l}\text { Constant volume flow } \\
\text { onto Teflon-coated } \\
\text { glass fiber filters; size } \\
\text { selection by } \\
\text { impaction. }\end{array}$ & $\begin{array}{l}\text { Weigh filters before } \\
\& \text { after sampling; } \\
\text { concentration } \\
\text { determined from mass } \\
\text { difference \& air } \\
\text { volume sampled. }\end{array}$ & $\begin{array}{l}\text { Integrated over } \\
\text { deployment period of } 1 \\
\text { week all-hours sampling } \\
\text { or } 1-2 \text { weeks school } \\
\text { hours sampling. }\end{array}$ \\
\hline $\mathrm{BC}$ & $\begin{array}{l}\text { Constant volume flow } \\
\text { onto Teflon-coated } \\
\text { glass fiber filters; size } \\
\text { selection by } \\
\text { impaction. }\end{array}$ & $\begin{array}{l}\text { Attenuation of light } \\
\text { passing through filter; } \\
\text { correlate to BC mass } \\
\text { measured by evolved } \\
\text { gas analyzer }\end{array}$ & $\begin{array}{l}\text { Integrated over } \\
\text { deployment period of } 1 \\
\text { week all-hours sampling } \\
\text { or } 1-2 \text { weeks school } \\
\text { hours only. }\end{array}$ \\
\hline $\begin{array}{l}\mathrm{NO}_{\mathrm{X}} \\
\mathrm{NO}_{2} \\
(\mathrm{NO})\end{array}$ & $\begin{array}{l}\text { Passive diffusion onto } \\
\text { cellulose-fiber pads } \\
\text { coated for collection } \\
\text { of } \mathrm{NO}_{\mathrm{X}} \text { and } \mathrm{NO}_{2} .\end{array}$ & $\begin{array}{l}\text { Extract pads into DI } \\
\text { water, mix with color- } \\
\text { producing reagent, \& } \\
\text { measure light } \\
\text { absorption at } 545 \mathrm{~nm} \text {; } \\
\text { NO by difference }\end{array}$ & $\begin{array}{l}\text { Integrated sample over } \\
\text { deployment period of } 1 \\
\text { or } 2 \text { weeks. }\end{array}$ \\
\hline VOCs & $\begin{array}{l}\text { Passive diffusion onto } \\
\text { charcoal sorbent pads } \\
\text { (3M Organic Vapor } \\
\text { Monitors). }\end{array}$ & $\begin{array}{l}\text { Extract pads with } \\
\text { carbon disulfide; } \\
\text { resolve, identify, \& } \\
\text { quantify individual } \\
\text { VOCs by GC/MS. }\end{array}$ & $\begin{array}{l}\text { Integrated sample over } \\
\text { deployment period of } 4 \\
\text { weeks. }\end{array}$ \\
\hline
\end{tabular}


Table 2.2. Summary of important traffic-related sources nearby ${ }^{1}$ to monitoring sites.

\begin{tabular}{|c|c|c|c|c|}
\hline School $^{1}$ & Nearby source $^{1}$ & $\begin{array}{l}\text { Distance }^{2} \\
(\mathrm{~m})\end{array}$ & Direction & Notes \\
\hline 2 & CA92 & $190 \pm 40$ & W-NW & Mostly commute traffic \\
\hline 2 & I- 880 & $350 \pm 70$ & NE-E & Source downwind \\
\hline 3 & $\mathrm{I}-880$ & $300 \pm 60$ & E-NE & Source downwind \\
\hline 5 & $\mathrm{I}-880$ & $150 \pm 30$ & W-SW & Source upwind \\
\hline 8 & I-580 & $320 \pm 50$ & E-NE & $\begin{array}{l}\text { Mostly commute; no large } \\
\text { trucks; source upwind }\end{array}$ \\
\hline 9 & I- 880 & $130 \pm 30$ & SW & Source upwind \\
\hline 10 & $\mathrm{I}-880$ & $60 \pm 20$ & S-SW & Source upwind \\
\hline 10 & $\begin{array}{l}\text { Shopping center } \\
\text { parking lot }\end{array}$ & $\geq 60$ & SE & $>100$ spaces, all-day traffic \\
\hline 10 & Freeway access road & 40 & S-SW & $\begin{array}{l}\text { 1-lane, continuous traffic, } \\
\text { upwind source }\end{array}$ \\
\hline
\end{tabular}

(1) Includes only freeways within $500 \mathrm{~m}$ and other potentially significant sources with $50 \mathrm{~m}$. No such sources are located nearby to schools $1,4,6,7$, and 8.

(2) Estimated from scaled maps, after confirming accurate placement of schools on map. Uncertainty is for placement of monitor; school grounds sometimes extend beyond this range (i.e. boundaries of school grounds are closer and farther to traffic than range indicated).

Table 2.3. Spring 2001 sampling schedule for $\mathrm{CO}, \mathrm{PM}$ mass, $\mathrm{BC}, \mathrm{NO}_{\mathrm{X}}$ and $\mathrm{NO}_{2}$.

\begin{tabular}{|c|c|c|c|c|c|}
\hline Week(s) & Begin date & End date & $\begin{array}{c}\text { Filter sample } \\
\text { period }\end{array}$ & $\begin{array}{l}\text { Schools } \\
\text { sampled }\end{array}$ & Notes \\
\hline 1 & 14-Mar & 21-Mar & All hours & $1-9$ & Limited $\mathrm{PM}_{10}, \mathrm{PM}_{2.5}$ data ${ }^{1}$ \\
\hline 2 & 21-Mar & 28-Mar & All hours & $1-9$ & $\begin{array}{l}\text { Limited } \mathrm{PM}_{10} \text { data }^{1} ; \mathrm{No} \mathrm{NO}^{2} \\
\text { data }^{2}\end{array}$ \\
\hline 3 & 28-Mar & 4-Apr & All hours & All & \\
\hline 4 & 4-Apr & 11-Apr & School hours & All & Sch. 5 inter-session April 2-20 \\
\hline $5-6$ & 11-Apr & 24-Apr & School hours & All & All schools on break April 16-20 \\
\hline 7 & 25-Apr & 2-May & School hours & $2,3,4,7,8$ & Indoor-Outdoor at $1^{\text {st }}$ group of 5 \\
\hline 8 & 2-May & 8-May & All hours & All & \\
\hline 9 & 9-May & 16-May & School hours & $1,5,6,9^{4}, 10$ & Indoor-Outdoor at $2^{\text {nd }}$ group of 5 \\
\hline 10 & 16-May & 23-May & All hours & $1-8,10$ & Equipment stolen from Sch. 9 \\
\hline $11-12$ & 23-May & 6-Jun & School hours & All & \\
\hline 13 & 6-Jun & 13-Jun & All hours & All & \\
\hline 14 & 13-Jun & 20-Jun & All hours & All & \\
\hline
\end{tabular}

(1) Several filters stuck to masks and were damaged upon removal from size-selective inlets; several additional filters are not included in final data $b / c$ of suspected damage.

(2) Possible mix-up of sample vials by outside laboratory.

(3) School 5 on 12-month schedule.

(4) Equipment stolen from school 9 outdoor location during week 9; indoor samples okay. 
Table 2.3a. Spring 2001 pollutant monitoring.

\begin{tabular}{|l|c|c|c|c|c|c|c|c|c|c|c|c|c|c|}
\hline Week & $1 *$ & $2 *$ & 3 & 4 & 5 & 6 & 7 & 8 & 9 & 10 & 11 & 12 & 13 & 14 \\
\hline $\mathrm{CO}$ & $\mathrm{x}$ & $\mathrm{x}$ & $\mathrm{x}$ & $\mathrm{x}$ & $\mathrm{x}$ & & $\mathrm{x}$ & $\mathrm{x}$ & $\mathrm{x}$ & $\mathrm{x}$ & $\mathrm{x}$ & $\mathrm{x}$ & $\mathrm{x}$ & $\mathrm{x}$ \\
\hline $\mathrm{NO}_{\mathrm{x}}$ & $\mathrm{x}$ & $(\mathrm{x})$ & $\mathrm{x}$ & $\mathrm{x}$ & $\mathrm{x}$ & $\mathrm{x}$ & $\mathrm{x}$ & $\mathrm{x}$ & $\mathrm{x}$ & $(\mathrm{x})$ & $\mathrm{x}$ & $\mathrm{x}$ & $\mathrm{x}$ & $\mathrm{x}$ \\
\hline $\mathrm{NO}_{2}$ & $\mathrm{x}$ & $\mathrm{x}$ & $\mathrm{x}$ & $\mathrm{x}$ & $\mathrm{x}$ & $\mathrm{x}$ & $\mathrm{x}$ & $\mathrm{x}$ & $\mathrm{x}$ & $(\mathrm{x})$ & $\mathrm{x}$ & $\mathrm{x}$ & $\mathrm{x}$ & $\mathrm{x}$ \\
\hline $\mathrm{PM}_{10}$ & (all) & (all) & all & $\mathrm{S}$ & $\mathrm{S}$ & $\mathrm{I} / \mathrm{o} 1$ & all & $\mathrm{I} / \mathrm{o} 2$ & all & $\mathrm{S}$ & all & all \\
\hline $\mathrm{PM}_{2.5}$ & (all) & all & all & $\mathrm{S}$ & $\mathrm{S}$ & $\mathrm{I} / \mathrm{o} 1$ & all & $\mathrm{I} / \mathrm{o} 2$ & all & $\mathrm{S}$ & all & all \\
\hline $\mathrm{VOC}$ & \multicolumn{1}{|c|}{$\mathrm{A}$} & \multicolumn{10}{|c|}{$\mathrm{C}$} & \multicolumn{10}{|c|}{$\mathrm{C}$} & & \\
\hline
\end{tabular}

*School 10 not monitored

()$=$ missing some or all data due to technical problems

$\mathrm{I} / \mathrm{o}=$ simultaneous indoor and outdoor measurements. Week $7 @$ schools 2, 3, 4, 7, 8; week $9 @$ schools $1,5,6,9,10$.

Mask used for black carbon on $\mathrm{PM}_{10}$ throughout (except week 3). No masks for black carbon on $\mathrm{PM}_{2.5}$. $\mathrm{S}=$ particle samples collected during school hours only.

VOC: letter indicates measurement period.

Table 2.4. Fall 2001 sampling schedule for $\mathrm{PM}$ mass, $\mathrm{BC}, \mathrm{NO}_{\mathrm{X}}$ and $\mathrm{NO}_{2}$.

\begin{tabular}{|c|c|c|c|c|}
\hline Week & $\begin{array}{c}\text { Begin date } \\
2001\end{array}$ & $\begin{array}{c}\text { End date } \\
2001\end{array}$ & $\mathrm{PM}_{10}$ period & $\mathrm{PM}_{2.5}$ period \\
\hline 15 & $26-$ Sep & 3-Oct & School hours & All hours \\
16 & 3 -Oct & 10-Oct & School hours & All hours \\
17 & $10-$-Oct & $17-$-Oct & All hours & School hours \\
18 & $17-$-Oct & $24-$-Oct & All hours & School hours \\
19 & $24-$-Oct & $31-$-Oct & School hours & All hours \\
20 & $31-$-Oct & 7-Nov & School hours & All hours \\
21 & 7-Nov & 14-Nov & All hours & School hours \\
22 & 15-Nov & 21-Nov & All hours & School hours \\
\hline
\end{tabular}

Table 2.4a. Fall 2001 pollutant monitoring.

\begin{tabular}{|l|c|c|c|c|c|c|c|c|}
\hline Week & 15 & 16 & 17 & 18 & 19 & 20 & 21 & 22 \\
\hline $\mathrm{CO}$ & - & - & - & - & - & - & - & - \\
\hline $\mathrm{NO}_{\mathrm{X}}$ & $\mathrm{x}$ & $\mathrm{x}$ & $\mathrm{x}$ & $\mathrm{x}$ & $\mathrm{x}$ & $\mathrm{x}$ & $\mathrm{x}$ & $\mathrm{x}$ \\
\hline $\mathrm{NO}_{2}$ & $\mathrm{x}$ & $\mathrm{x}$ & $\mathrm{x}$ & $\mathrm{x}$ & $\mathrm{x}$ & $\mathrm{x}$ & $\mathrm{x}$ & $\mathrm{x}$ \\
\hline $\mathrm{PM}_{10}$ & \multicolumn{2}{|c|}{$\mathrm{S}$} & $\mathrm{all}$ & $\mathrm{all}$ & \multicolumn{2}{|c|}{$\mathrm{S}$} & all & all \\
\hline $\mathrm{PM}_{2.5}$ & all & all & \multicolumn{2}{|c|}{$\mathrm{S}$} & all & all & \multicolumn{2}{|c|}{$\mathrm{S}$} \\
\hline
\end{tabular}

CO monitored but not calibrated weekly

Masks used for black carbon on all filter samples $\left(\mathrm{PM}_{10}\right.$ and $\left.\mathrm{PM}_{2.5}\right)$

VOC samples collected during two 4-week periods in Jan-Feb 2002. 
Table 2.5. Co-location events for PEM validation.

\begin{tabular}{cccccccccc}
\hline Event & $\begin{array}{c}\text { Begin } \\
\text { date }\end{array}$ & $\begin{array}{c}\text { End } \\
\text { date }\end{array}$ & Site $\begin{array}{c}\text { Sample } \\
\text { time } \\
(\mathrm{min})\end{array}$ & $\begin{array}{c}\text { Mean } \\
\mathrm{PM}_{2.5}\end{array}$ & $\begin{array}{c}\text { Mean } \\
\left.\mathrm{PM}_{2.5} / \text { filter }\right) \\
\left(\mu \mathrm{g} / \mathrm{m}^{3}\right)\end{array}$ & $\begin{array}{c}\text { Mean } \\
\mathrm{PM}_{10} \text { mass } \\
(\mu \mathrm{g} / \mathrm{filter})\end{array}$ & $\begin{array}{c}\text { Mean } \\
\mathrm{PM}_{10}\left(\mu \mathrm{g} / \mathrm{m}^{3}\right)\end{array}$ & $\begin{array}{c}\text { Mean BC } \\
\text { conc. }^{1} \\
\left(\mu \mathrm{g} / \mathrm{m}^{3}\right)\end{array}$ \\
\hline 1 & 27-Feb & 28-Feb LBNL & 1275 & 19 & 7.5 & 23 & 8.9 & $\mathrm{NA}$ \\
2 & 28-Feb & 5-Mar LBNL & 6705 & 74 & 7.1 & 119 & 11.4 & 1.05 \\
3 & 5-Mar & 8-Mar & LBNL & 4740 & 65 & 6.9 & 171 & 18.1 & 1.35 \\
4 & 16-Jul & 20-Jul & 10 & 5876 & $\mathrm{NA}$ & $\mathrm{NA}$ & 321 & 27.3 & 2.25 \\
5 & 20-Jul & 25-Jul & 10 & 7075 & 124 & 8.7 & $\mathrm{NA}$ & $\mathrm{NA}$ & $\mathrm{NA}$ \\
6 & 26-Jul & 30-Jul & 10 & 5874 & 121 & 10.2 & $\mathrm{NA}$ & $\mathrm{NA}$ & $\mathrm{NA}$ \\
7 & 30-Jul & 6-Aug & 10 & 10114 & $\mathrm{NA}$ & $\mathrm{NA}$ & 300 & 14.8 & 0.56 \\
\hline
\end{tabular}

Table 2.6. Response of each PEM relative to event averages.

\begin{tabular}{cccccc}
\hline & & Mass & BC & Mass & BC \\
PEM \# & Cut Size $(\mu \mathrm{m})$ & Mean & Mean & Stdev. & Stdev. \\
\hline 1 & 2.5 & 0.96 & 1.00 & 0.11 & 0.04 \\
2 & 2.5 & 0.96 & 0.95 & 0.18 & 0.03 \\
3 & 2.5 & 0.93 & 0.98 & 0.03 & 0.04 \\
4 & 2.5 & 0.98 & 1.01 & 0.05 & 0.03 \\
5 & 2.5 & 1.05 & 1.02 & 0.11 & 0.04 \\
6 & 2.5 & 0.95 & 1.03 & 0.17 & 0.08 \\
7 & 2.5 & 1.03 & 1.02 & 0.06 & 0.04 \\
8 & 2.5 & 1.09 & 1.01 & 0.08 & 0.04 \\
9 & 2.5 & 0.96 & 1.02 & 0.08 & 0.04 \\
10 & 2.5 & 1.10 & 0.98 & 0.11 & 0.05 \\
21 & 2.5 & 0.99 & 0.96 & 0.03 & 0.04 \\
11 & 10 & 1.01 & 1.02 & 0.01 & 0.06 \\
12 & 10 & 0.96 & 1.02 & 0.05 & 0.03 \\
13 & 10 & 0.99 & 1.00 & 0.05 & 0.02 \\
14 & 10 & 1.08 & 0.98 & 0.09 & 0.04 \\
15 & 10 & 1.03 & 0.96 & 0.10 & 0.05 \\
16 & 10 & 1.00 & 0.96 & 0.07 & 0.05 \\
17 & 10 & 0.93 & 1.00 & 0.08 & 0.03 \\
18 & 10 & 1.01 & 1.03 & 0.07 & 0.05 \\
19 & 10 & $0.98 *$ & 1.04 & $0.05 *$ & 0.04 \\
20 & 10 & 0.91 & 1.02 & 0.03 & 0.03 \\
22 & 10 & 0.97 & 0.95 & 0.02 & 0.03 \\
\hline
\end{tabular}

*PEM19 mean and stdev. doesn't include event 4. 
Table 2.7. Co-located field samples of $\mathrm{NO}_{\mathrm{X}}$ and $\mathrm{NO}_{2}$ during spring monitoring period.

\begin{tabular}{|cc|ccc|ccc|}
\hline Week School & $\begin{array}{c}\text { Sampler 1 } \\
\mathrm{NO}_{\mathrm{X}}(\mathrm{ng})\end{array}$ & $\begin{array}{c}\text { Sampler 2 } \\
\mathrm{NO}_{\mathrm{x}}(\mathrm{ng})\end{array}$ & $\begin{array}{c}\mathrm{NO}_{\mathrm{X}} \\
\text { Deviation* }\end{array}$ & $\begin{array}{c}\text { Sampler 1 } \\
\mathrm{NO}_{2}(\mathrm{ng})\end{array}$ & $\begin{array}{c}\text { Sampler 2 } \\
\mathrm{NO}_{2}(\mathrm{ng})\end{array}$ & $\begin{array}{c}\mathrm{NO}_{2} \\
\text { Deviation* }\end{array}$ \\
\hline 3 & 10 & 10888 & 10434 & 0.04 & 4416 & 4452 & 0.01 \\
9 & 10 & 9937 & 10128 & 0.02 & 5446 & 5404 & 0.01 \\
11 & 8 & 6759 & 4487 & 0.34 & 3705 & 3028 & 0.18 \\
13 & 10 & 9737 & 9872 & 0.01 & 6361 & 6104 & 0.04 \\
14 & 5 & 10737 & 11965 & 0.11 & 6254 & 5513 & 0.12 \\
\hline
\end{tabular}

$*$ Deviation $=$ absolute value of the difference divided by the average.

Table 2.8. Co-located field samples for $\mathrm{NO}_{\mathrm{X}}$ and $\mathrm{NO}_{2}$ during fall monitoring period.

\begin{tabular}{|cc|ccc|ccc|}
\hline Wk & School & $\begin{array}{c}\text { Sampler 1 } \\
\mathrm{NO}_{\mathrm{X}}(\mathrm{ng})\end{array}$ & $\begin{array}{c}\text { Sampler 2 } \\
\mathrm{NO}_{\mathrm{X}}(\mathrm{ng})\end{array}$ & $\begin{array}{c}\mathrm{NO}_{\mathrm{X}} \\
\text { Deviation* }\end{array}$ & $\begin{array}{c}\text { Sampler 1 } \\
\mathrm{NO}_{2}(\mathrm{ng})\end{array}$ & $\begin{array}{c}\text { Sampler 2 } \\
\mathrm{NO}_{2}(\mathrm{ng})\end{array}$ & $\begin{array}{c}\mathrm{NO}_{2} \\
\text { Deviation* }\end{array}$ \\
\hline 15 & 1 & 6530 & 6931 & 0.06 & 3821 & 3741 & 0.02 \\
15 & 6 & 6618 & 6442 & 0.03 & 3693 & 3797 & 0.03 \\
15 & 10 & 10003 & 9787 & 0.02 & 4840 & 4760 & 0.02 \\
16 & 6 & 4315 & 4271 & 0.01 & 2724 & 2767 & 0.02 \\
16 & 9 & 8191 & 8043 & 0.02 & 4161 & 3943 & 0.06 \\
17 & 1 & 9464 & 9668 & 0.02 & 5285 & 5350 & 0.01 \\
17 & 9 & 12978 & 12764 & 0.02 & 5535 & 5888 & 0.06 \\
18 & 2 & 12428 & 11456 & 0.08 & 4602 & 4688 & 0.02 \\
18 & 7 & 6996 & 6619 & 0.06 & 3881 & 3865 & 0.00 \\
20 & 3 & 10940 & 10817 & 0.01 & 4654 & 4593 & 0.01 \\
20 & 8 & 8654 & 7813 & 0.11 & 4050 & 4198 & 0.04 \\
21 & 4 & 10980 & 11683 & 0.06 & 4401 & 4527 & 0.03 \\
21 & 9 & 14099 & 15050 & 0.06 & 5033 & 5204 & 0.03 \\
22 & 8 & 7662 & 7349 & 0.04 & 3840 & 3702 & 0.04 \\
\hline
\end{tabular}

$*$ Deviation $=$ absolute value of the difference divided by the average. 
Table 2.9. Target VOCs associated with gasoline (group 1) and diesel (group 2) vehicle use.

\begin{tabular}{|l|c|c|c|c|}
\hline Compound & Group & $\begin{array}{c}\text { Sampling } \\
\text { rate }^{1} \\
\left.\mathrm{~cm}^{3} / \mathrm{min}\right)\end{array}$ & $\begin{array}{c}\text { Mean (stdev.) } \\
\text { mass on blanks } \\
\text { (ng/ } \mu \text { L extract) }\end{array}$ & $\begin{array}{c}\text { Mass range on } \\
\text { spring samples } \\
(\mathrm{ng} / \mu \text { L extract) }\end{array}$ \\
\hline Methylcyclopentane & 1 & $32^{2}$ & n.d. & $0.6-1.1$ \\
2-Methylhexane & 1 & $32^{2}$ & n.d. & $0.3-0.6$ \\
3-Methylhexane & 1 & $32^{2}$ & n.d. & $0.7-1.8$ \\
2,2,4-Trimethypentane & 1 & $32^{2}$ & $0.26(0.05)$ & $0.6-1.2$ \\
n-Heptane & 1 & 28.9 & n.d. & $0.3-1.4$ \\
Benzene & 1 & 35.5 & n.d. & $0.7-1.5$ \\
Methylcyclohexane & 1 & 28.9 & n.d. & $0.24-0.44$ \\
Toluene & 1 & 31.4 & $0.13(0.02)$ & $2.9-8.5$ \\
Ethylbenzene & 1 & 27.3 & n.d. & $0.4-1.0$ \\
m,p-Xylene & 1 & 27.3 & n.d. & $1.3-3.0$ \\
o-Xylene & 1 & 30.8 & n.d. & $0.5-1.1$ \\
3-Ethyltoluene & 1 & $30^{2}$ & n.d. & $0.3-0.5$ \\
1,2,4-Trimethylbenzene & 1 & $28.4^{3}$ & n.d. & $0.4-1.3$ \\
n-Undecane & 2 & $21^{2}$ & $0.25(0.03)$ & $0.6-1.2$ \\
Decahydronapthalene & 2 & $20.1^{2}$ & n.d. & n.d.-0.5 \\
Naphthalene & 2 & 24.6 & $0.02(0.01)$ & $0.1-0.2$ \\
n-Dodecane & 2 & $20.1^{3}$ & $0.16(0.01)$ & $0.3-0.9$ \\
n-Tridecane & 2 & $19.0^{3}$ & $0.87(0.12)$ & $0.7-1.2$ \\
n-Tetradecane & 2 & $18.2^{3}$ & $0.87(0.09)$ & $0.8-1.2$ \\
n-Pentadecane & 2 & $17.5^{3}$ & $1.12(0.08)$ & $0.9-1.5$ \\
n-Hexadecane & 2 & $16.8^{3}$ & $1.67(0.25)$ & $1.4-3.2$ \\
n-Heptadecane & 2 & $16.3^{3}$ & $1.41(0.27)$ & $1.0-3.8$ \\
\hline
\end{tabular}

(1) 3M Technical Data Bulletin 1028, Organic Vapor Monitor Sampling and Analysis Guide, 10/01/99.

(2) Shields, H.C. and C.J. Weschler, JAPCA 37: 1039-1045 (1987).

(3) Value inferred from sampling rates for similar compounds.

(4) Non-detectable amounts.

(3) Combined cis- and trans- isomers. 
Table 2.10. Summary statistics comparing inside versus outside equipment housing deployment of passive VOC samplers, based on analysis of samples from eight schools.

\begin{tabular}{lccccc}
\hline & Mean & Stdev. & RSD & T value & T dist. \\
\hline Methylcyclopentane & 0.94 & 0.06 & 0.06 & 0.013 & 0.990 \\
2-Methylhexane & 0.94 & 0.07 & 0.07 & 0.046 & 0.965 \\
3-Methylhexane & 0.95 & 0.06 & 0.06 & 0.032 & 0.975 \\
2,2,4-Trimethylpentane & 0.97 & 0.09 & 0.10 & 0.391 & 0.707 \\
n-Heptane & 0.95 & 0.11 & 0.12 & 0.265 & 0.799 \\
Benzene & 0.94 & 0.05 & 0.05 & 0.009 & 0.993 \\
Methylcyclohexane & 0.93 & 0.06 & 0.07 & 0.010 & 0.993 \\
Toluene & 0.94 & 0.04 & 0.05 & 0.004 & 0.997 \\
Ethylbenzene & 0.96 & 0.05 & 0.05 & 0.042 & 0.968 \\
m,p-Xylene & 0.95 & 0.04 & 0.05 & 0.008 & 0.994 \\
o-Xylene & 0.95 & 0.04 & 0.04 & 0.003 & 0.998 \\
3-Ethyltoluene & 1.04 & 0.27 & 0.26 & 0.635 & 0.545 \\
1,2,4-Trimethylbenzene & 0.98 & 0.14 & 0.14 & 0.848 & 0.424 \\
n-Undecane & 0.94 & 0.31 & 0.33 & 0.451 & 0.666 \\
n-Dodecane & 0.93 & 0.23 & 0.24 & 0.306 & 0.768 \\
\hline
\end{tabular}


Table 3.1. Data completeness for spring monitoring period

\begin{tabular}{|c|c|c|c|c|}
\hline Pollutant, Period ${ }^{1}$ & Location & $\begin{array}{c}\text { Attempted } \\
\text { Measurements }\end{array}$ & $\begin{array}{c}\text { Valid } \\
\text { Measurements }\end{array}$ & $\begin{array}{c}\text { Percent } \\
\text { Valid }\end{array}$ \\
\hline \multirow[t]{2}{*}{$\mathrm{CO}_{2}$} & Outdoor & 118 & 111 & 94 \\
\hline & Indoor & 10 & 10 & 100 \\
\hline \multirow[t]{2}{*}{$\mathrm{NO}_{2}, 24-\mathrm{h}$} & Outdoor & 118 & 105 & 89 \\
\hline & Indoor & 10 & 9 & 90 \\
\hline \multirow[t]{2}{*}{$\mathrm{NO}_{\mathrm{X}}, 24-\mathrm{h}$} & Outdoor & 118 & 97 & 82 \\
\hline & Indoor & 10 & 9 & 90 \\
\hline $\mathrm{PM}_{2.5}, 24-\mathrm{h}$ & Outdoor & 68 & 63 & 93 \\
\hline \multirow[t]{2}{*}{$\mathrm{PM}_{2.5}$, School-h } & Outdoor & 40 & 36 & 90 \\
\hline & Indoor & 10 & 9 & 90 \\
\hline $\mathrm{PM}_{10}, 24-\mathrm{h}$ & Outdoor & 68 & 56 & 82 \\
\hline \multirow[t]{2}{*}{$\mathrm{PM}_{10}$, School-h } & Outdoor & 40 & 35 & 88 \\
\hline & Indoor & 10 & 9 & 90 \\
\hline $2.5-\mu \mathrm{m} \mathrm{BC}, 24-\mathrm{h}$ & Outdoor & 68 & 67 & 99 \\
\hline $2.5-\mu \mathrm{m}$ BC, School-h & Outdoor & 40 & 33 & 83 \\
\hline $10-\mu \mathrm{m} \mathrm{BC}, 24-\mathrm{h}$ & Outdoor & 68 & 65 & 96 \\
\hline \multirow[t]{2}{*}{$10-\mu \mathrm{m} \mathrm{BC}$, School-h } & Outdoor & 40 & 37 & 93 \\
\hline & Indoor & 10 & 9 & 90 \\
\hline VOCs & Outdoor & 29 & 27 & 93 \\
\hline
\end{tabular}

(1) Sampling over 1-week periods for 24-hour sampling, 1- or 2-week periods for school-hour sampling, and 4-week integrated sampling for VOCs.

(2) Hourly data used to calculate averages for 24-hour and school-hour sampling periods. Time-resolved; 10-min average data also available. 
Table 3.2. Data completeness for fall monitoring period.

\begin{tabular}{|lccc|}
\hline Pollutant & $\begin{array}{c}\text { Attempted } \\
\text { Measurements }\end{array}$ & $\begin{array}{c}\text { Valid } \\
\text { Measurements }\end{array}$ & Percent Valid \\
\hline $\mathrm{NO}_{2}$ & 80 & 80 & 100 \\
$\mathrm{NO}_{\mathrm{X}}$ & 80 & 80 & 100 \\
$\mathrm{PM}_{2.5}$, All hours & 40 & 39 & 98 \\
$\mathrm{PM}_{2.5}$, School hours & 20 & 20 & 100 \\
$\mathrm{PM}_{10}$, All hours & 40 & 40 & 100 \\
$\mathrm{PM}_{10}$, School hours & 20 & 19 & 95 \\
2.5 -um BC, All hours & 40 & 40 & 100 \\
2.5-um BC, School hours & 20 & 20 & 100 \\
10-um BC, All hours & 40 & 40 & 100 \\
10-um BC, School hours & 20 & 19 & 95 \\
VOCs* & 20 & 20 & 100 \\
\hline
\end{tabular}

*Results for deployed in

Table 3.3. Ambient Air Quality Standards.

\begin{tabular}{|l|l|c|c|}
\hline Pollutant & Averaging time & CA standard & Federal primary standard \\
\hline \multirow{2}{*}{ PM $_{10}$ mass } & 24-hr & $50 \mu \mathrm{g} / \mathrm{m}^{3}$ & $150 \mu \mathrm{g} / \mathrm{m}^{3}$ \\
& Annual arithmetic mean & $20 \mu \mathrm{g} / \mathrm{m}^{3}$ & $50 \mu \mathrm{g} / \mathrm{m}^{3}$ \\
\hline \multirow{2}{*}{$\mathrm{PM}_{2.5}$ mass } & $24-\mathrm{hr}$ & $25 \mu \mathrm{g} / \mathrm{m}^{3} *$ & $65 \mu \mathrm{g} / \mathrm{m}^{3}$ \\
& Annual arithmetic mean & $12 \mu \mathrm{g} / \mathrm{m}^{3}$ & $15 \mu \mathrm{g} / \mathrm{m}^{3}$ \\
\hline \multirow{2}{*}{$\mathrm{CO}$} & 8-hr & $9 \mathrm{ppm}$ & $9 \mathrm{ppm}$ \\
& $1-\mathrm{hr}$ & $20 \mathrm{ppm}$ & $35 \mathrm{ppm}$ \\
\hline $\mathrm{NO}_{2}$ & Annual arithmetic mean & & $53 \mathrm{ppb}\left(100 \mu \mathrm{g} / \mathrm{m}^{3}\right)$ \\
\hline
\end{tabular}

*proposed but not adopted at the time of this report. 
Table 3.4. $\mathrm{NO}_{\mathrm{X}}$ concentrations (ppb) during fall, spring and both periods.

\begin{tabular}{|c|c|c|c|c|c|c|c|c|c|}
\hline \multirow{2}{*}{ School } & \multicolumn{3}{|c|}{ Fall } & \multicolumn{3}{|c|}{ Spring } & \multicolumn{3}{|c|}{ Both periods } \\
\hline & $\mathrm{n}^{*}$ & Mean & S.D. & $\mathrm{n}^{*}$ & Mean & S.D. & $\mathrm{n}^{*}$ & Mean & S.D. \\
\hline 1 & 8 & 52.4 & 13 & 10 & 33.8 & 10 & 18 & 42.1 & 15 \\
\hline 2 & 8 & 72.6 & 17 & 10 & 43.6 & 14 & 18 & 56.5 & 21 \\
\hline 3 & 8 & 65.3 & 20 & 10 & 39.1 & 13 & 18 & 50.8 & 21 \\
\hline 4 & 8 & 55.9 & 18 & 10 & 31.0 & 10 & 18 & 42.1 & 19 \\
\hline 5 & 8 & 67.1 & 14 & 10 & 53.8 & 10 & 18 & 59.7 & 14 \\
\hline 6 & 8 & 47.3 & 11 & 10 & 31.8 & 8 & 18 & 38.7 & 12 \\
\hline 7 & 8 & 38.2 & 9 & 9 & 28.2 & 8 & 17 & 32.9 & 10 \\
\hline 8 & 8 & 56.0 & 12 & 10 & 36.6 & 11 & 18 & 45.3 & 15 \\
\hline 9 & 8 & 68.4 & 13 & 9 & 48.8 & 14 & 17 & 58.0 & 16 \\
\hline 10 & 8 & 79.4 & 19 & 9 & 56.9 & 10 & 17 & 67.5 & 18 \\
\hline Avg.** & 8 & 60.3 & 14 & 10 & 40.2 & 10 & 18 & 49.1 & 15 \\
\hline
\end{tabular}

$*_{\mathrm{n}}=$ number of independent samples. All fall samples were collected over 1 week. During spring monitoring, there were two 2-week sampling periods. Each sample was weighted equally.

**Average of sampling period means. 
Table 3.5. $\mathrm{NO}_{2}$ concentrations (ppb) during fall, spring and both periods.

\begin{tabular}{|c|ccc|ccc|ccc|}
\hline \multirow{2}{*}{ School } & \multicolumn{3}{|c|}{ Fall } & \multicolumn{3}{c|}{ Spring } & \multicolumn{3}{c|}{ Both periods } \\
\hline 1 & 8 & 25.7 & 4.5 & 10 & 19.4 & 5.2 & 18 & 22.2 & 5.7 \\
2 & 8 & 29.1 & 5.3 & 11 & 21.1 & 6.4 & 19 & 24.5 & 7.1 \\
3 & 8 & 25.8 & 5.1 & 11 & 17.6 & 5.8 & 19 & 21.1 & 6.8 \\
4 & 8 & 23.7 & 4.7 & 11 & 15.5 & 5.1 & 19 & 18.9 & 6.3 \\
5 & 8 & 29.9 & 4.7 & 11 & 23.5 & 5.8 & 19 & 26.2 & 6.2 \\
6 & 8 & 24.6 & 4.6 & 11 & 18.5 & 6.0 & 19 & 21.1 & 6.2 \\
7 & 8 & 22.6 & 3.1 & 10 & 19.0 & 6.1 & 18 & 20.6 & 5.2 \\
8 & 8 & 26.1 & 4.6 & 11 & 21.3 & 6.6 & 19 & 23.3 & 6.2 \\
9 & 8 & 28.3 & 3.1 & 10 & 24.1 & 5.8 & 18 & 26.0 & 5.1 \\
10 & 8 & 32.1 & 3.5 & 9 & 29.6 & 6.0 & 17 & 30.8 & 5.0 \\
Avg.** & 8 & 26.8 & 4.1 & 11 & 20.7 & 5.6 & 19 & 23.2 & 5.8 \\
\hline
\end{tabular}

$*_{\mathrm{n}}=$ number of independent samples. All fall samples were collected over 1 week. During spring monitoring, there were two 2-week sampling periods. Each sample was weighted equally.

**Average of sampling period means.

Table 3.6. Normalized $\mathrm{NO}_{\mathrm{X}}$ concentrations during fall, spring and both periods.

\begin{tabular}{|c|ccc|ccc|ccc|}
\hline \multirow{2}{*}{ School } & \multicolumn{4}{|c|}{ Fall } & \multicolumn{3}{c|}{ Spring } & \multicolumn{3}{c|}{ Both periods } \\
& $\mathrm{n}^{*}$ & Mean & S.D. & $\mathrm{n} *$ & Mean & S.D. & $\mathrm{n}^{*}$ & Mean & S.D. \\
\hline 1 & 8 & 0.87 & 0.04 & 10 & 0.83 & 0.05 & 18 & 0.85 & 0.05 \\
2 & 8 & 1.21 & 0.07 & 10 & 1.07 & 0.10 & 18 & 1.13 & 0.11 \\
4 & 8 & 1.07 & 0.09 & 10 & 0.96 & 0.13 & 18 & 1.01 & 0.13 \\
5 & 8 & 0.91 & 0.10 & 10 & 0.76 & 0.08 & 18 & 0.83 & 0.12 \\
6 & 8 & 1.12 & 0.07 & 10 & 1.37 & 0.26 & 18 & 1.26 & 0.23 \\
7 & 8 & 0.78 & 0.06 & 10 & 0.79 & 0.04 & 18 & 0.79 & 0.05 \\
8 & 8 & 0.64 & 0.08 & 9 & 0.69 & 0.07 & 17 & 0.66 & 0.08 \\
9 & 8 & 1.15 & 0.09 & 9 & 1.18 & 0.11 & 17 & 1.17 & 0.10 \\
10 & 8 & 1.32 & 0.13 & 9 & 1.49 & 0.19 & 17 & 1.41 & 0.18 \\
\hline
\end{tabular}

$*_{\mathrm{n}}=$ number of independent samples. All fall samples were collected over 1 week. During spring monitoring, there were two 2-week sampling periods. Each sample was weighted equally. 
Table 3.7. Normalized $\mathrm{NO}_{2}$ concentrations during fall, spring and both periods.

\begin{tabular}{|c|ccc|ccc|ccc|}
\hline \multirow{2}{*}{ School } & \multicolumn{4}{|c|}{ Fall } & \multicolumn{3}{c|}{ Spring } & \multicolumn{3}{c|}{ Both periods } \\
& $\mathrm{n}^{*}$ & Mean & S.D. & $\mathrm{n}^{*}$ & Mean & S.D. & $\mathrm{n}^{*}$ & Mean & S.D. \\
\hline 1 & 8 & 0.95 & 0.03 & 10 & 0.91 & 0.04 & 18 & 0.93 & 0.04 \\
2 & 8 & 1.08 & 0.06 & 11 & 1.02 & 0.08 & 19 & 1.04 & 0.08 \\
3 & 8 & 0.96 & 0.05 & 11 & 0.84 & 0.09 & 19 & 0.89 & 0.09 \\
4 & 8 & 0.88 & 0.05 & 11 & 0.74 & 0.06 & 19 & 0.80 & 0.09 \\
5 & 8 & 1.12 & 0.07 & 11 & 1.15 & 0.08 & 19 & 1.14 & 0.07 \\
6 & 8 & 0.92 & 0.06 & 11 & 0.89 & 0.06 & 19 & 0.90 & 0.06 \\
7 & 8 & 0.85 & 0.07 & 10 & 0.89 & 0.08 & 18 & 0.87 & 0.08 \\
8 & 8 & 0.97 & 0.10 & 11 & 1.02 & 0.10 & 19 & 1.00 & 0.10 \\
9 & 8 & 1.07 & 0.08 & 10 & 1.16 & 0.12 & 18 & 1.12 & 0.11 \\
10 & 8 & 1.21 & 0.11 & 9 & 1.45 & 0.12 & 17 & 1.34 & 0.17 \\
\hline
\end{tabular}

$*_{\mathrm{n}}=$ number of independent samples. All fall samples were collected over 1 week. During spring monitoring, there were two 2-week sampling periods. Each sample was weighted equally.

Table 3.8. $\mathrm{PM}_{2.5}$ mass $\left(\mu \mathrm{g} \mathrm{m}^{-3}\right)$ for all-hours sampling during fall, spring and both periods.

\begin{tabular}{|c|ccc|ccc|ccc|}
\hline \multirow{2}{*}{ School } & \multicolumn{4}{|c|}{ Fall } & Mean & S.D. & $\mathrm{n} *$ & Spring & \multicolumn{3}{c|}{ Mean } & S.D. & $\mathrm{n}^{*}$ & Mean & S.D. \\
\hline 1 & 4 & 12.1 & 2.3 & 6 & 11.5 & 2.8 & 10 & 11.7 & 2.5 \\
2 & 4 & 13.5 & 1.4 & 6 & 12.9 & 3.6 & 10 & 13.1 & 2.9 \\
3 & 4 & 13.0 & 2.7 & 6 & 11.3 & 4.8 & 10 & 12.0 & 4.0 \\
4 & 4 & 11.6 & 2.3 & 7 & 11.5 & 5.4 & 11 & 11.5 & 4.4 \\
5 & 4 & 12.3 & 2.5 & 6 & 11.5 & 4.2 & 10 & 11.8 & 3.5 \\
6 & 4 & 11.5 & 2.6 & 5 & 12.2 & 3.3 & 9 & 11.9 & 2.8 \\
7 & 4 & 11.9 & 2.1 & 6 & 10.2 & 5.5 & 10 & 10.9 & 4.4 \\
8 & 3 & 12.4 & 2.7 & 7 & 11.8 & 3.8 & 10 & 12.0 & 3.4 \\
9 & 4 & 12.2 & 2.4 & 5 & 11.2 & 3.9 & 9 & 11.6 & 3.2 \\
10 & 4 & 14.4 & 2.5 & 5 & 15.5 & 3.0 & 9 & 15.0 & 2.7 \\
Avg.** & 4 & 12.5 & 2.2 & 7 & 11.7 & 3.7 & 11 & 12.0 & 3.1 \\
\hline
\end{tabular}

$*_{\mathrm{n}}=$ number of independent samples. All fall samples were collected over 1 week.

**Average of sampling period means.

Includes damage category 7 (consult database for details) 
Table 3.9. $\mathrm{PM}_{10}$ mass $\left(\mu \mathrm{g} \mathrm{m}^{-3}\right)$ for all-hours sampling during fall, spring and both periods.

\begin{tabular}{|c|ccc|ccc|ccc|}
\hline School & \multicolumn{4}{c}{ Fall } & \multicolumn{3}{c|}{ Spring } & \multicolumn{3}{c|}{ Both periods } \\
\hline 1 & 4 & 30.8 & 2.8 & 5 & 28.8 & 7.3 & 9 & 29.7 & 5.5 \\
2 & 4 & 31.3 & 3.0 & 5 & 27.3 & 7.2 & 9 & 29.1 & 5.8 \\
3 & 4 & 34.9 & 3.0 & 5 & 27.0 & 9.0 & 9 & 30.5 & 7.8 \\
4 & 4 & 31.7 & 3.9 & 5 & 28.1 & 7.3 & 9 & 29.7 & 6.0 \\
5 & 4 & 31.1 & 3.7 & 5 & 25.9 & 9.1 & 9 & 28.2 & 7.3 \\
6 & 4 & 32.6 & 3.6 & 4 & 30.5 & 8.2 & 8 & 31.5 & 6.0 \\
7 & 4 & 28.3 & 2.3 & 6 & 26.4 & 8.0 & 10 & 27.2 & 6.2 \\
8 & 4 & 30.4 & 6.5 & 6 & 26.7 & 7.2 & 10 & 28.1 & 6.8 \\
9 & 4 & 30.6 & 3.2 & 4 & 27.5 & 12.1 & 8 & 29.1 & 8.4 \\
10 & 4 & 32.7 & 3.1 & 5 & 32.0 & 9.0 & 9 & 32.3 & 6.7 \\
Avg. ${ }^{* *}$ & 4 & 31.4 & 3.2 & 7 & 26.7 & 7.6 & 11 & 28.4 & 6.6 \\
\hline
\end{tabular}

$* \mathrm{n}=$ number of independent samples. All fall samples were collected over 1 week.

**Average of sampling period means.

Includes damage category 7 (consult database for details)

Table 3.10. Normalized $\mathrm{PM}_{2.5}$ for all-hours sampling during fall, spring and both periods.

\begin{tabular}{|c|ccc|ccc|ccc|}
\hline \multirow{2}{*}{ School } & \multicolumn{4}{|c|}{ Fall } & \multicolumn{3}{c|}{ Spring } & \multicolumn{3}{c|}{ Both periods } \\
& $\mathrm{n}^{*}$ & Mean & S.D. & $\mathrm{n}^{*}$ & Mean & S.D. & $\mathrm{n}^{*}$ & Mean & S.D. \\
\hline 1 & 4 & 0.97 & 0.04 & 7 & 1.06 & 0.22 & 11 & 1.03 & 0.18 \\
2 & 4 & 1.10 & 0.12 & 7 & 1.20 & 0.29 & 11 & 1.16 & 0.24 \\
3 & 4 & 1.03 & 0.06 & 6 & 0.94 & 0.09 & 10 & 0.97 & 0.09 \\
5 & 4 & 0.93 & 0.03 & 7 & 0.96 & 0.16 & 11 & 0.95 & 0.13 \\
6 & 4 & 0.97 & 0.03 & 7 & 0.97 & 0.10 & 11 & 0.97 & 0.08 \\
7 & 4 & 0.91 & 0.07 & 5 & 0.97 & 0.09 & 9 & 0.95 & 0.08 \\
8 & 3 & 0.95 & 0.07 & 7 & 0.84 & 0.25 & 11 & 0.88 & 0.21 \\
9 & 4 & 0.97 & 0.05 & 5 & 1.00 & 0.18 & 9 & 0.99 & 0.13 \\
10 & 4 & 1.15 & 0.05 & 5 & 1.27 & 0.20 & 9 & 1.22 & 0.16 \\
\hline
\end{tabular}

$*_{\mathrm{n}}=$ number of independent samples. All fall samples were collected over 1 week. During spring monitoring, there were two 2 -week sampling periods. Each sample was weighted equally. Includes damage category 7 (consult database for details) 
Table 3.11. Normalized $\mathrm{PM}_{10}$ for all-hours sampling during fall, spring and both periods.

\begin{tabular}{|c|ccc|ccc|ccc|}
\hline \multirow{2}{*}{ School } & \multicolumn{4}{|c|}{ Fall } & \multicolumn{3}{|c|}{ Spring } & \multicolumn{3}{c|}{ Both periods } \\
& $\mathrm{n}^{*}$ & Mean & S.D. & $\mathrm{n}^{*}$ & Mean & S.D. & $\mathrm{n}^{*}$ & Mean & S.D. \\
\hline 1 & 4 & 0.98 & 0.02 & 5 & 1.00 & 0.09 & 9 & 0.99 & 0.07 \\
2 & 4 & 1.00 & 0.01 & 5 & 0.94 & 0.05 & 9 & 0.97 & 0.04 \\
3 & 4 & 1.11 & 0.03 & 5 & 1.05 & 0.07 & 9 & 1.07 & 0.06 \\
4 & 4 & 1.01 & 0.03 & 6 & 0.97 & 0.05 & 10 & 0.99 & 0.04 \\
5 & 4 & 0.99 & 0.06 & 5 & 0.98 & 0.07 & 9 & 0.98 & 0.06 \\
6 & 4 & 1.04 & 0.07 & 5 & 0.98 & 0.09 & 9 & 1.00 & 0.08 \\
7 & 4 & 0.90 & 0.02 & 6 & 0.98 & 0.14 & 10 & 0.95 & 0.12 \\
8 & 4 & 0.96 & 0.11 & 5 & 0.97 & 0.03 & 9 & 0.96 & 0.07 \\
9 & 4 & 0.97 & 0.07 & 4 & 1.00 & 0.12 & 8 & 0.99 & 0.10 \\
10 & 4 & 1.04 & 0.05 & 5 & 1.11 & 0.09 & 9 & 1.08 & 0.08 \\
\hline
\end{tabular}

$*_{n}=$ number of independent samples. All fall samples were collected over 1 week. During spring monitoring, there were two 2-week sampling periods. Each sample was weighted equally. Includes damage category 7 (consult database for details)

Table 3.12. $\mathrm{PM}_{2.5}$ mass $\left(\mu \mathrm{g} \mathrm{m}^{-3}\right)$ for school-hours sampling during fall, spring and both periods.

\begin{tabular}{|c|ccc|ccc|ccc|}
\hline \multirow{2}{*}{ School } & \multicolumn{3}{|c|}{ Fall } & \multicolumn{3}{c|}{ Spring } & \multicolumn{3}{c|}{ Both periods } \\
& $\mathrm{n}^{*}$ & Mean & S.D. & $\mathrm{n}^{*}$ & Mean & S.D. & $\mathrm{n}^{*}$ & Mean & S.D. \\
\hline 1 & 2 & 18.12 & 3.66 & 4 & 16.89 & 4.74 & 6 & 17.30 & 4.07 \\
3 & 2 & 18.62 & 2.95 & 3 & 15.58 & 2.52 & 5 & 16.80 & 2.85 \\
4 & 2 & 18.69 & 3.75 & 3 & 15.44 & 4.32 & 5 & 16.74 & 4.00 \\
5 & 2 & 17.17 & 5.00 & 4 & 13.74 & 3.22 & 6 & 14.88 & 3.79 \\
6 & 2 & 17.23 & 5.27 & 4 & 14.73 & 5.55 & 6 & 15.56 & 5.07 \\
7 & 2 & 19.00 & 4.20 & 4 & 15.14 & 4.99 & 6 & 16.43 & 4.74 \\
8 & 2 & 21.15 & 2.23 & 3 & 15.12 & 2.66 & 5 & 17.53 & 3.96 \\
9 & 2 & 17.99 & 4.91 & 3 & 13.24 & 4.32 & 5 & 15.14 & 4.70 \\
10 & 2 & 24.49 & 6.25 & 4 & 20.63 & 2.82 & 6 & 21.92 & 4.07 \\
Avg.** & 2 & 19.44 & 4.14 & 5 & 16.56 & 3.84 & 7 & 17.38 & 3.83 \\
\hline
\end{tabular}

$*_{n}=$ number of independent samples. All fall samples were collected over 1 week. During spring monitoring, there were two 2-week sampling periods. Each sample was weighted equally.

**Average of sampling period means. 
Table 3.13. $\mathrm{PM}_{10}$ mass $\left(\mu \mathrm{g} \mathrm{m}^{-3}\right)$ for school-hours sampling during fall, spring and both periods.

\begin{tabular}{|c|ccc|ccc|ccc|}
\hline \multirow{2}{*}{ School } & \multicolumn{4}{|c|}{ Fall } & \multicolumn{3}{c|}{ Spring } & \multicolumn{3}{c|}{ Both periods } \\
& $\mathrm{n}^{*}$ & Mean & S.D. & $\mathrm{n} *$ & Mean & S.D. & $\mathrm{n}^{*}$ & Mean & S.D. \\
\hline 1 & 2 & 35.29 & 1.16 & 4 & 45.52 & 16.89 & 6 & 42.11 & 14.12 \\
2 & 2 & 35.86 & 2.14 & 4 & 27.24 & 5.55 & 6 & 30.11 & 6.26 \\
4 & 2 & 40.21 & 1.34 & 4 & 29.13 & 6.57 & 6 & 32.82 & 7.68 \\
5 & 2 & 33.40 & 0.62 & 3 & 27.73 & 2.48 & 5 & 30.00 & 3.58 \\
6 & 2 & 38.01 & 6.79 & 4 & 31.62 & 8.90 & 6 & 33.75 & 8.22 \\
7 & 2 & 36.17 & 0.45 & 4 & 32.24 & 10.89 & 6 & 33.55 & 8.68 \\
8 & 2 & 32.32 & 2.50 & 3 & 29.28 & 6.35 & 5 & 30.50 & 4.95 \\
9 & 2 & 35.54 & 0.80 & 3 & 28.97 & 8.69 & 5 & 31.60 & 7.14 \\
10 & 2 & 39.71 & 2.59 & 4 & 34.66 & 5.86 & 6 & 36.34 & 5.36 \\
Avg.** & 2 & 35.94 & 0.65 & 5 & 33.68 & 9.23 & 7 & 34.33 & 7.62 \\
\hline
\end{tabular}

$*_{n}=$ number of independent samples. All fall samples were collected over 1 week. During spring monitoring, there were two 2-week sampling periods. Each sample was weighted equally.

**Average of sampling period means.

Table 3.14. Normalized $\mathrm{PM}_{2.5}$ for school-hours sampling during fall, spring and both periods.

\begin{tabular}{|c|ccc|ccccccc|}
\hline \multirow{2}{*}{ School } & \multicolumn{4}{|c|}{ Fall } & \multicolumn{3}{c|}{ Spring } & \multicolumn{3}{c|}{ Both periods } \\
& $\mathrm{n}^{*}$ & Mean & S.D. & $\mathrm{n} *$ & Mean & S.D. & $\mathrm{n}^{*}$ & Mean & S.D. \\
\hline 1 & 2 & 0.93 & 0.01 & 3 & 1.02 & 0.04 & 5 & 0.98 & 0.06 \\
3 & 2 & 0.96 & 0.05 & 2 & 0.96 & 0.01 & 4 & 0.96 & 0.03 \\
4 & 2 & 0.96 & 0.01 & 3 & 1.07 & 0.30 & 5 & 1.03 & 0.22 \\
5 & 2 & 0.88 & 0.07 & 3 & 0.87 & 0.06 & 5 & 0.87 & 0.05 \\
6 & 2 & 0.88 & 0.08 & 3 & 0.86 & 0.15 & 5 & 0.87 & 0.11 \\
7 & 2 & 1.14 & 0.08 & 3 & 0.97 & 0.08 & 5 & 1.03 & 0.12 \\
8 & 2 & 1.10 & 0.12 & 2 & 1.06 & 0.04 & 4 & 1.08 & 0.08 \\
9 & 2 & 0.92 & 0.06 & 3 & 0.90 & 0.11 & 5 & 0.91 & 0.09 \\
10 & 2 & 1.25 & 0.05 & 3 & 1.41 & 0.28 & 5 & 1.34 & 0.22 \\
\hline
\end{tabular}

$*_{n}=$ number of independent samples. All fall samples were collected over 1 week. During spring monitoring, there were two 2-week sampling periods and three 1-week periods, but only one-half of the schools were sampled during two of the 1-week periods. Normalized concentrations were calculated only for the three spring periods when all schools were sampled simultaneously. 
Table 3.15. Normalized $\mathrm{PM}_{10}$ for school-hours sampling during fall, spring and both periods.

\begin{tabular}{|c|ccc|ccc|ccc|}
\hline \multirow{2}{*}{ School } & \multicolumn{4}{|c|}{ Fall } & \multicolumn{3}{|c|}{ Spring } & \multicolumn{3}{c|}{ Both periods } \\
& $\mathrm{n}^{*}$ & Mean & S.D. & $\mathrm{n} *$ & Mean & S.D. & $\mathrm{n}^{*}$ & Mean & S.D. \\
\hline 1 & 2 & 0.98 & 0.01 & 3 & 1.24 & 0.02 & 5 & 1.14 & 0.14 \\
2 & 2 & 1.00 & 0.08 & 3 & 0.87 & 0.03 & 5 & 0.92 & 0.08 \\
3 & 2 & 1.12 & 0.06 & 3 & 0.94 & 0.08 & 5 & 1.01 & 0.12 \\
4 & 2 & 0.93 & 0.00 & 2 & 0.99 & 0.16 & 4 & 0.96 & 0.10 \\
5 & 2 & 1.06 & 0.17 & 3 & 0.94 & 0.07 & 5 & 0.98 & 0.12 \\
6 & 2 & 1.01 & 0.03 & 3 & 0.93 & 0.14 & 5 & 0.96 & 0.11 \\
7 & 2 & 0.92 & 0.02 & 1 & 0.96 & & 3 & 0.93 & 0.03 \\
8 & 2 & 0.90 & 0.05 & 2 & 1.08 & 0.05 & 4 & 0.99 & 0.11 \\
9 & 2 & 0.99 & 0.00 & 3 & 0.95 & 0.18 & 5 & 0.96 & 0.13 \\
10 & 2 & 1.11 & 0.09 & 3 & 1.10 & 0.10 & 5 & 1.10 & 0.09 \\
\hline
\end{tabular}

$*_{\mathrm{n}}=$ number of independent samples. All fall samples were collected over 1 week. During spring monitoring, there were two 2-week sampling periods and three 1-week periods, but only one-half of the schools were sampled during two of the 1-week periods. Normalized concentrations were calculated only for the three spring periods when all schools were sampled simultaneously.

Table 3.16. $\mathrm{BC}\left(\mu \mathrm{g} \mathrm{m}^{-3}\right)$ from $\mathrm{PM}_{2.5}$ all-hours sampling during fall, spring and both periods.

\begin{tabular}{|c|ccc|ccc|ccc|}
\hline \multirow{2}{*}{ School } & \multicolumn{3}{|c|}{ Fall } & \multicolumn{3}{|c|}{ Spring } & \multicolumn{3}{c|}{ Both periods } \\
& $\mathrm{N}^{\mathbf{a}}$ & Mean & S.D. & $\mathrm{N}^{\mathbf{a}}$ & Mean & S.D. & $\mathrm{N}^{\mathbf{a}}$ & Mean & S.D. \\
\hline 1 & 4 & 0.80 & 0.24 & 7 & 0.60 & 0.16 & 11 & 0.68 & 0.20 \\
3 & 4 & 0.96 & 0.27 & 7 & 0.75 & 0.24 & 11 & 0.83 & 0.26 \\
4 & 4 & 0.89 & 0.25 & 7 & 0.65 & 0.26 & 11 & 0.74 & 0.28 \\
5 & 4 & 0.86 & 0.25 & 7 & 0.64 & 0.21 & 11 & 0.72 & 0.24 \\
6 & 4 & 0.96 & 0.22 & 7 & 0.79 & 0.16 & 11 & 0.86 & 0.19 \\
7 & 4 & 0.69 & 0.18 & 7 & 0.60 & 0.18 & 11 & 0.63 & 0.18 \\
8 & 3 & 0.69 & 0.15 & 7 & 0.63 & 0.21 & 10 & 0.65 & 0.19 \\
9 & 4 & 0.99 & 0.25 & 6 & 0.85 & 0.30 & 10 & 0.90 & 0.28 \\
10 & 4 & 1.03 & 0.16 & 5 & 1.00 & 0.17 & 9 & 1.01 & 0.16 \\
Avg. & 4 & 0.87 & 0.23 & 7 & 0.70 & 0.20 & 11 & 0.76 & 0.22 \\
\hline
\end{tabular}

${ }^{\mathrm{a}} \mathrm{N}=$ number of independent samples. All fall samples were collected over 1 week. During spring monitoring, there were two 2-week sampling periods. Each sample was weighted equally.

${ }^{\mathrm{b}}$ Average of sampling period means. 
Table 3.17. $\mathrm{BC}\left(\mu \mathrm{g} \mathrm{m}^{-3}\right)$ from $\mathrm{PM}_{10}$ all-hours sampling during fall, spring and both periods.

\begin{tabular}{|c|ccc|ccc|ccc|}
\hline \multirow{2}{*}{ School } & \multicolumn{3}{|c|}{ Fall } & \multicolumn{3}{|c|}{ Spring } & \multicolumn{3}{c|}{ Both periods } \\
& $\mathrm{N}^{\mathrm{a}}$ & Mean & S.D. & $\mathrm{N}^{\mathrm{a}}$ & Mean & S.D. & $\mathrm{N}^{\mathrm{a}}$ & Mean & S.D. \\
\hline 1 & 4 & 1.03 & 0.20 & 7 & 0.58 & 0.14 & 11 & 0.74 & 0.28 \\
3 & 4 & 1.24 & 0.21 & 7 & 0.68 & 0.18 & 11 & 0.88 & 0.33 \\
4 & 4 & 1.26 & 0.25 & 7 & 0.64 & 0.20 & 11 & 0.87 & 0.37 \\
5 & 4 & 1.21 & 0.27 & 7 & 0.61 & 0.19 & 11 & 0.83 & 0.37 \\
6 & 4 & 1.21 & 0.26 & 6 & 0.71 & 0.13 & 10 & 0.91 & 0.31 \\
7 & 4 & 0.94 & 0.17 & 6 & 0.60 & 0.15 & 10 & 0.74 & 0.23 \\
8 & 4 & 0.96 & 0.17 & 7 & 0.58 & 0.15 & 11 & 0.72 & 0.24 \\
9 & 4 & 1.24 & 0.17 & 6 & 0.78 & 0.22 & 10 & 0.96 & 0.30 \\
10 & 4 & 1.36 & 0.21 & 5 & 0.90 & 0.15 & 9 & 1.10 & 0.30 \\
Avg. & 4 & 1.13 & 0.19 & 7 & 0.65 & 0.16 & 11 & 0.82 & 0.29 \\
\hline
\end{tabular}

${ }^{a} \mathrm{~N}=$ number of independent samples. All fall samples were collected over 1 week. During spring monitoring, there were two 2-week sampling periods. Each sample was weighted equally.

${ }^{\mathrm{b}}$ Average of sampling period means.

Table 3.18. Normalized $\mathrm{BC}$ concentrations from $\mathrm{PM}_{2.5}$ for all-hours sampling during fall, spring and both periods.

\begin{tabular}{|c|ccc|ccc|ccc|}
\hline \multirow{2}{*}{ School } & \multicolumn{3}{|c|}{ Fall } & \multicolumn{3}{|c|}{ Spring } & \multicolumn{3}{c|}{ Both periods } \\
\hline 1 & 4 & 0.91 & 0.04 & 7 & 0.88 & 0.08 & 11 & 0.89 & 0.07 \\
2 & 4 & 1.09 & 0.04 & 7 & 1.07 & 0.08 & 11 & 1.08 & 0.06 \\
3 & 4 & 1.02 & 0.05 & 7 & 0.91 & 0.16 & 11 & 0.95 & 0.14 \\
4 & 4 & 0.98 & 0.05 & 7 & 0.91 & 0.08 & 11 & 0.93 & 0.08 \\
5 & 4 & 1.11 & 0.05 & 7 & 1.17 & 0.14 & 11 & 1.15 & 0.12 \\
6 & 4 & 0.84 & 0.06 & 7 & 0.85 & 0.07 & 11 & 0.85 & 0.07 \\
7 & 4 & 0.79 & 0.02 & 7 & 0.85 & 0.08 & 11 & 0.83 & 0.07 \\
8 & 3 & 0.88 & 0.05 & 7 & 0.90 & 0.06 & 10 & 0.89 & 0.06 \\
9 & 4 & 1.14 & 0.06 & 6 & 1.22 & 0.08 & 10 & 1.18 & 0.08 \\
10 & 4 & 1.21 & 0.15 & 5 & 1.39 & 0.25 & 9 & 1.31 & 0.22 \\
\hline
\end{tabular}

$* n=$ Number of independent samples. 
Table 3.19. Normalized $\mathrm{BC}$ concentrations from $\mathrm{PM}_{10}$ for all-hours sampling during fall, spring and both periods.

\begin{tabular}{|c|ccc|ccc|ccc|}
\hline \multirow{2}{*}{ School } & \multicolumn{3}{|c|}{ Fall } & \multicolumn{3}{c|}{ Spring } & \multicolumn{3}{c|}{ Both periods } \\
& $\mathrm{n}^{*}$ & Mean & S.D. & $\mathrm{n} *$ & Mean & S.D. & $\mathrm{n}^{*}$ & Mean & S.D. \\
\hline 1 & 4 & 0.91 & 0.02 & 7 & 0.89 & 0.09 & 11 & 0.90 & 0.07 \\
3 & 4 & 1.09 & 0.02 & 7 & 1.05 & 0.08 & 11 & 1.06 & 0.07 \\
4 & 4 & 1.11 & 0.03 & 7 & 0.98 & 0.10 & 11 & 1.03 & 0.11 \\
5 & 4 & 1.06 & 0.06 & 7 & 0.93 & 0.09 & 11 & 0.98 & 0.10 \\
6 & 4 & 1.07 & 0.09 & 6 & 1.12 & 0.14 & 10 & 1.10 & 0.12 \\
7 & 4 & 0.83 & 0.02 & 6 & 0.88 & 0.08 & 10 & 0.86 & 0.06 \\
8 & 4 & 0.85 & 0.07 & 7 & 0.89 & 0.04 & 11 & 0.88 & 0.05 \\
9 & 4 & 1.10 & 0.10 & 6 & 1.18 & 0.09 & 10 & 1.15 & 0.10 \\
10 & 4 & 1.21 & 0.09 & 5 & 1.38 & 0.20 & 9 & 1.30 & 0.18 \\
\hline
\end{tabular}

$* \mathrm{n}=$ Number of independent samples.

Table 3.20. $\mathrm{BC}\left(\mu \mathrm{g} \mathrm{m}^{-3}\right)$ from $\mathrm{PM}_{2.5}$ school-hours sampling during fall, spring and both periods.

\begin{tabular}{|c|ccc|ccc|ccc|}
\hline \multirow{2}{*}{ School } & \multicolumn{3}{|c|}{ Fall } & \multicolumn{3}{|c|}{ Spring } & \multicolumn{3}{c|}{ Both periods } \\
& $\mathrm{N}^{\mathrm{a}}$ & Mean & S.D. & $\mathrm{N}^{\mathrm{a}}$ & Mean & S.D. & $\mathrm{N}^{\mathrm{a}}$ & Mean & S.D. \\
\hline 1 & 2 & 1.44 & 0.08 & 4 & 0.86 & 0.41 & 6 & 1.05 & 0.44 \\
3 & 2 & 1.51 & 0.18 & 3 & 0.81 & 0.42 & 5 & 1.09 & 0.49 \\
4 & 2 & 1.47 & 0.28 & 3 & 0.92 & 0.19 & 5 & 1.14 & 0.36 \\
5 & 2 & 1.48 & 0.33 & 3 & 0.76 & 0.28 & 5 & 1.05 & 0.47 \\
6 & 2 & 1.66 & 0.31 & 4 & 1.30 & 0.50 & 6 & 1.42 & 0.45 \\
7 & 2 & 1.21 & 0.04 & 4 & 0.86 & 0.55 & 6 & 0.97 & 0.46 \\
8 & 2 & 1.57 & 0.10 & 2 & 0.68 & 0.12 & 4 & 1.12 & 0.52 \\
9 & 2 & 1.86 & 0.09 & 3 & 1.09 & 0.48 & 5 & 1.40 & 0.54 \\
10 & 2 & 2.39 & 0.35 & 4 & 2.09 & 0.44 & 6 & 2.19 & 0.41 \\
Avg. & 2 & 1.60 & 0.18 & 4 & 1.14 & 0.42 & 6 & 1.30 & 0.41 \\
\hline
\end{tabular}

${ }^{\mathrm{a}} \mathrm{N}=$ number of independent samples. All fall samples were collected over 1 week. During spring monitoring, there were two 2-week sampling periods. Each sample was weighted equally.

${ }^{\mathrm{b}}$ Average of sampling period means. 
Table 3.21. $\mathrm{BC}\left(\mu \mathrm{g} \mathrm{m}^{-3}\right)$ from $\mathrm{PM}_{10}$ school-hours sampling during fall, spring and both periods.

\begin{tabular}{|c|ccc|ccc|ccc|}
\hline \multirow{2}{*}{ School } & \multicolumn{3}{|c|}{ Fall } & \multicolumn{3}{|c|}{ Spring } & \multicolumn{3}{c|}{ Both periods } \\
& $\mathrm{N}^{\mathbf{a}}$ & Mean & S.D. & $\mathrm{N}^{\mathbf{a}}$ & Mean & S.D. & $\mathrm{N}^{\mathbf{a}}$ & Mean & S.D. \\
\hline 1 & 2 & 1.25 & 0.17 & 4 & 0.88 & 0.12 & 6 & 1.01 & 0.22 \\
3 & 2 & 1.31 & 0.22 & 4 & 0.68 & 0.22 & 6 & 0.89 & 0.38 \\
4 & 2 & 1.35 & 0.35 & 4 & 0.63 & 0.21 & 6 & 0.87 & 0.43 \\
5 & 2 & 1.30 & 0.28 & 3 & 0.57 & 0.06 & 5 & 0.86 & 0.42 \\
6 & 1 & 1.34 & - & 4 & 0.80 & 0.28 & 5 & 0.91 & 0.34 \\
7 & 2 & 1.29 & 0.15 & 4 & 0.69 & 0.30 & 6 & 0.89 & 0.39 \\
8 & 2 & 1.17 & 0.10 & 3 & 0.64 & 0.07 & 5 & 0.85 & 0.30 \\
9 & 2 & 1.50 & 0.11 & 3 & 1.00 & 0.12 & 5 & 1.20 & 0.29 \\
10 & 2 & 2.04 & 0.30 & 4 & 1.59 & 0.12 & 6 & 1.74 & 0.28 \\
Avg. ${ }^{\text {b }}$ & 2 & 1.41 & 0.19 & 5 & 0.88 & 0.29 & 7 & 1.03 & 0.36 \\
\hline
\end{tabular}

${ }^{a} \mathrm{~N}=$ number of independent samples. All fall samples were collected over 1 week. During spring monitoring, there were two 2-week sampling periods. Each sample was weighted equally.

${ }^{\mathrm{b}}$ Average of sampling period means.

Table 3.22. Normalized BC concentrations for school-hours sampling during fall, spring and both monitoring periods.

\begin{tabular}{|c|ccc|ccc|ccc|}
\hline \multirow{2}{*}{ School } & \multicolumn{3}{|c|}{ Fall } & \multicolumn{3}{c|}{ Spring } & \multicolumn{3}{c|}{ Both periods } \\
& $\mathrm{n}^{*}$ & Mean & S.D. & $\mathrm{n}^{*}$ & Mean & S.D. & $\mathrm{n}^{*}$ & Mean & S.D. \\
\hline 1 & 4 & 0.90 & 0.04 & 3 & 0.86 & 0.06 & 7 & 0.89 & 0.05 \\
2 & 4 & 0.96 & 0.02 & 3 & 0.74 & 0.10 & 7 & 0.86 & 0.13 \\
4 & 4 & 0.94 & 0.08 & 3 & 0.86 & 0.13 & 7 & 0.91 & 0.10 \\
5 & 4 & 0.91 & 0.06 & 3 & 0.74 & 0.12 & 7 & 0.84 & 0.12 \\
6 & 4 & 1.08 & 0.07 & 3 & 1.18 & 0.12 & 7 & 1.12 & 0.10 \\
7 & 4 & 0.79 & 0.11 & 3 & 0.77 & 0.20 & 6 & 0.78 & 0.14 \\
8 & 4 & 0.91 & 0.08 & 2 & 0.88 & 0.06 & 6 & 0.90 & 0.07 \\
9 & 4 & 1.11 & 0.06 & 3 & 1.08 & 0.06 & 7 & 1.10 & 0.06 \\
10 & 4 & 1.45 & 0.05 & 3 & 1.94 & 0.35 & 7 & 1.66 & 0.33 \\
\hline
\end{tabular}

$*^{*} \mathrm{n}=$ number of independent samples. Spring results are based on the average normalized school hours black carbon associated with $\mathrm{PM}_{10}$ and $\mathrm{PM}_{2.5}$ (sampled on the same weeks), and include two 2-week samples and one 1-week sample. Fall results are based on two 2-week $\mathrm{PM}_{10}$ and two 2-week $\mathrm{PM}_{2.5}$ samples. 
Table 3.23. Mean VOC concentrations $\left(\mu \mathrm{g} \mathrm{m}^{-3}\right)$ measured at each school (S1-S10) during 8-12 weeks of passive sampling during spring monitoring period. Also shown are the valid sampling periods (A, B and C) for each school.

\begin{tabular}{|c|c|c|c|c|c|c|c|c|c|c|}
\hline Compound & S1 & S2 & S3 & S4 & S5 & S6 & S7 & S8 & S9 & S10 \\
\hline Methylcyclopentane & 1.05 & 0.91 & 1.02 & 0.91 & 1.17 & 0.86 & 0.81 & 1.04 & 1.06 & 1.36 \\
\hline 2-Methylhexane & 0.49 & 0.42 & 0.46 & 0.42 & 0.53 & 0.40 & 0.37 & 0.47 & 0.62 & 0.63 \\
\hline $2,2,4-\mathrm{TMP}^{1}$ & 0.98 & 0.80 & 0.95 & 0.71 & 0.99 & 0.74 & 0.69 & 0.93 & 0.87 & 1.16 \\
\hline Heptane & 0.60 & 0.49 & 0.54 & 0.55 & 0.63 & 0.48 & 0.43 & 0.56 & 1.19 & 0.73 \\
\hline Benzene & 1.22 & 1.15 & 1.23 & 1.02 & 1.38 & 1.02 & 0.98 & 1.21 & 1.25 & 1.50 \\
\hline Methylcyclohexane & 0.51 & 0.39 & 0.46 & 0.45 & 0.52 & 0.36 & 0.33 & 0.43 & 0.50 & 0.58 \\
\hline Toluene & 4.43 & 3.76 & 4.20 & 3.81 & 4.70 & 3.38 & 3.20 & 4.24 & 7.22 & 5.59 \\
\hline Ethylbenzene & 0.62 & 0.53 & 0.59 & 0.56 & 0.66 & 0.48 & 0.47 & 0.59 & 0.79 & 0.73 \\
\hline m,p-Xylene & 2.58 & 2.20 & 2.47 & 2.27 & 2.76 & 1.98 & 1.93 & 2.45 & 3.22 & 3.12 \\
\hline o-Xylene & 0.91 & 0.78 & 0.86 & 0.80 & 0.97 & 0.70 & 0.69 & 0.86 & 1.15 & 1.07 \\
\hline 3-Ethyltoluene & 0.60 & 0.52 & 0.57 & 0.66 & 0.66 & 0.45 & 0.65 & 0.55 & 0.57 & 0.72 \\
\hline $1,2,4-\mathrm{TMB}^{2}$ & 0.81 & 0.69 & 0.79 & 0.80 & 0.89 & 0.62 & 0.99 & 0.76 & 0.77 & 0.99 \\
\hline Undecane (n-C11) & 0.07 & 0.06 & 0.09 & 0.08 & 0.09 & 0.08 & 0.11 & 0.09 & 0.10 & 0.10 \\
\hline Dodecane (n-C12) & 0.04 & 0.03 & 0.05 & 0.04 & 0.05 & 0.04 & 0.05 & 0.05 & 0.04 & 0.05 \\
\hline Sampling Periods & $\mathrm{A}-\mathrm{C}$ & $\mathrm{A}-\mathrm{C}$ & $\mathrm{A}-\mathrm{B}$ & $\mathrm{A}-\mathrm{C}$ & $\mathrm{A}-\mathrm{C}$ & $\mathrm{A}-\mathrm{C}$ & $\mathrm{A}-\mathrm{C}$ & $\mathrm{A}-\mathrm{C}$ & A-B & $\mathrm{B}-\mathrm{C}$ \\
\hline
\end{tabular}

(1) 2,2,4-trimethylpentane

(2) 1,2,4-trimethylbenzene 
Table 3.24. Mean VOC concentrations $\left(\mu \mathrm{g} \mathrm{m}^{-3}\right)$ measured at each school (S1-S10) during 8 weeks of passive sampling during winter monitoring (Jan-Feb 2002).

\begin{tabular}{lcccccccccc}
\hline Compound & S1 & S2 & S3 & S4 & S5 & S6 & S7 & S8 & S9 & S10 \\
\hline Methylcyclopentane & 2.23 & 2.08 & 2.42 & 2.45 & 2.49 & 1.56 & 1.42 & 2.08 & 1.99 & 3.41 \\
2-Methylhexane & 1.23 & 1.11 & 1.32 & 1.36 & 1.37 & 0.86 & 0.75 & 1.14 & 1.08 & 1.90 \\
3-Methylhexane & 1.88 & 1.81 & 2.09 & 2.19 & 2.08 & 1.36 & 1.28 & 1.83 & 1.69 & 2.87 \\
2,2,4-TMP & 2.36 & 2.10 & 2.31 & 2.40 & 2.37 & 1.75 & 1.61 & 2.03 & 2.06 & 3.53 \\
Heptane & 1.30 & 1.19 & 1.39 & 1.46 & 1.43 & 0.92 & 0.80 & 1.17 & 1.12 & 1.98 \\
Benzene & 2.92 & 2.82 & 3.06 & 3.03 & 3.12 & 2.21 & 2.00 & 2.72 & 2.63 & 3.83 \\
Methylcyclohexane & 1.00 & 0.92 & 1.07 & 1.12 & 1.11 & 0.69 & 0.60 & 0.86 & 0.85 & 1.48 \\
Toluene & 8.79 & 8.38 & 9.74 & 10.10 & 9.63 & 6.47 & 5.75 & 8.62 & 8.14 & 13.31 \\
Ethylbenzene & 1.34 & 1.26 & 1.45 & 1.52 & 1.47 & 0.93 & 1.00 & 1.23 & 1.17 & 1.94 \\
m,p-Xylene & 5.59 & 5.22 & 6.08 & 6.36 & 6.13 & 3.83 & 4.01 & 5.19 & 4.90 & 8.38 \\
o-Xylene & 1.89 & 1.80 & 2.06 & 2.18 & 2.06 & 1.31 & 1.34 & 1.78 & 1.68 & 2.82 \\
3-Ethyltoluene & 0.57 & 0.55 & 0.64 & 0.63 & 0.63 & 0.40 & 0.37 & 0.53 & 0.51 & 0.87 \\
1,2,4-TMB & 1.78 & 1.72 & 2.00 & 2.00 & 1.98 & 1.21 & 1.15 & 1.68 & 1.58 & 2.82 \\
\hline
\end{tabular}

(3) 2,2,4-trimethylpentane

(4) 1,2,4-trimethylbenzene 
Table 3.25. Correlation coefficients for pair-wise linear relationships for combined spring and fall monitoring data at all schools.

\begin{tabular}{|c|c|c|c|c|c|c|c|c|c|c|c|}
\hline $\begin{array}{l}\text { Correlation } \\
\text { coefficients }\end{array}$ & $\mathrm{NO}$ & $\mathrm{NO}_{2}$ & $\mathrm{NO}_{\mathrm{X}}$ & $\begin{array}{c}\mathrm{BC}_{10} \\
\text { School } \\
\text { hours }\end{array}$ & $\begin{array}{c}\mathrm{BC}_{10} \\
\text { All } \\
\text { hours } \\
\end{array}$ & $\begin{array}{c}\mathrm{BC}_{2.5} \\
\text { School } \\
\text { hours } \\
\end{array}$ & $\begin{array}{c}\mathrm{BC}_{2.5} \\
\text { All } \\
\text { hours } \\
\end{array}$ & $\begin{array}{c}\mathrm{PM}_{10} \\
\text { School } \\
\text { hours } \\
\end{array}$ & $\begin{array}{c}\mathrm{PM}_{10} \\
\text { All } \\
\text { hours } \\
\end{array}$ & $\begin{array}{c}\mathrm{PM}_{2.5} \\
\text { School } \\
\text { hours }\end{array}$ & $\begin{array}{c}\mathrm{PM}_{2.5} \\
\text { All } \\
\text { hours } \\
\end{array}$ \\
\hline $\mathrm{NO}$ & 1 & 0.697 & 0.968 & 0.678 & 0.895 & 0.606 & 0.824 & 0.071 & 0.403 & 0.408 & 0.474 \\
\hline $\mathrm{NO}_{2}$ & 0.697 & 1 & 0.854 & 0.807 & 0.687 & 0.759 & 0.834 & 0.196 & 0.771 & 0.541 & 0.792 \\
\hline $\mathrm{NO}_{\mathrm{X}}$ & 0.968 & 0.854 & 1 & 0.77 & 0.905 & 0.679 & 0.912 & 0.119 & 0.57 & 0.47 & 0.649 \\
\hline $\begin{array}{l}\mathrm{BC}_{10} \\
\text { School hours }\end{array}$ & 0.678 & 0.807 & 0.77 & 1 & . & 0.928 & 0.756 & 0.434 & . & 0.521 & 0.651 \\
\hline $\begin{array}{l}\mathrm{BC}_{10} \\
\text { All hours }\end{array}$ & 0.895 & 0.687 & 0.905 & . & 1 & 0.686 & 0.917 & . & 0.588 & 0.513 & 0.717 \\
\hline $\begin{array}{l}\mathrm{BC}_{2.5} \\
\text { School hours }\end{array}$ & 0.606 & 0.759 & 0.679 & 0.928 & 0.686 & 1 & . & 0.394 & 0.238 & 0.749 & . \\
\hline $\begin{array}{l}\mathrm{BC}_{2.5} \\
\text { All hours }\end{array}$ & 0.824 & 0.834 & 0.912 & 0.756 & 0.917 & . & 1 & 0.217 & 0.731 & . & 0.687 \\
\hline $\begin{array}{l}\mathrm{PM}_{10} \\
\text { School hours }\end{array}$ & 0.071 & 0.196 & 0.119 & 0.434 & . & 0.394 & 0.217 & 1 & 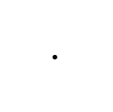 & 0.603 & 0.169 \\
\hline $\begin{array}{l}\mathrm{PM}_{10} \\
\text { All hours }\end{array}$ & 0.403 & 0.771 & 0.57 & . & 0.588 & 0.238 & 0.731 & . & 1 & 0.429 & 0.838 \\
\hline $\begin{array}{l}\mathrm{PM}_{2.5} \\
\text { School hours }\end{array}$ & 0.408 & 0.541 & 0.47 & 0.521 & 0.513 & 0.749 & . & 0.603 & 0.429 & 1 & . \\
\hline $\begin{array}{l}\mathrm{PM}_{2.5} \\
\text { All hours }\end{array}$ & 0.474 & 0.792 & 0.649 & 0.651 & 0.717 & 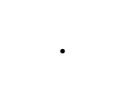 & 0.687 & 0.169 & 0.838 & . & 1 \\
\hline
\end{tabular}


Table 3.26. Number of data pairs used to calculate correlation coefficients in Table 3.25.

\begin{tabular}{|c|c|c|c|c|c|c|c|c|c|c|c|}
\hline $\begin{array}{l}\text { Correlation } \\
\text { coefficients }\end{array}$ & NO & $\mathrm{NO}_{2}$ & $\mathrm{NO}_{\mathrm{X}}$ & $\begin{array}{c}\mathrm{BC}_{10} \\
\text { School } \\
\text { hours }\end{array}$ & $\begin{array}{c}\mathrm{BC}_{10} \\
\text { All } \\
\text { hours } \\
\end{array}$ & $\begin{array}{c}\mathrm{BC}_{2.5} \\
\text { School } \\
\text { hours } \\
\end{array}$ & $\begin{array}{c}\mathrm{BC}_{2.5} \\
\text { All } \\
\text { hours } \\
\end{array}$ & $\begin{array}{c}\mathrm{PM}_{10} \\
\text { School } \\
\text { hours }\end{array}$ & $\begin{array}{c}\mathrm{PM}_{10} \\
\text { All } \\
\text { hours }\end{array}$ & $\begin{array}{c}\mathrm{PM}_{2.5} \\
\text { School } \\
\text { hours }\end{array}$ & $\begin{array}{c}\mathrm{PM}_{2.5} \\
\text { All } \\
\text { hours } \\
\end{array}$ \\
\hline $\mathrm{NO}$ & 177 & 177 & 177 & 56 & 88 & 52 & 88 & 55 & 83 & 55 & 85 \\
\hline $\mathrm{NO}_{2}$ & 177 & 177 & 177 & 56 & 88 & 52 & 88 & 55 & 83 & 55 & 85 \\
\hline $\mathrm{NO}_{\mathrm{X}}$ & 177 & 177 & 177 & 56 & 88 & 52 & 88 & 55 & 83 & 55 & 85 \\
\hline $\begin{array}{l}\mathrm{BC}_{10} \text { School } \\
\text { hours }\end{array}$ & 56 & 56 & 56 & 57 & 0 & 32 & 19 & 55 & 0 & 35 & 19 \\
\hline $\begin{array}{l}\mathrm{BC}_{10} \text { All } \\
\text { hours }\end{array}$ & 88 & 88 & 88 & 0 & 105 & 20 & 65 & 0 & 96 & 20 & 61 \\
\hline $\begin{array}{l}\mathrm{BC}_{2.5} \text { School } \\
\text { hours }\end{array}$ & 52 & 52 & 52 & 32 & 20 & 53 & 0 & 30 & 20 & 52 & 0 \\
\hline $\begin{array}{l}\mathrm{BC}_{2.5} \text { All } \\
\text { hours }\end{array}$ & 88 & 88 & 88 & 19 & 65 & 0 & 106 & 19 & 56 & 0 & 102 \\
\hline $\begin{array}{l}\mathrm{PM}_{10} \text { School } \\
\text { hours }\end{array}$ & 55 & 55 & 55 & 55 & 0 & 30 & 19 & 55 & 0 & 33 & 19 \\
\hline $\begin{array}{l}\mathrm{PM}_{10} \text { All } \\
\text { hours }\end{array}$ & 83 & 83 & 83 & 0 & 96 & 20 & 56 & 0 & 96 & 20 & 52 \\
\hline $\begin{array}{l}\mathrm{PM}_{2.5} \text { School } \\
\text { hours }\end{array}$ & 55 & 55 & 55 & 35 & 20 & 52 & 0 & 33 & 20 & 56 & 0 \\
\hline $\begin{array}{l}\mathrm{PM}_{2.5} \text { All } \\
\text { hours }\end{array}$ & 85 & 85 & 85 & 19 & 61 & 0 & 102 & 19 & 52 & 0 & 102 \\
\hline
\end{tabular}


Table 3.27. Results from neighborhood study at school 6 .

\begin{tabular}{lcccc}
\hline Location & $\mathrm{NO}_{2}(\mathrm{ppb})$ & $\mathrm{NO}_{\mathrm{x}}(\mathrm{ppb})$ & $\mathrm{NO}_{2} /$ Fremont & $\mathrm{NO}_{\mathrm{x}} /$ Fremont \\
\hline School 1 & 14.3 & 20.6 & 1.05 & 1.18 \\
School 2 & 17.7 & 25.1 & 1.30 & 1.44 \\
School 3 & 13.7 & 18.3 & 1.01 & 1.05 \\
School 4 & 12.4 & 17.2 & 0.90 & 0.99 \\
School 5 & 23.6 & 33.8 & 1.73 & 1.94 \\
School 6 (n=3) & 13.6 & 17.8 & 1.00 & 1.02 \\
School 7 & 12.5 & 16.1 & 0.91 & 0.92 \\
School 8 & 14.1 & 17.3 & 1.03 & 0.99 \\
School 9 & 22.3 & 31.2 & 1.63 & 1.79 \\
School 10 & 26.7 & 43.0 & 1.95 & 2.47 \\
Fremont station (n=3) & 13.7 & 17.4 & 1.00 & 1.00 \\
\hline S6 Neighborhood Sites & & & & \\
2513 & 12.1 & 15.8 & 0.89 & 0.91 \\
2312 & 12.6 & 16.4 & 0.92 & 0.94 \\
1007 & 12.6 & 17.0 & 0.92 & 0.98 \\
1615 & 13.6 & 17.7 & 1.00 & 1.02 \\
1113 & 13.6 & 18.3 & 1.00 & 1.05 \\
1206 & 14.1 & 18.9 & 1.03 & 1.09 \\
1204 & 15.7 & 19.7 & 1.15 & 1.13 \\
2442 & 15.3 & 20.7 & 1.12 & 1.19 \\
1220 & 14.6 & 21.9 & 1.06 & 1.26 \\
1518 & 15.1 & 22.8 & 1.11 & 1.31 \\
1219 & 16.2 & 24.2 & 1.18 & 1.39 \\
2415 & 16.3 & 24.4 & 1.19 & 1.40 \\
2404 & 17.1 & 24.7 & 1.25 & 1.42 \\
2501 & 18.7 & 35.4 & 1.37 & 2.03 \\
1208 & 17.0 & 39.9 & 1.24 & 2.29 \\
\hline School 6 mean & 15.0 & 22.5 & 1.10 & 1.29 \\
School 6 geomean & 14.9 & 21.7 & 1.09 & 1.25 \\
School 6 median & 15.1 & 20.7 & 1.11 & 1.19 \\
\hline
\end{tabular}


Table 3.28. Results from neighborhood study at schools 3 and 5 .

\begin{tabular}{|c|c|c|c|c|}
\hline Location & $\mathrm{NO}_{2}(\mathrm{ppb})$ & $\mathrm{NO}_{\mathrm{X}}(\mathrm{ppb})$ & $\mathrm{NO}_{2} /$ Fremont & $\mathrm{NO}_{\mathrm{X}} /$ Fremont \\
\hline $\begin{array}{l}\text { School } 1 \\
\end{array}$ & 13.6 & 19.7 & 1.02 & 1.04 \\
\hline School 2 & 16.3 & 26.9 & 1.23 & 1.42 \\
\hline School $3(n=2)$ & 10.6 & 17.3 & 0.80 & 0.91 \\
\hline School 4 & 11.4 & 17.4 & 0.86 & 0.92 \\
\hline School $5(\mathrm{n}=2)$ & 23.1 & 36.2 & 1.74 & 1.91 \\
\hline School 6 & 13.7 & 19.1 & 1.04 & 1.01 \\
\hline School 7 & 13.6 & 16.8 & 1.02 & 0.88 \\
\hline School 8 & 13.3 & 18.8 & 1.00 & 0.99 \\
\hline School 9 & 22.1 & 33.9 & 1.67 & 1.79 \\
\hline School 10 & 29.7 & 53.1 & 2.24 & 2.81 \\
\hline Fremont station $(\mathrm{n}=2)$ & 13.2 & 18.9 & 1.00 & 1.00 \\
\hline \multicolumn{5}{|l|}{ S3 Neighborhood Sites } \\
\hline 3321 & 9.6 & 16.2 & 0.72 & 0.85 \\
\hline 0218 & 10.0 & 16.6 & 0.75 & 0.88 \\
\hline 0226 & 10.2 & 16.8 & 0.77 & 0.89 \\
\hline 1608 & 9.7 & 17.1 & 0.73 & 0.90 \\
\hline 1601 & 10.6 & 17.2 & 0.80 & 0.91 \\
\hline 0204 & 9.8 & 17.4 & 0.74 & 0.92 \\
\hline 0718 & 10.3 & 17.4 & 0.77 & 0.92 \\
\hline 0704 & 13.0 & 17.6 & 0.98 & 0.93 \\
\hline 3322 & 10.1 & 18.5 & 0.77 & 0.98 \\
\hline 0202 & 11.8 & 19.4 & 0.89 & 1.02 \\
\hline 0709 & 12.6 & 22.5 & 0.95 & 1.19 \\
\hline 0108 & 13.6 & 23.0 & 1.02 & 1.21 \\
\hline 2112 & 11.0 & 25.3 & 0.83 & 1.34 \\
\hline S3 neighborhood mean & 10.9 & 18.8 & 0.83 & 1.00 \\
\hline S3 neighborhood geomean & 10.9 & 18.7 & 0.82 & 0.99 \\
\hline S3 neighborhood median & 10.3 & 17.4 & 0.77 & 0.92 \\
\hline \multicolumn{5}{|l|}{ S5 Neighborhood Sites } \\
\hline 3304 & 9.3 & 15.8 & 0.70 & 0.83 \\
\hline SES & 11.9 & 16.9 & 0.90 & 0.89 \\
\hline 4603 & 12.3 & 17.8 & 0.93 & 0.94 \\
\hline 3614 & 13.7 & 19.4 & 1.03 & 1.03 \\
\hline 3323 & 13.5 & 19.5 & 1.02 & 1.03 \\
\hline 3314 & 14.1 & 21.3 & 1.06 & 1.12 \\
\hline 3607 & 18.1 & 26.0 & 1.37 & 1.37 \\
\hline 3307 & 17.5 & 27.0 & 1.32 & 1.42 \\
\hline 3604 & 20.0 & 31.0 & 1.51 & 1.64 \\
\hline 3401 & 18.6 & 33.6 & 1.40 & 1.77 \\
\hline 3609 & 22.2 & 36.8 & 1.67 & 1.94 \\
\hline 3327 & 23.4 & 43.8 & 1.77 & 2.31 \\
\hline 3610 & 32.6 & 70.3 & 2.46 & 3.71 \\
\hline S5 neighborhood mean & 17.5 & 29.1 & 1.32 & 1.54 \\
\hline S5 neighborhood geomean & 16.6 & 26.5 & 1.25 & 1.40 \\
\hline S5 neighborhood median & 17.5 & 26.0 & 1.32 & 1.37 \\
\hline
\end{tabular}




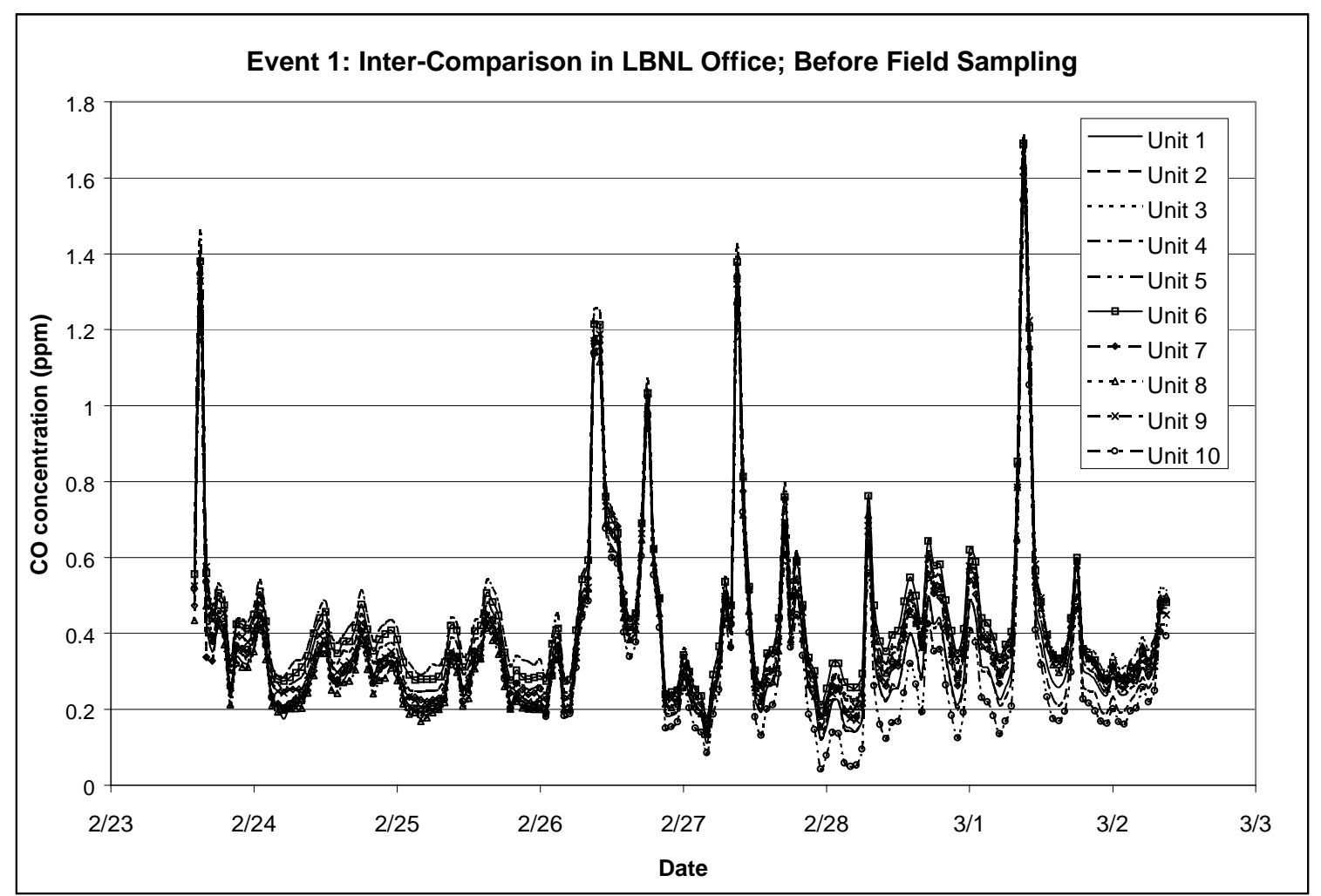

Figure 2.1a. Co-located CO measurements prior to start of spring period.

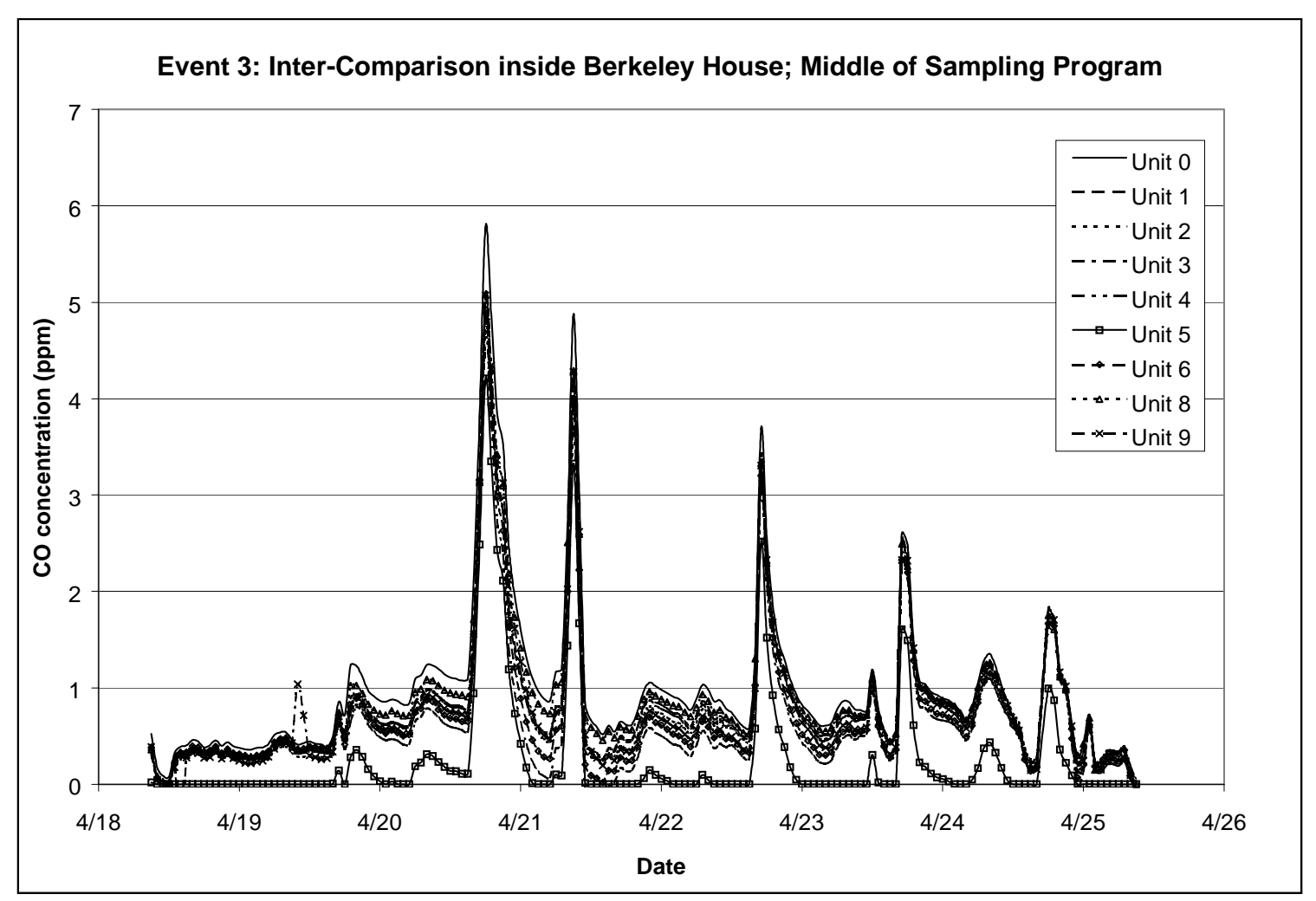

Figure 2.1b. Co-located CO measurements during spring period. 


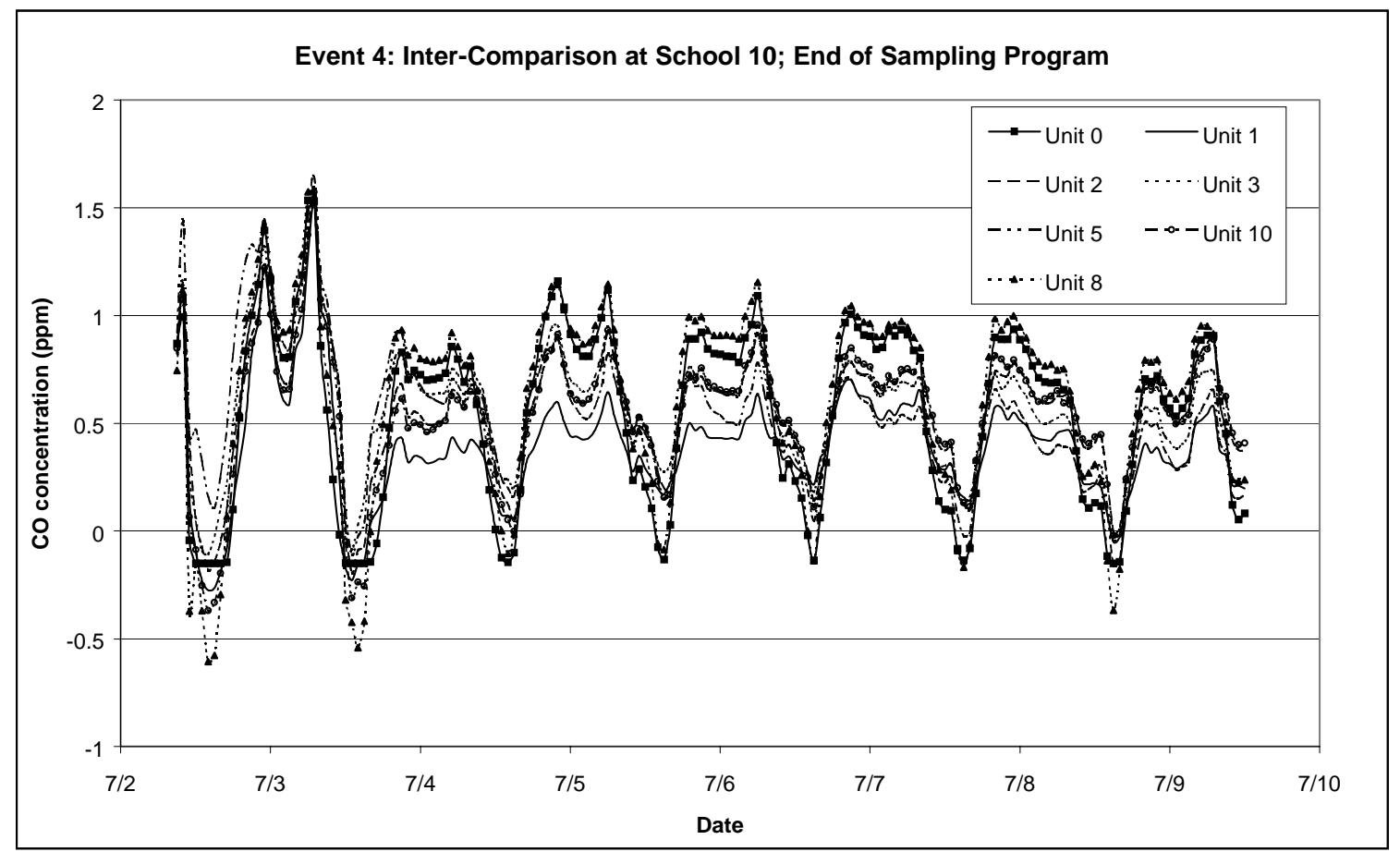

Figure 2.2a. Co-located CO measurements after completion of spring period; units that agree.

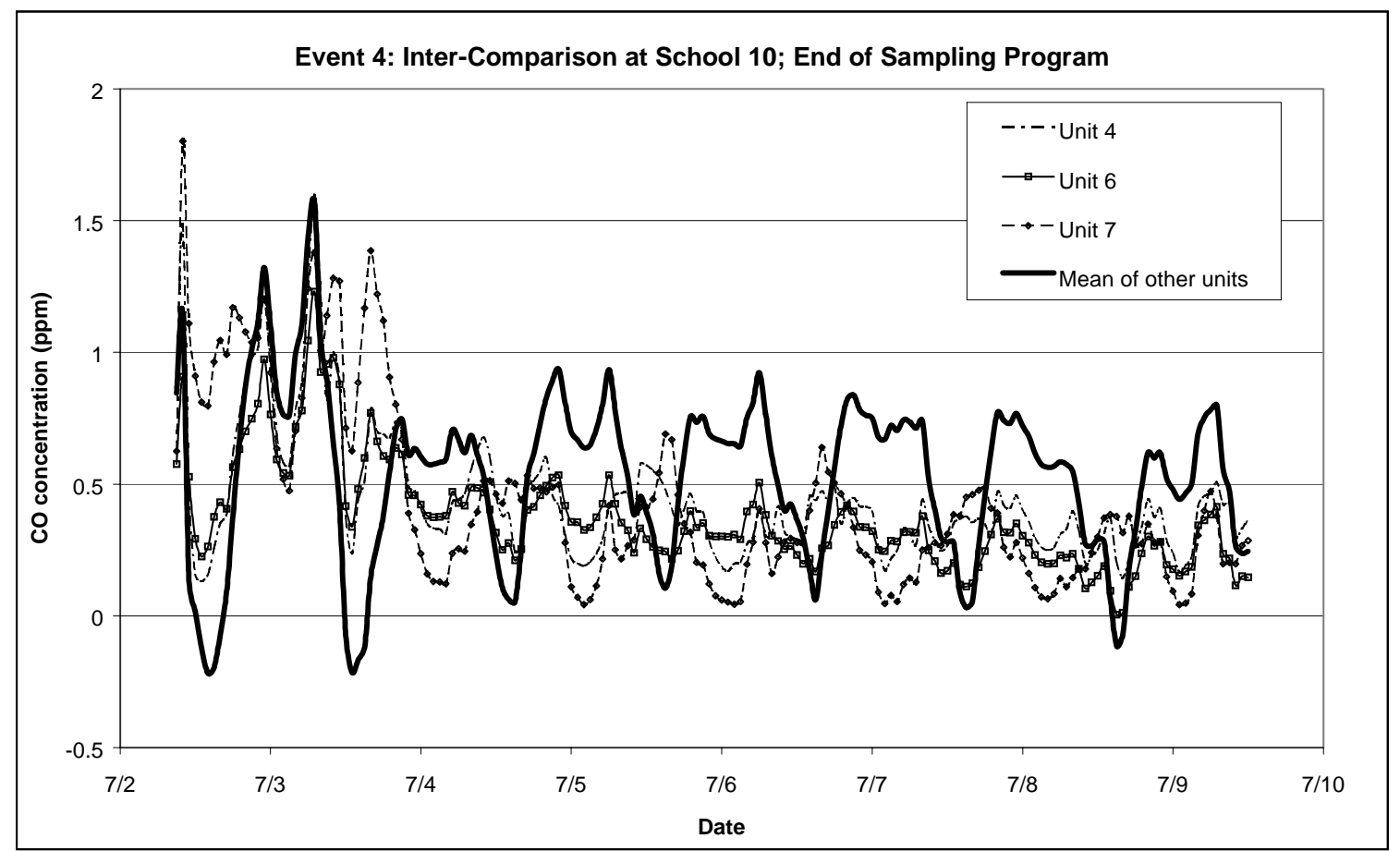

Figure 2.2b. Co-located CO measurements after completion of spring period; units that do not agree. 


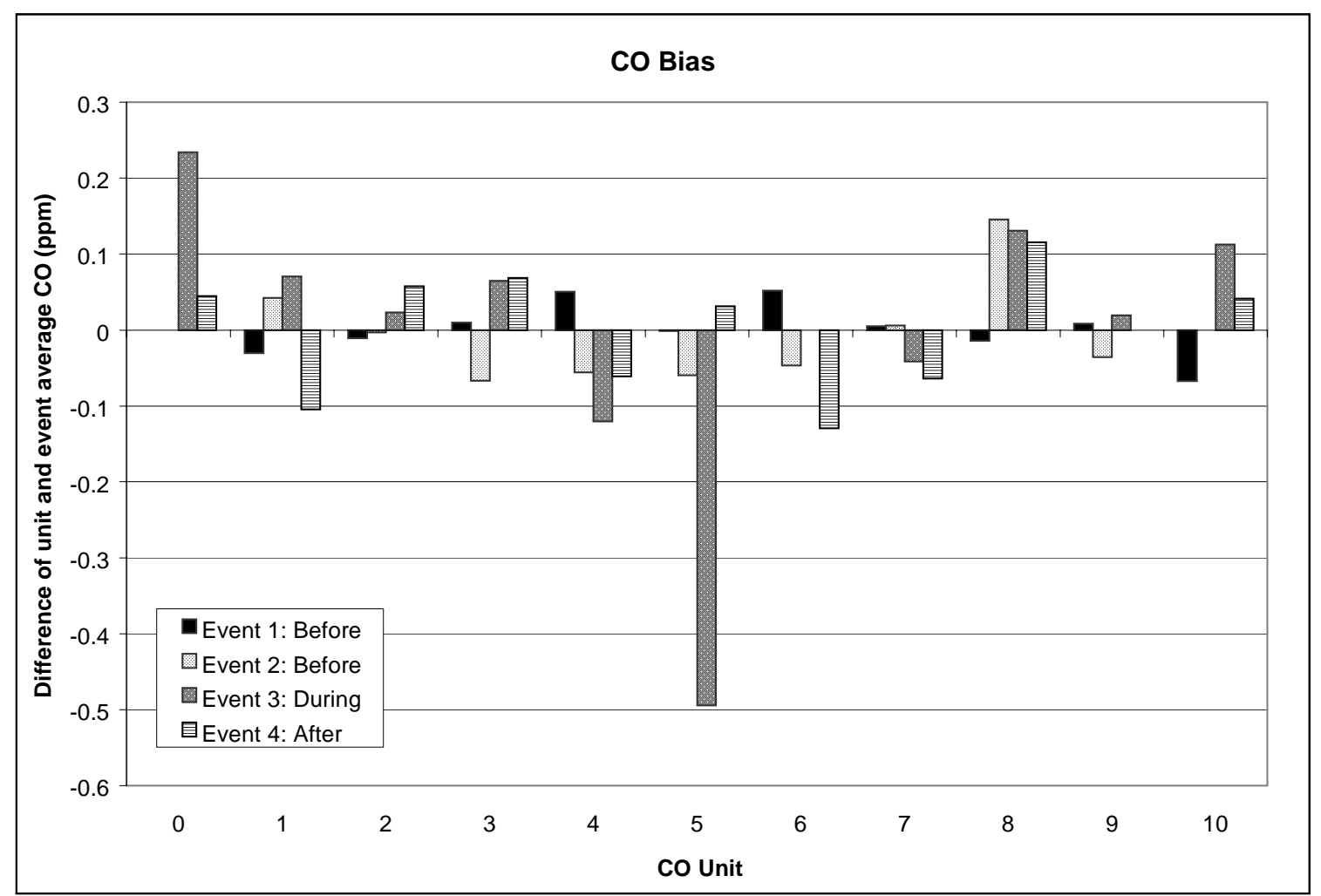

Figure 2.3. CO bias by co-location event.

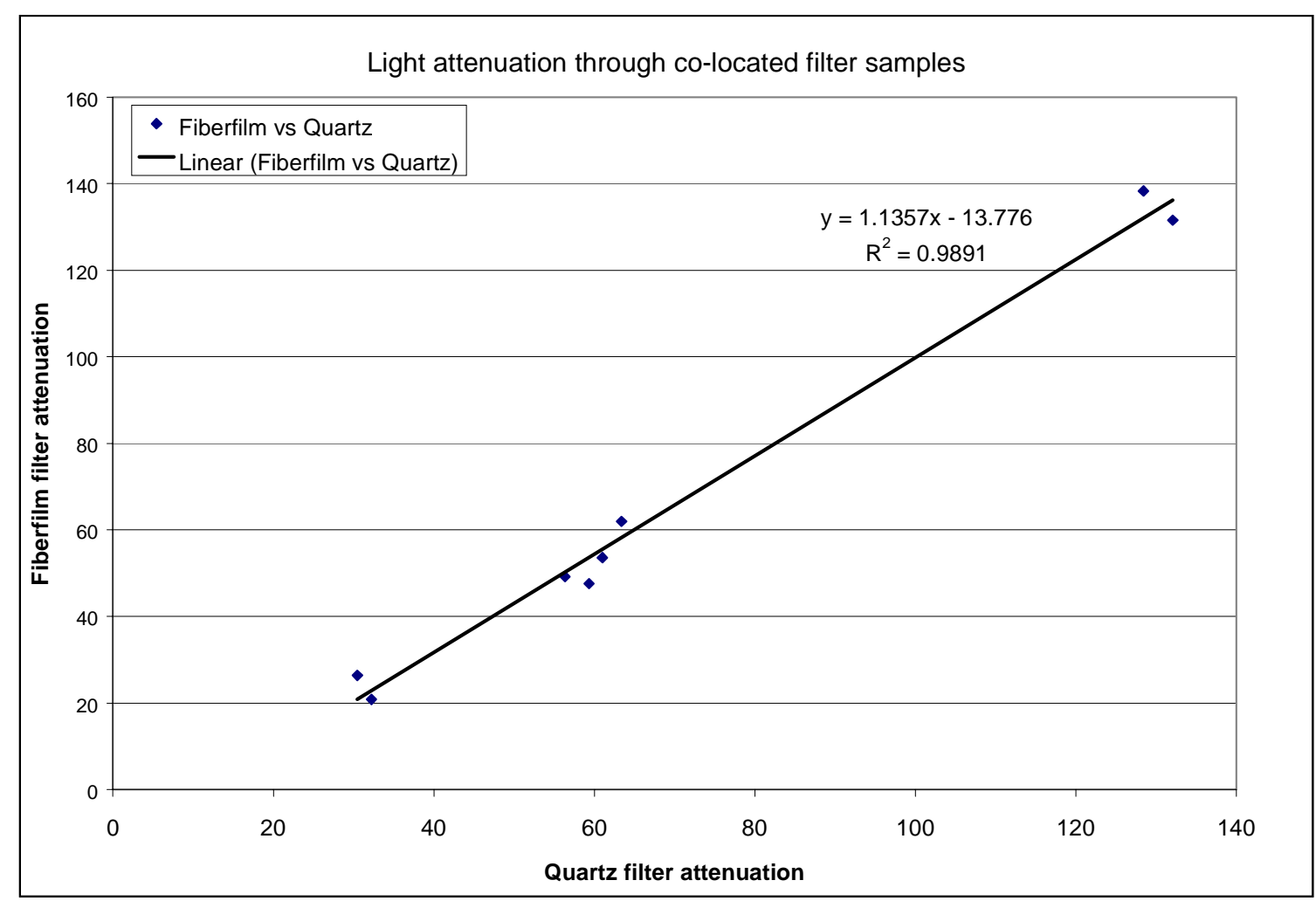

Figure 2.4. Comparison of black carbon quantiation on fiberfilm versus quartz filters. 


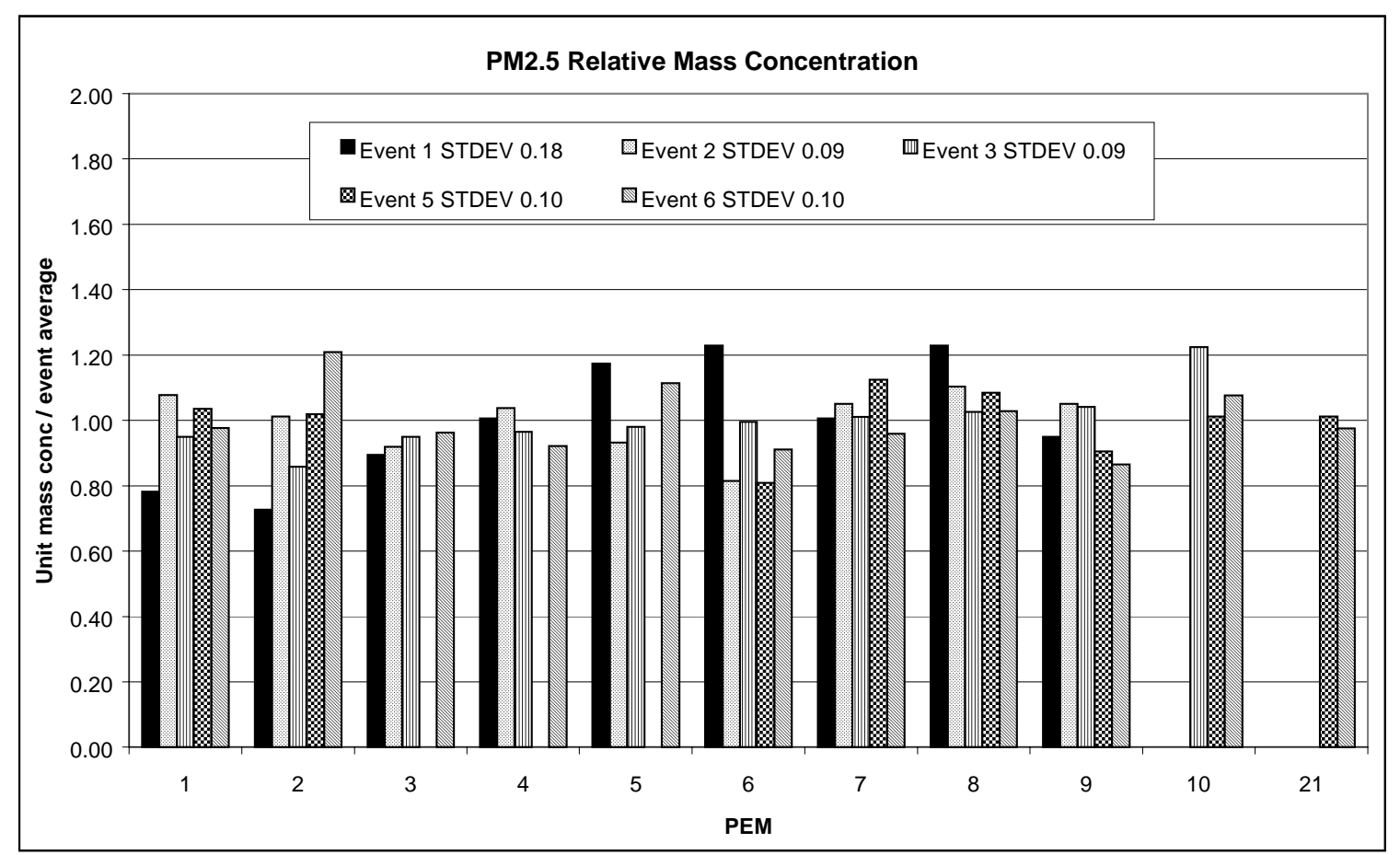

Figure 2.5. 2.5- $\mu \mathrm{m}$ Black carbon mass measured in co-location experiments; each unit was normalized to event-average of all units.

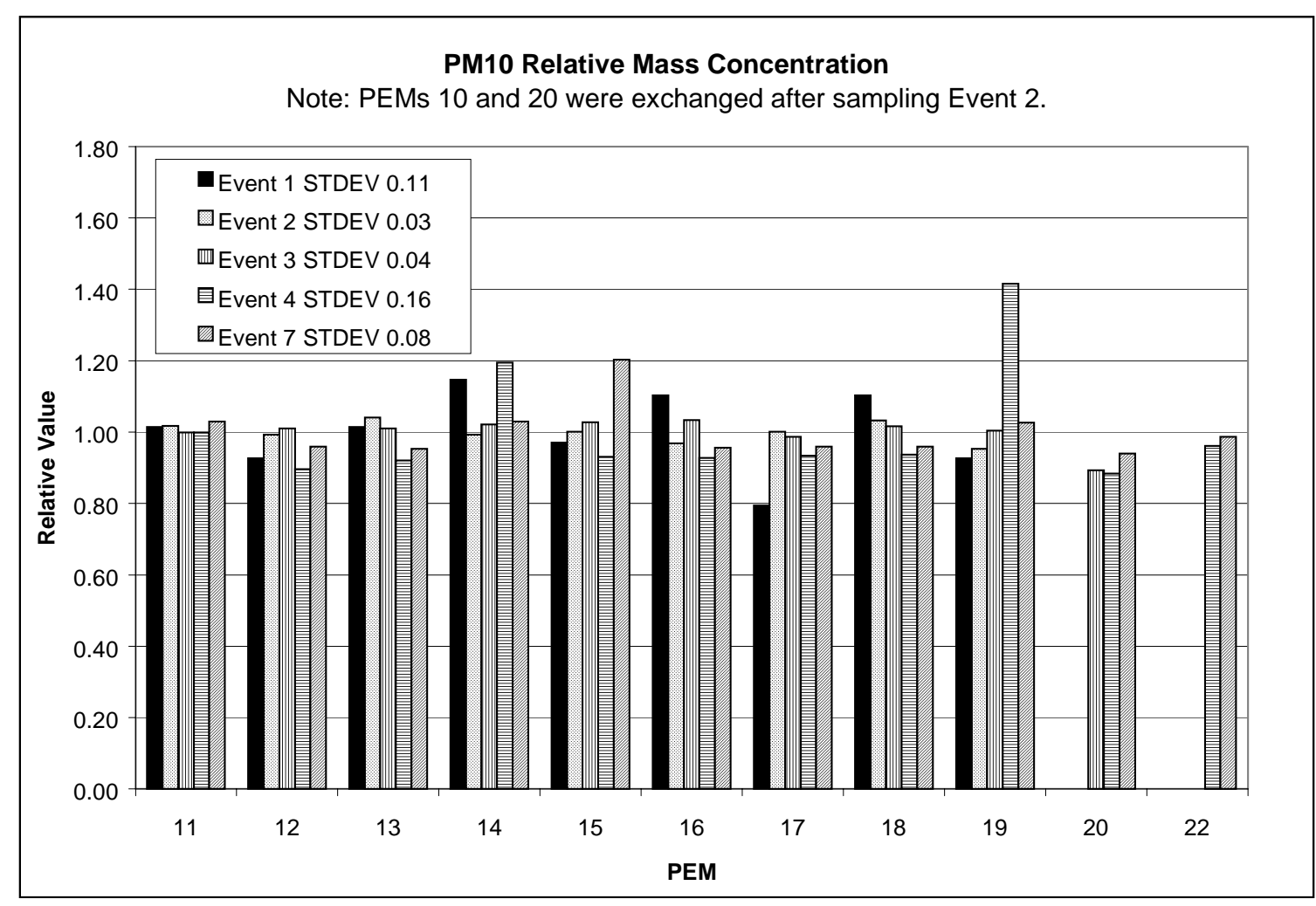

Figure 2.6. $\mathrm{PM}_{10}$ mass measured in co-location experiments; each unit was normalized to eventaverage of all units. 


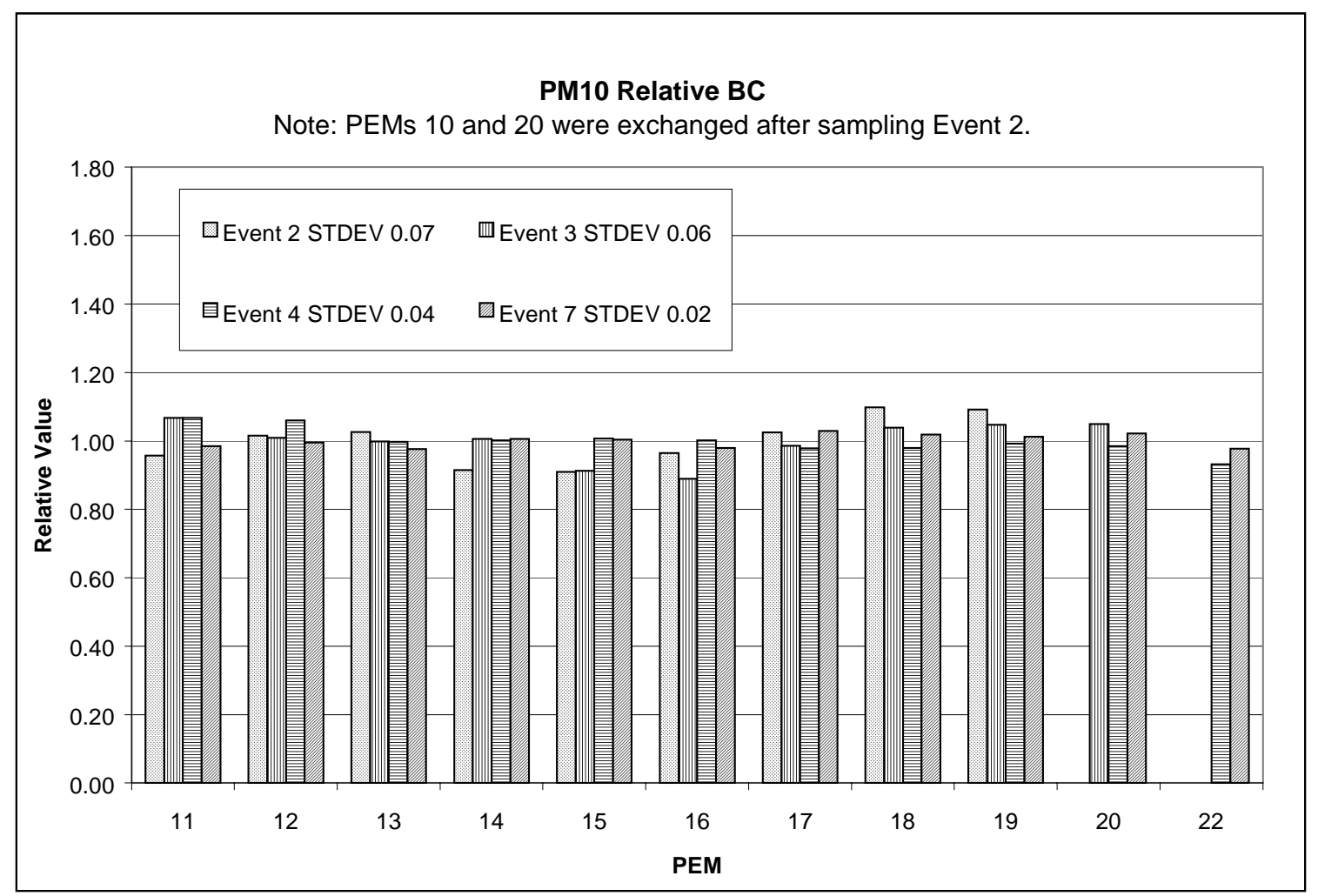

Figure 2.7. 10- $\mu \mathrm{m}$ Black carbon mass measured in co-location experiments; each unit normalized to event-average of all units. 


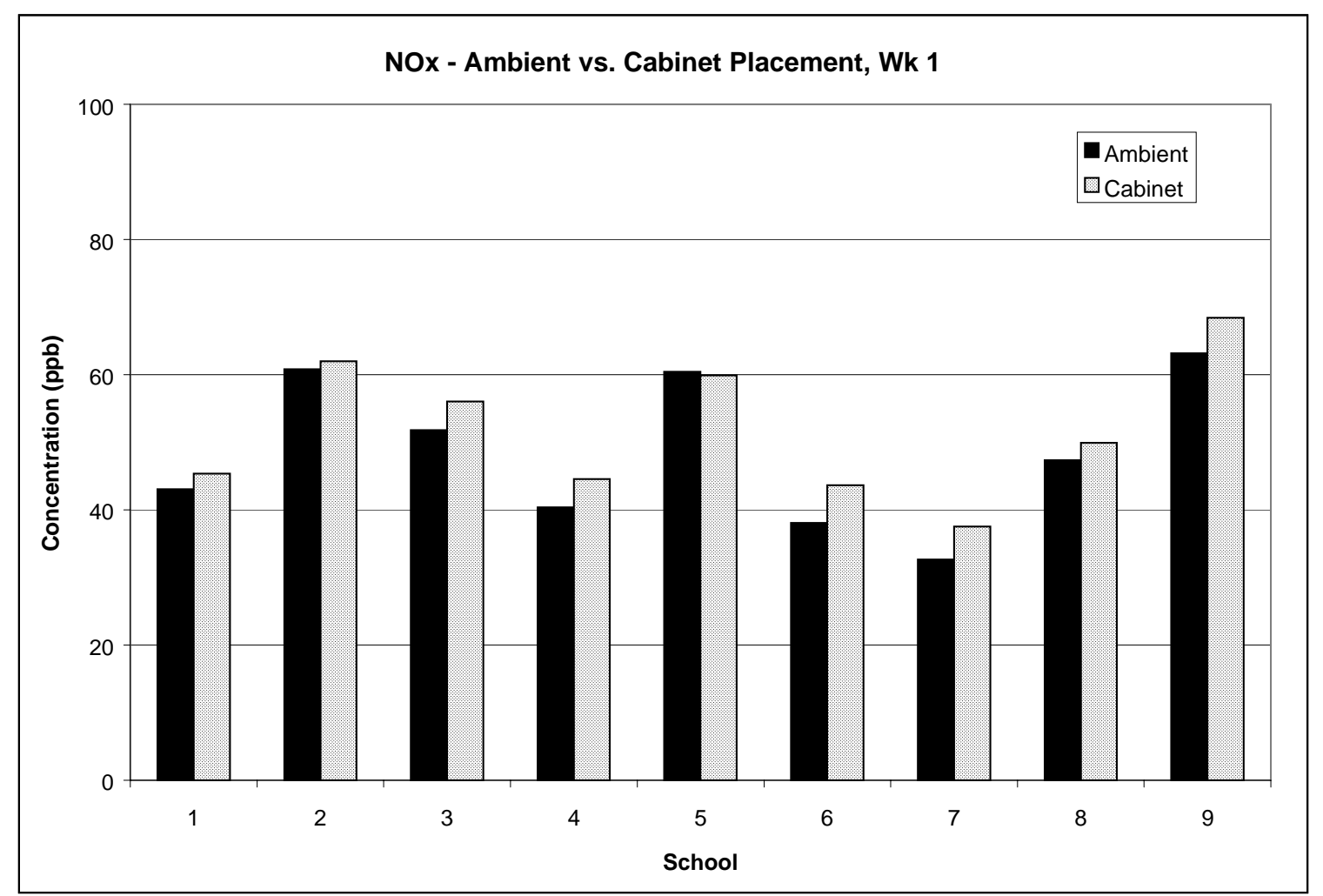

Figure 2.8a. Effect of inside versus outside equipment housing deployment on $\mathrm{NO}_{\mathrm{X}}$ concentrations during week 1 .

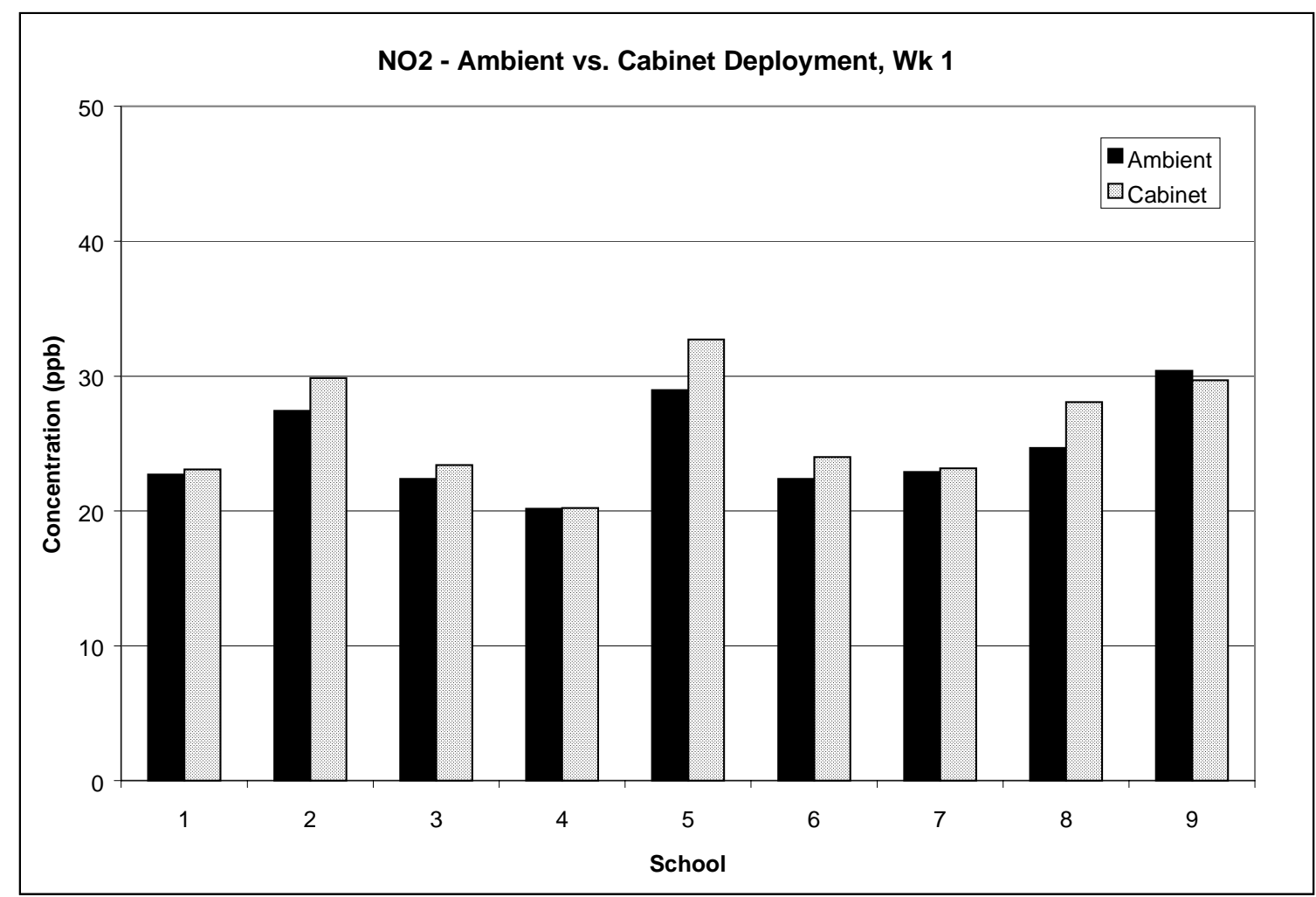

Figure 2.8b. Effect of inside versus outside equipment housing deployment on $\mathrm{NO}_{2}$ concentrations during week 1 . 


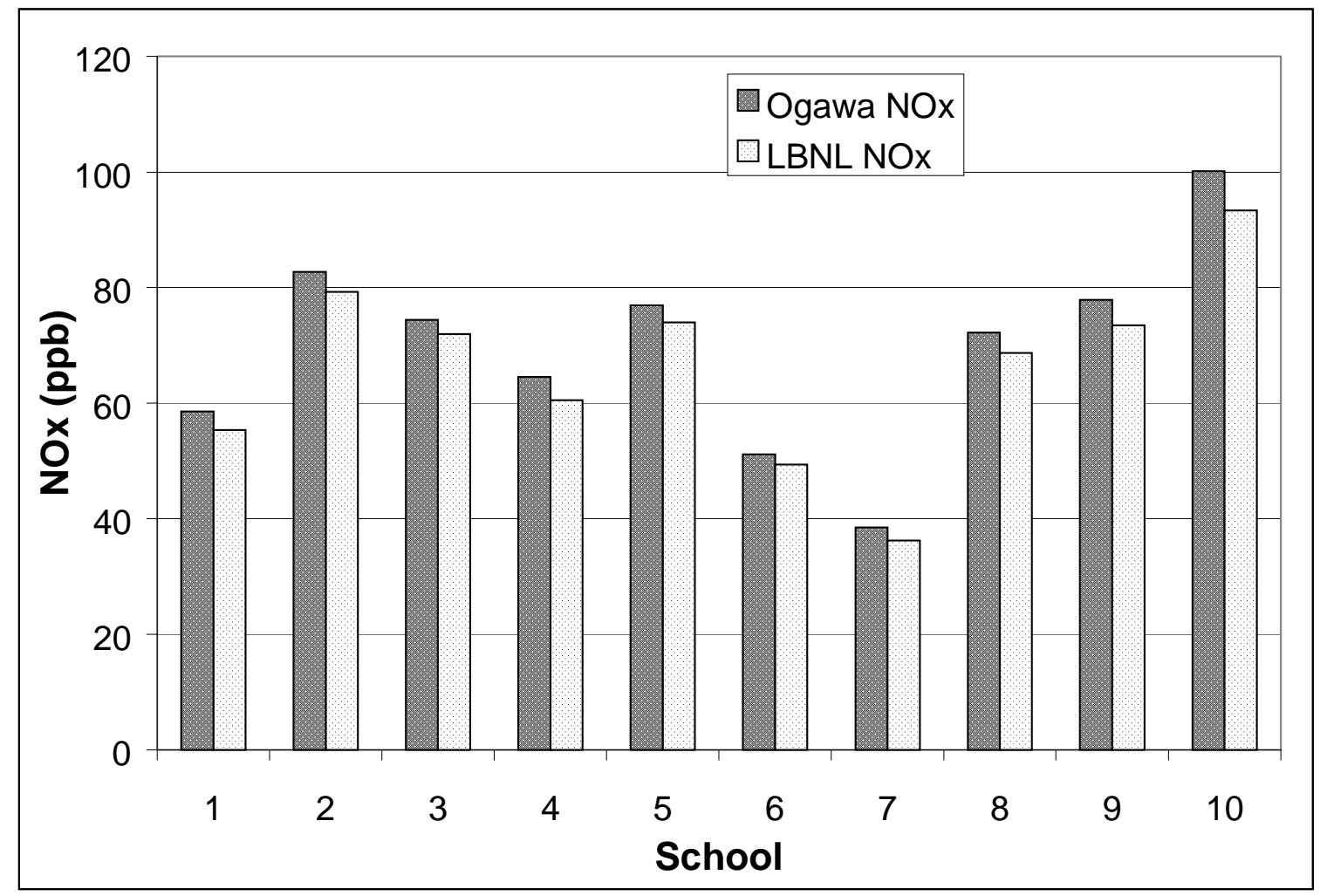

Figure 2.9a. Co-located $\mathrm{NO}_{\mathrm{X}}$ samples analyzed by Ogawa and LBNL laboratories (Week 17).

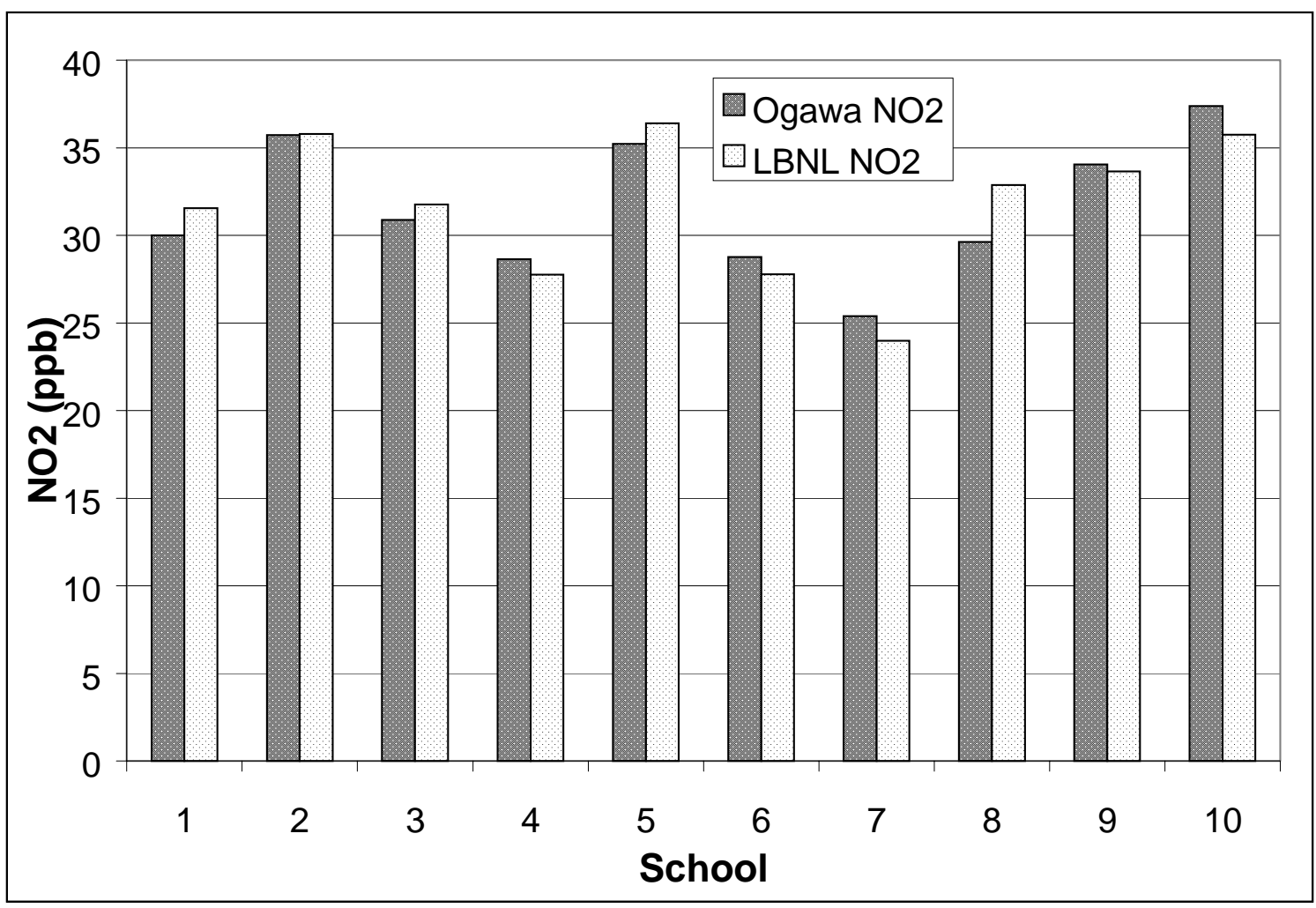

Figure 2.9b. Co-located $\mathrm{NO}_{2}$ samples analyzed by Ogawa and LBNL laboratories (Week 17). 


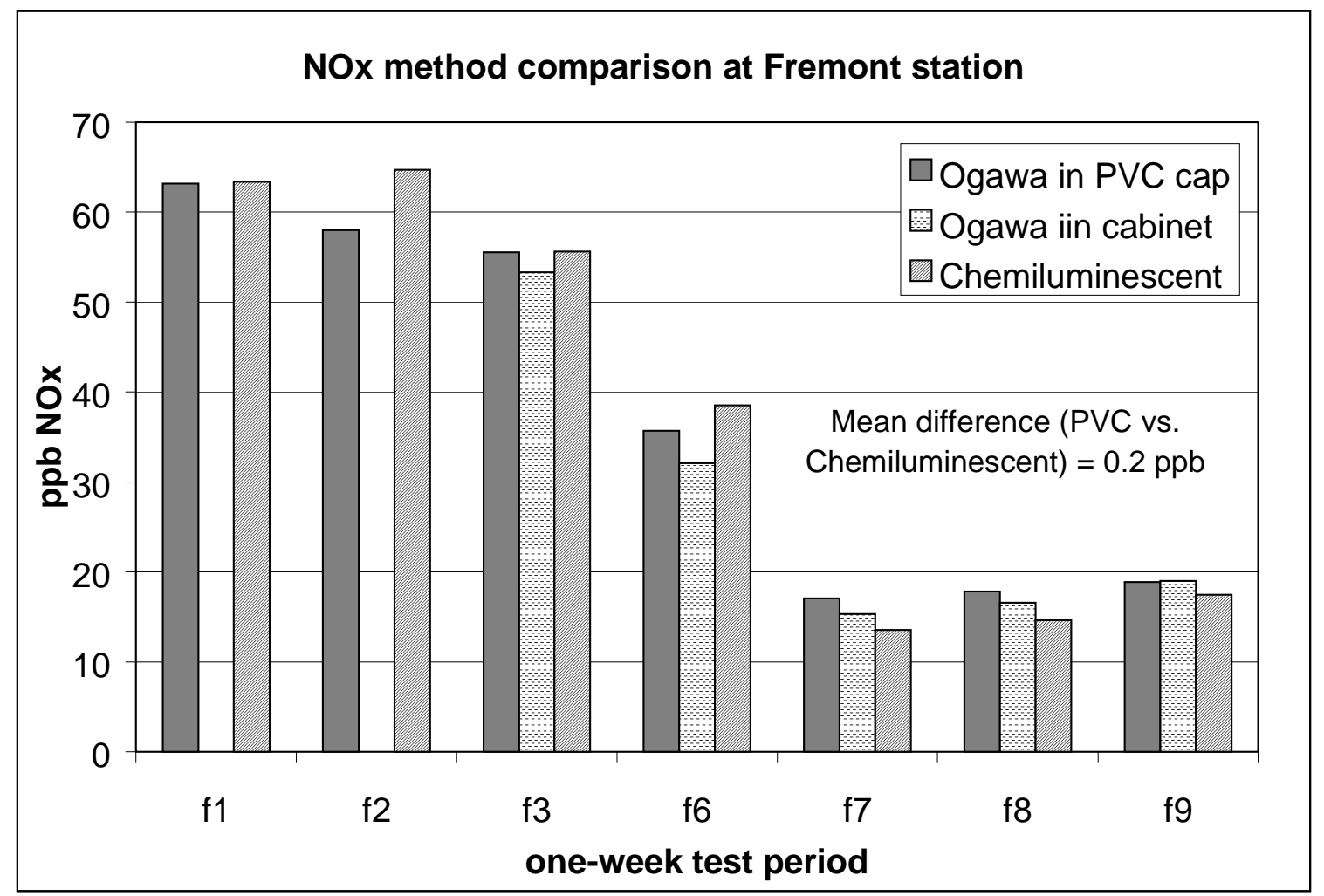

Figure 2.10. $\mathrm{NO}_{\mathrm{X}}$ concentrations measured by Ogawa passive samplers, deployed in a PVC protective cap and a metal cabinet, and a chemilumiscent analyzer at the BAAQMD Fremont monitoring station in Feb-Apr 2002. See text for details. 


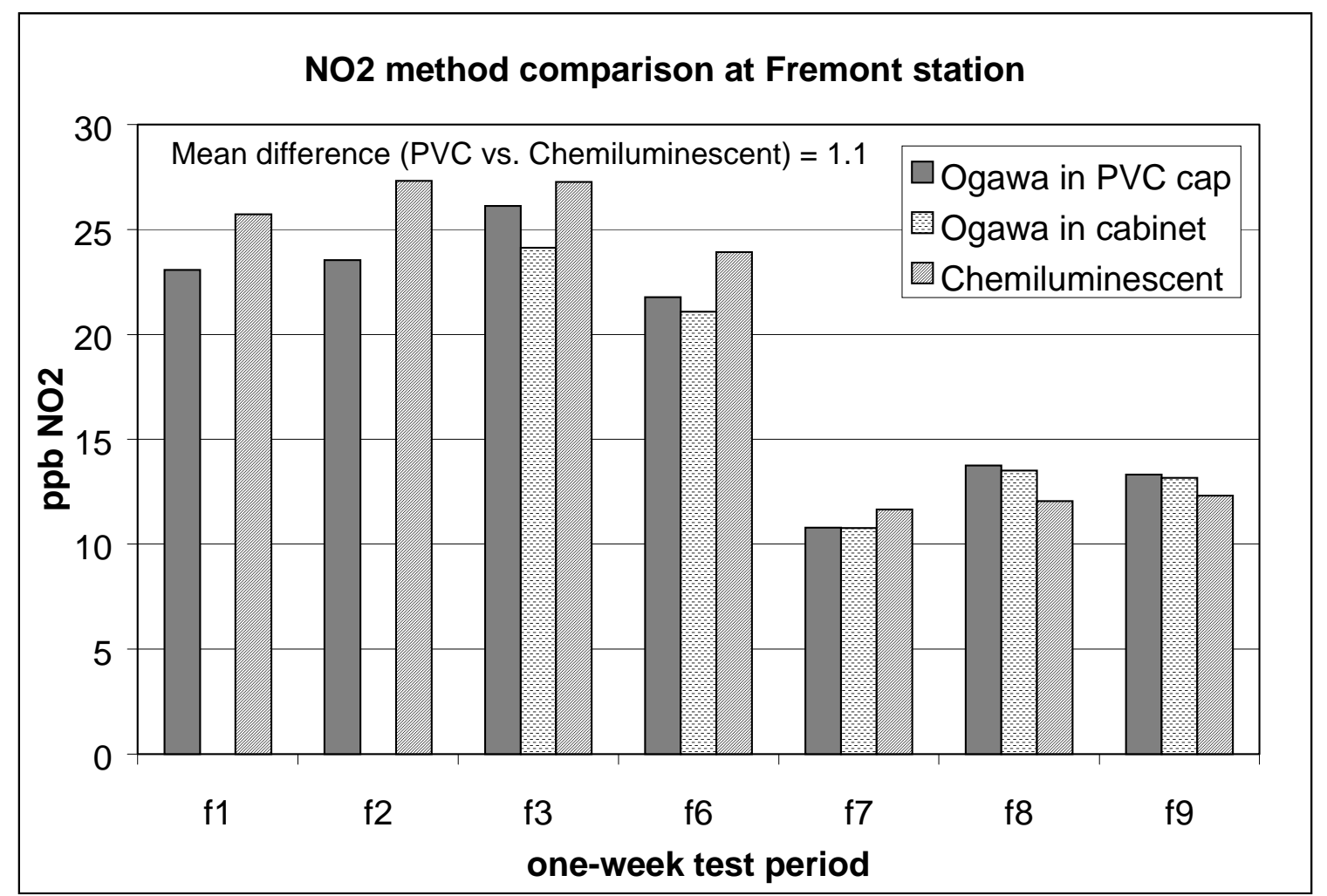

Figure 2.11. $\mathrm{NO}_{2}$ concentrations measured by Ogawa passive samplers, deployed in a PVC protective cap and a metal cabinet, and a chemilumiscent analyzer at the BAAQMD Fremont monitoring station in Feb-Apr 2002. See text for details.

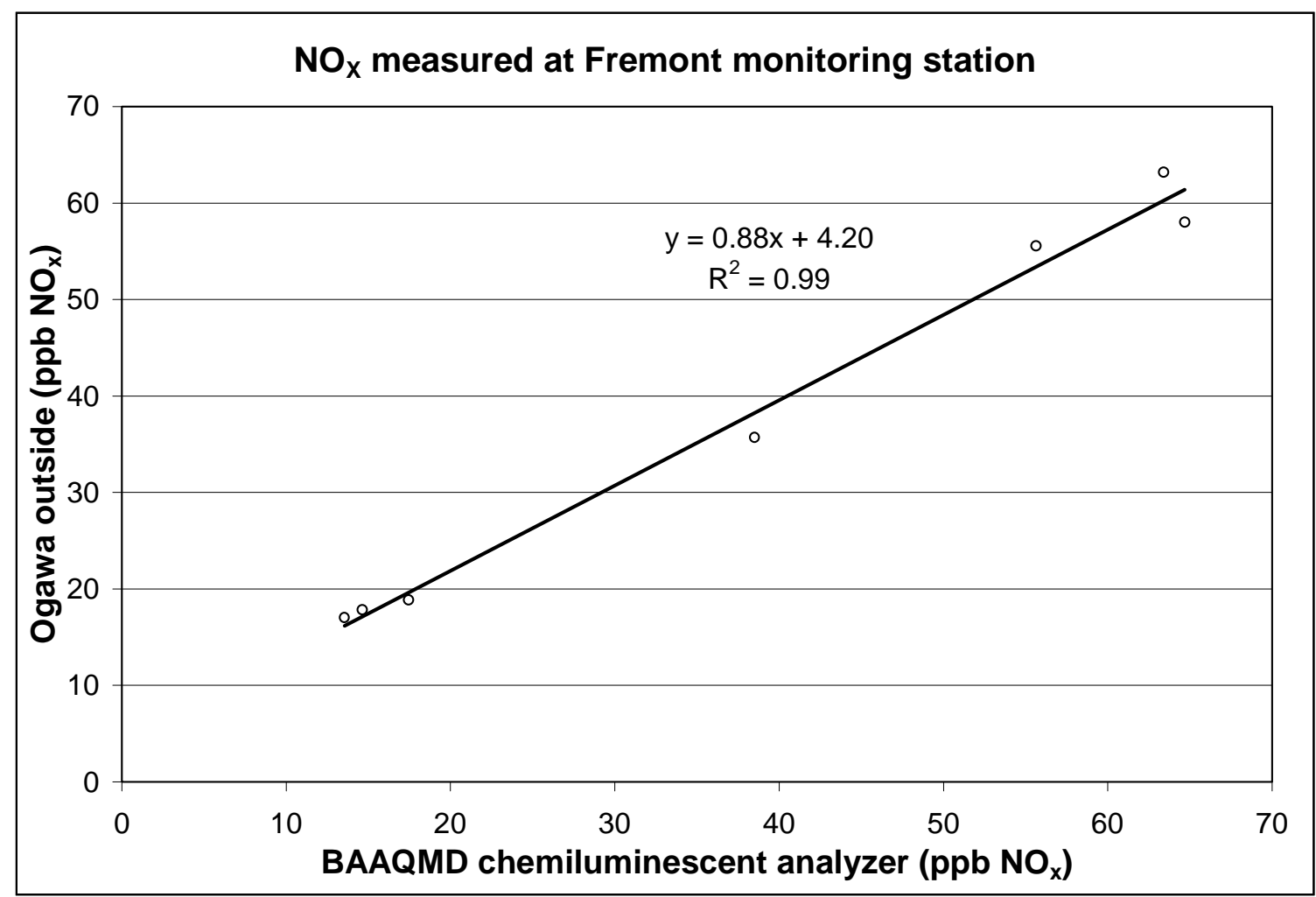

Figure 2.12. $\mathrm{NO}_{\mathrm{X}}$ concentrations measured by Ogawa passive samplers and a chemiluminescent analyzer at the BAAQMD Fremont station in Feb-Apr 2002. See text for details. 


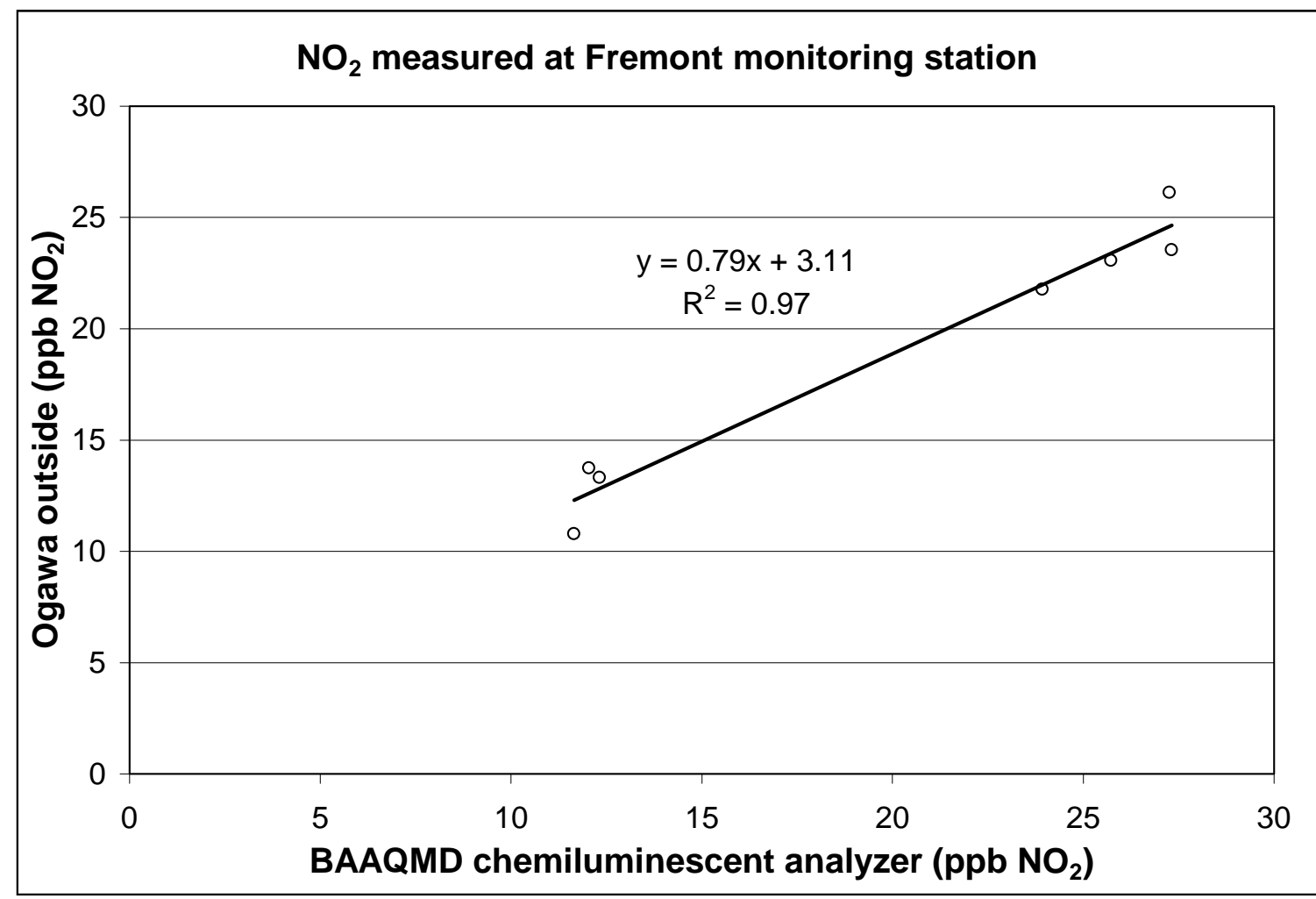

Figure 2.13. $\mathrm{NO}_{2}$ concentrations measured by Ogawa passive samplers and a chemiluminescent analyzer at the BAAQMD Fremont station in Feb-Apr 2002. See text for details. 


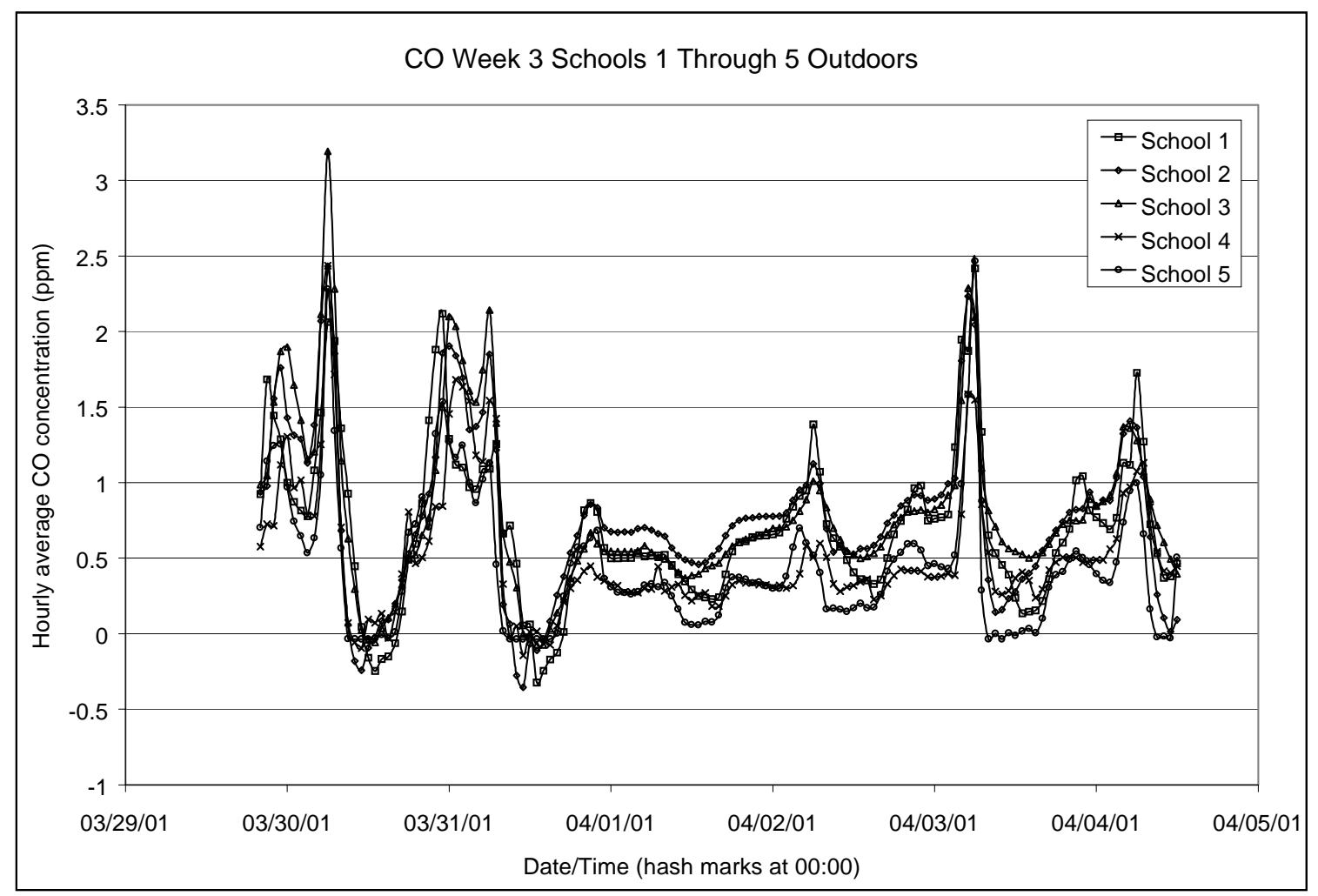

Figure 3.1a. Week 3 hourly CO concentrations at schools 1-5.

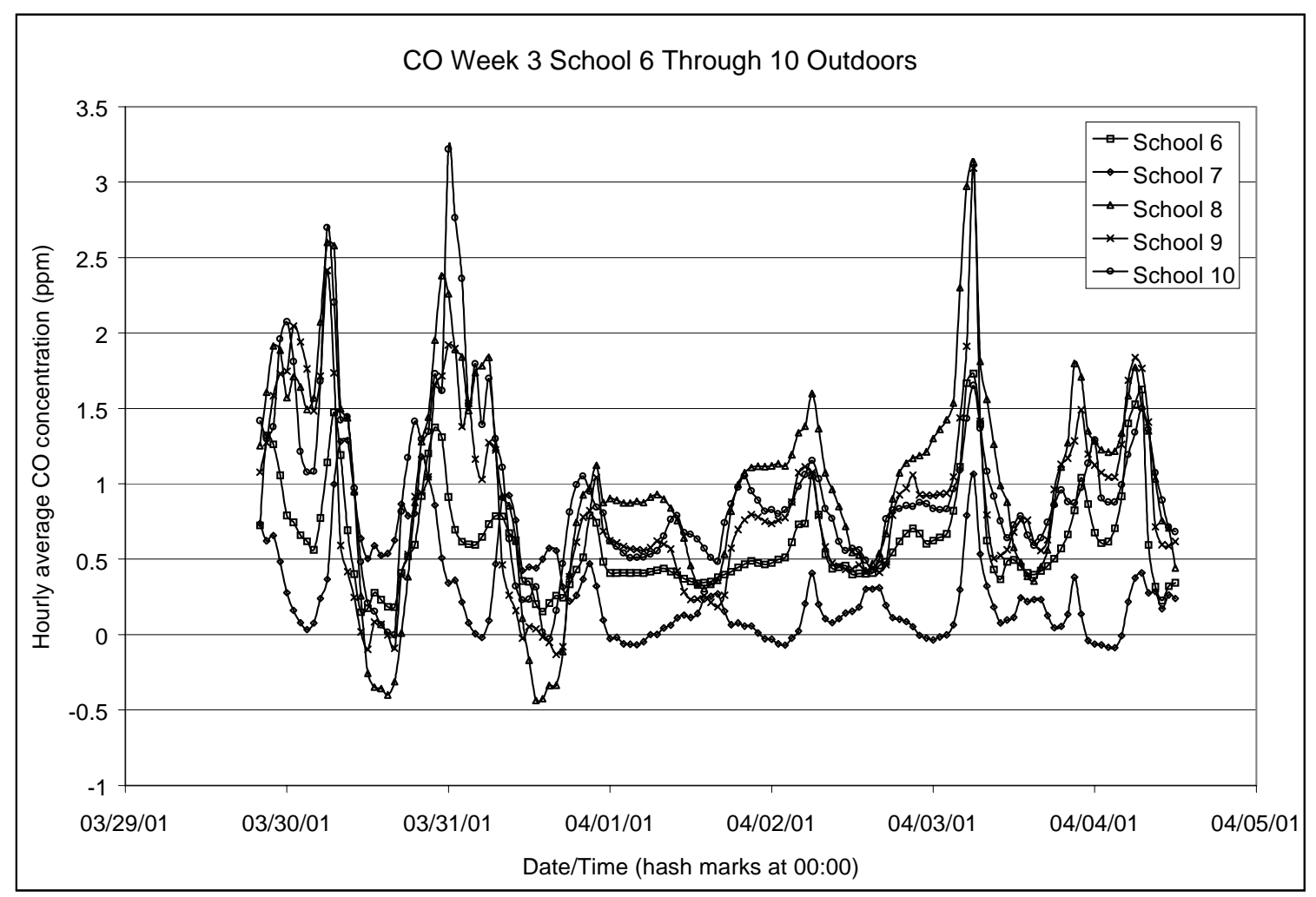

Figure 3.1b. Week 3 hourly CO concentrations at schools 6-10. 


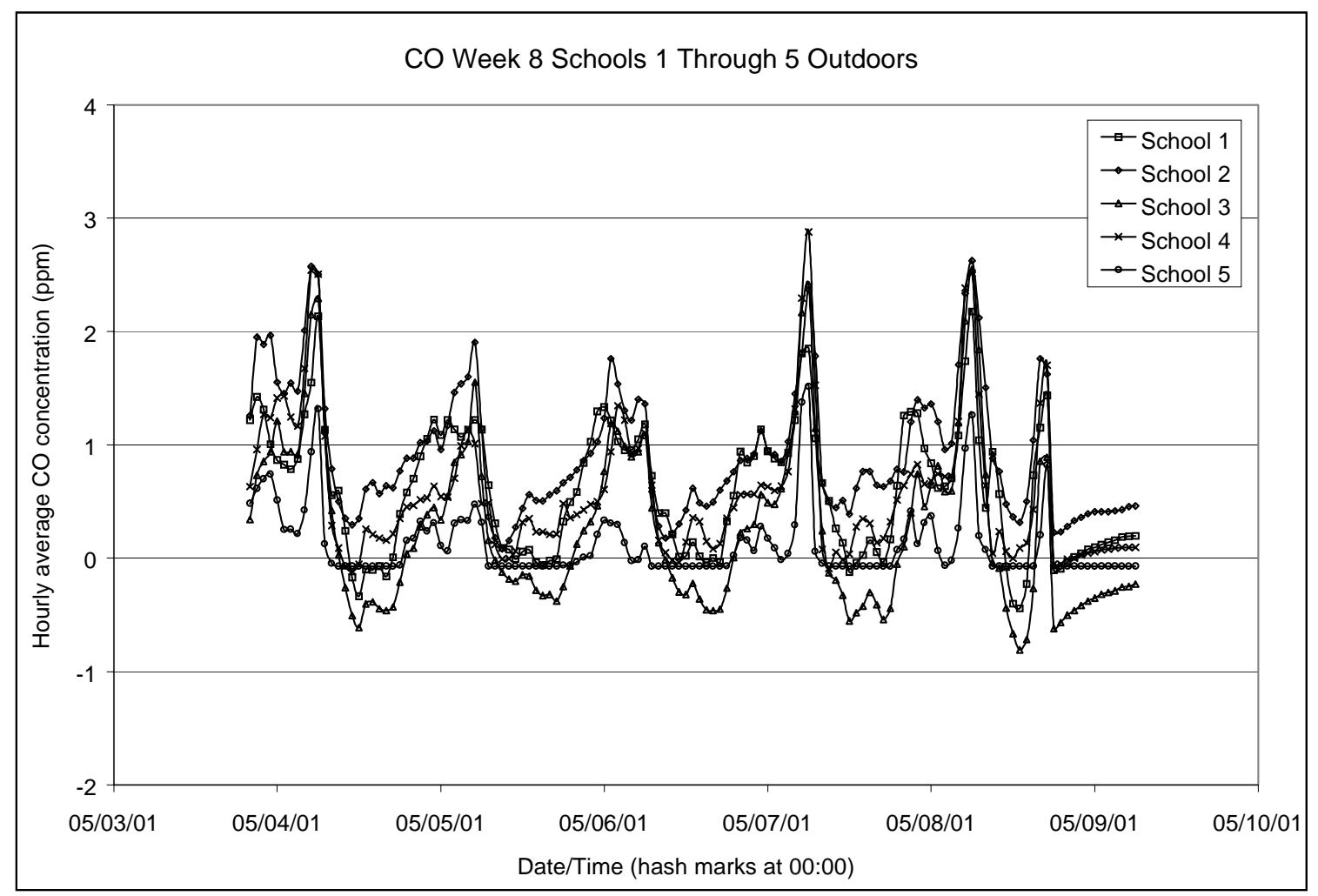

Figure 3.2a. Week 8 hourly $\mathrm{CO}$ concentrations at schools 1-5.

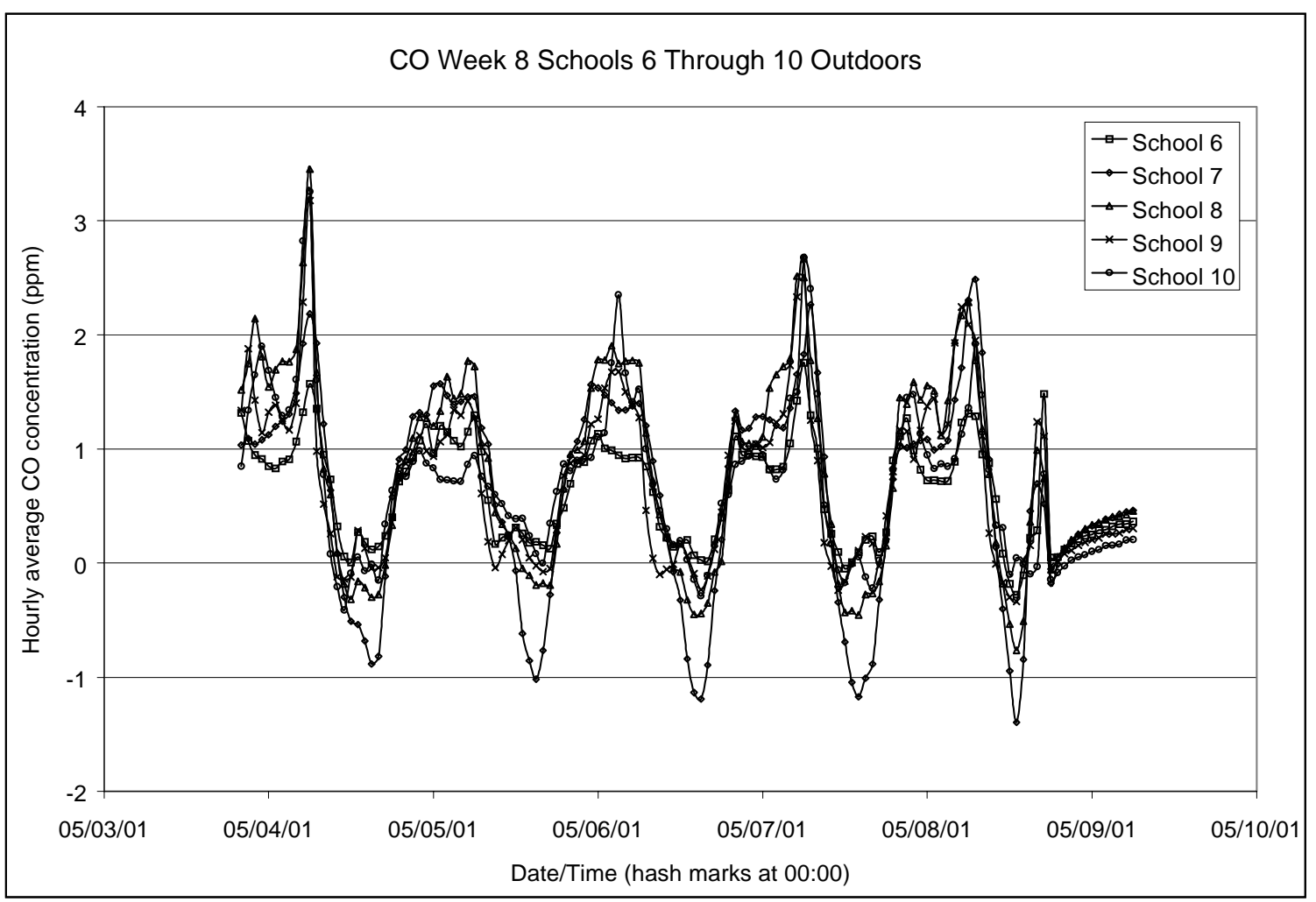

Figure 3.2b. Week 8 hourly CO concentrations at schools 6-10. 


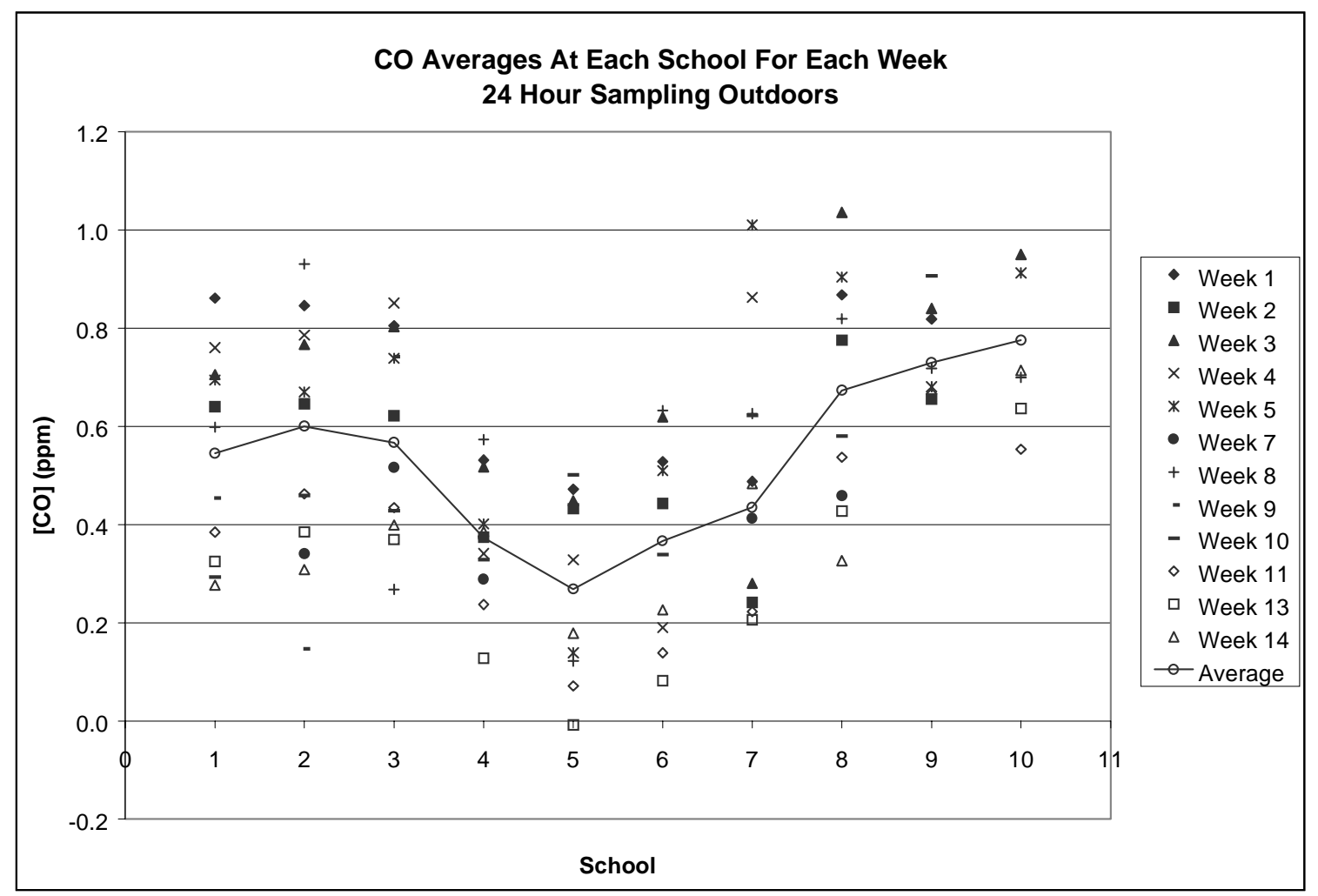

Figure 3.3. Mean CO concentrations averaged over all hours of each week.

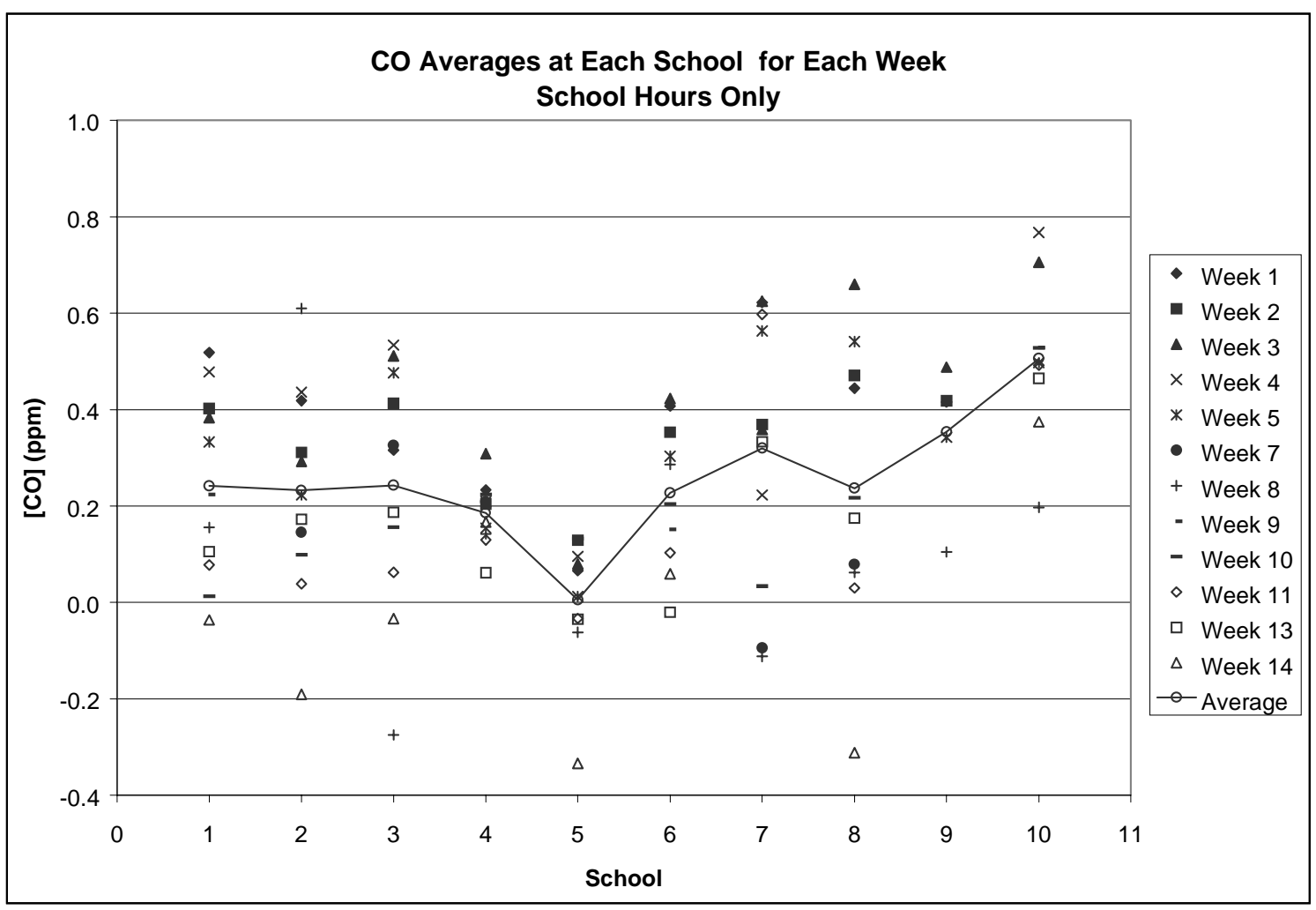

Figure 3.4. Mean CO concentrations averaged over school-hours of each week. 


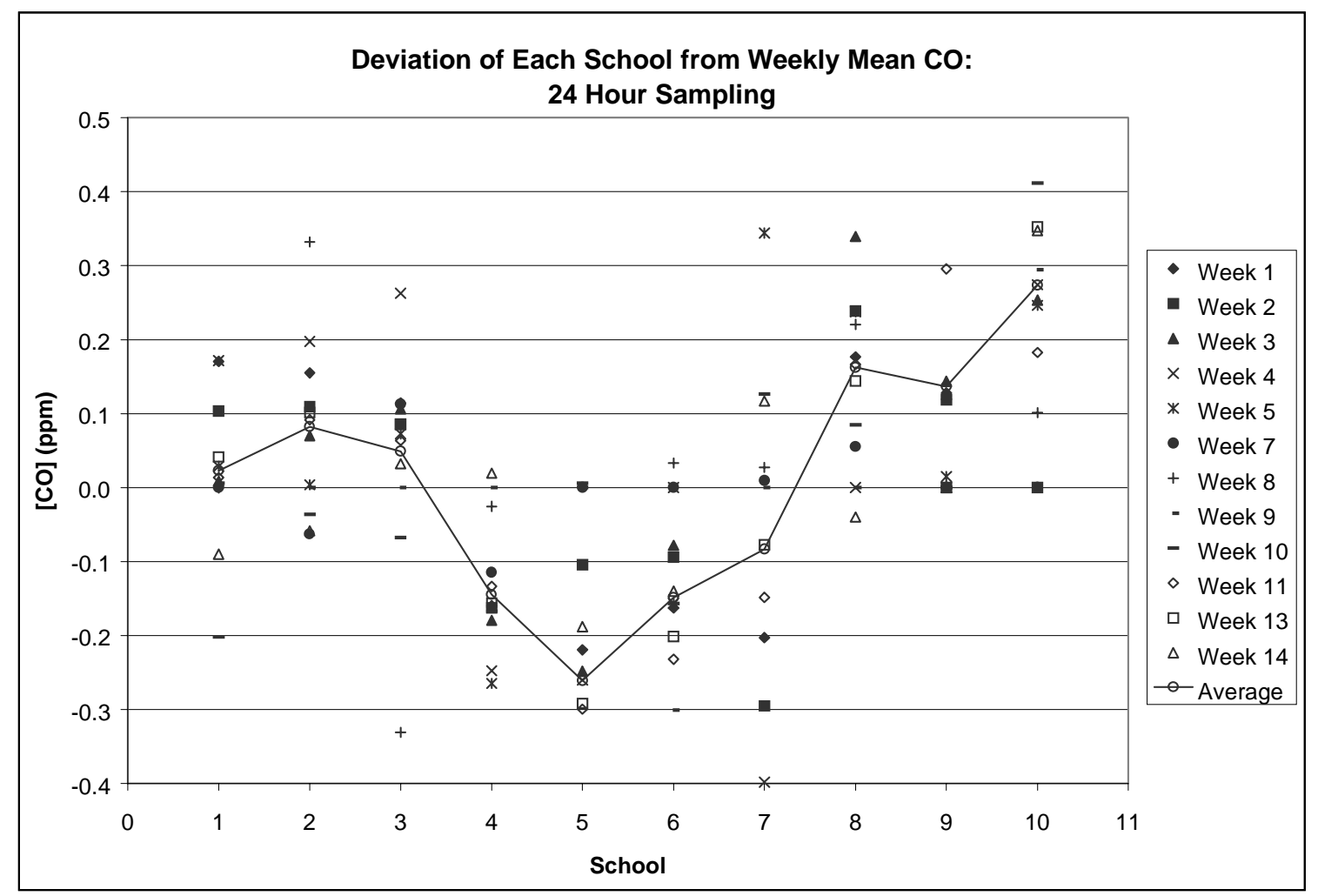

Figure 3.5. Deviations (ppm) between individual school and weekly mean CO concentrations during all-hours sampling.

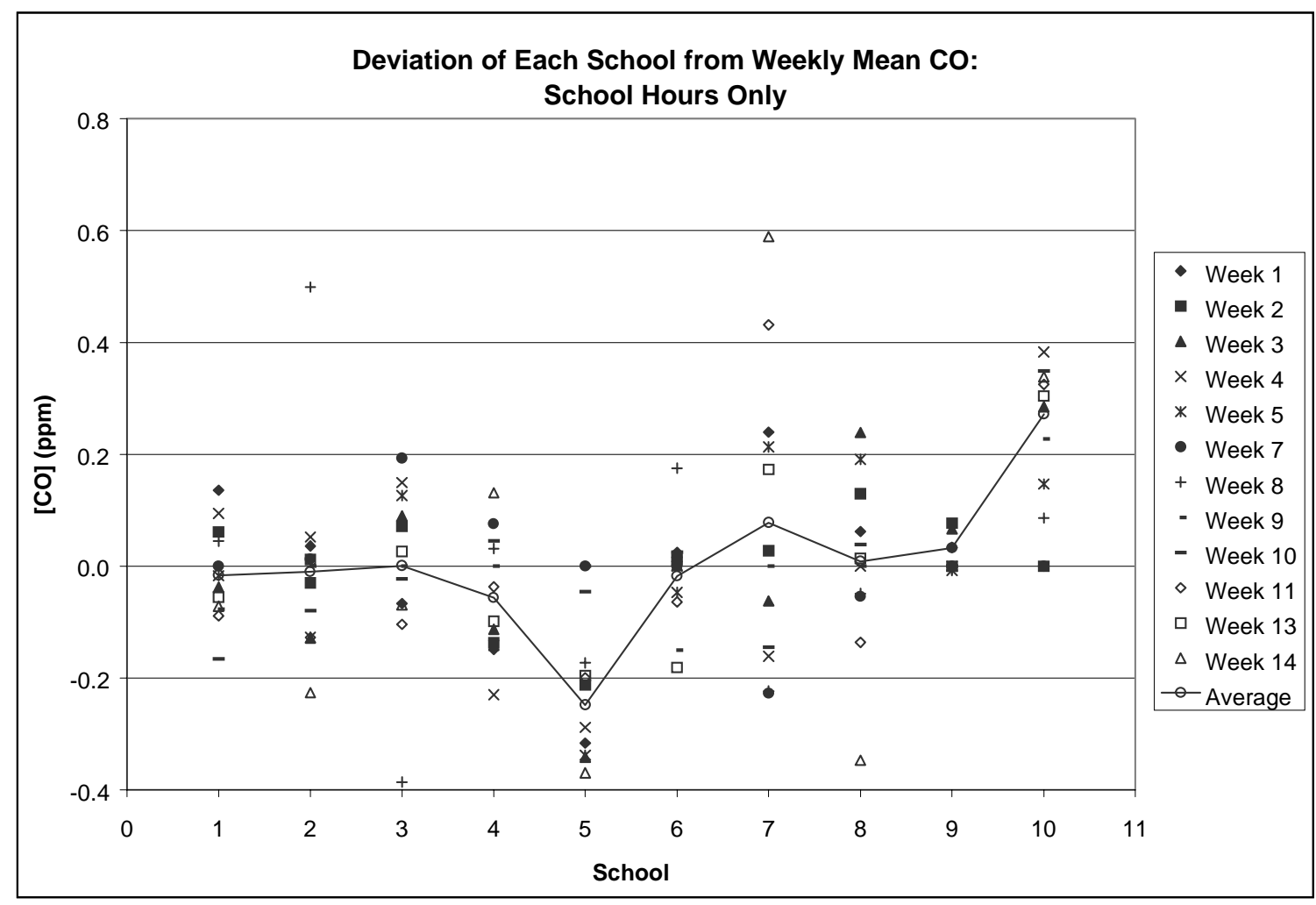

Figure 3.6. Deviations (ppm) between individual school and weekly mean CO concentrations during school-hours sampling. 


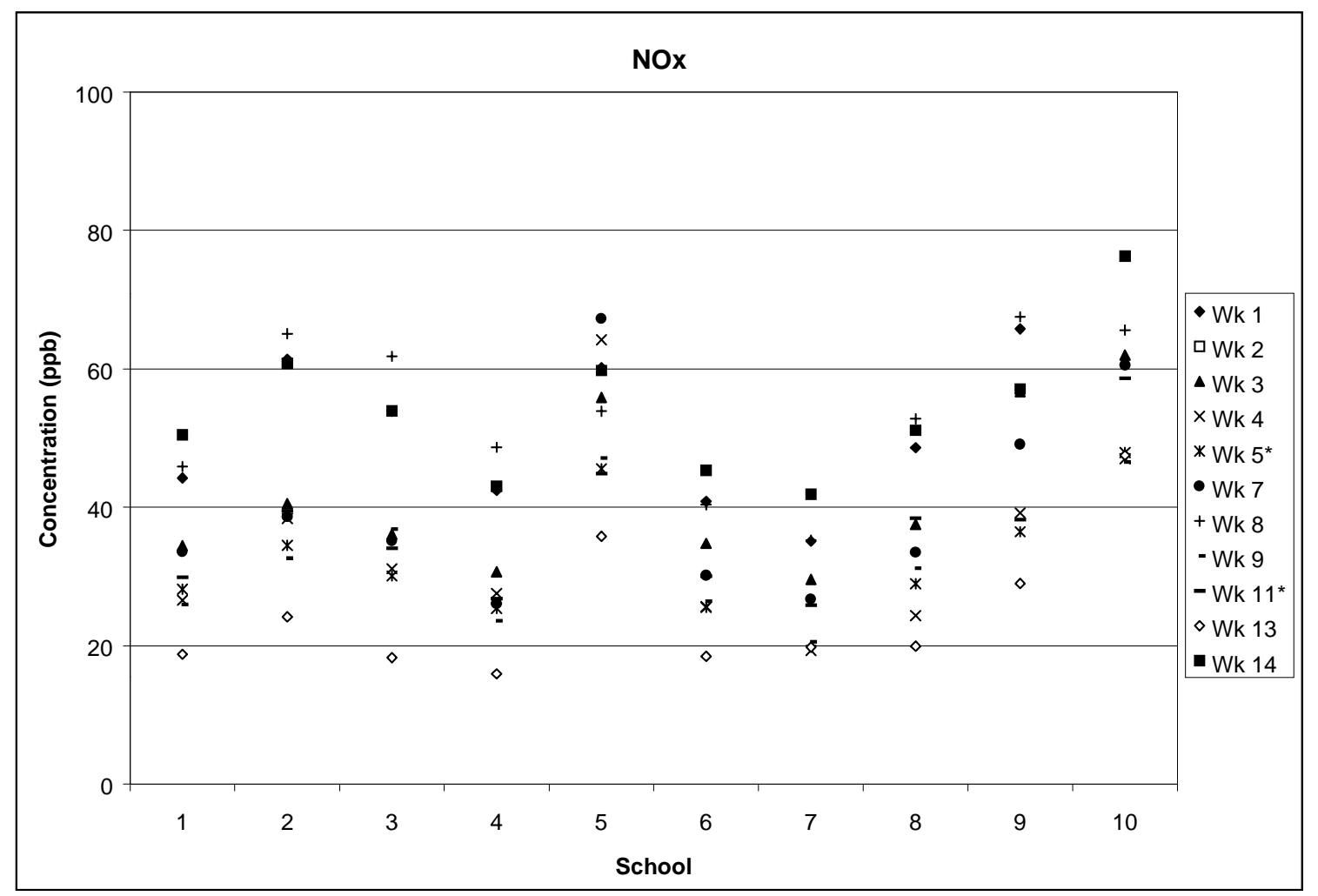

Figure 3.7. Weekly average $\mathrm{NO}_{\mathrm{X}}$ concentrations during spring period.

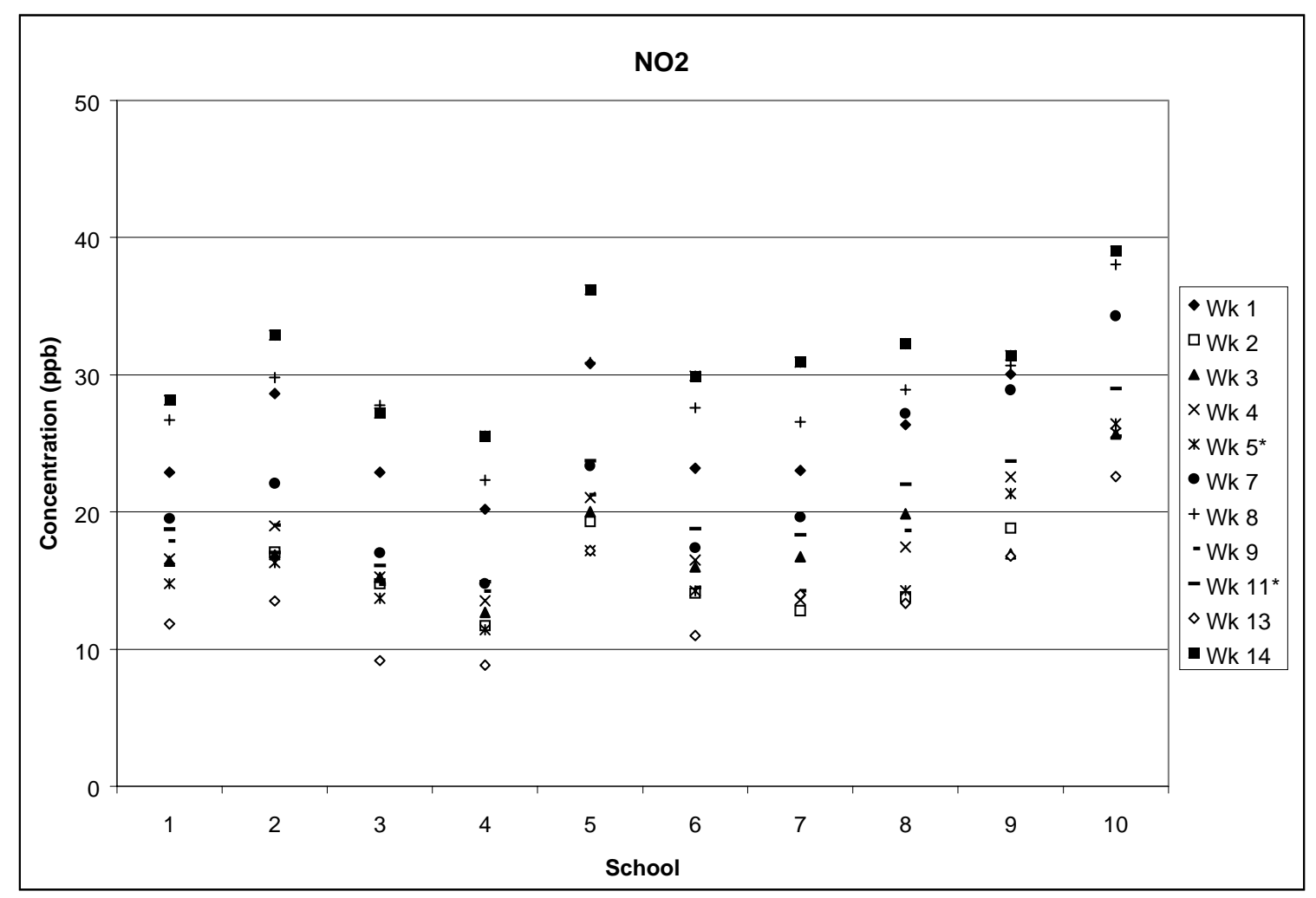

Figure 3.8. Weekly average $\mathrm{NO}_{2}$ concentrations during spring period. 


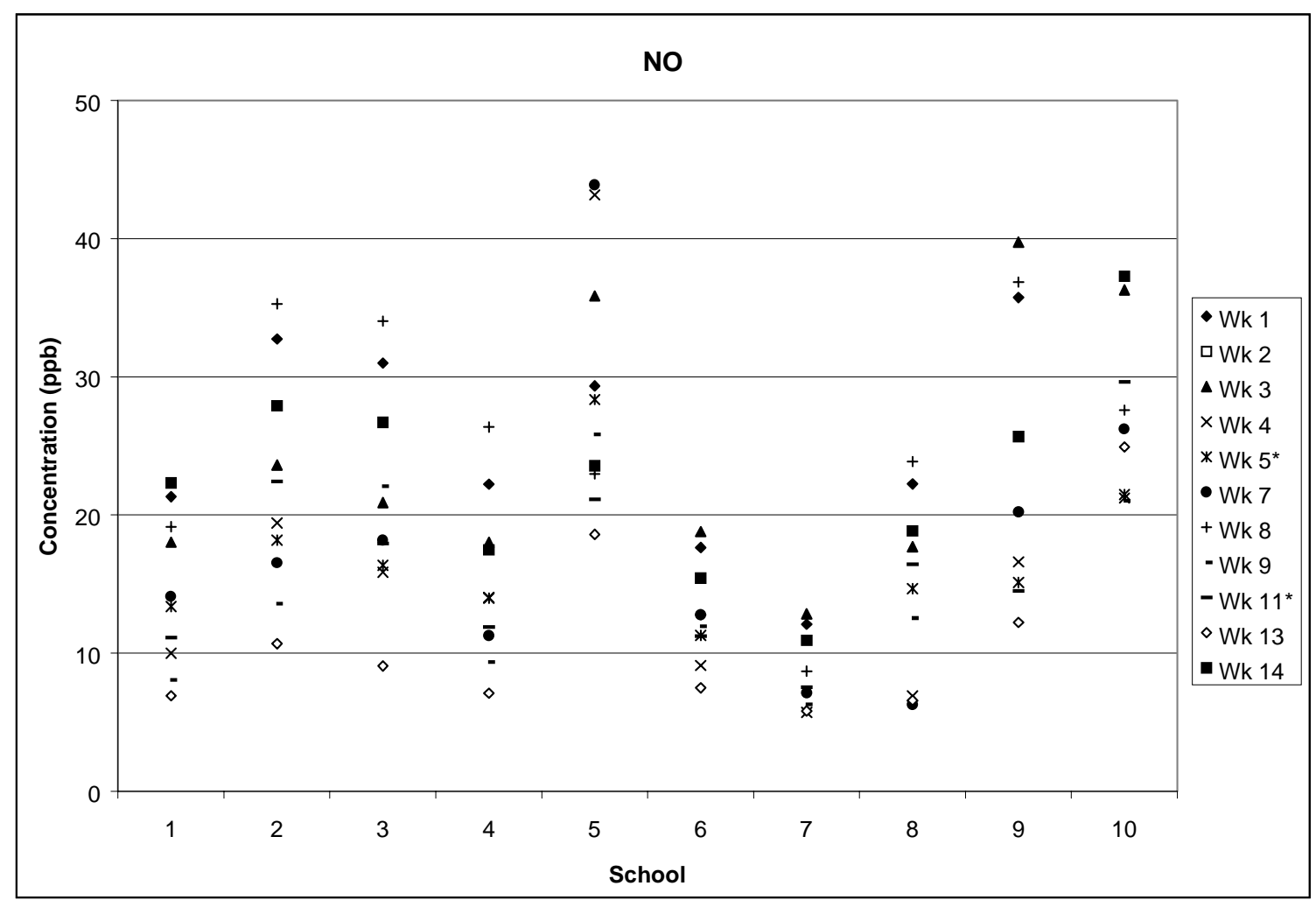

Figure 3.9. Weekly average NO concentrations during spring period.

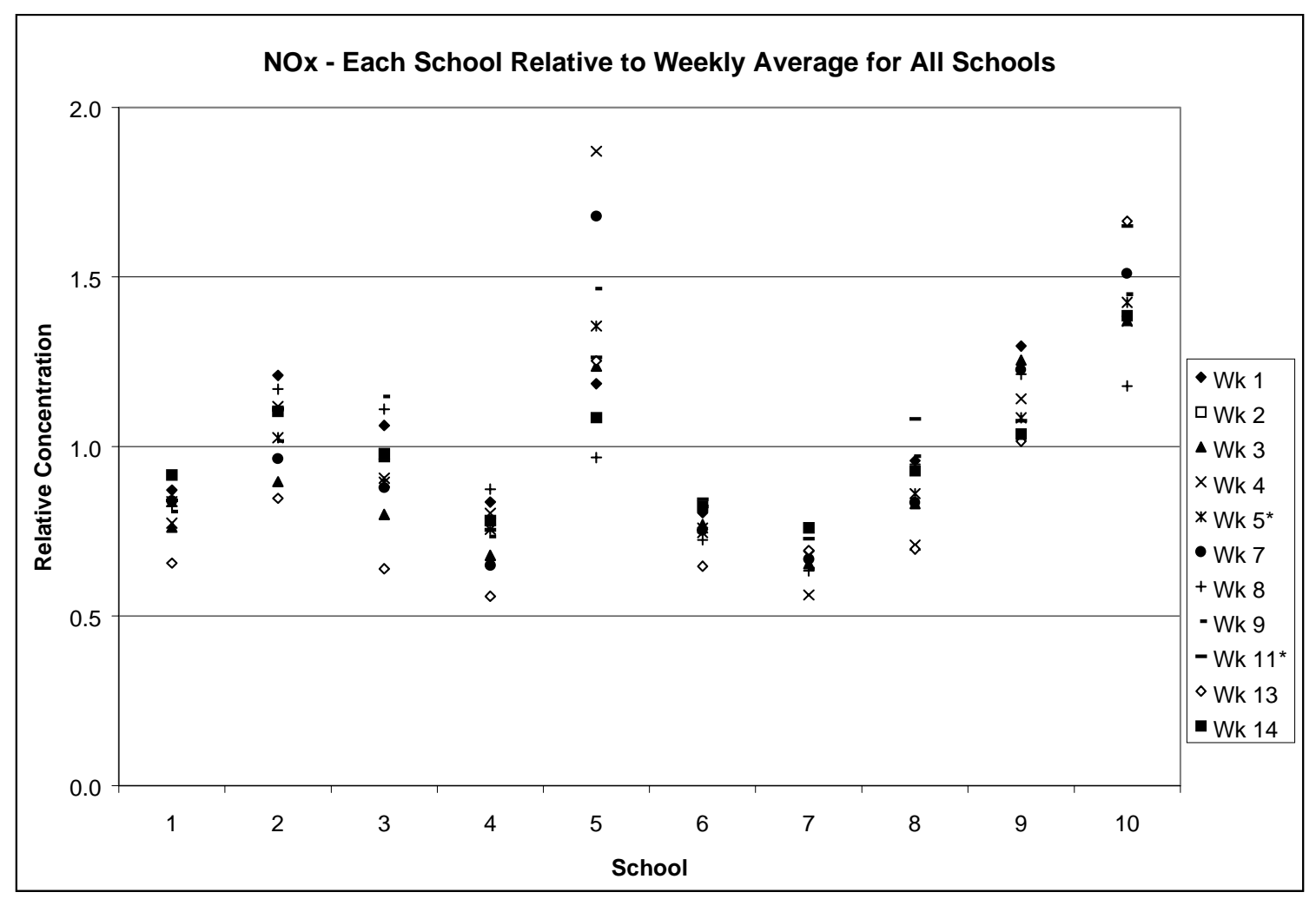

Figure 3.10. $\mathrm{NO}_{\mathrm{X}}$ normalized to weekly mean at all schools during spring period. 


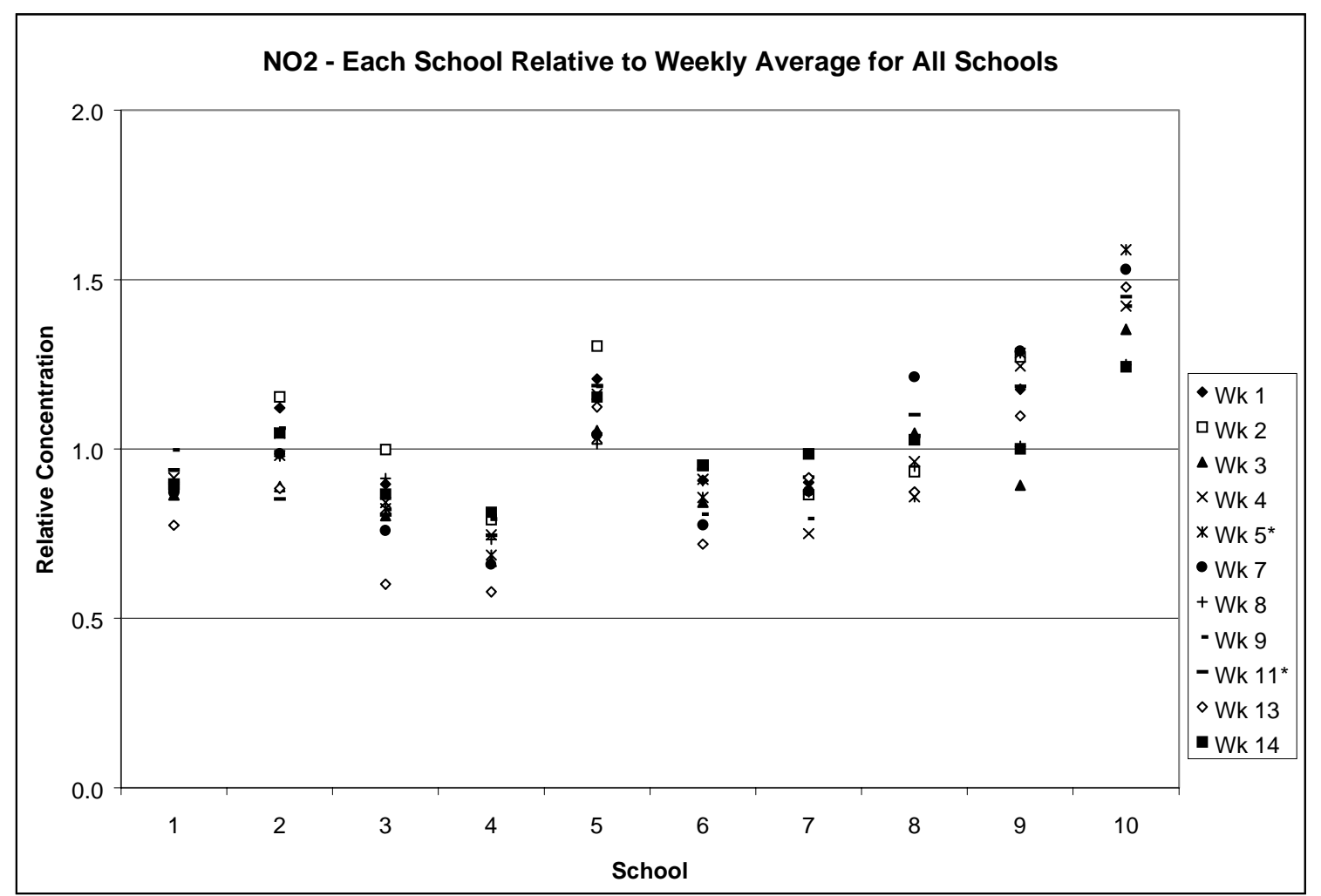

Figure 3.11. $\mathrm{NO}_{2}$ normalized to weekly mean at all schools during spring period.

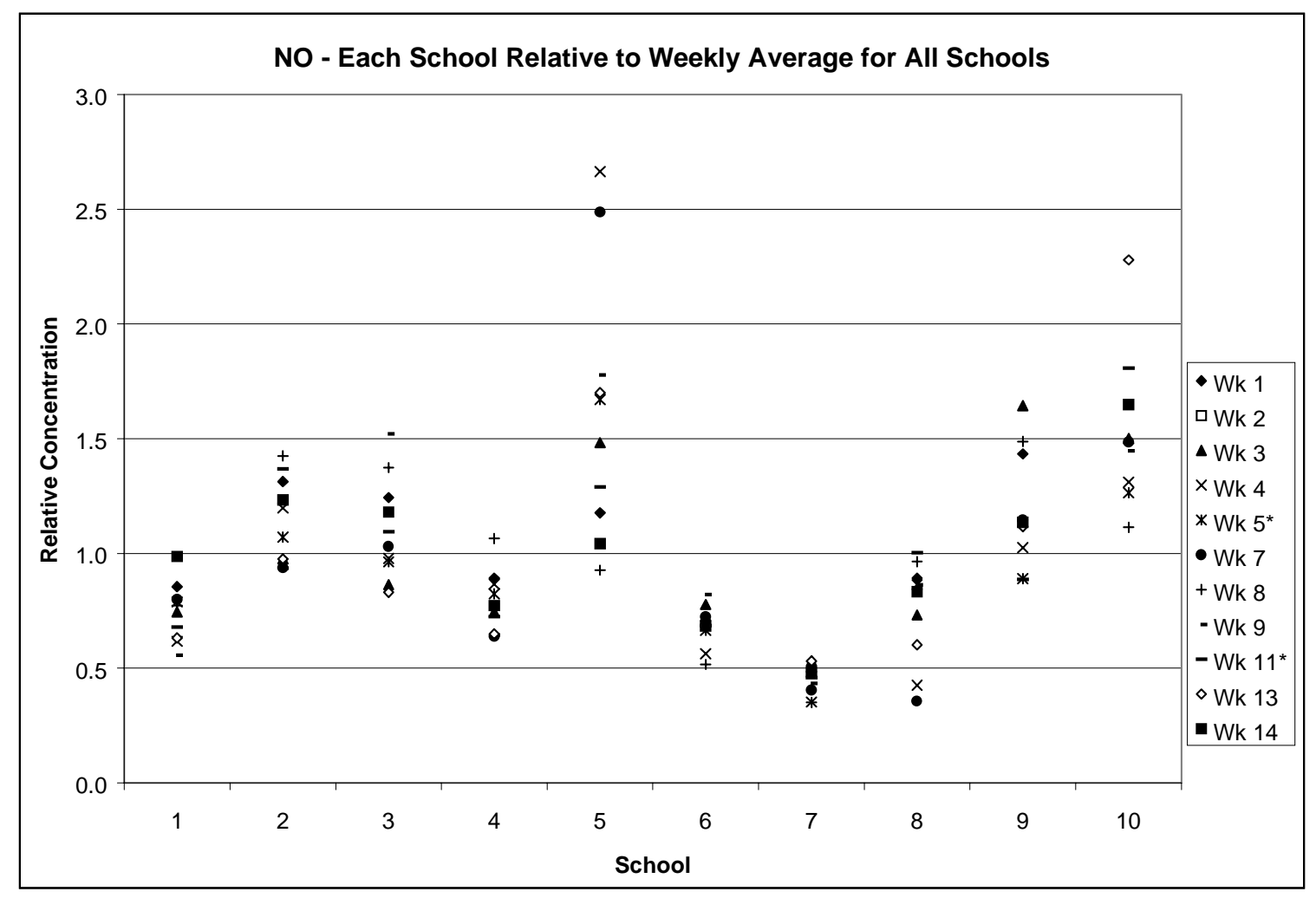

Figure 3.12. NO normalized to weekly mean at all schools during spring period. 


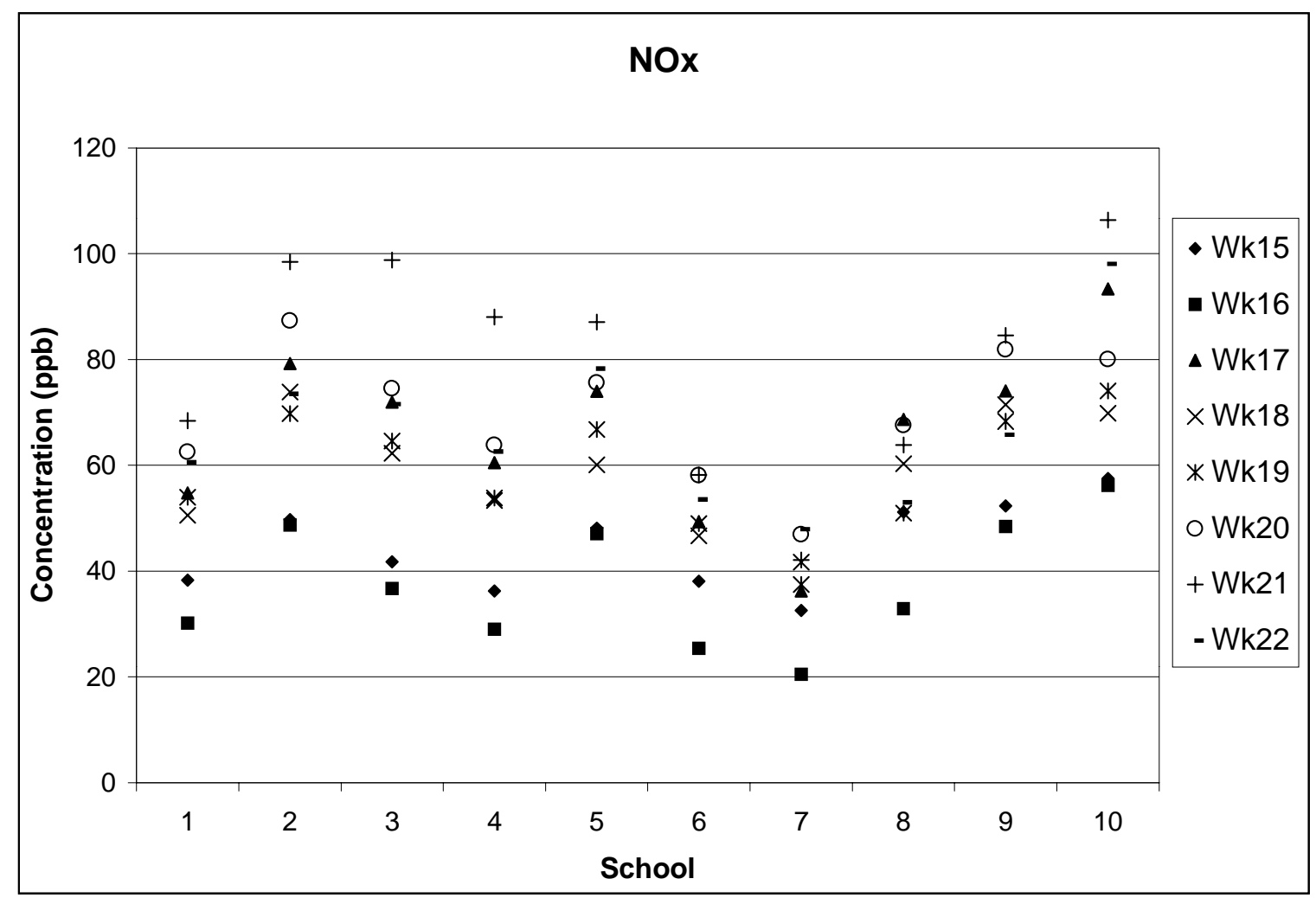

Figure 3.13. Weekly average $\mathrm{NO}_{\mathrm{X}}$ concentrations during fall period.

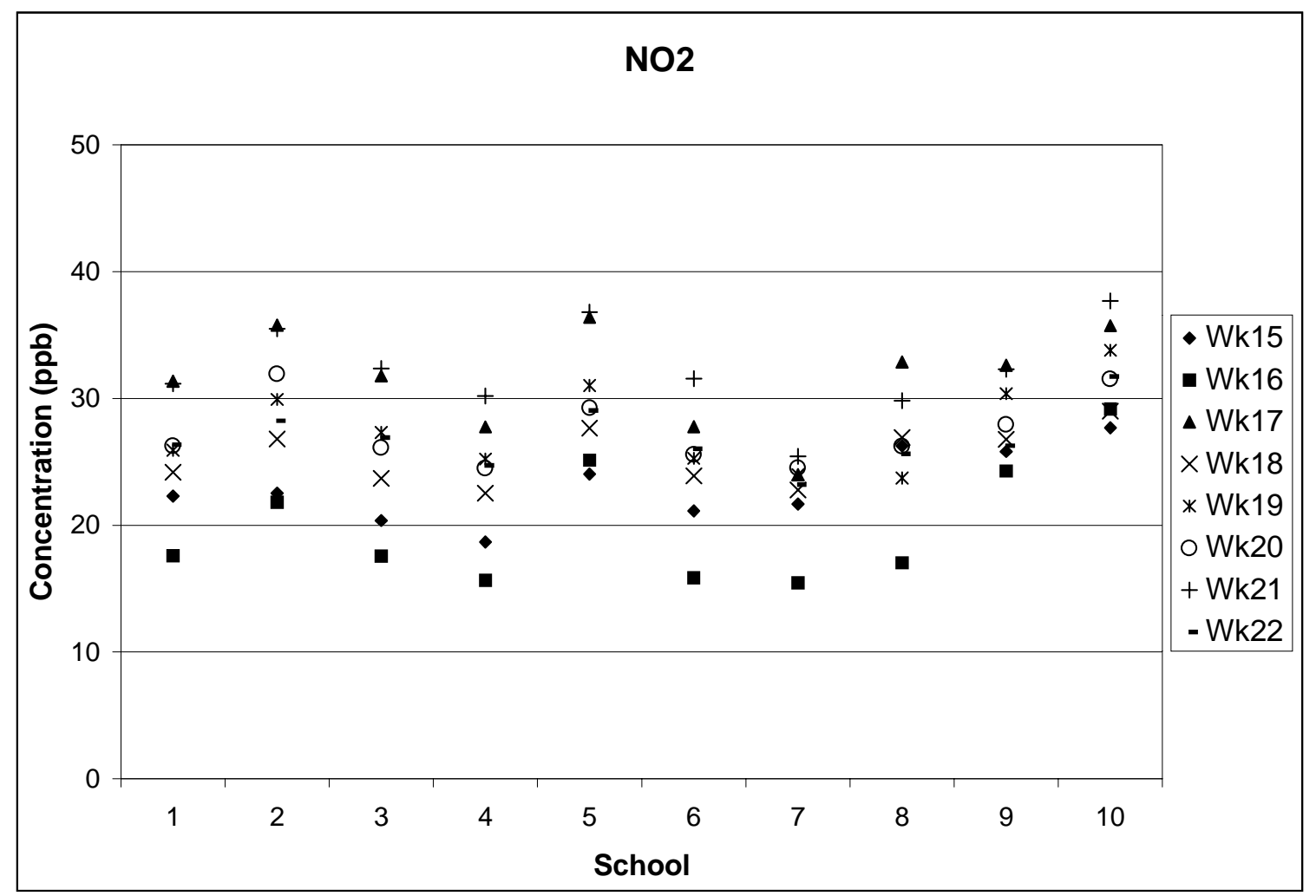

Figure 3.14. Weekly average $\mathrm{NO}_{2}$ concentrations during fall period. 


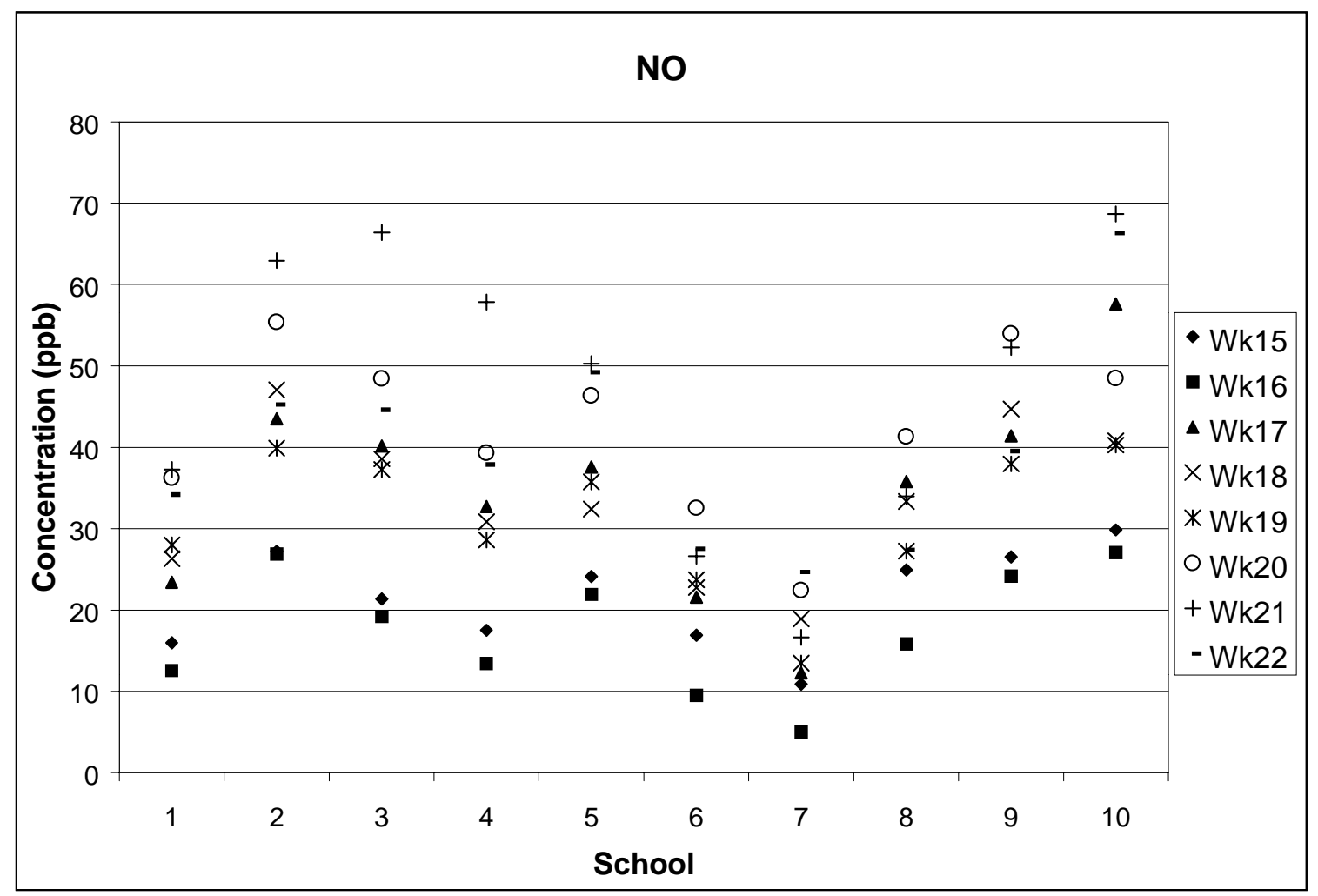

Figure 3.15. Weekly average NO concentrations during fall period.

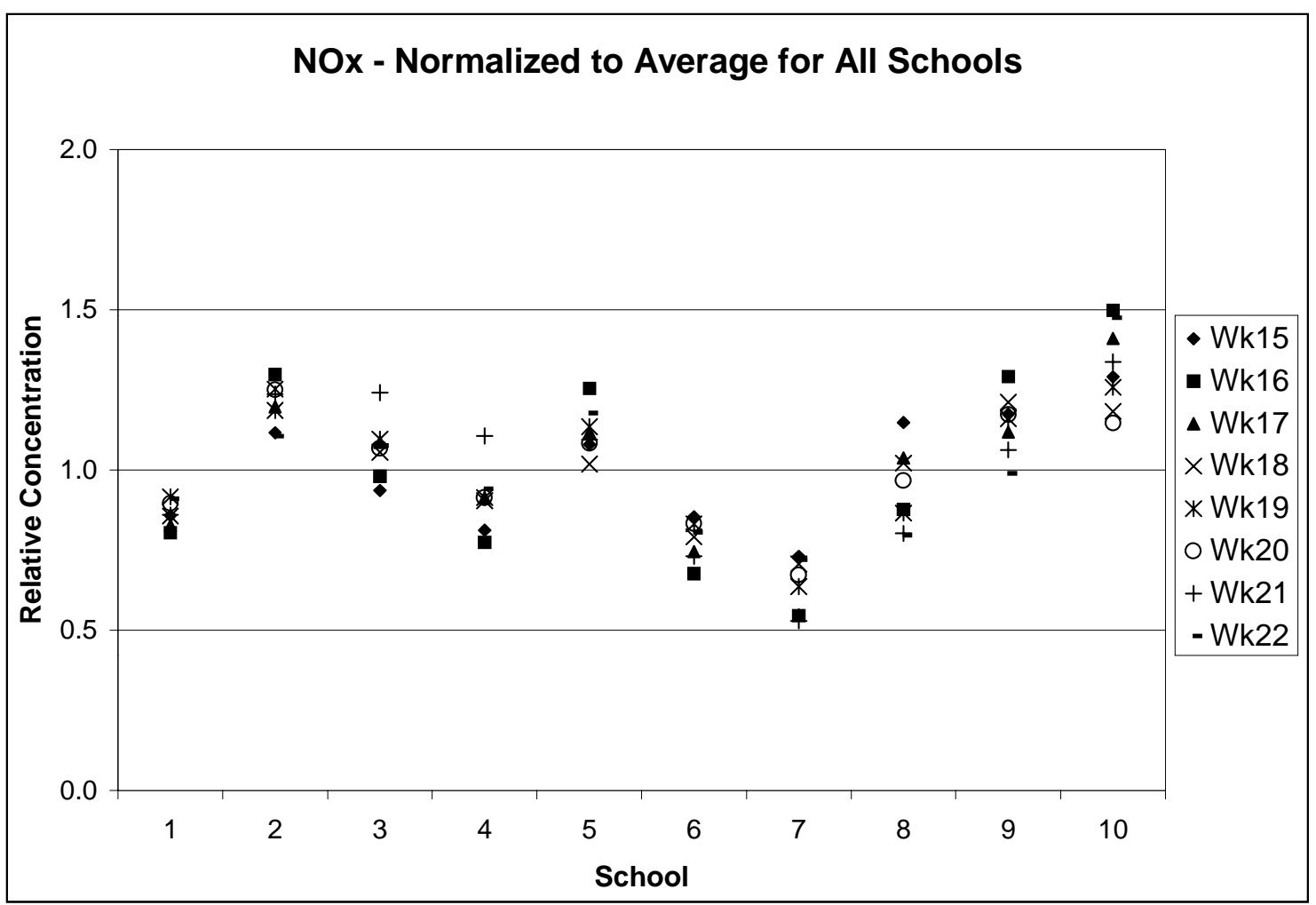

Figure 3.16. $\mathrm{NO}_{\mathrm{X}}$ normalized to weekly mean at all schools during fall period. 


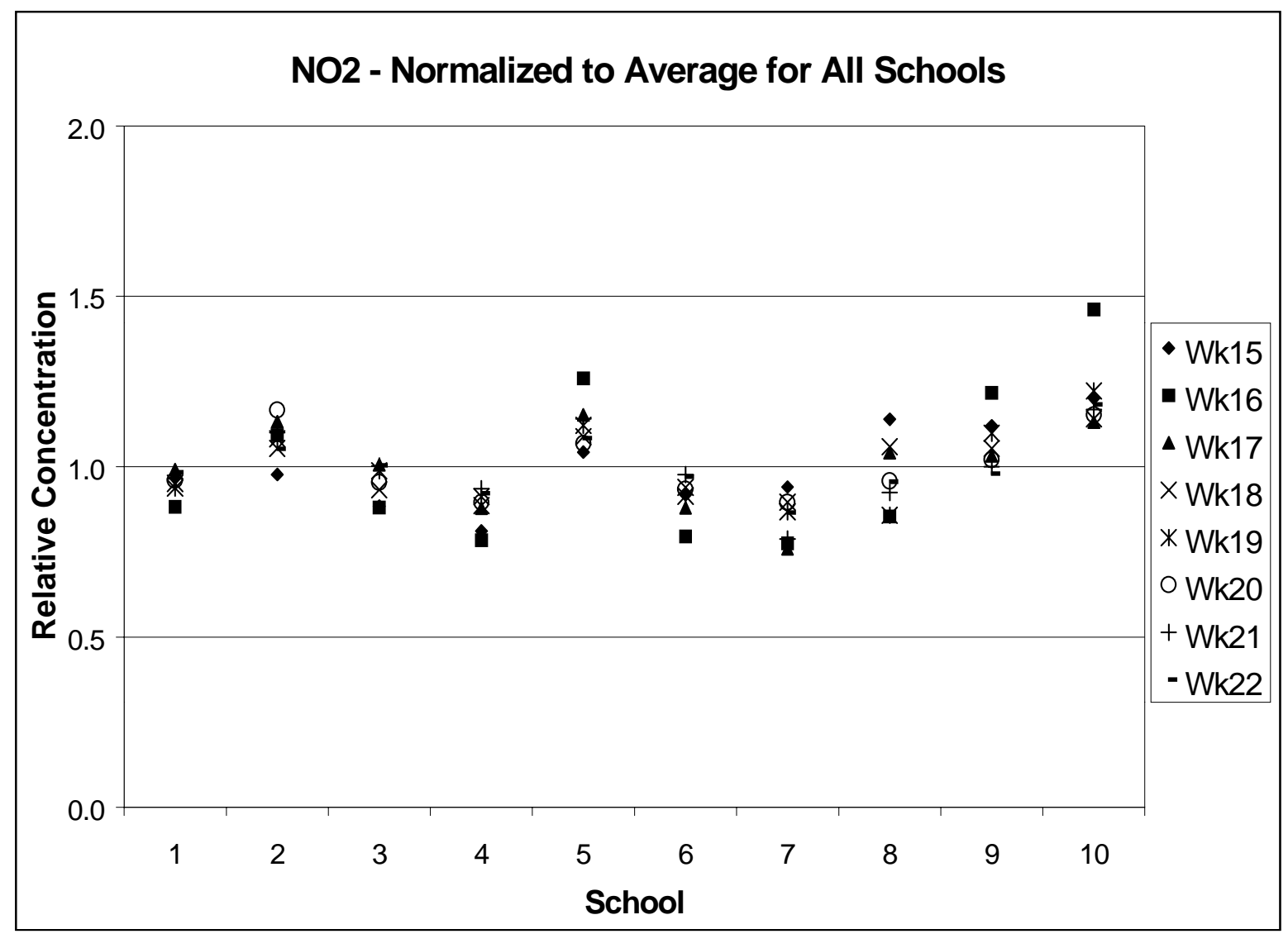

Figure 3.17. $\mathrm{NO}_{2}$ normalized to weekly mean at all schools during fall period.

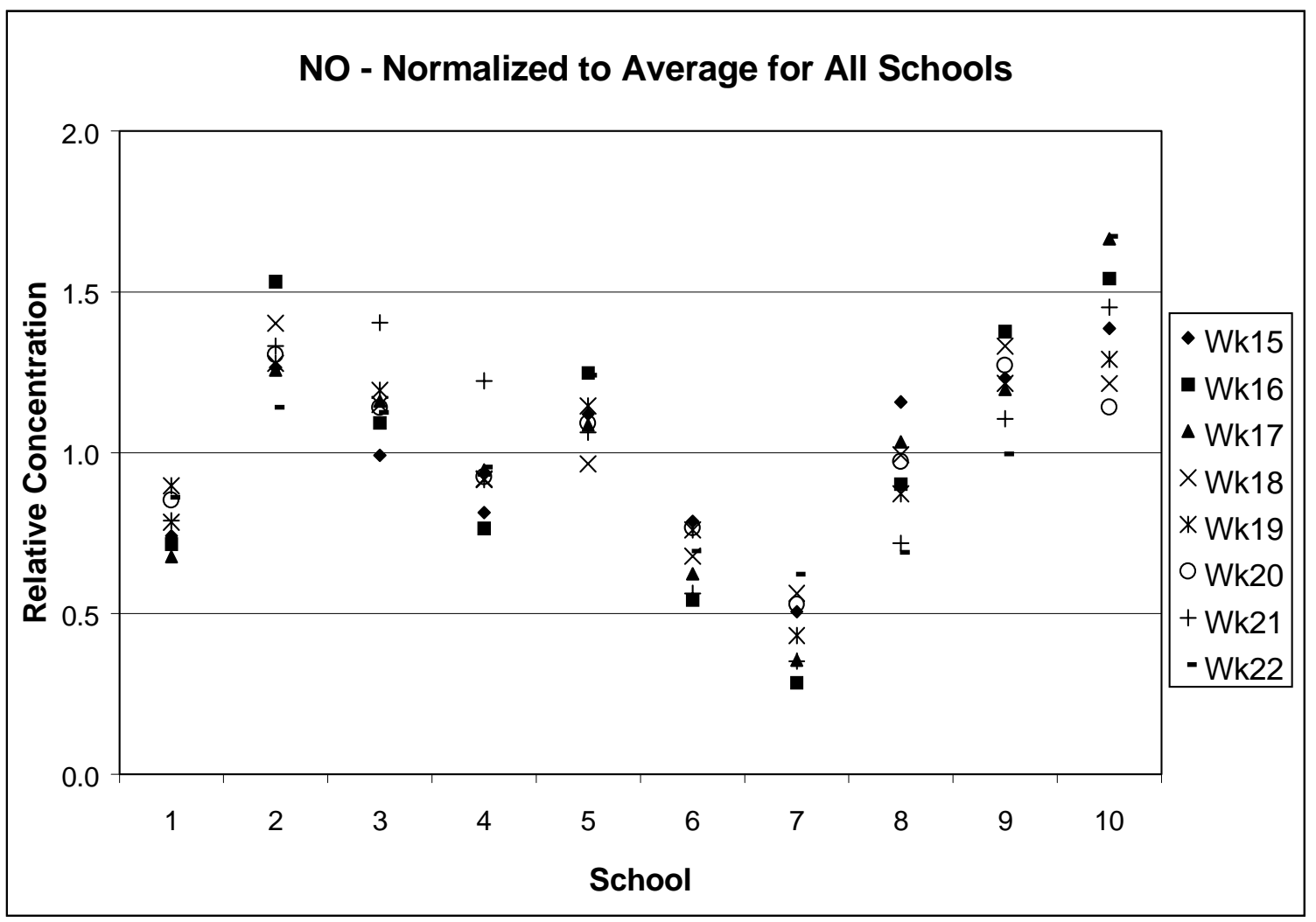

Figure 3.18. NO normalized to weekly mean at all schools during fall period. 


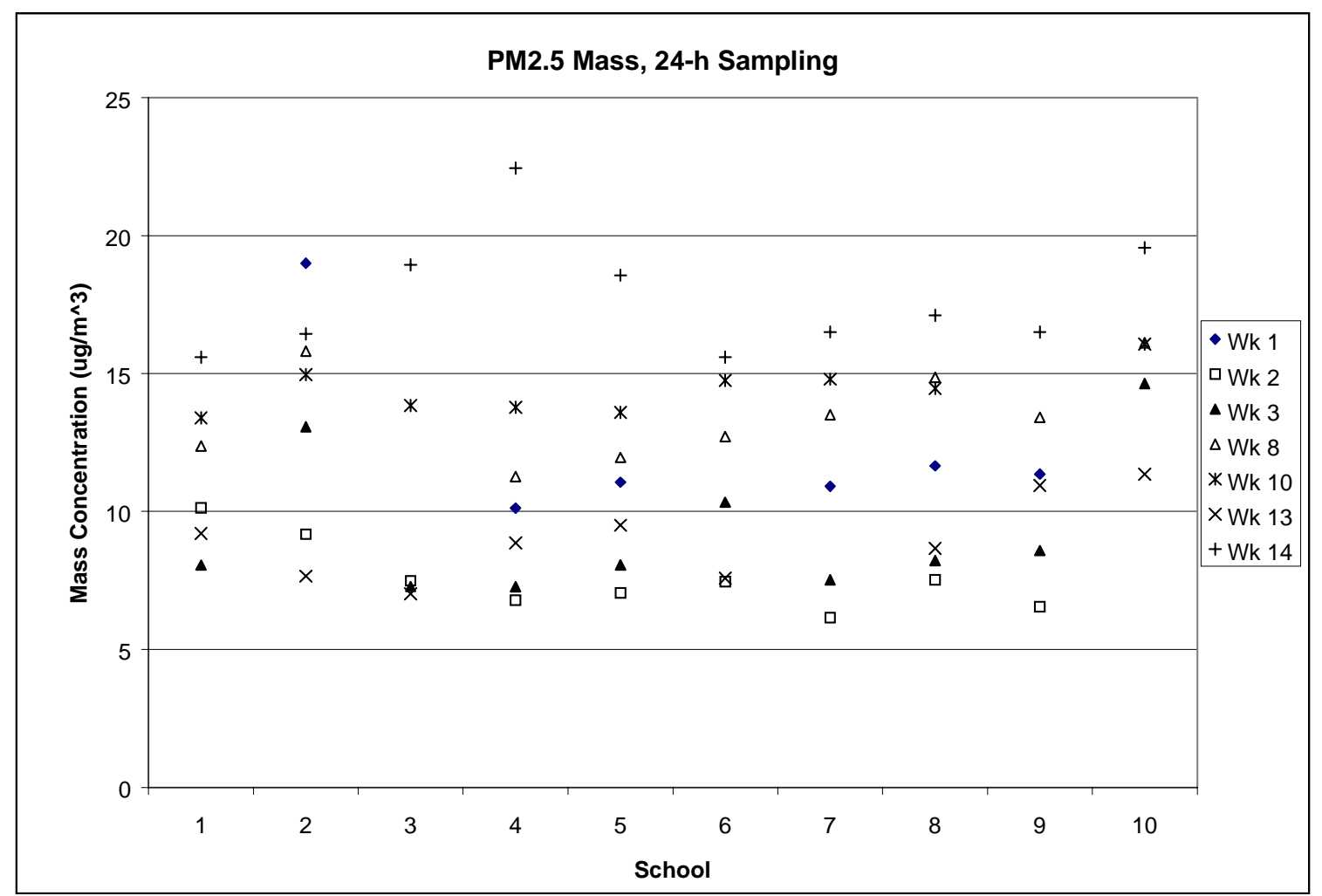

Figure 3.19. $\mathrm{PM}_{2.5}$ mass concentrations for all-hours sampling during spring period.

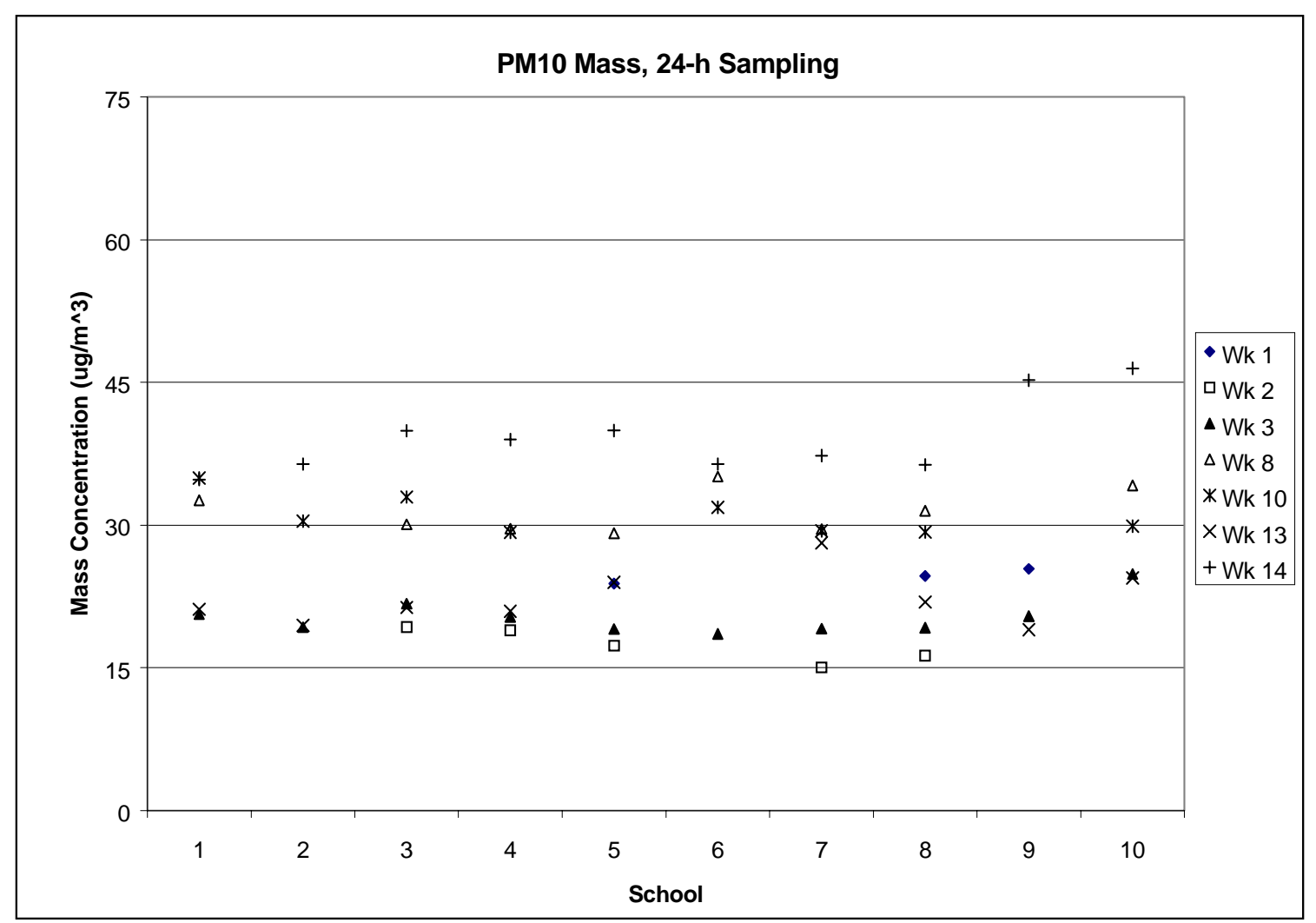

Figure 3.20. $\mathrm{PM}_{10}$ mass concentrations for all-hours sampling during spring period. 


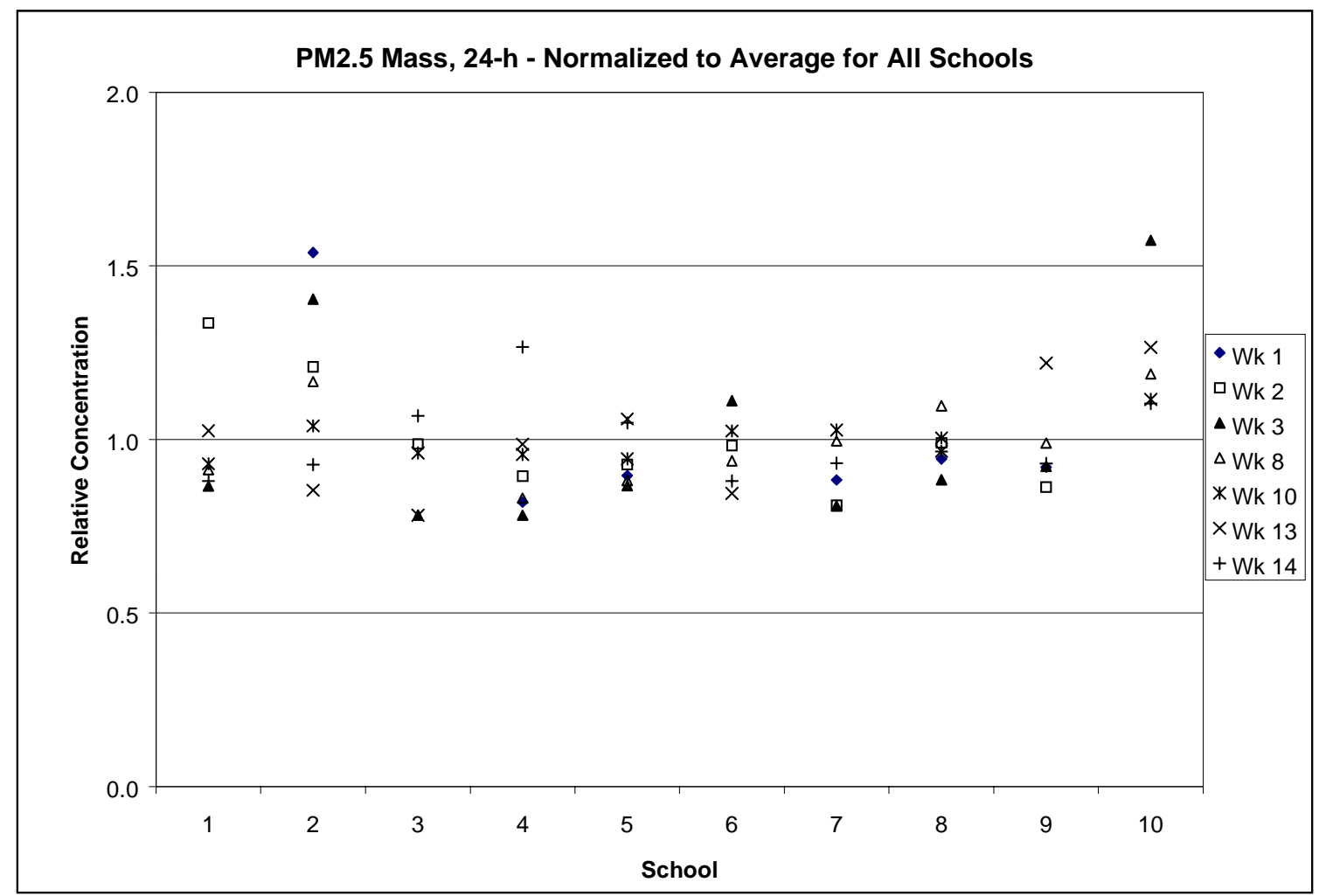

Figure 3.21. $\mathrm{PM}_{2.5}$ for all-hours sampling normalized to weekly mean at all schools during spring period.

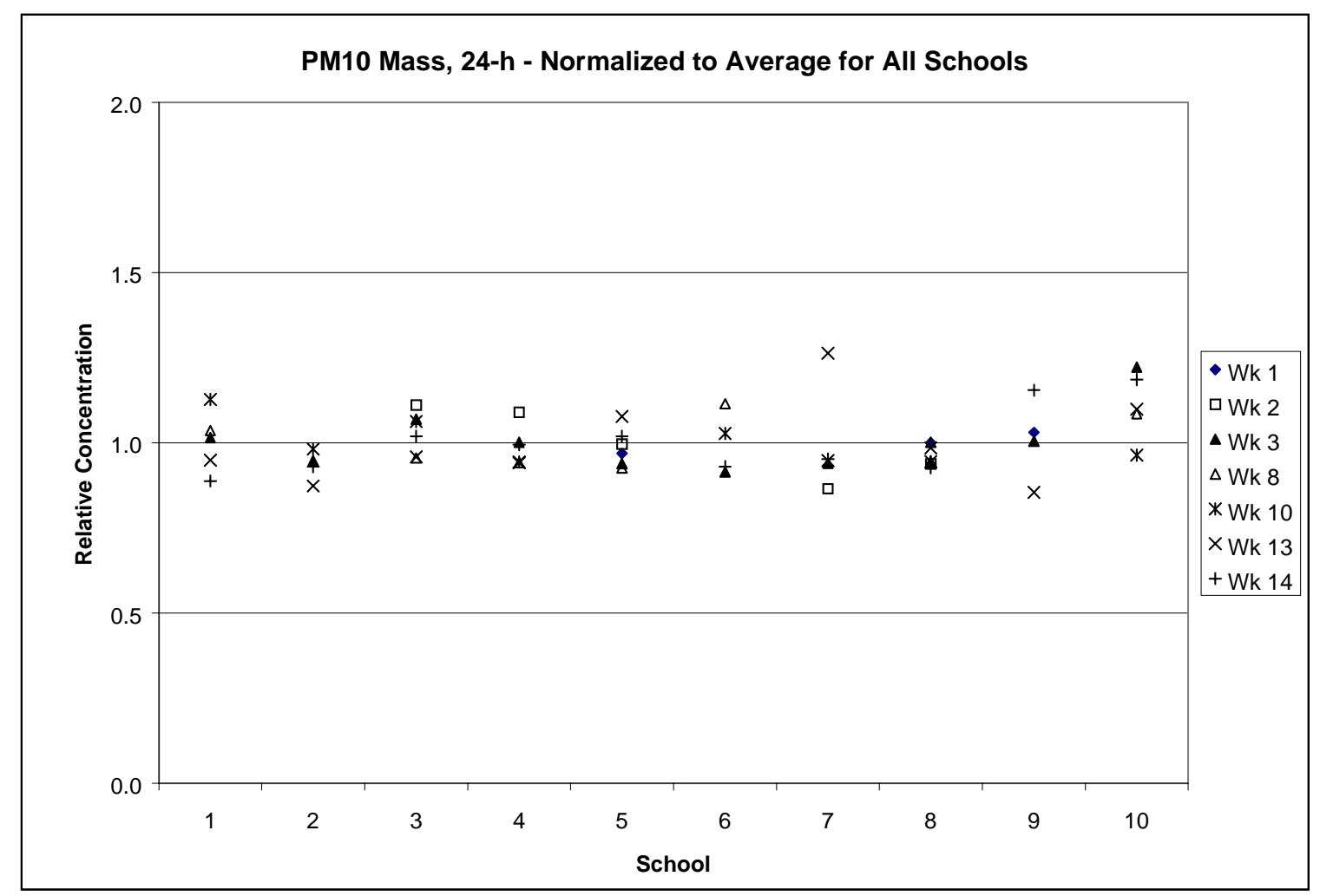

Figure 3.22. $\mathrm{PM}_{10}$ for all-hours sampling normalized to weekly mean at all schools during spring period. 


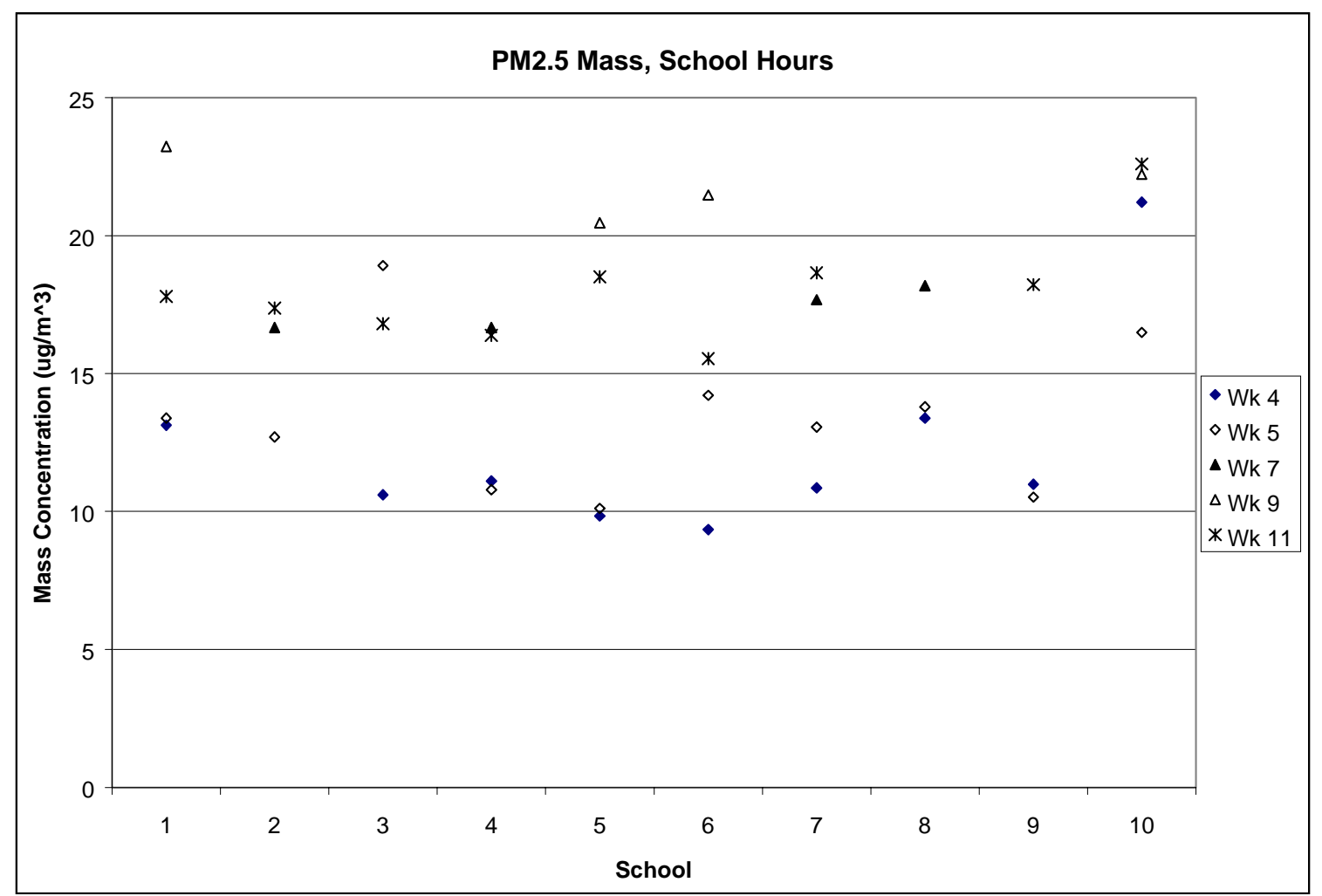

Figure 3.23. $\mathrm{PM}_{2.5}$ mass concentrations for school-hours sampling during spring period.

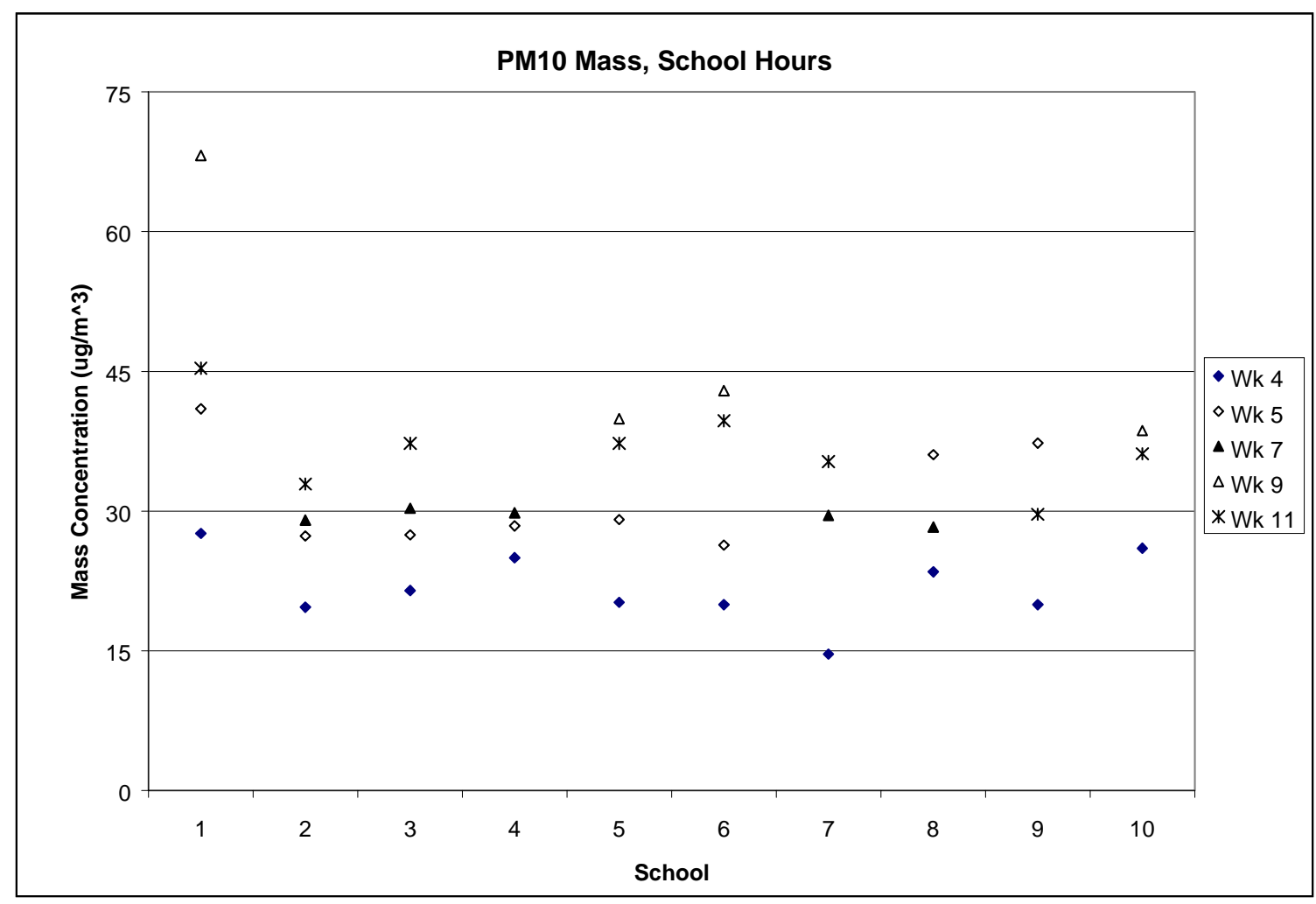

Figure 3.24. $\mathrm{PM}_{10}$ mass concentrations for school-hours sampling during spring period. 


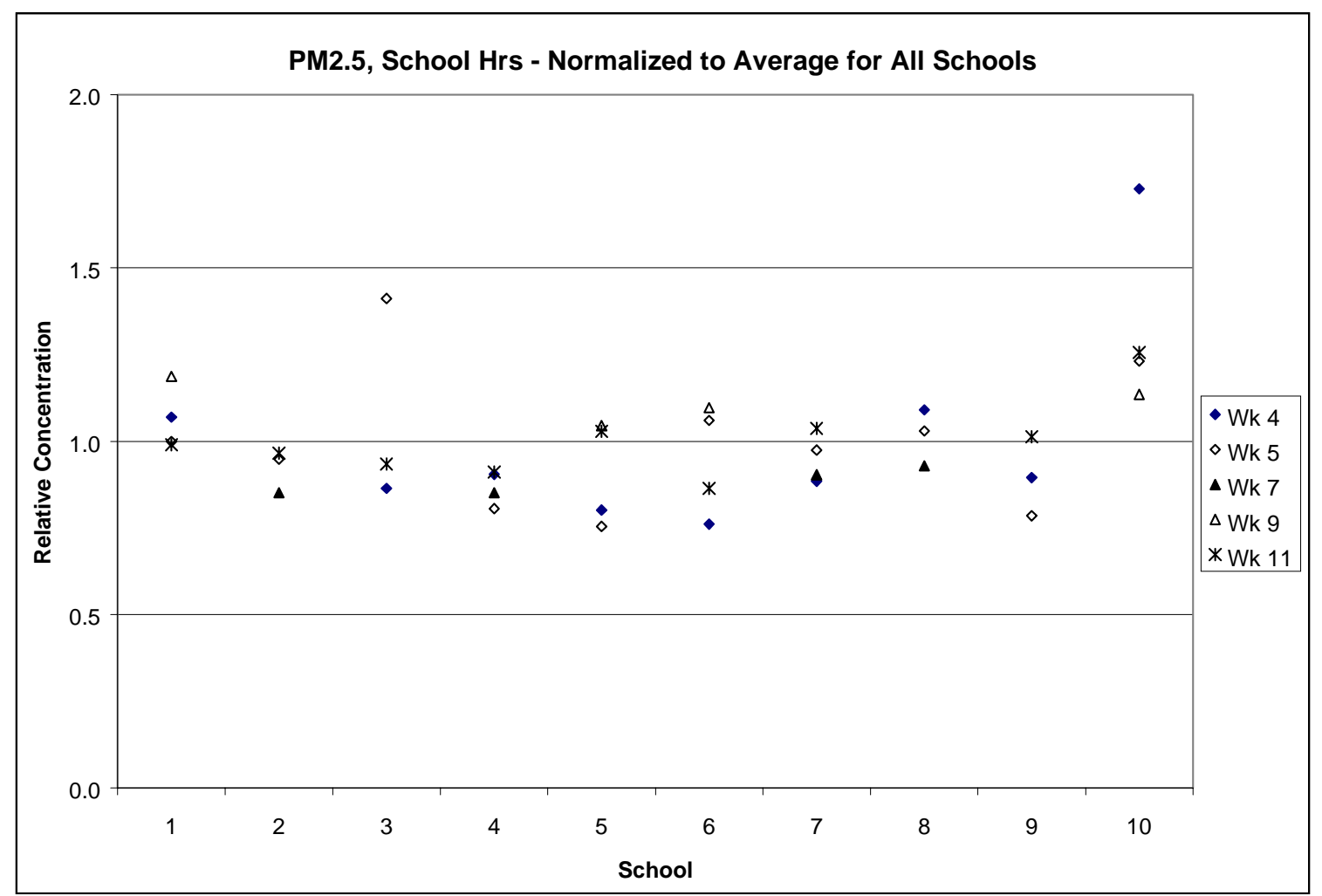

Figure 3.25. $\mathrm{PM}_{2.5}$ for school-hours sampling normalized to weekly mean at all schools during spring period.

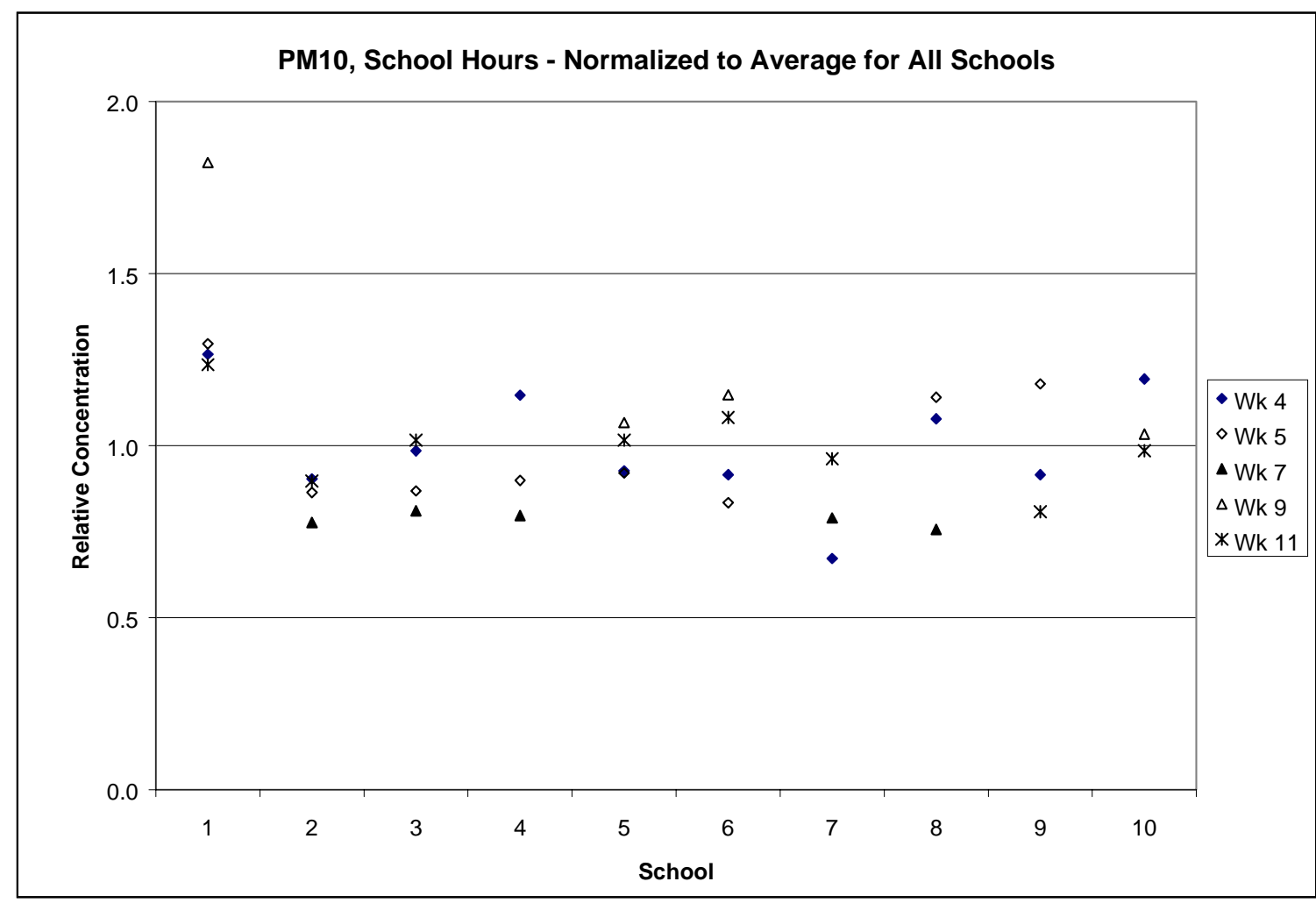

Figure 3.26. $\mathrm{PM}_{10}$ for school-hours sampling normalized to weekly mean at all schools during spring period. 


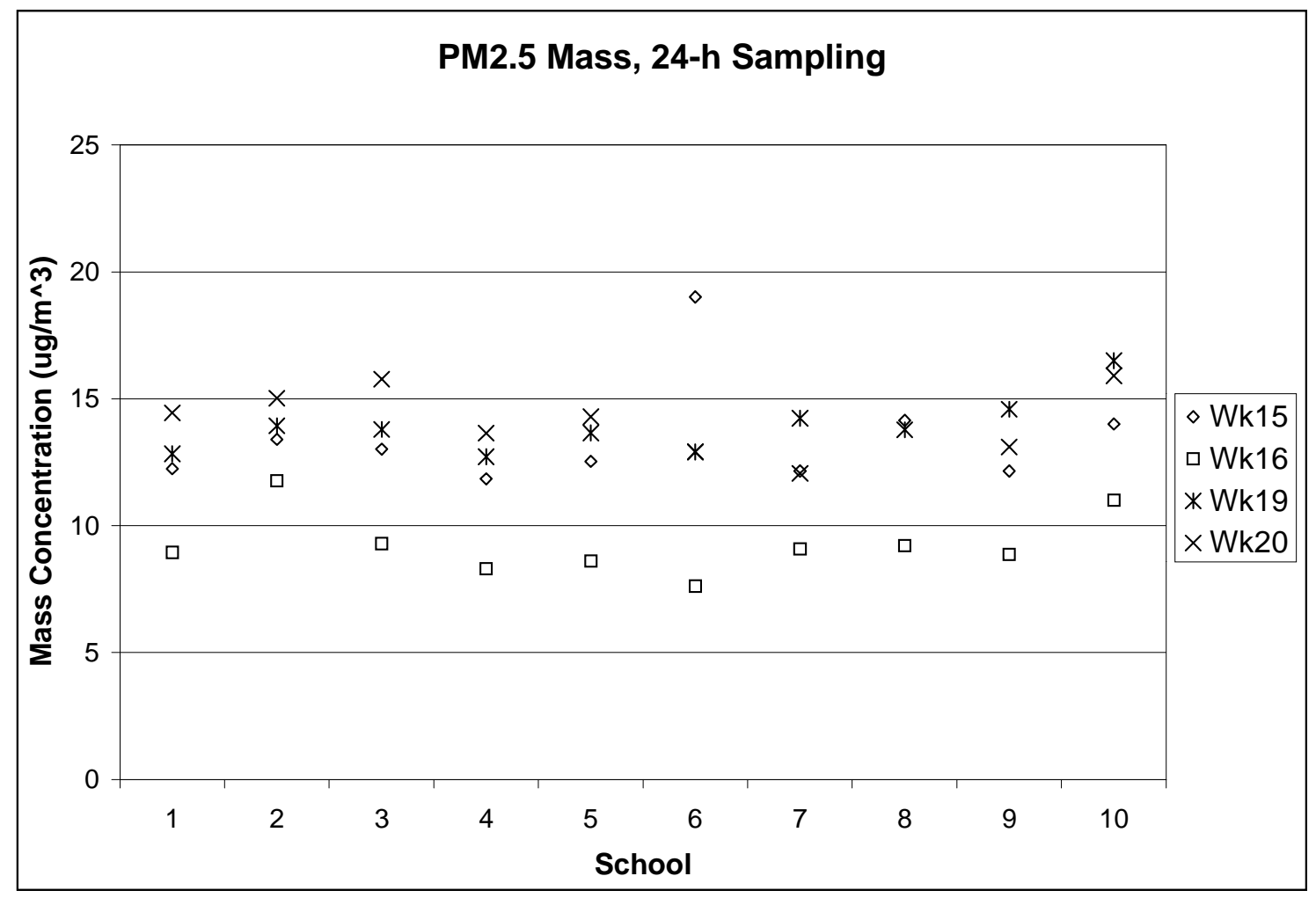

Figure 3.27. $\mathrm{PM}_{2.5}$ mass concentrations for all-hours sampling during fall period.

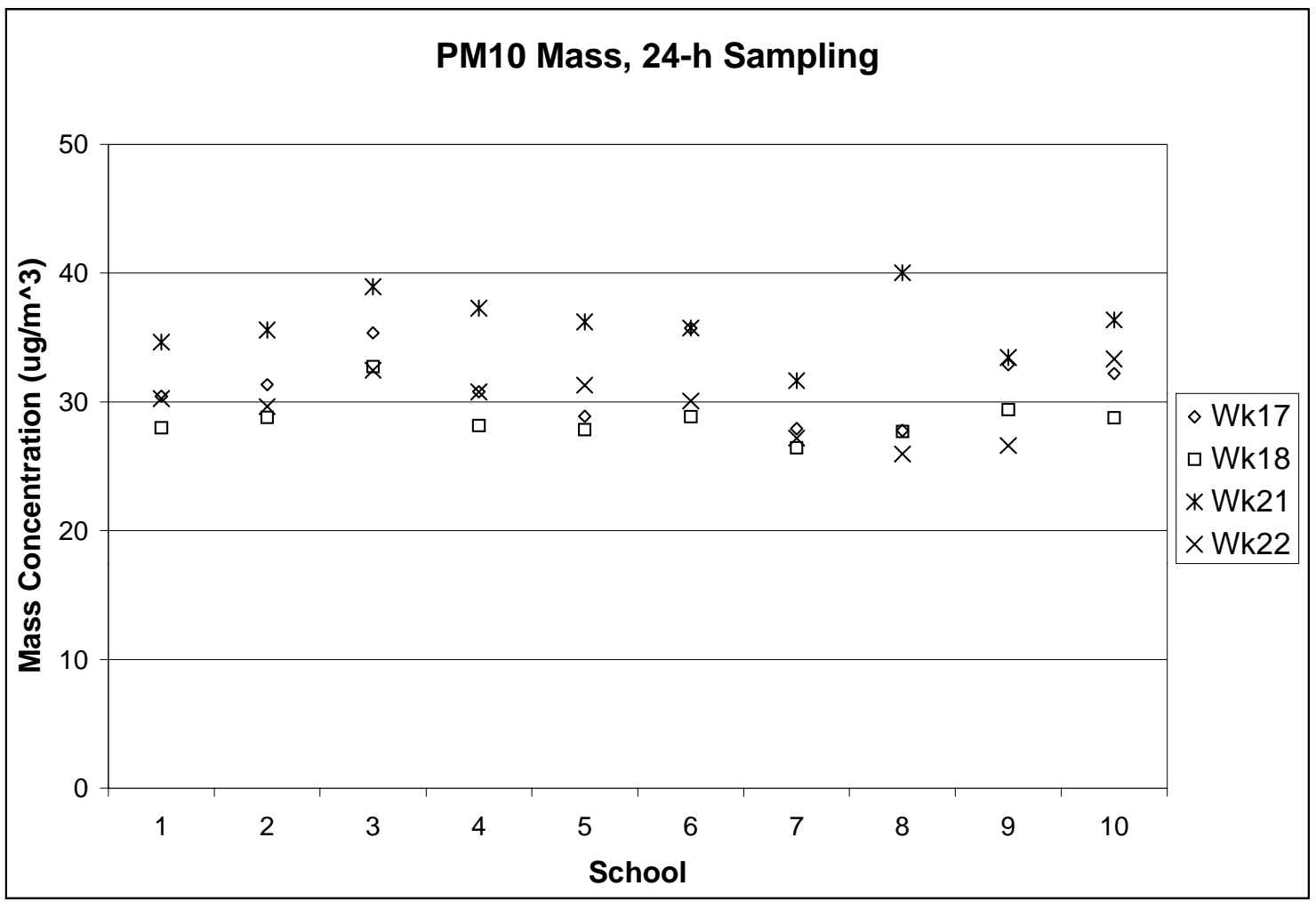

Figure 3.28. $\mathrm{PM}_{10}$ mass concentrations for all-hours sampling during fall period. 


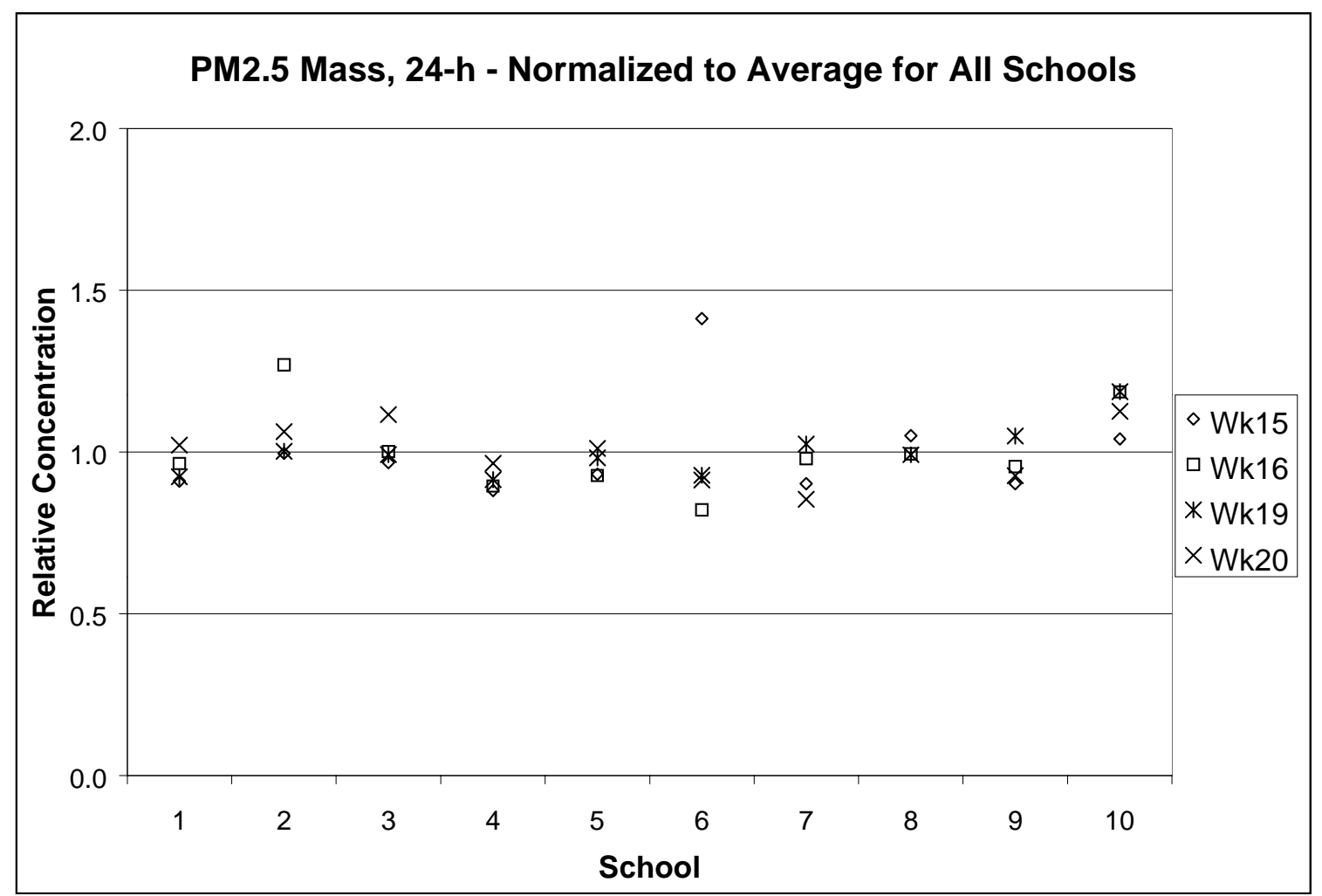

Figure 3.29. $\mathrm{PM}_{2.5}$ for all-hours sampling normalized to weekly mean at all schools during fall period.

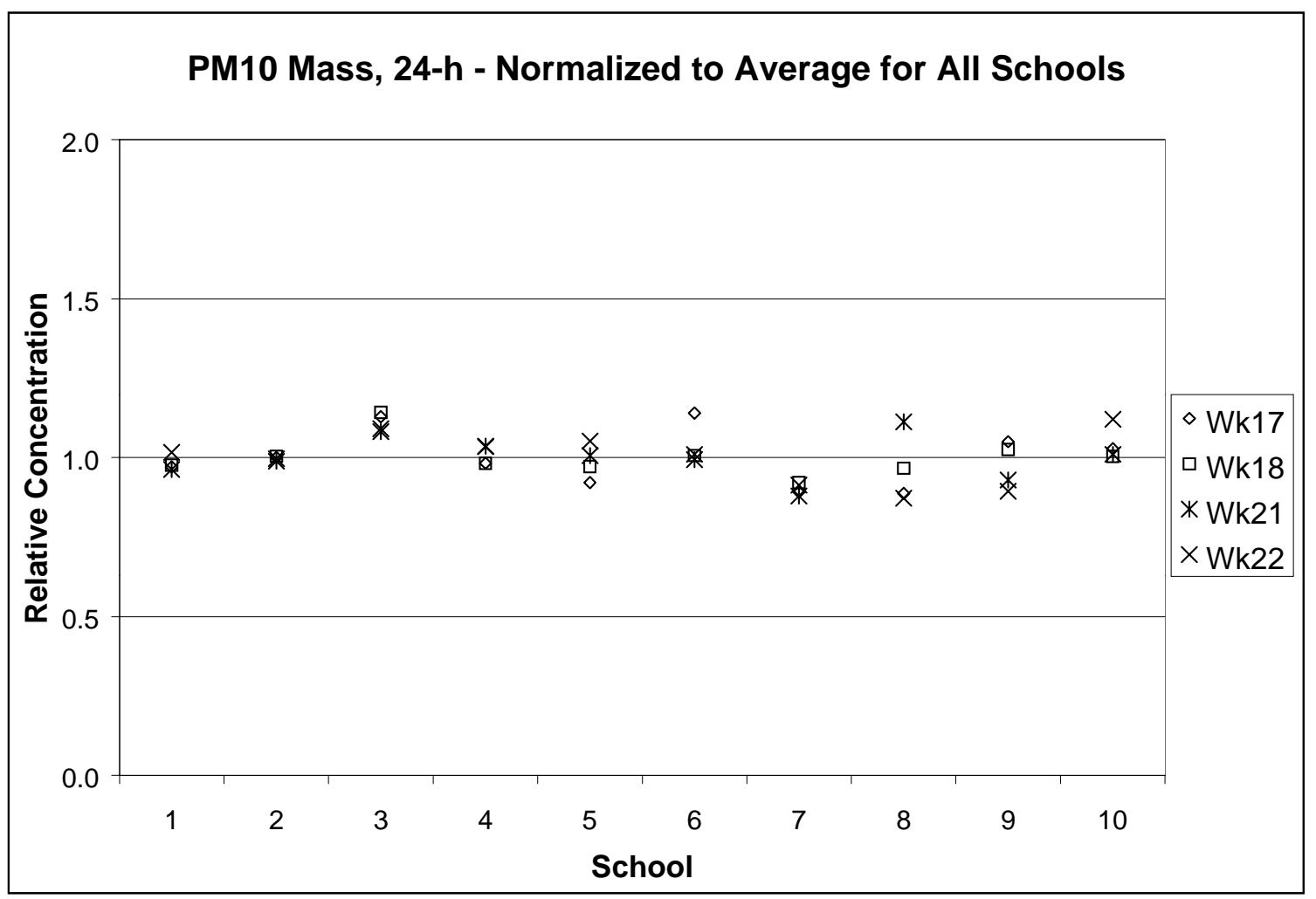

Figure 3.30. $\mathrm{PM}_{10}$ for all-hours sampling normalized to weekly mean at all schools during fall period. 


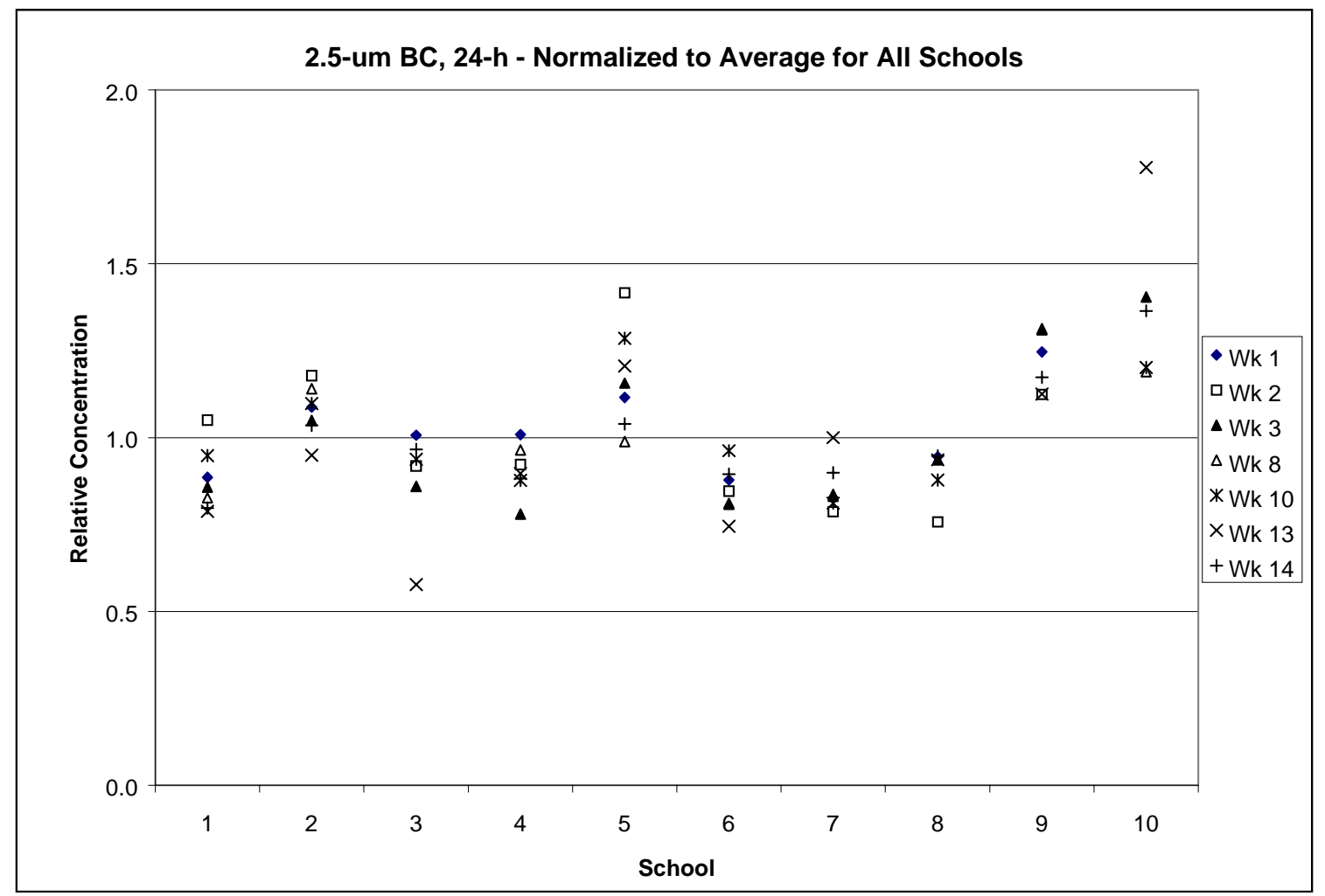

Figure 3.31. 2.5- $\mu \mathrm{m} \mathrm{BC}$ for all-hours sampling normalized to weekly mean at all schools during spring period.

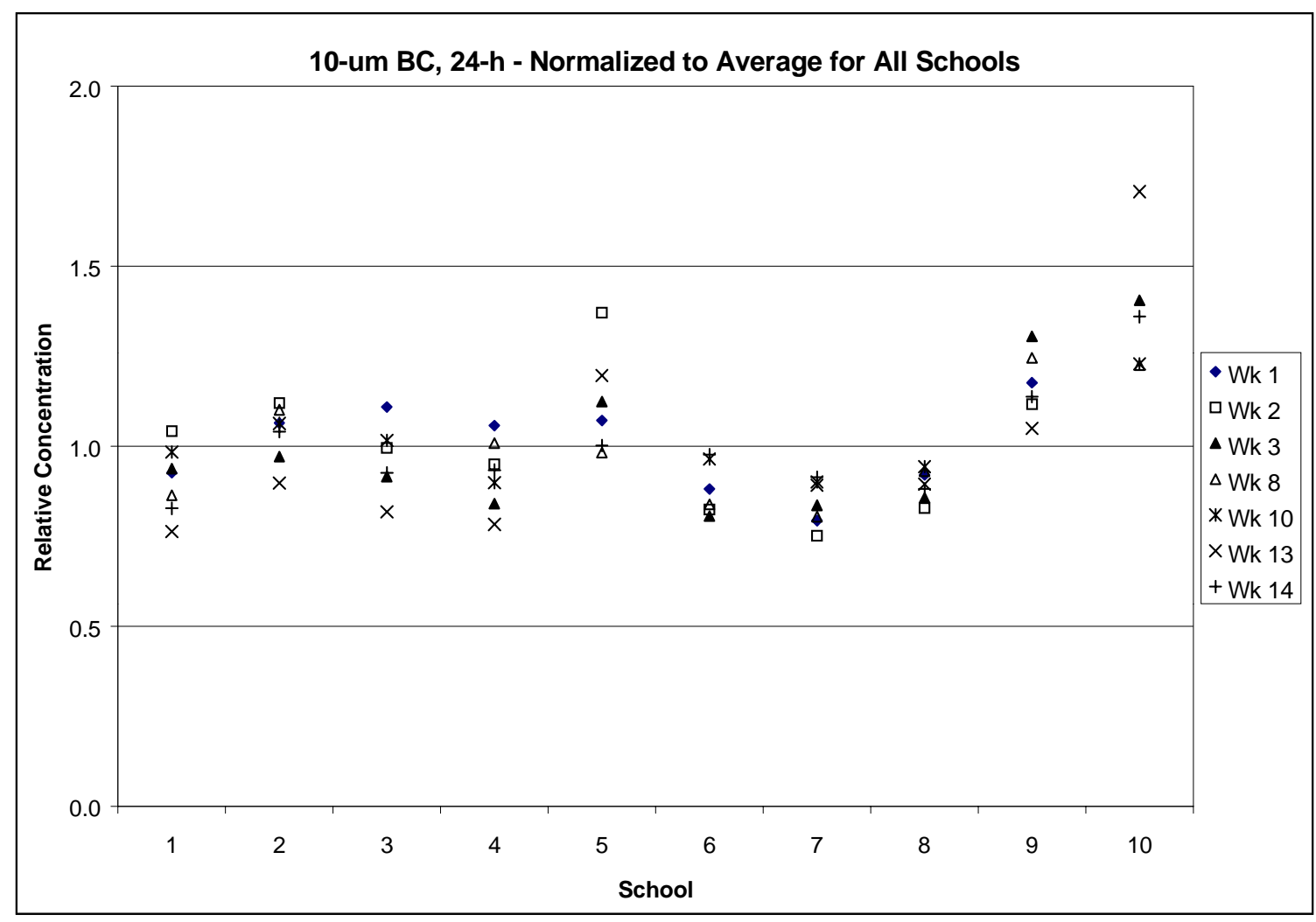

Figure 3.32. 10- $\mu \mathrm{m}$ BC for all-hours sampling normalized to weekly mean at all schools during spring period. 


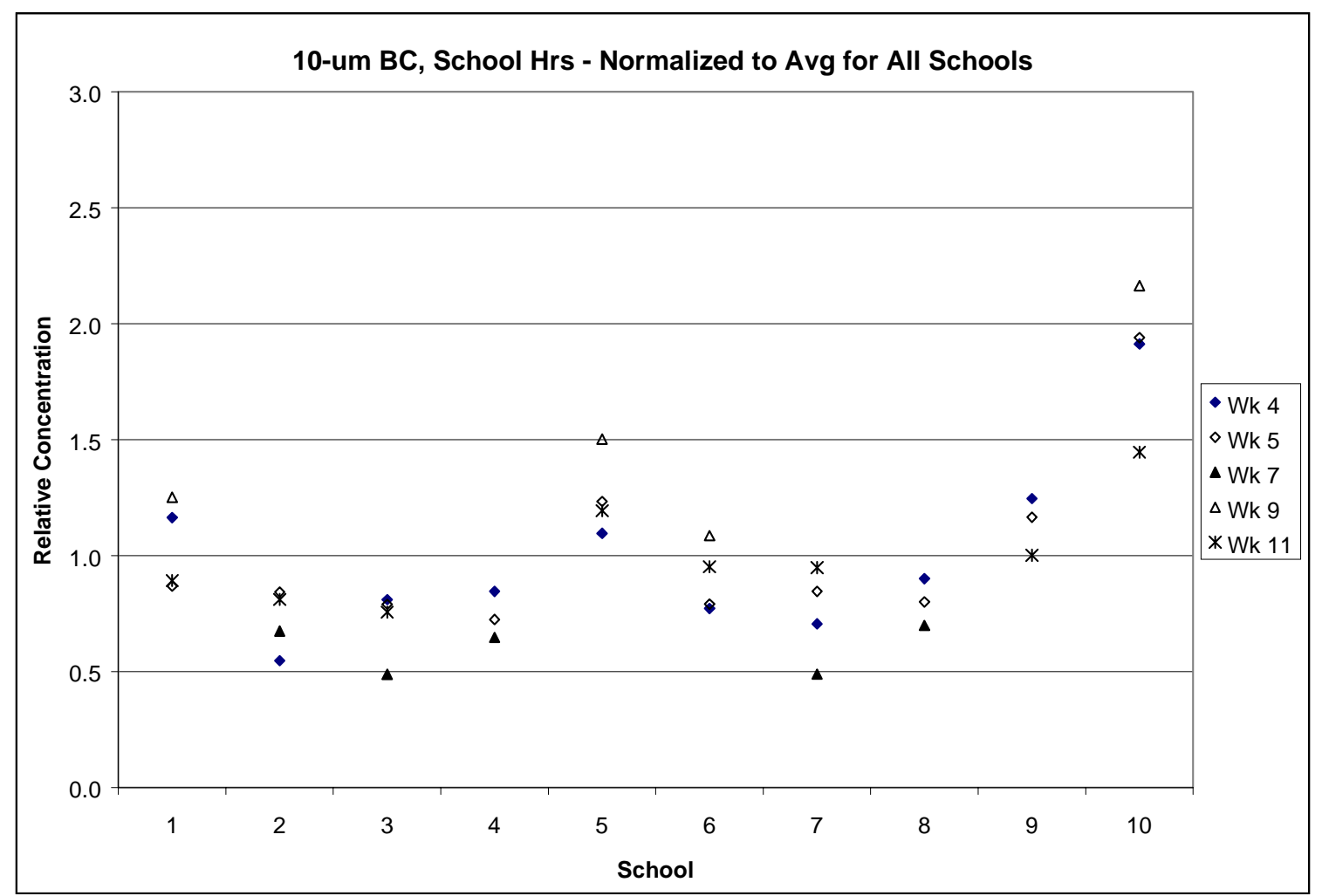

Figure 3.33. 10- $\mu \mathrm{m}$ BC for school-hours sampling normalized to weekly mean at all schools during spring period.

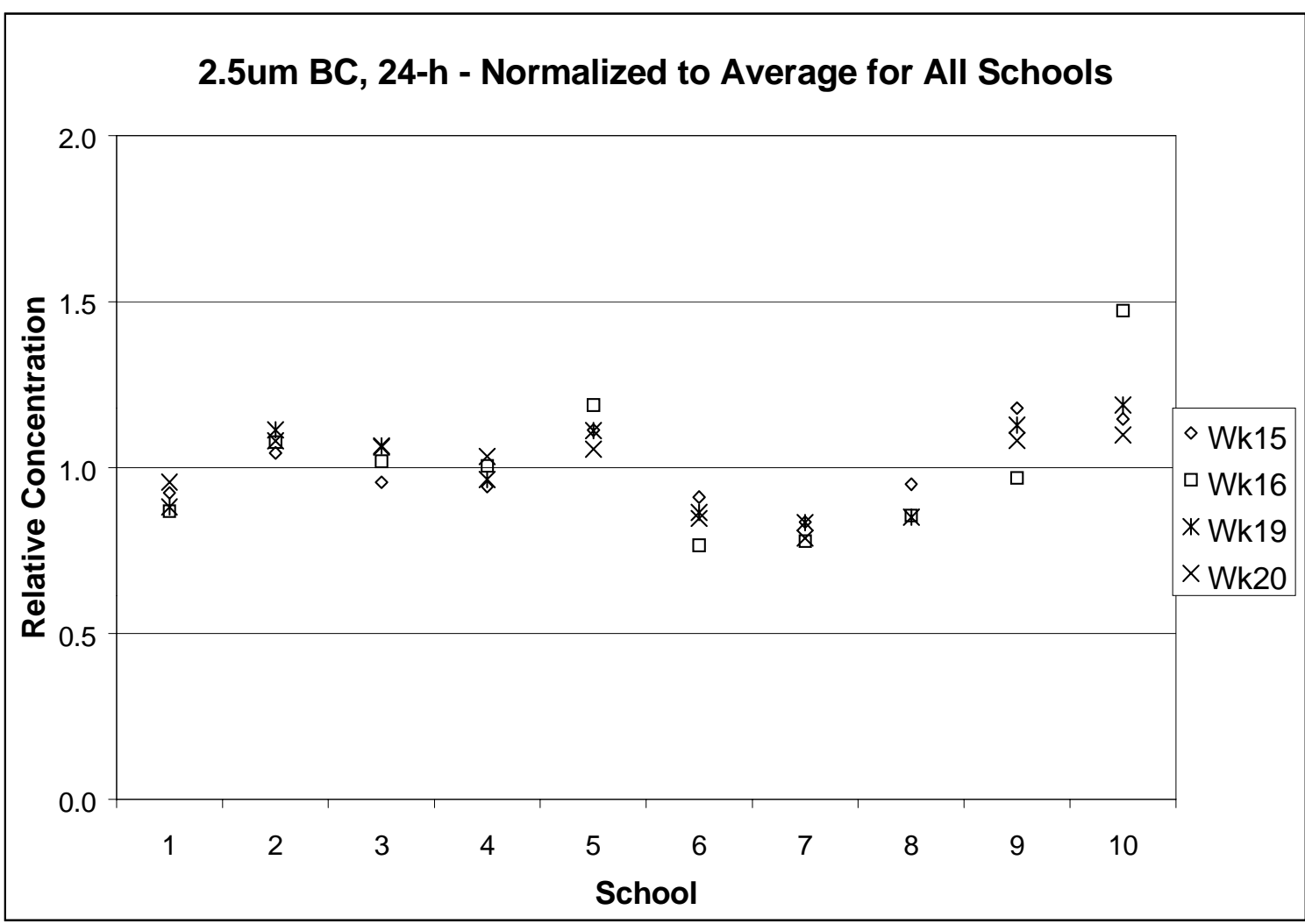

Figure 3.34. $2.5-\mu \mathrm{m} \mathrm{BC}$ for all-hours sampling normalized to weekly mean at all schools during fall period. 


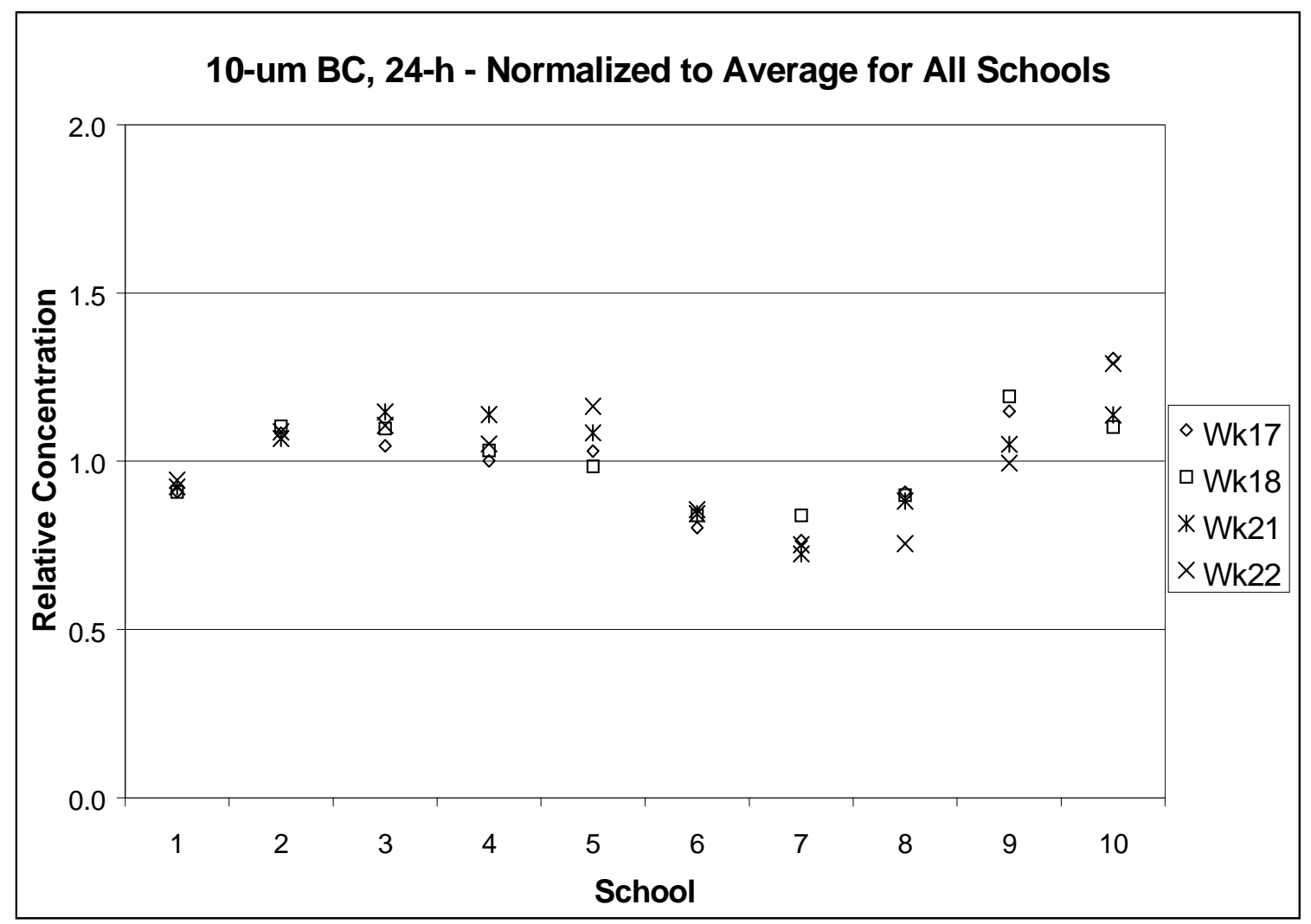

Figure 3.35. 10- $\mu \mathrm{m} \mathrm{BC}$ for all-hours sampling normalized to weekly mean at all schools during fall period.

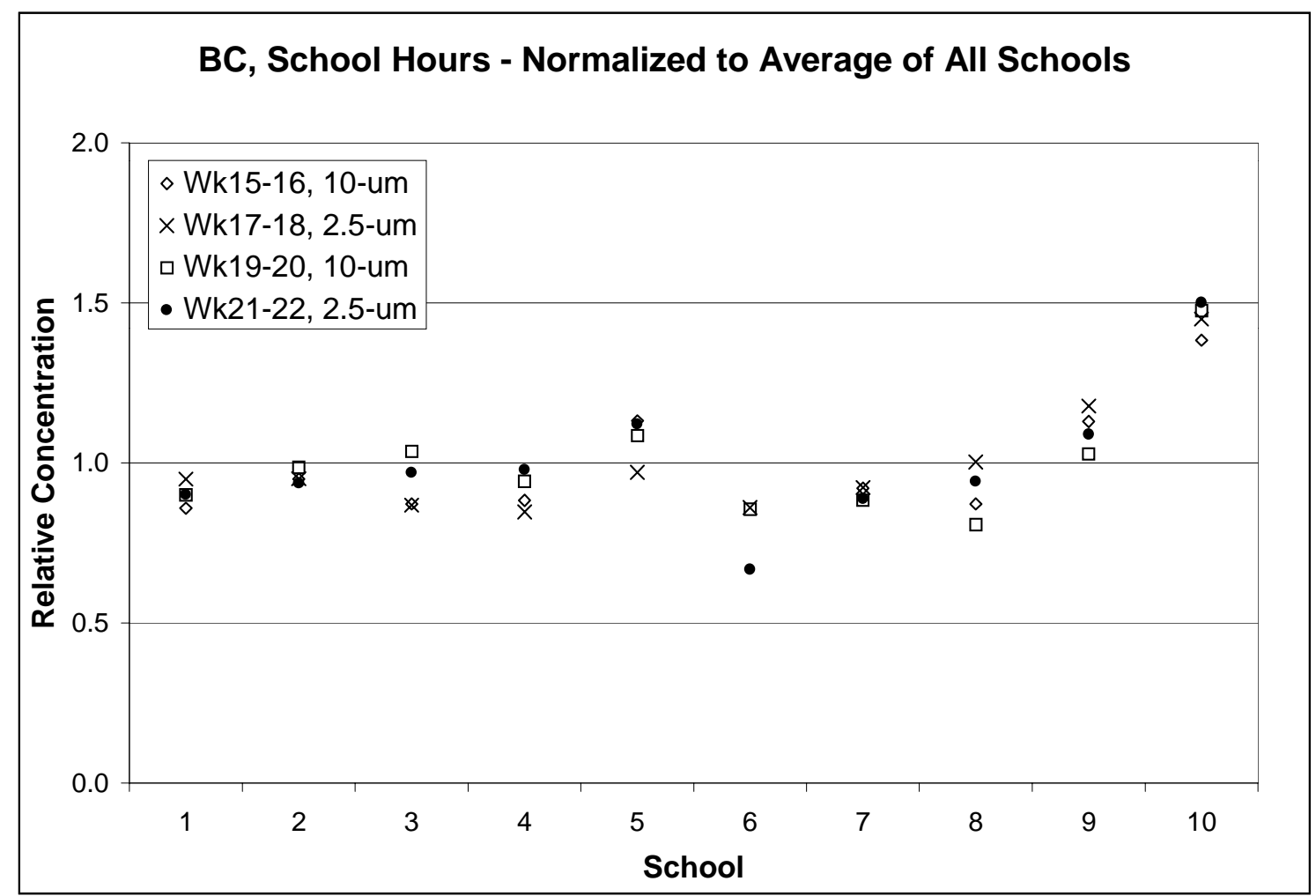

Figure 3.36. $2.5-\mu \mathrm{m}$ and $10-\mu \mathrm{m} \mathrm{BC}$ for school-hours sampling normalized to weekly mean at all schools during fall period. 


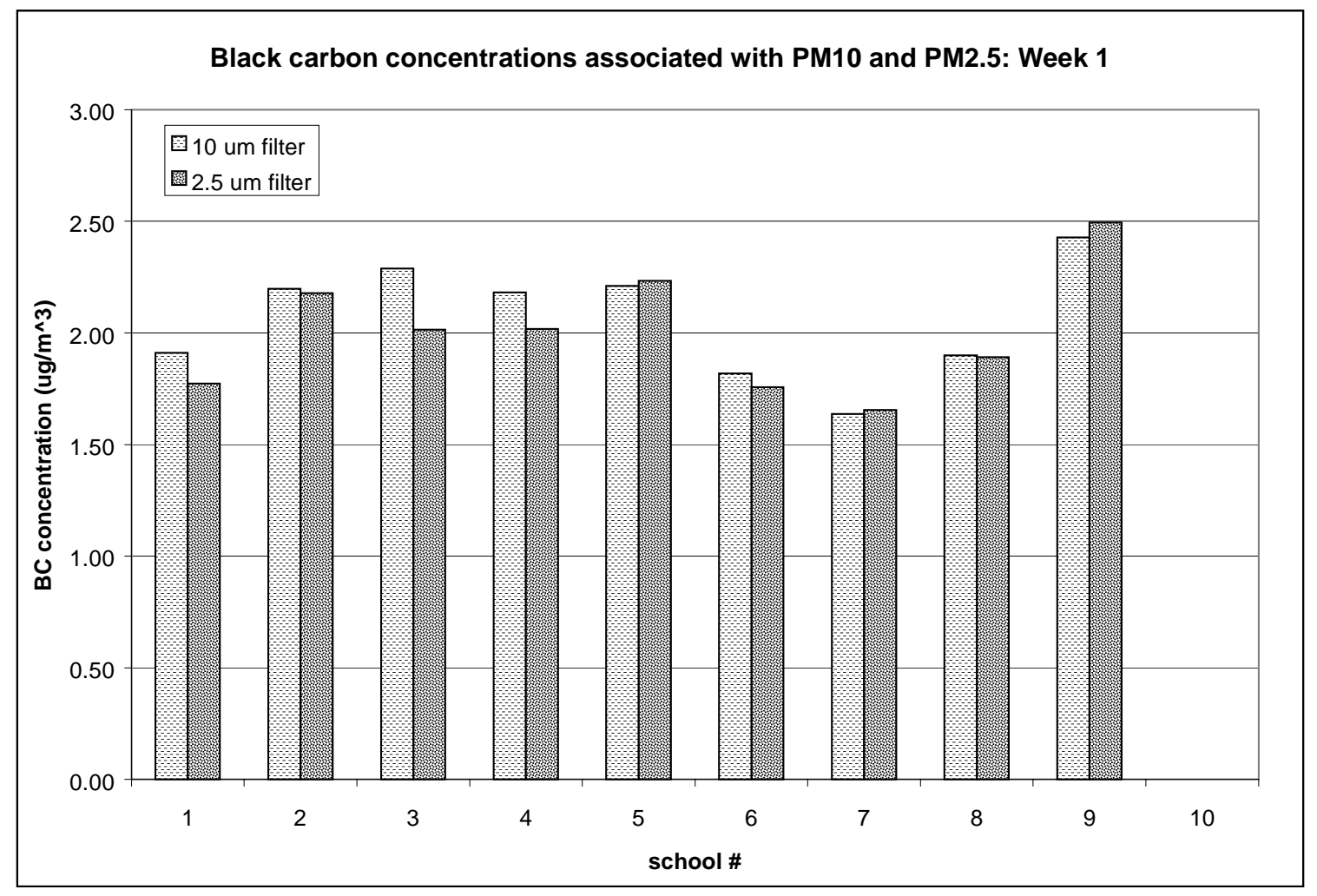

Figure 3.37. 2.5- $\mu \mathrm{m}$ and $10-\mu \mathrm{m}$ Black carbon concentrations during week 1 .

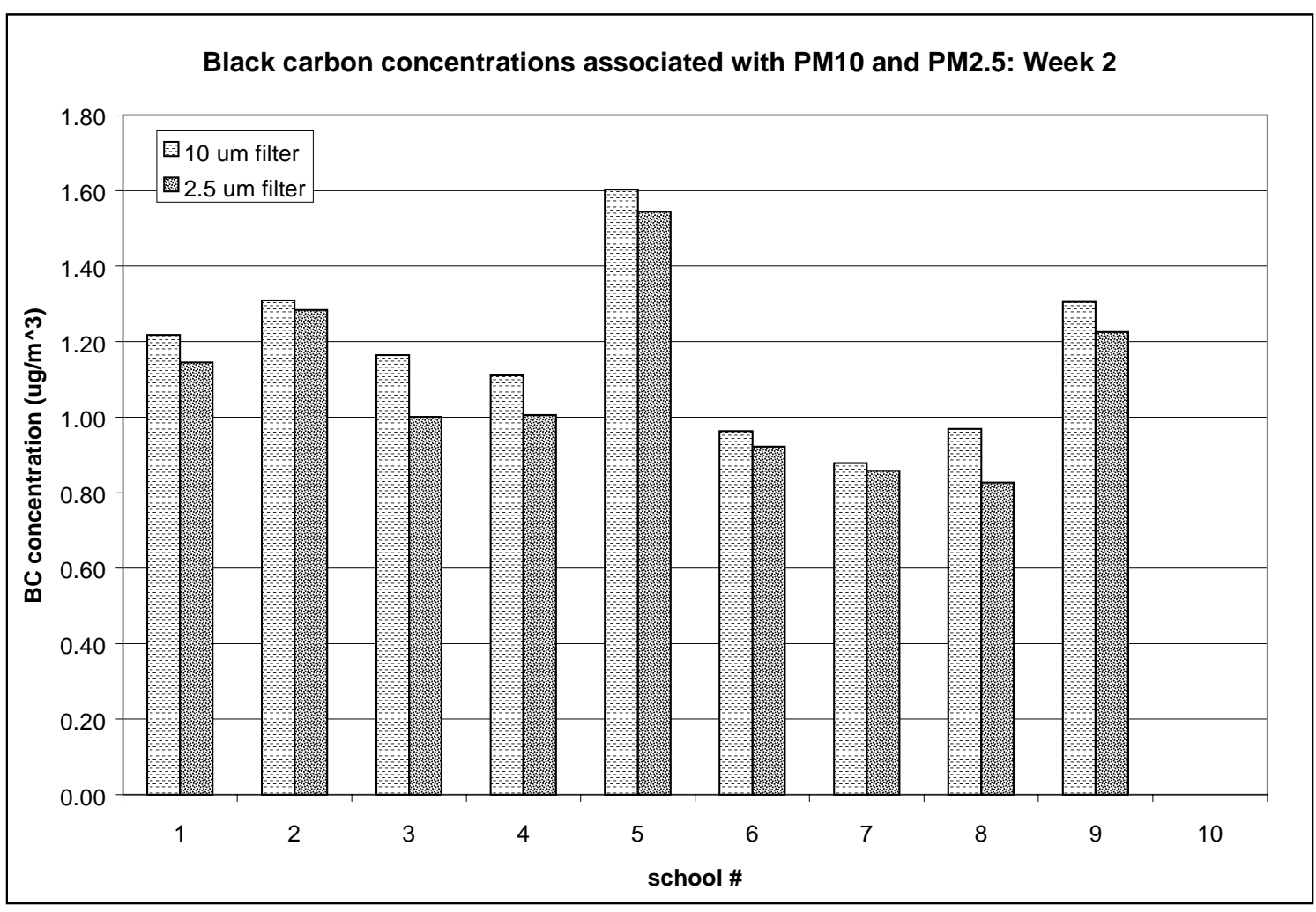

Figure 3.38. $2.5-\mu \mathrm{m}$ and $10-\mu \mathrm{m}$ Black carbon concentrations during week 2. 


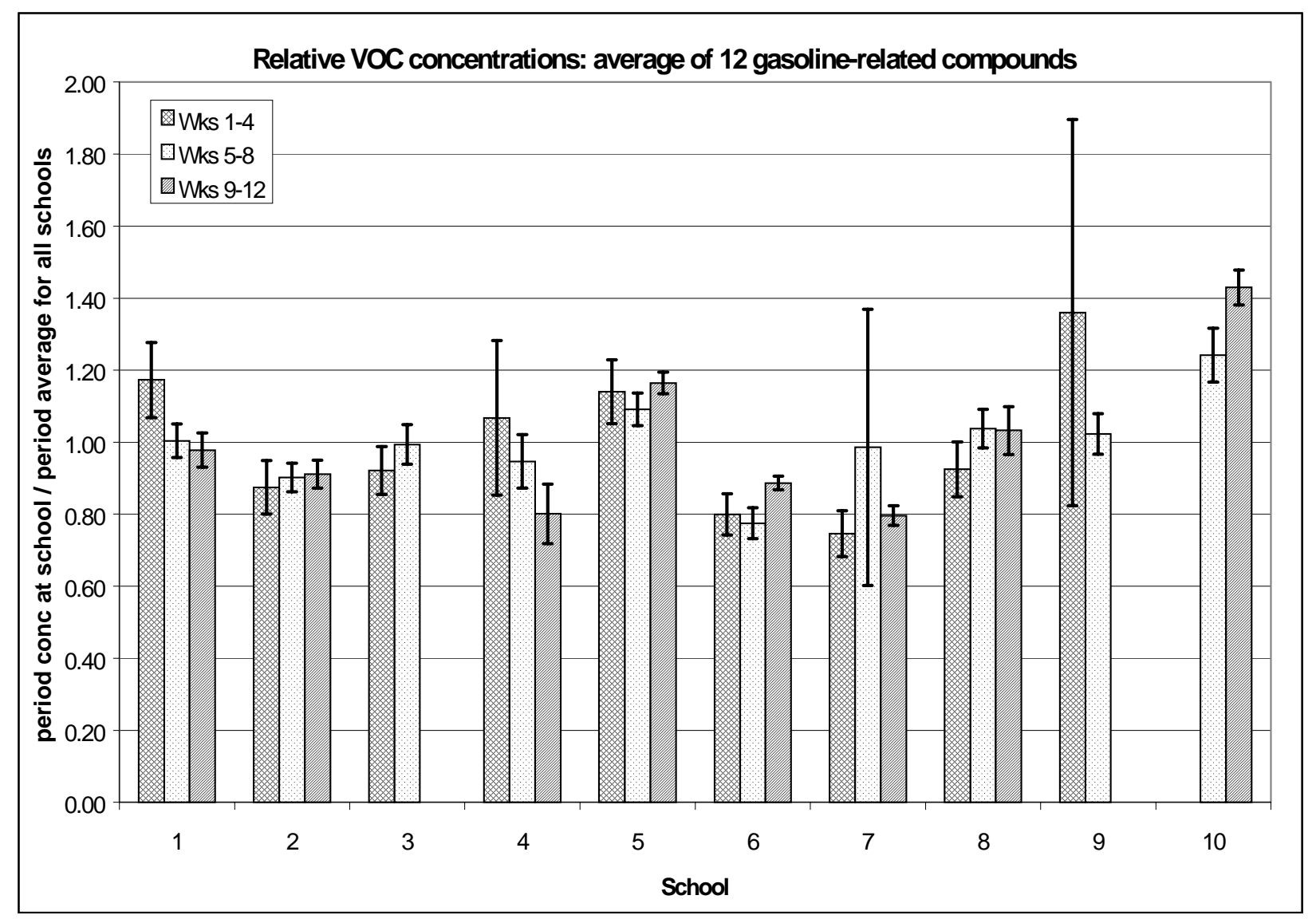

Figure 3.39. Mean ( \pm Stdev.) relative concentrations for 12 gasoline-related VOCs during spring period. The concentration of each compound at each site was normalized to the samplingperiod mean for that compound at all schools. 


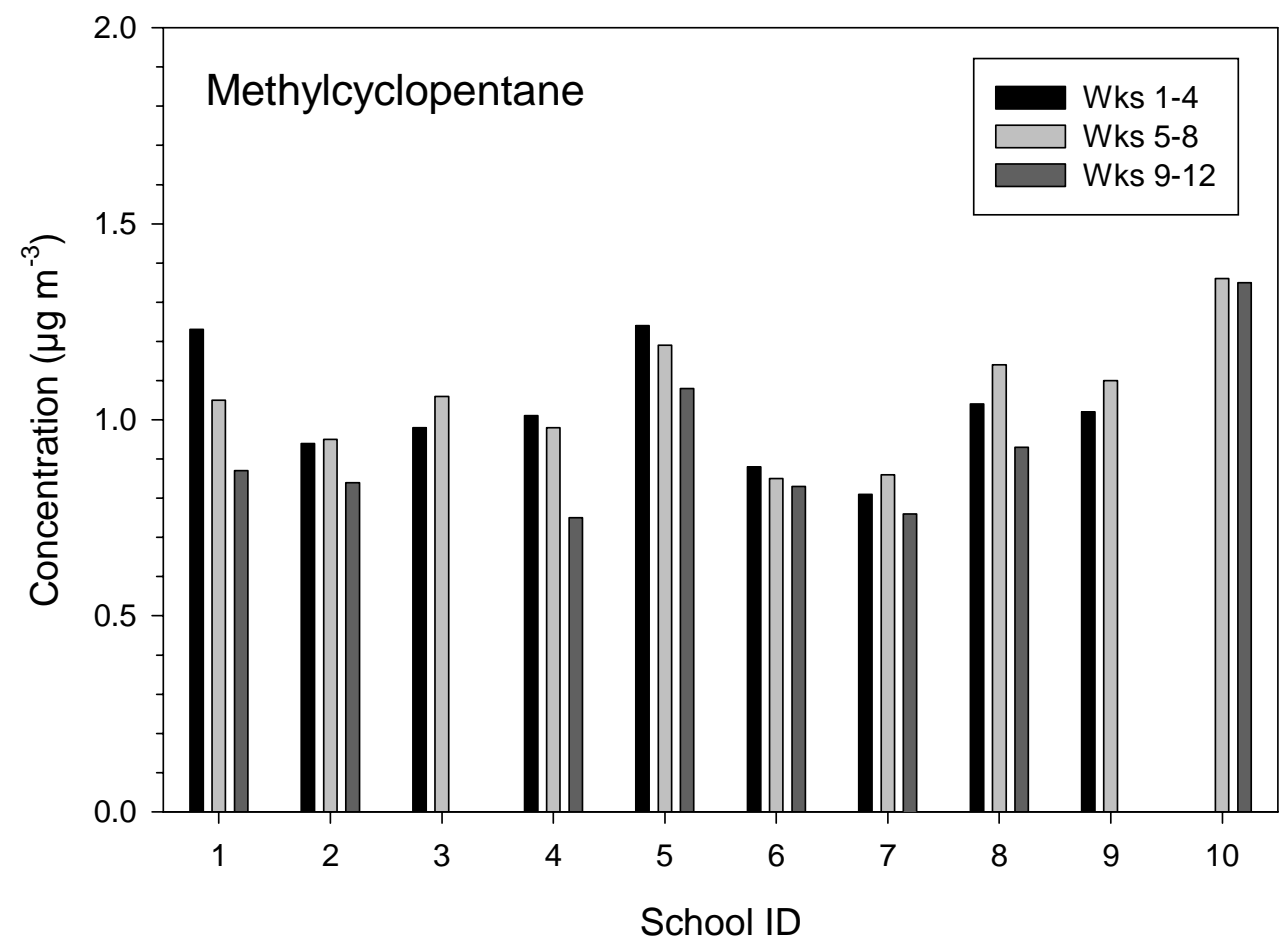

Figure 3.40. Methylcyclopentane concentrations during spring period.

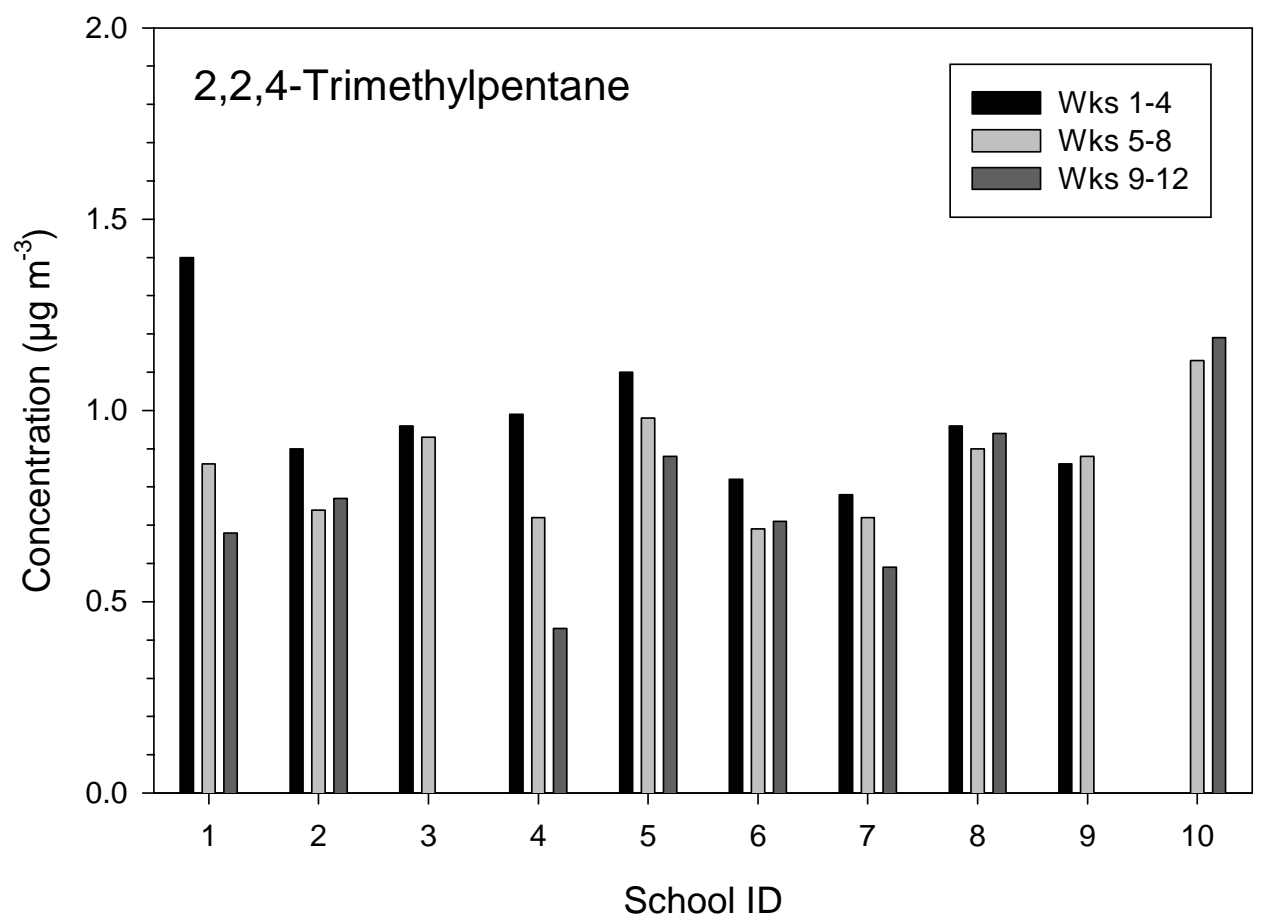

Figure 3.41. 2,2,4-Trimethylpentane concentrations during spring period. 


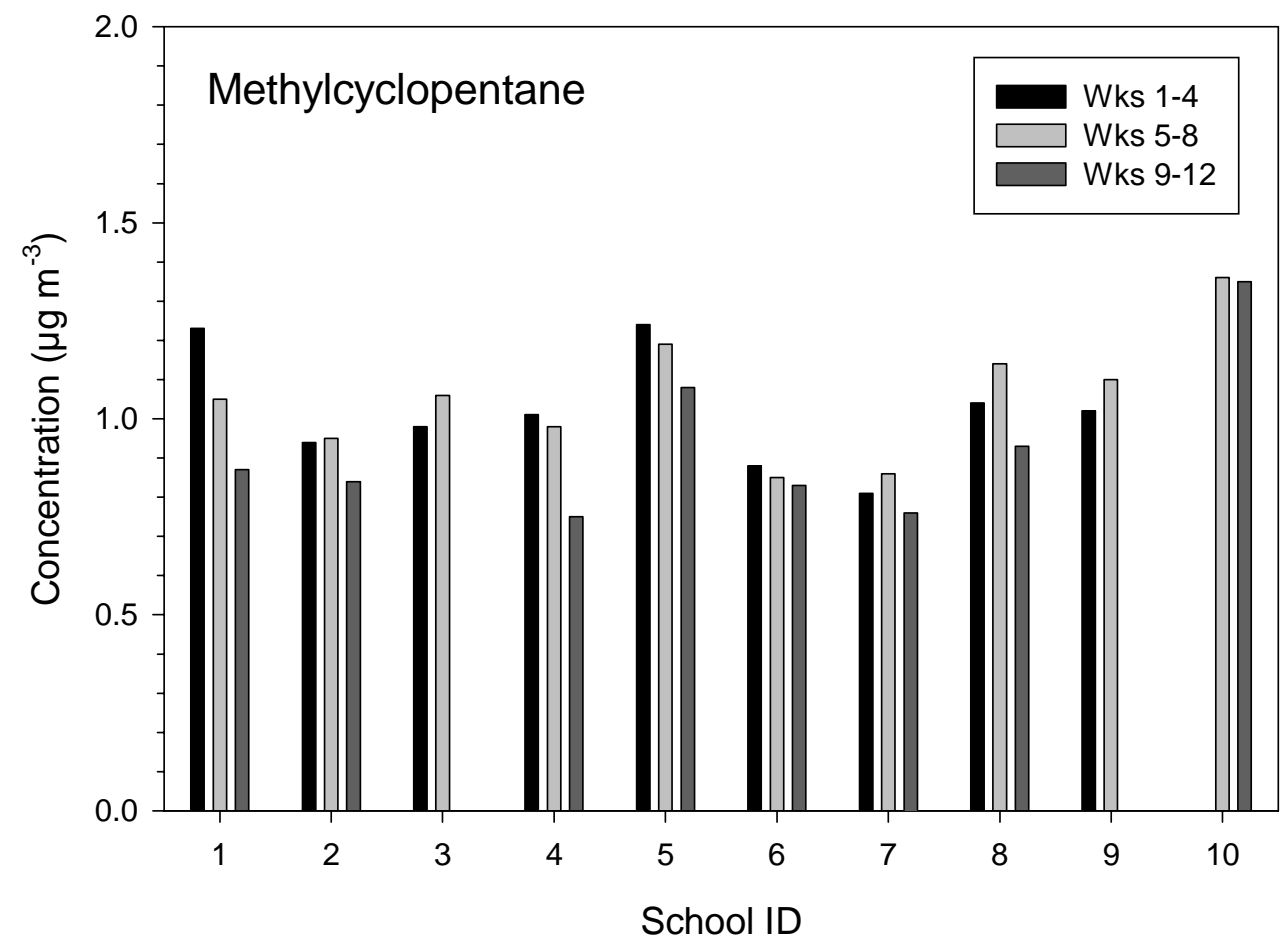

Figure 3.42. Benzene concentrations during spring period.

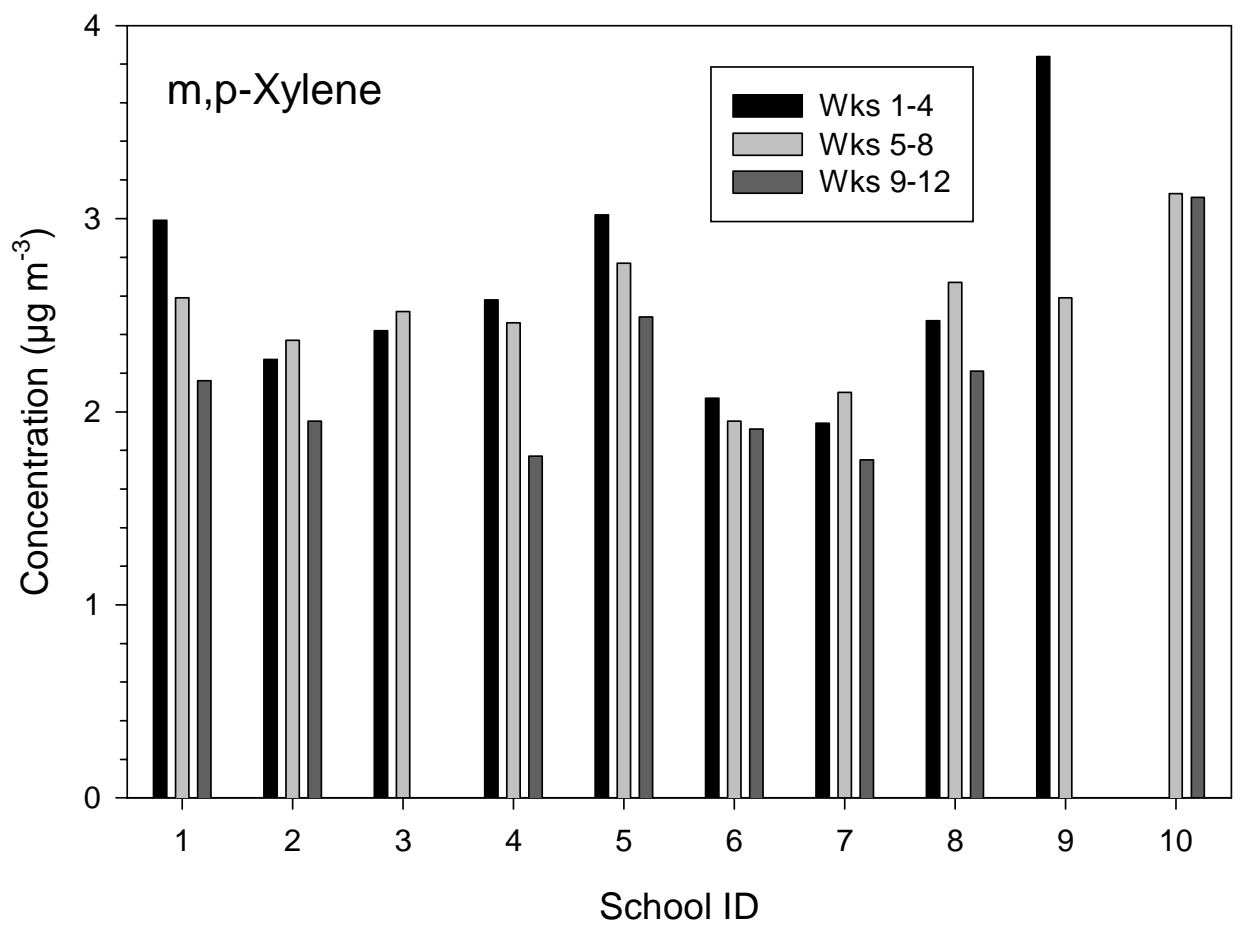

Figure 3.43. m, p-Xylene concentrations during spring period. 


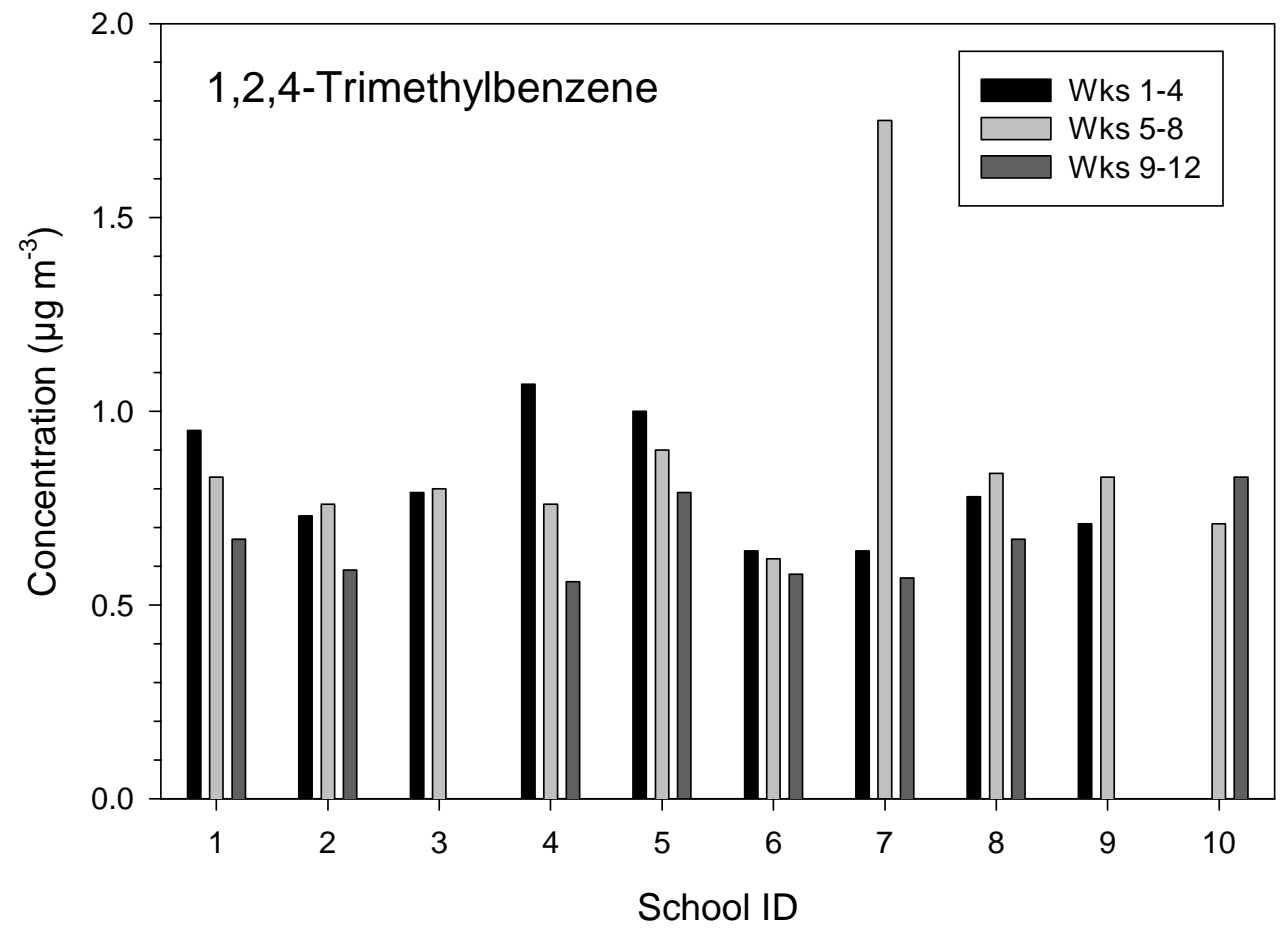

Figure 3.44. 1,2,4-Trimethylbenzene concentrations during spring period.

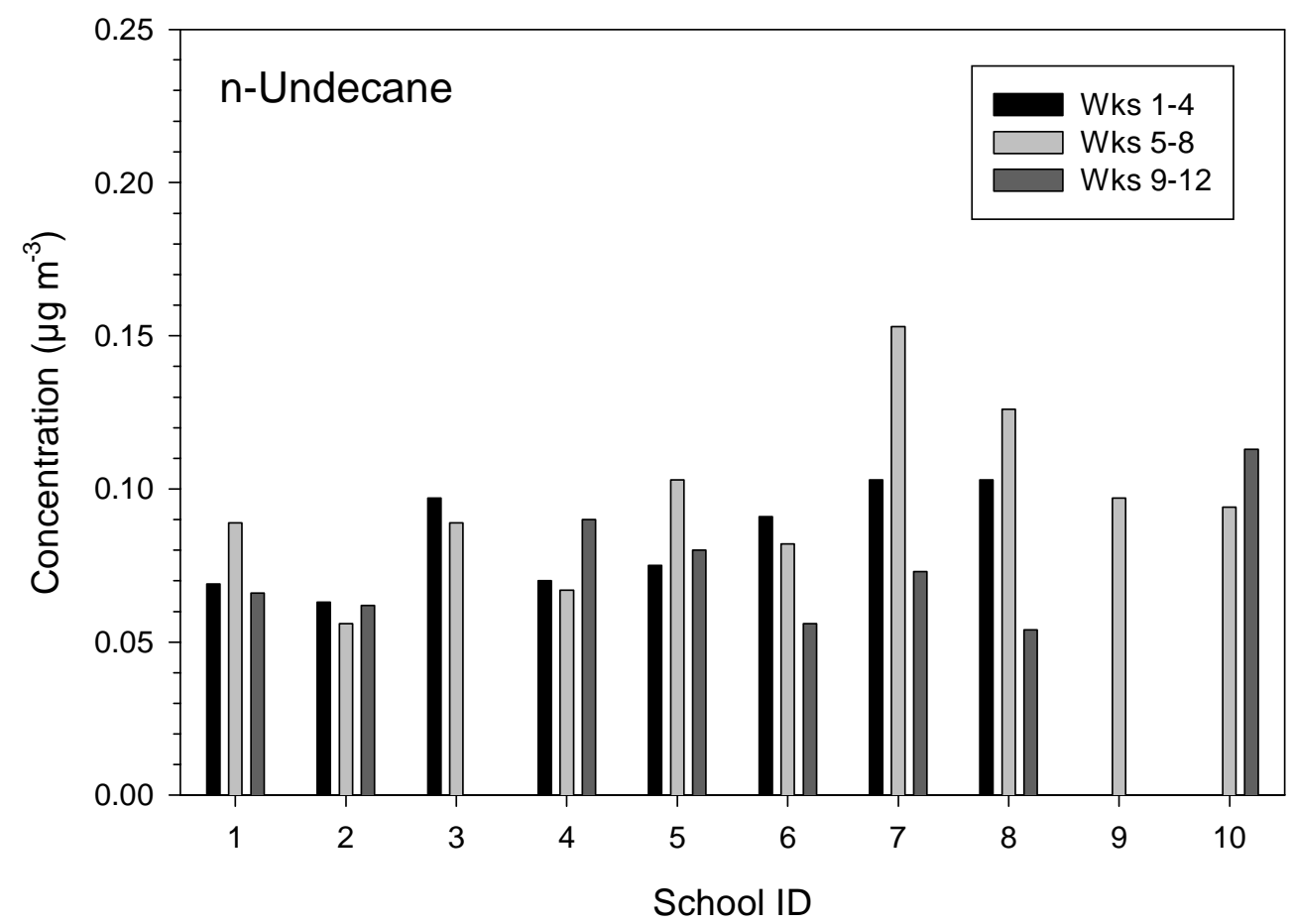

Figure 3.45. n-Undecane concentrations during spring period. 


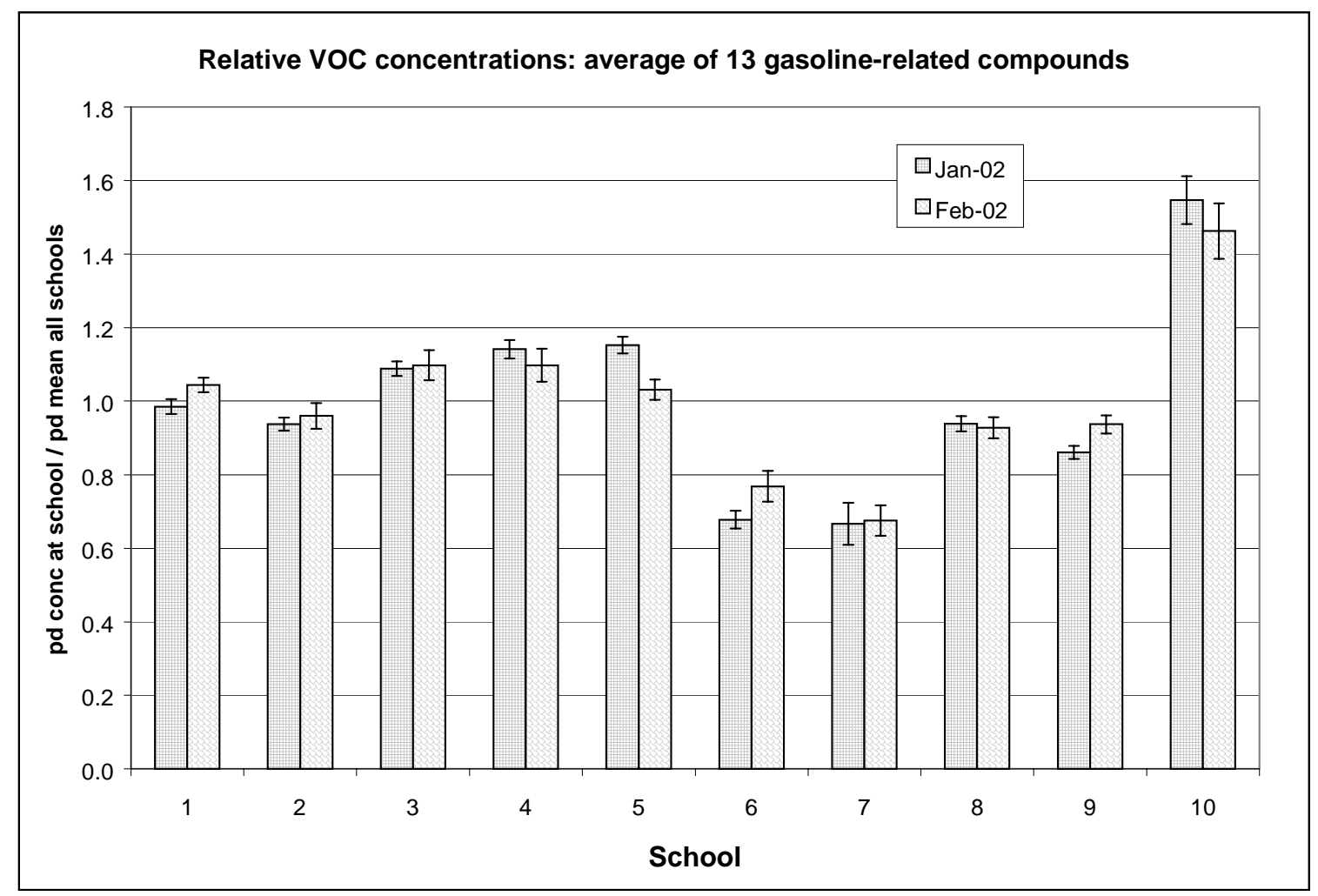

Figure 3.46. Mean ( \pm Stdev.) relative concentrations for 13 gasoline-related VOCs in Jan-Feb 2002. The concentration of each compound at each site was normalized to the samplingperiod mean for that compound at all schools. 


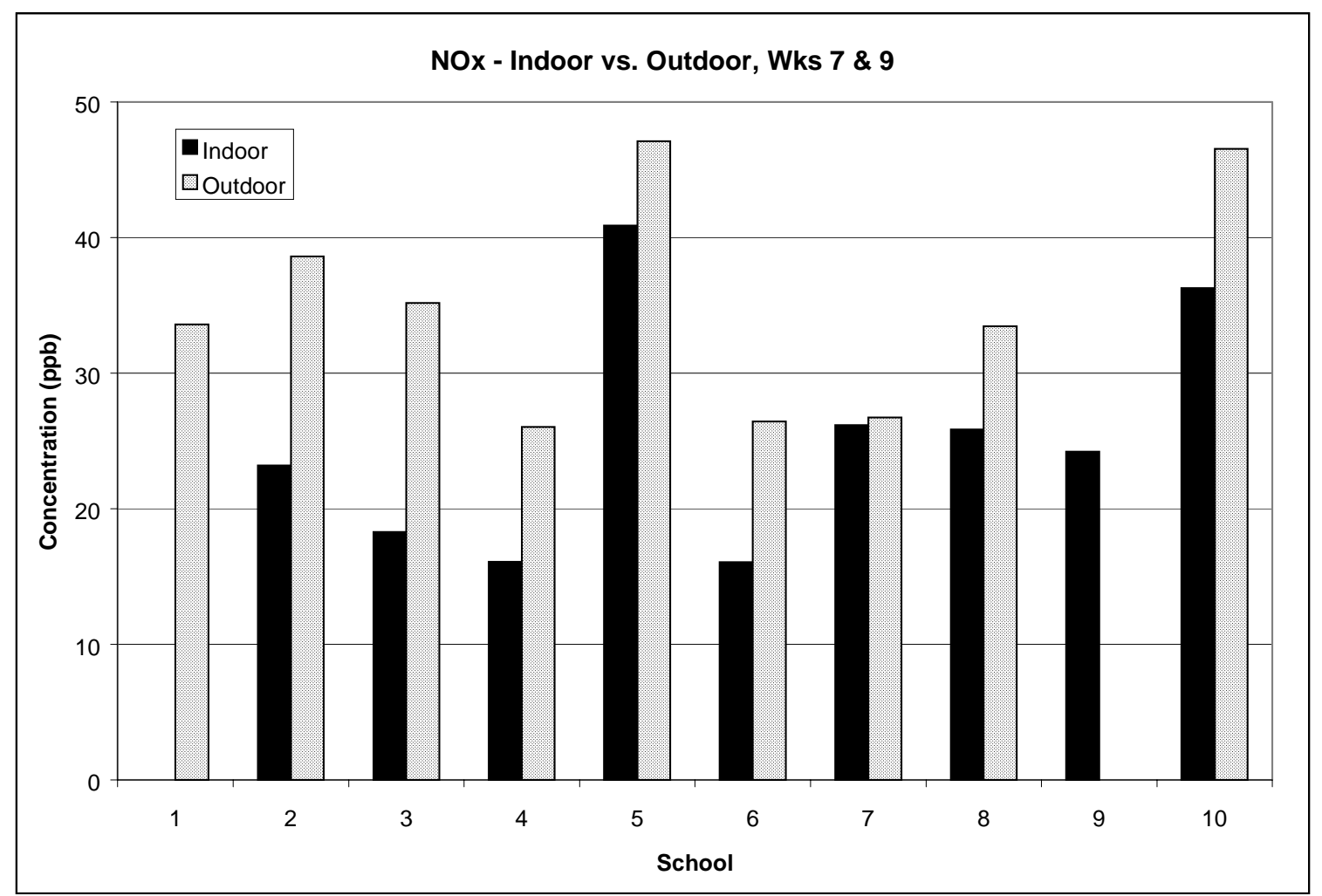

Figure 3.47. $\mathrm{NO}_{\mathrm{X}}$ concentrations measured in one classroom and outdoors at each school. Schools were monitored five at a time during two different one-week periods.

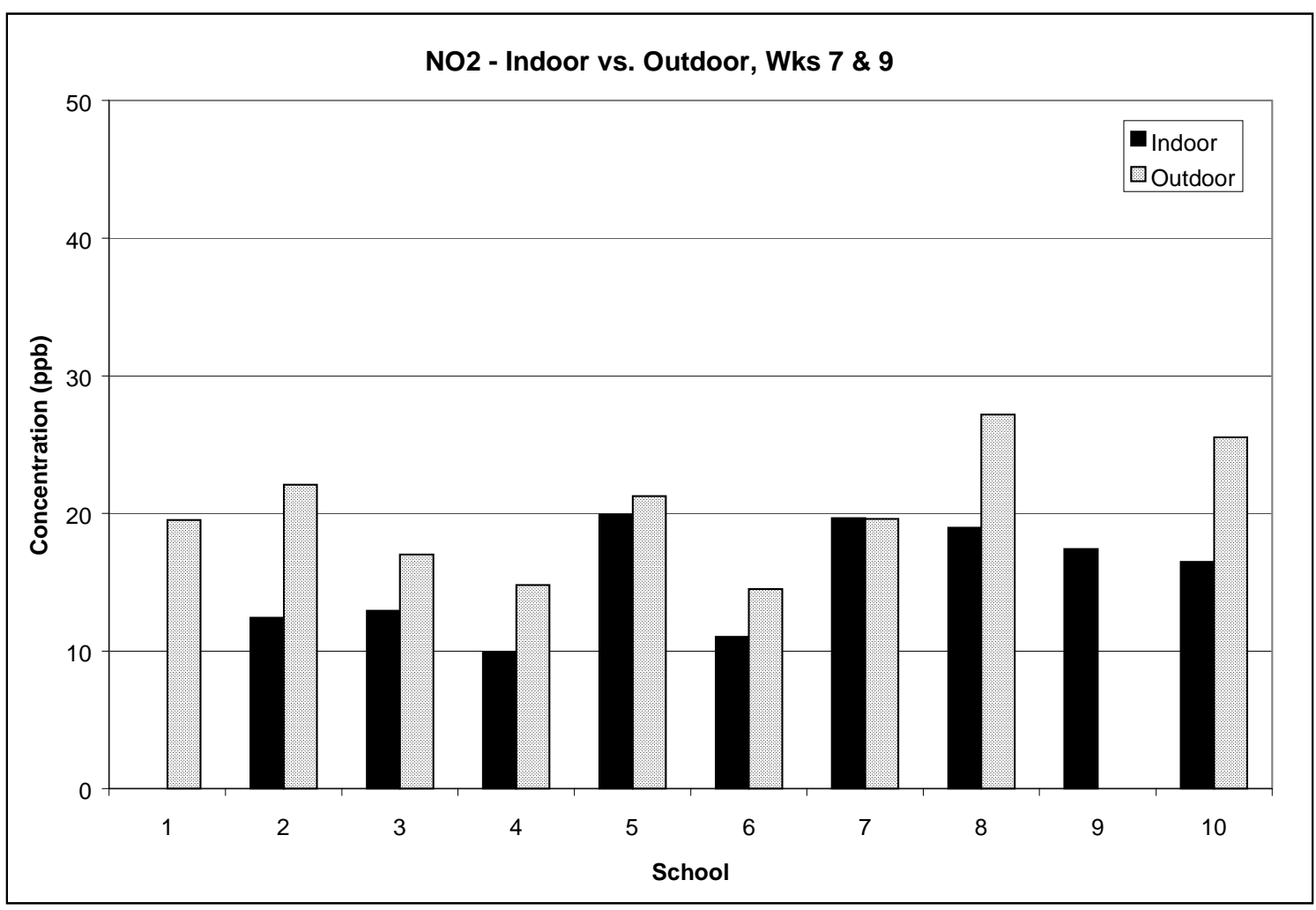

Figure 3.48. $\mathrm{NO}_{2}$ concentrations measured in one classroom and outdoors at each school. Schools were monitored five at a time during two different one-week periods. 


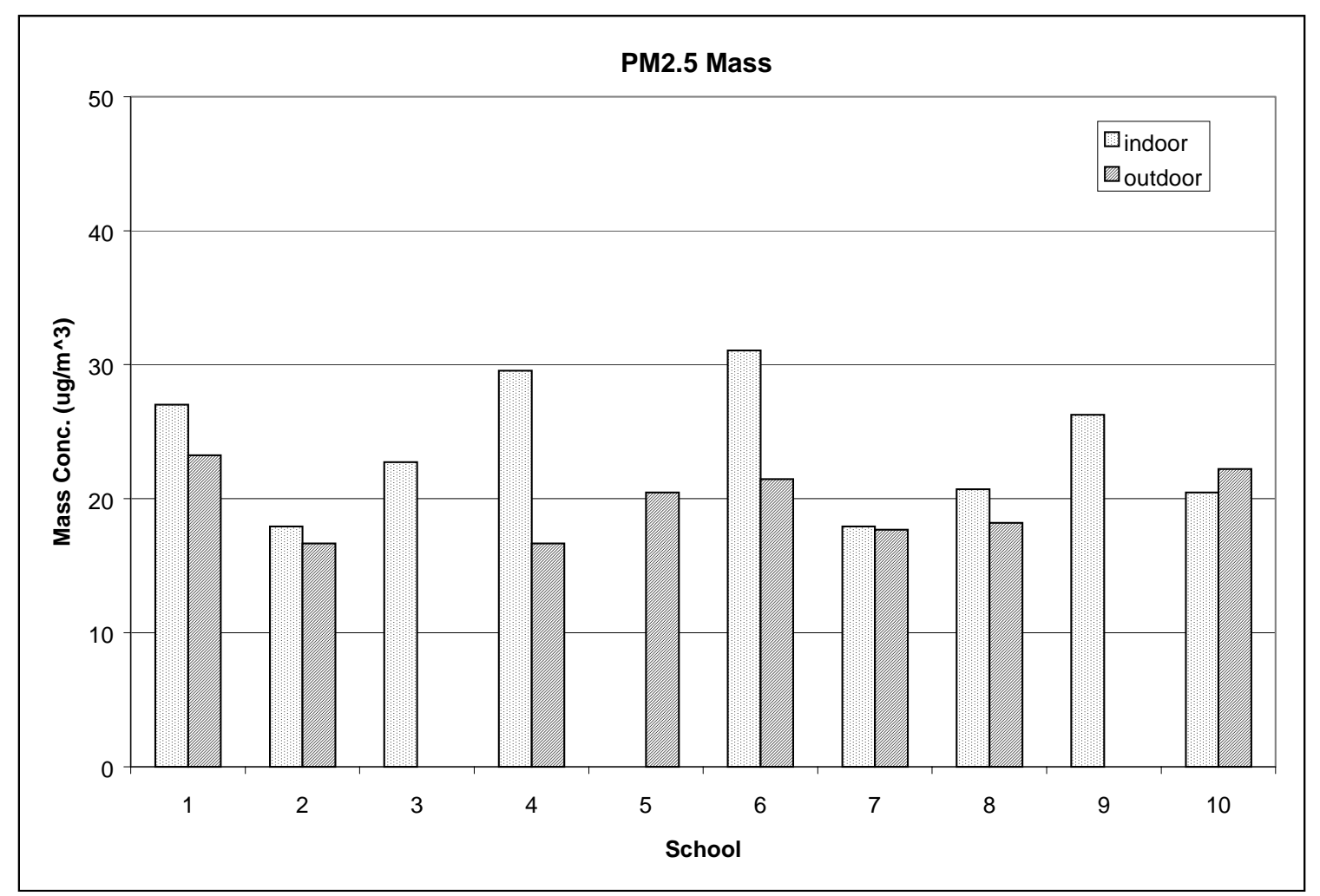

Figure 3.49. $\mathrm{PM}_{2.5}$ mass concentrations measured in one classroom and outdoors at each school. Schools were monitored five at a time during school hours of two one-week periods.

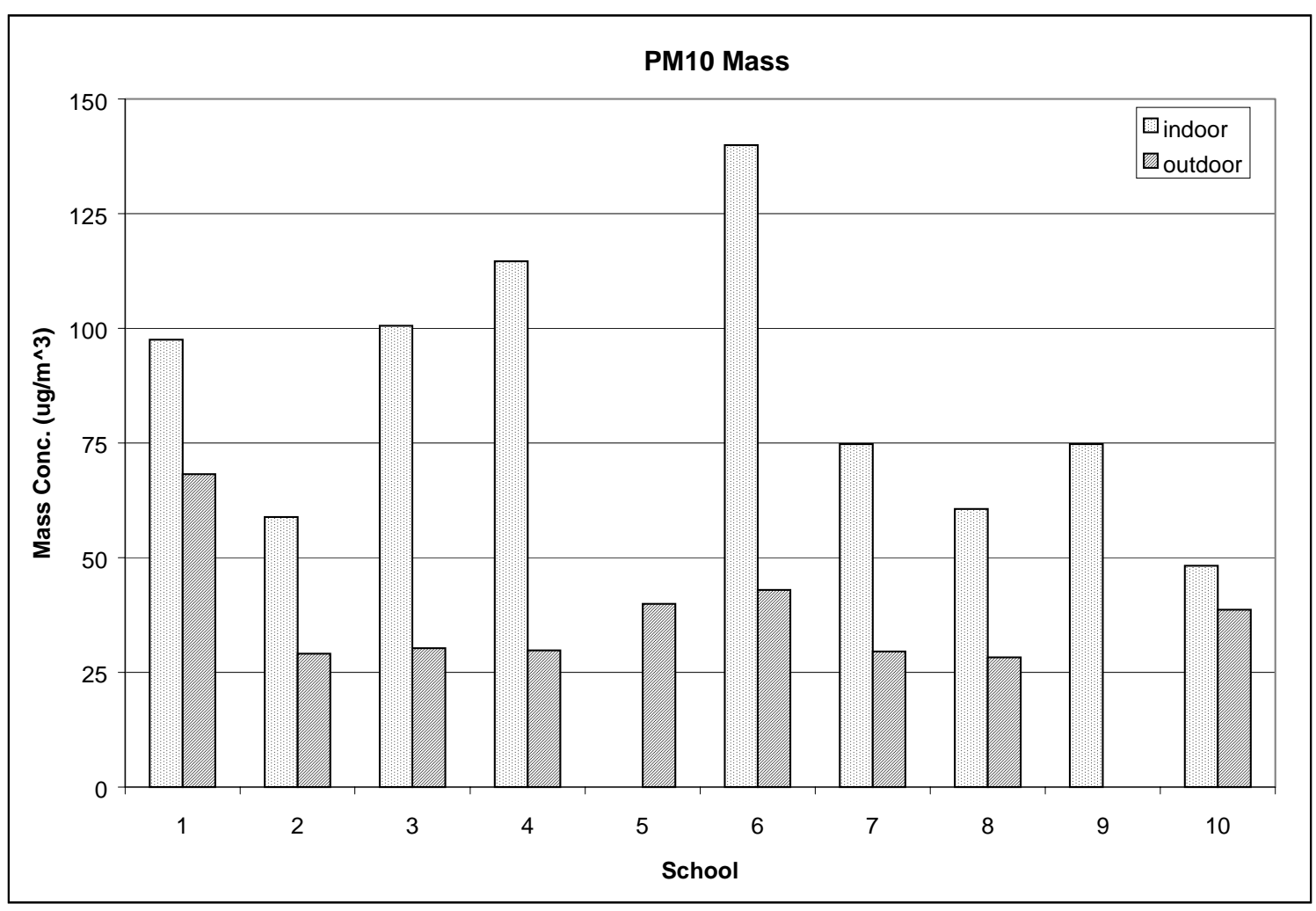

Figure 3.50. $\mathrm{PM}_{10}$ mass concentrations measured in one classroom and outdoors at each school. Schools were monitored five at a time during school hours of two one-week periods. 


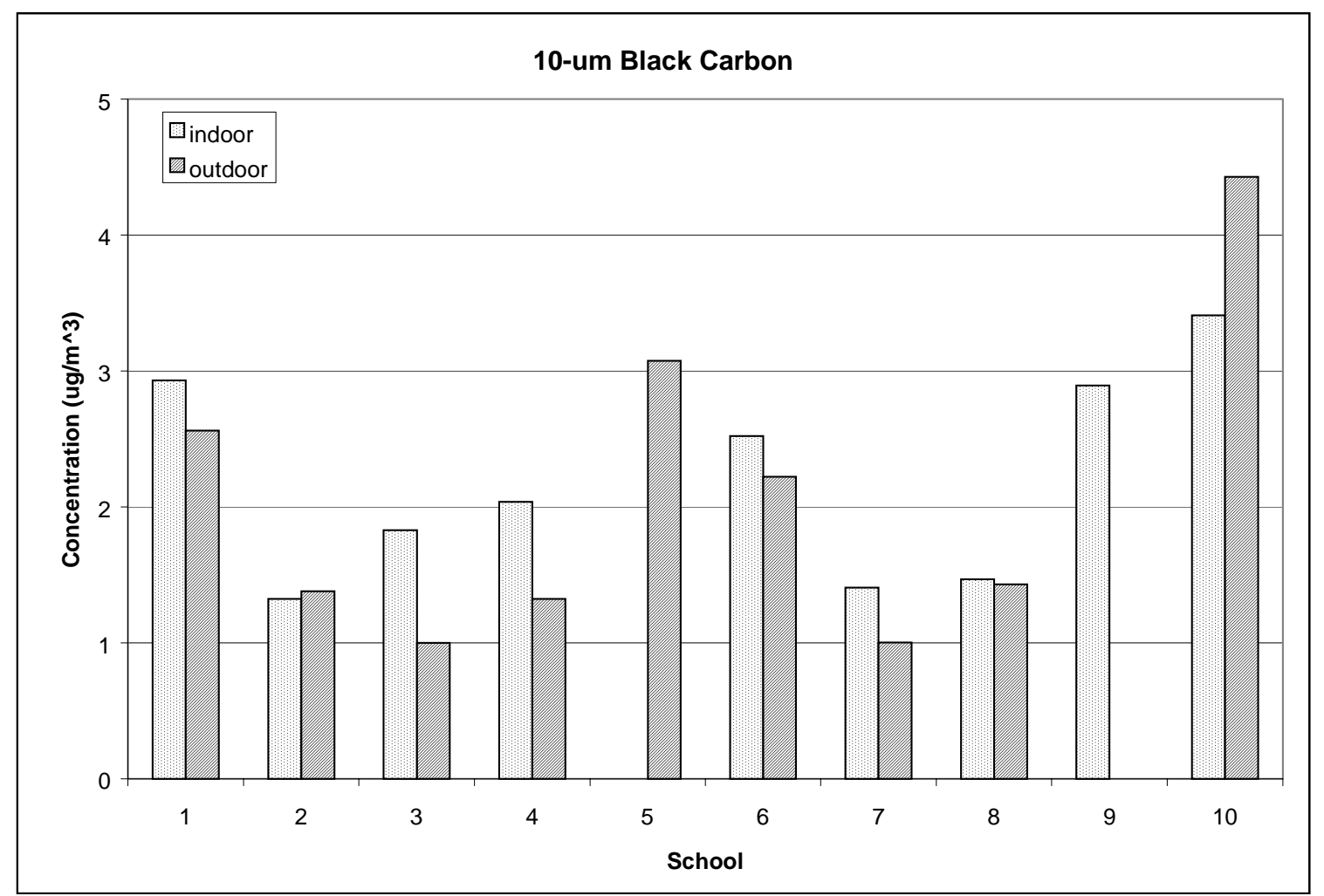

Figure 3.51. 10- $\mu \mathrm{m} \mathrm{BC}$ concentrations measured in one classroom and outdoors at each school. Schools were monitored five at a time during school hours of two one-week periods.

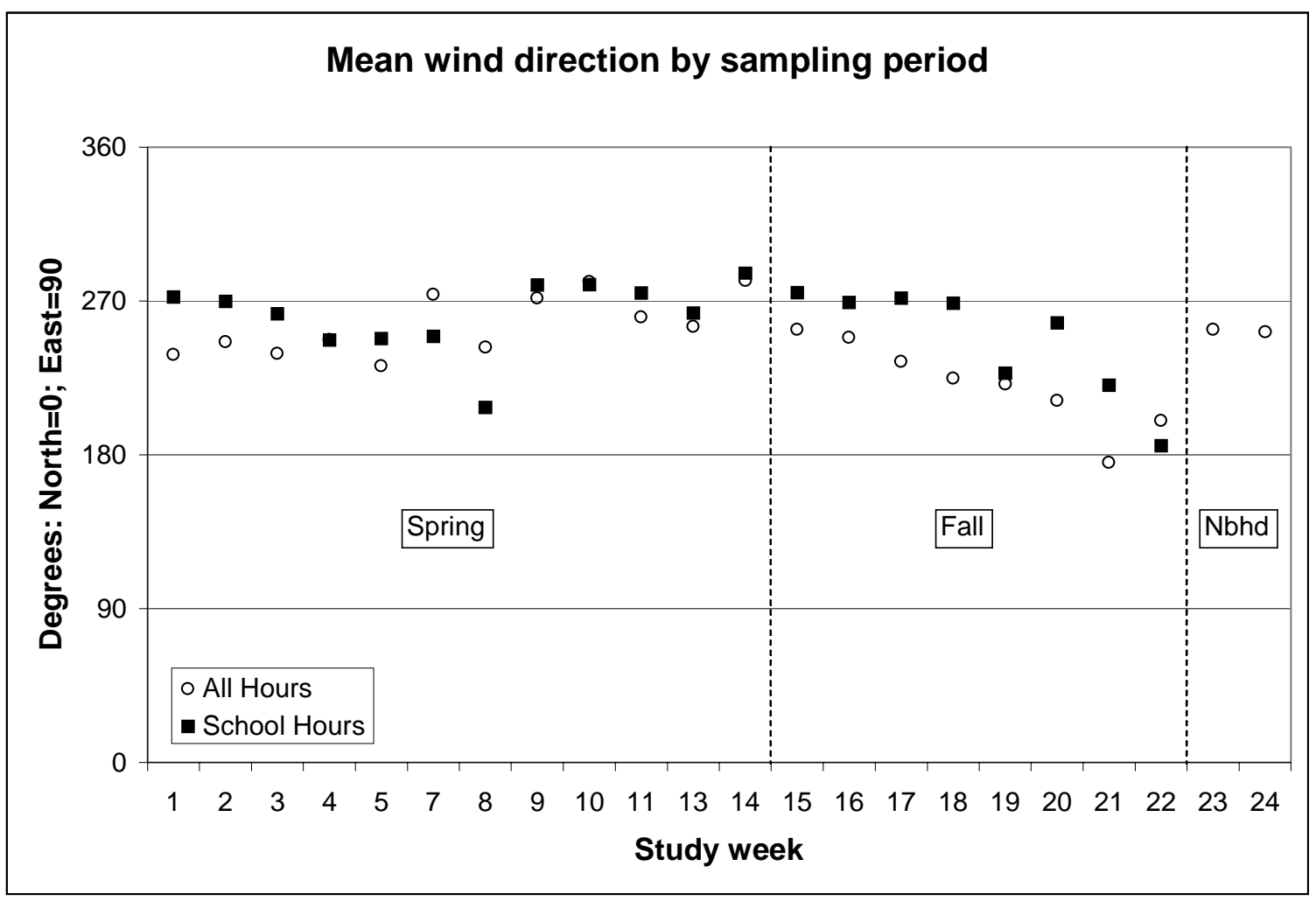

Figure 3.52. Mean wind direction during all-hours or school-hours for each one- or two-week sampling period. See text for details. 


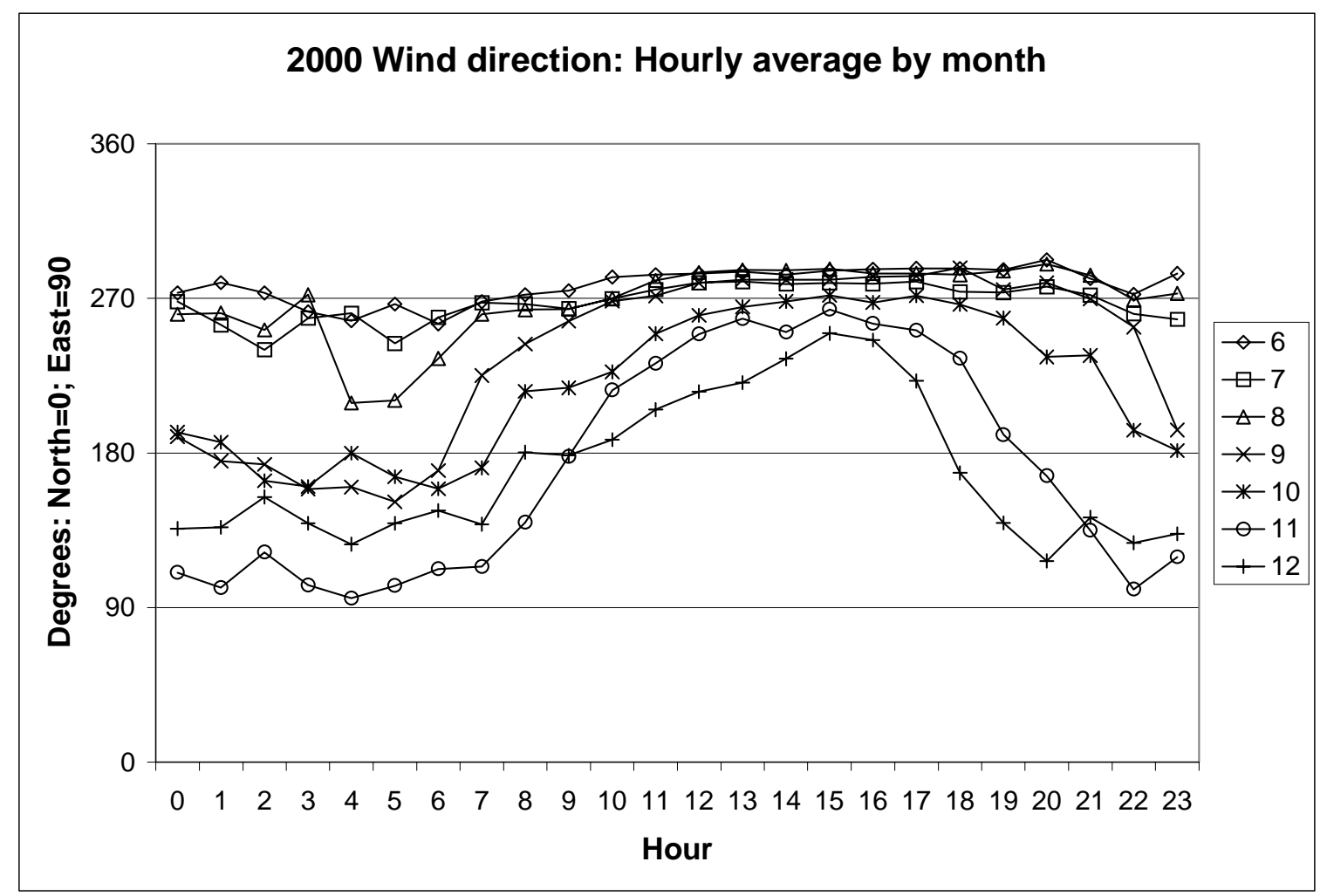

Figure 3.53. Hourly mean wind direction by month for June through December 2000; months are listed by number.

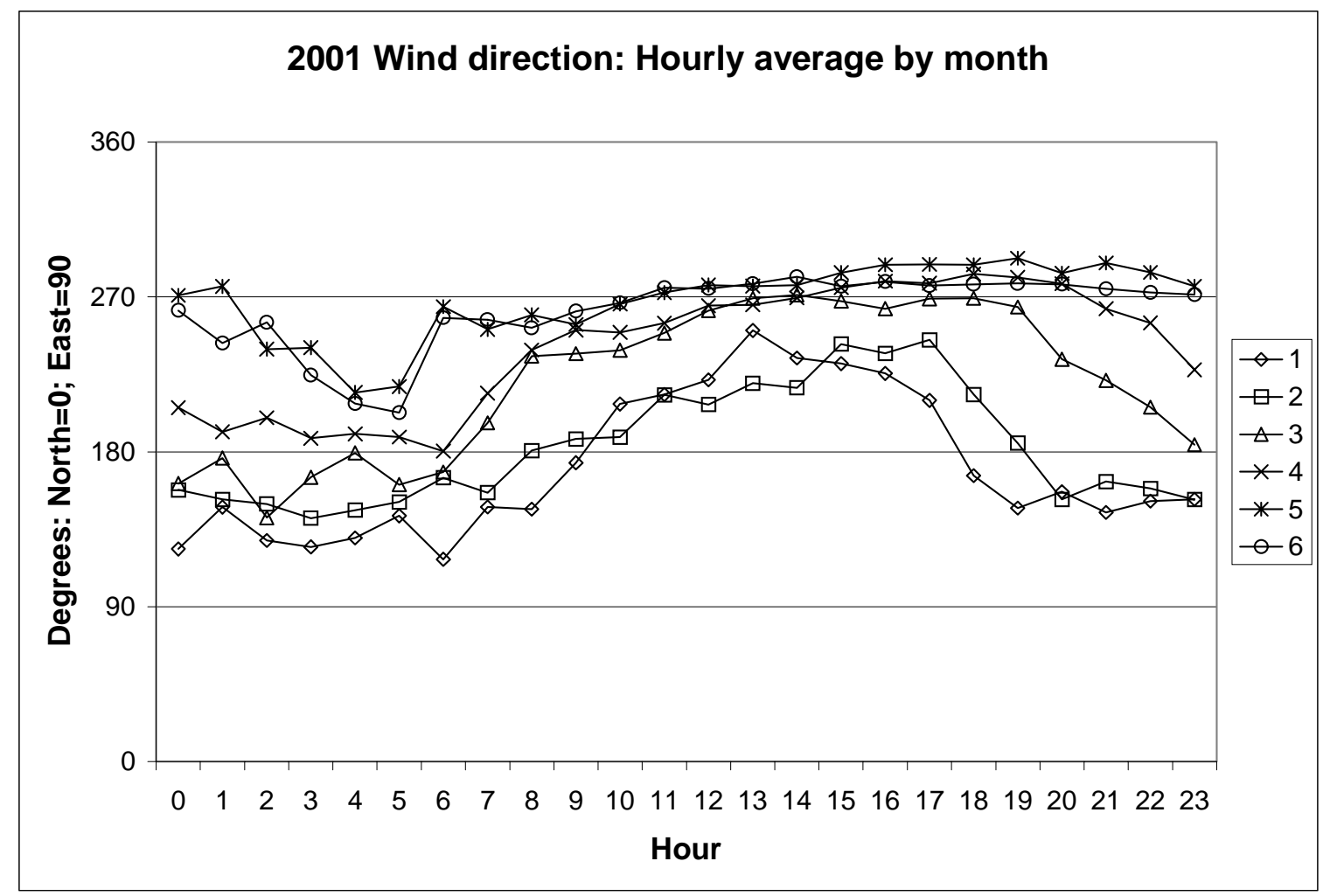

Figure 3.54. Hourly mean wind direction by month for January through June 2001; months are listed by number. 


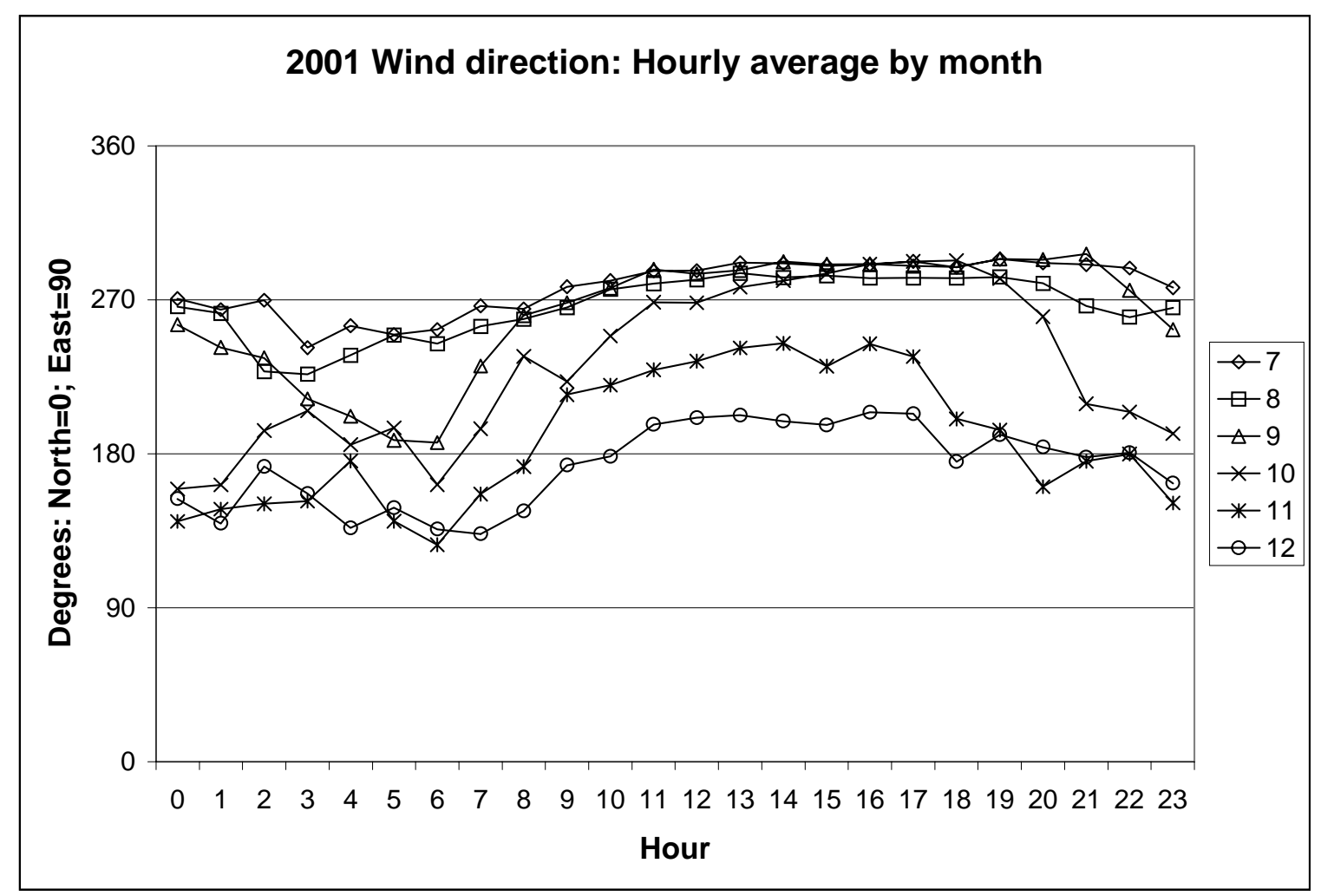

Figure 3.55. Hourly mean wind direction by month for July through December 2001; months are listed by number.

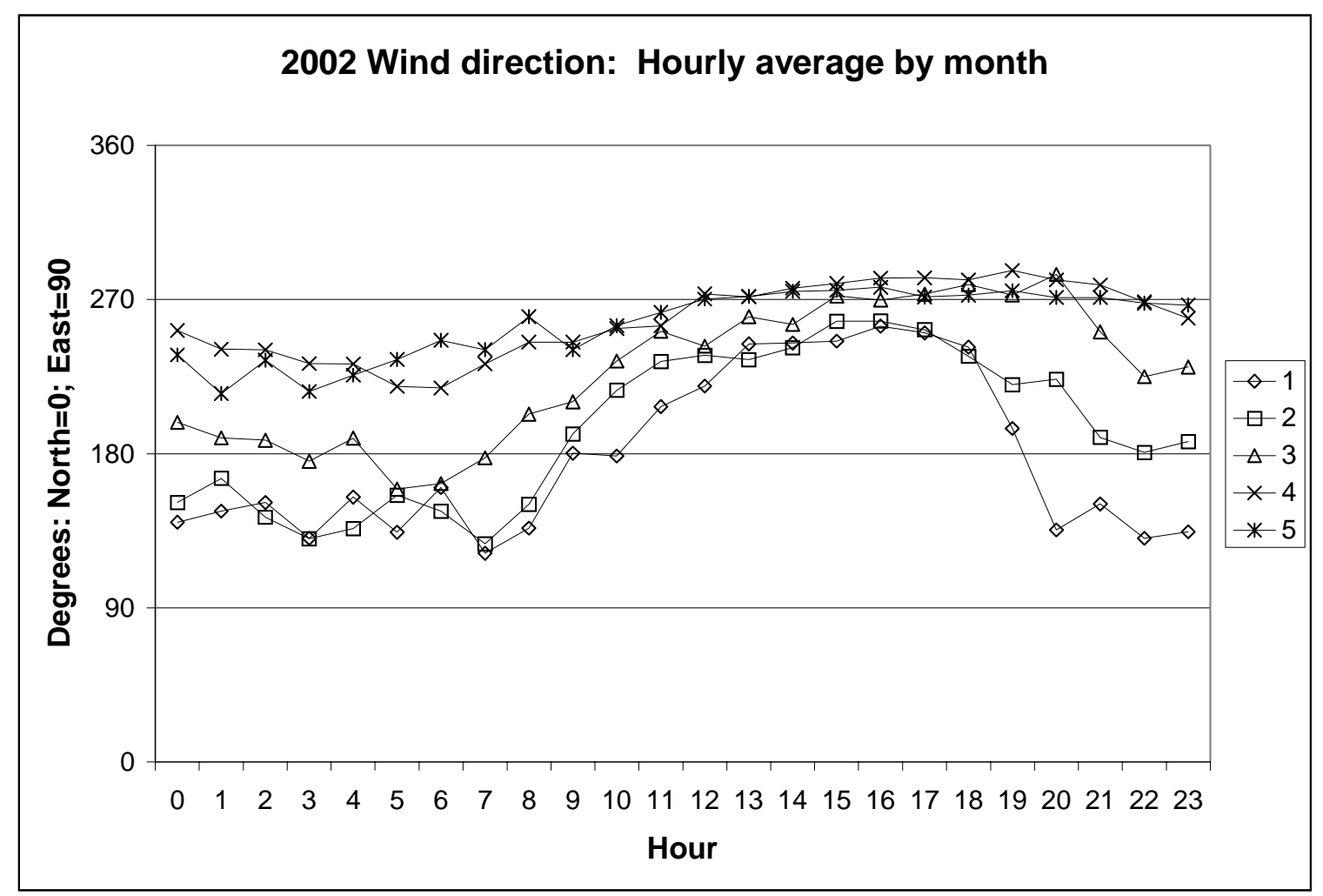

Figure 3.56. Hourly mean wind direction by month for January through May 2002; months are listed by number. 


\section{Appendix A. Photographs of School Monitoring Sites and Equipment Housing and Diagrams of PEM Impactor and $\mathrm{NO}_{\mathrm{X}}$ Sampler}

Photographs were taken at each of the ten schools to show the spring monitoring sites and the placement of the equipment housings with respect to the buildings and other features in the immediate vicinities of the monitoring sites. Another photograph shows the monitoring equipment and instruments positioned on the top shelf of the equipment housing. A Personal Environmental Monitor (PEM) impactor for size selective collection of fine particle samples is shown in an exploded diagram (with permission from MSP Corp.). 


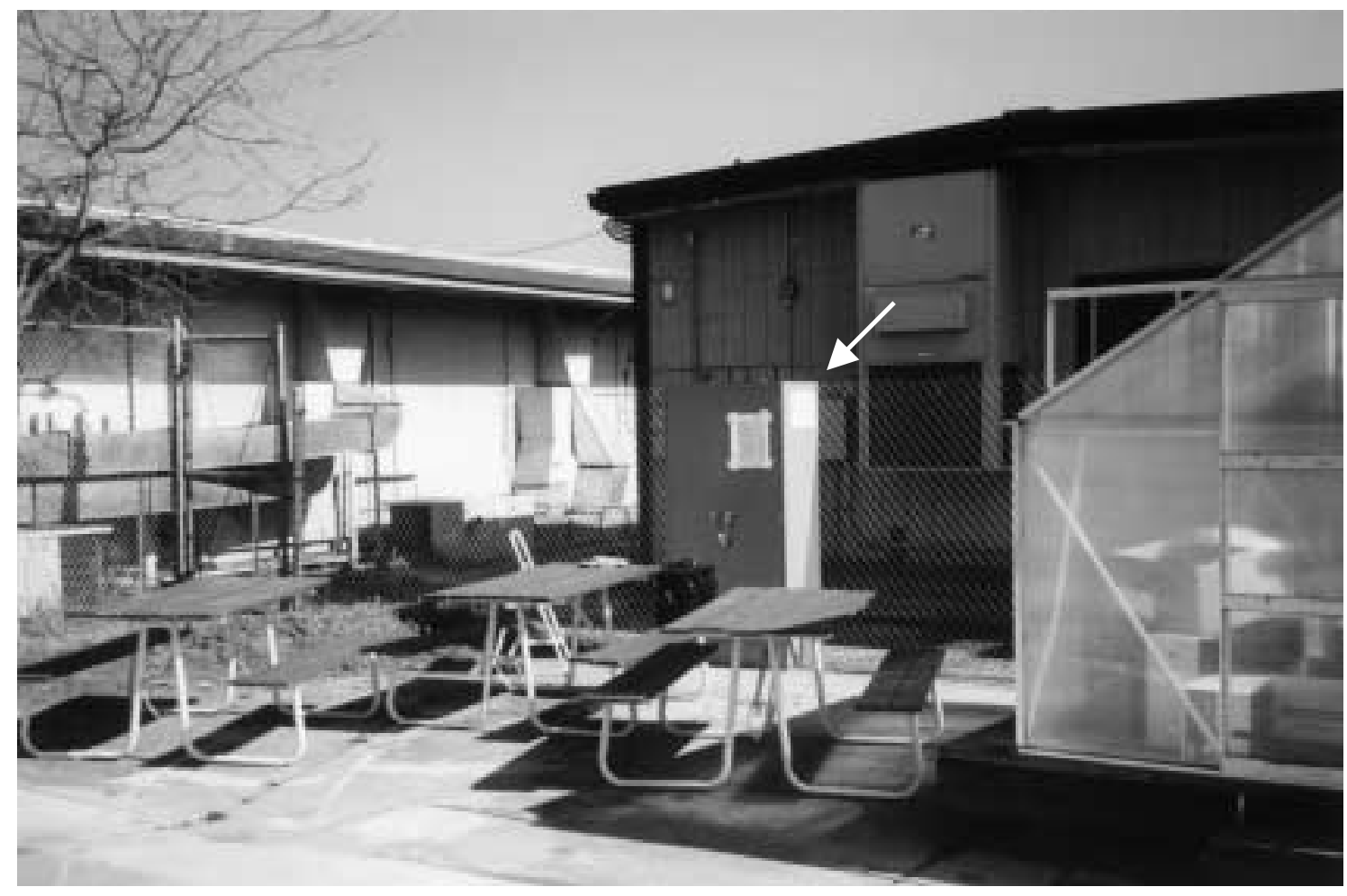

School 1

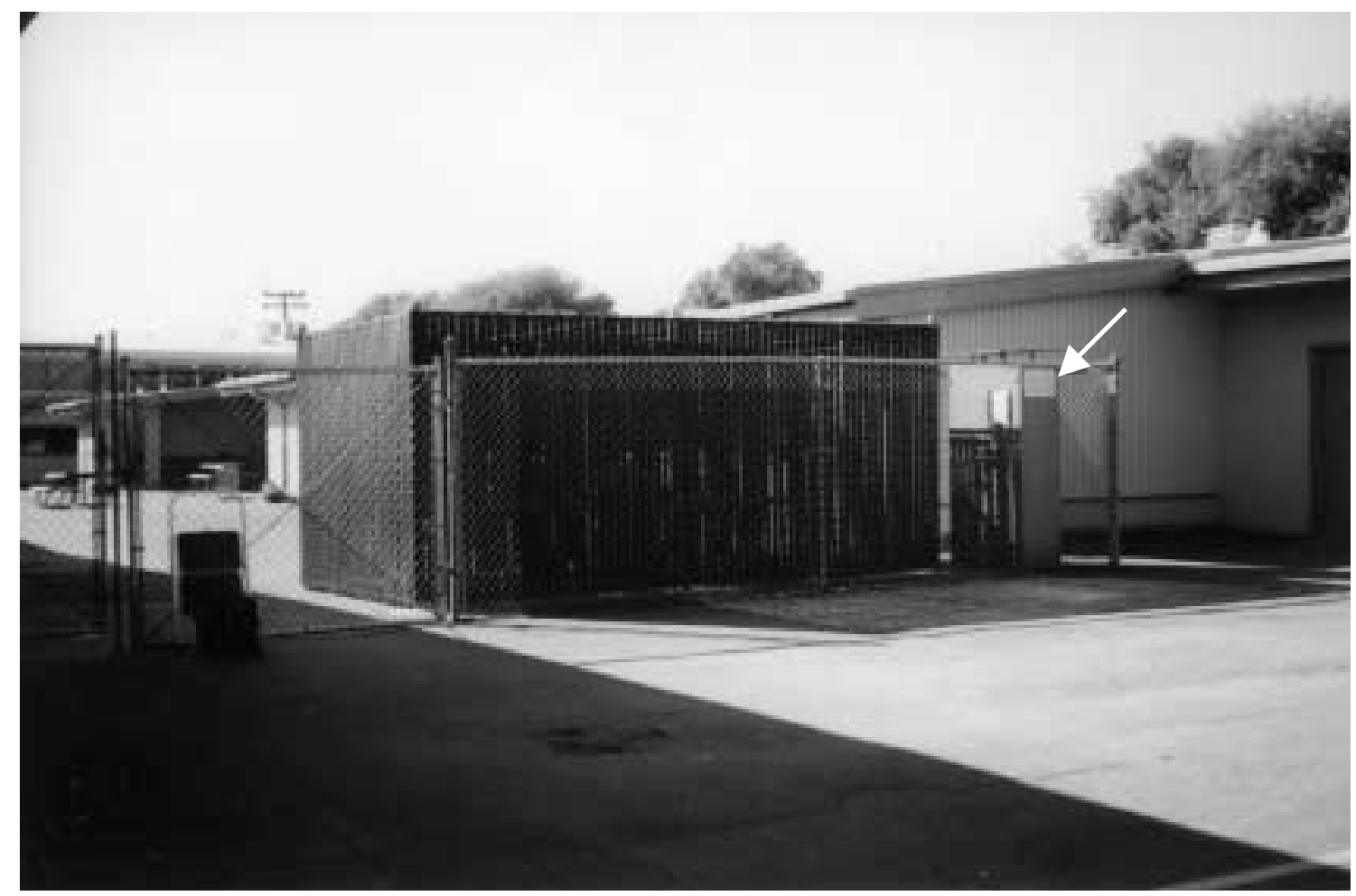

School 2 


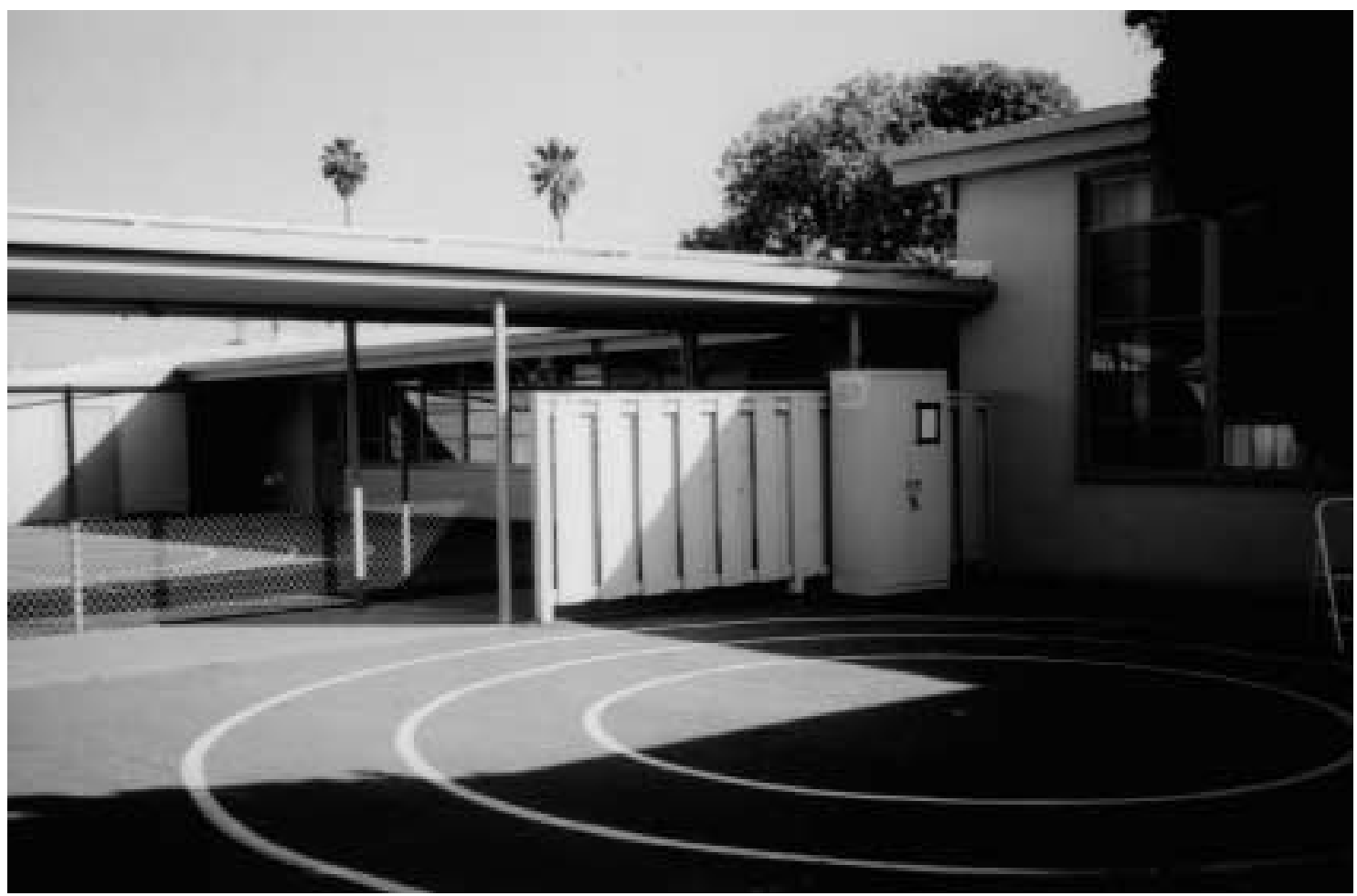

School 3

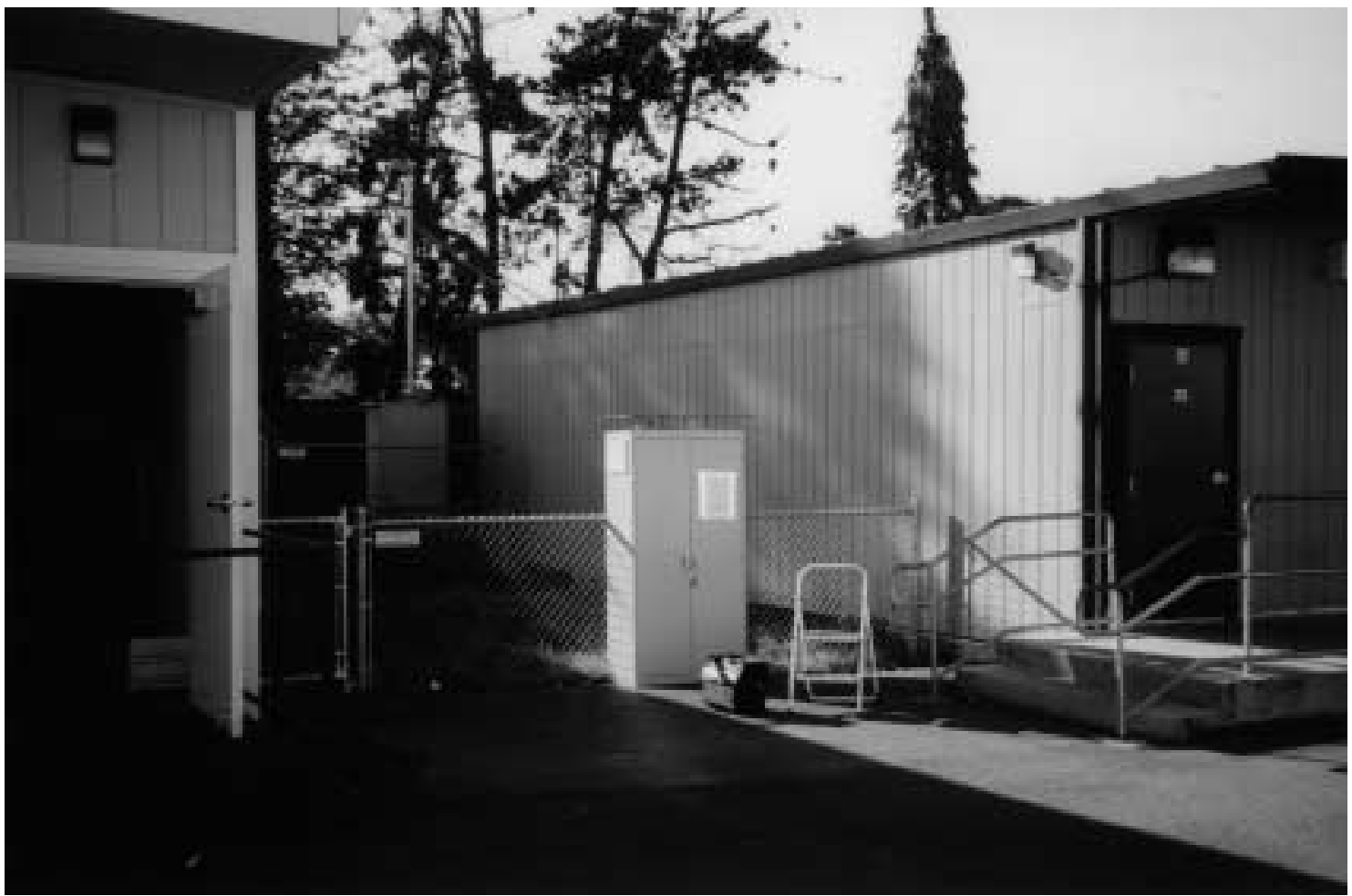

School 4 


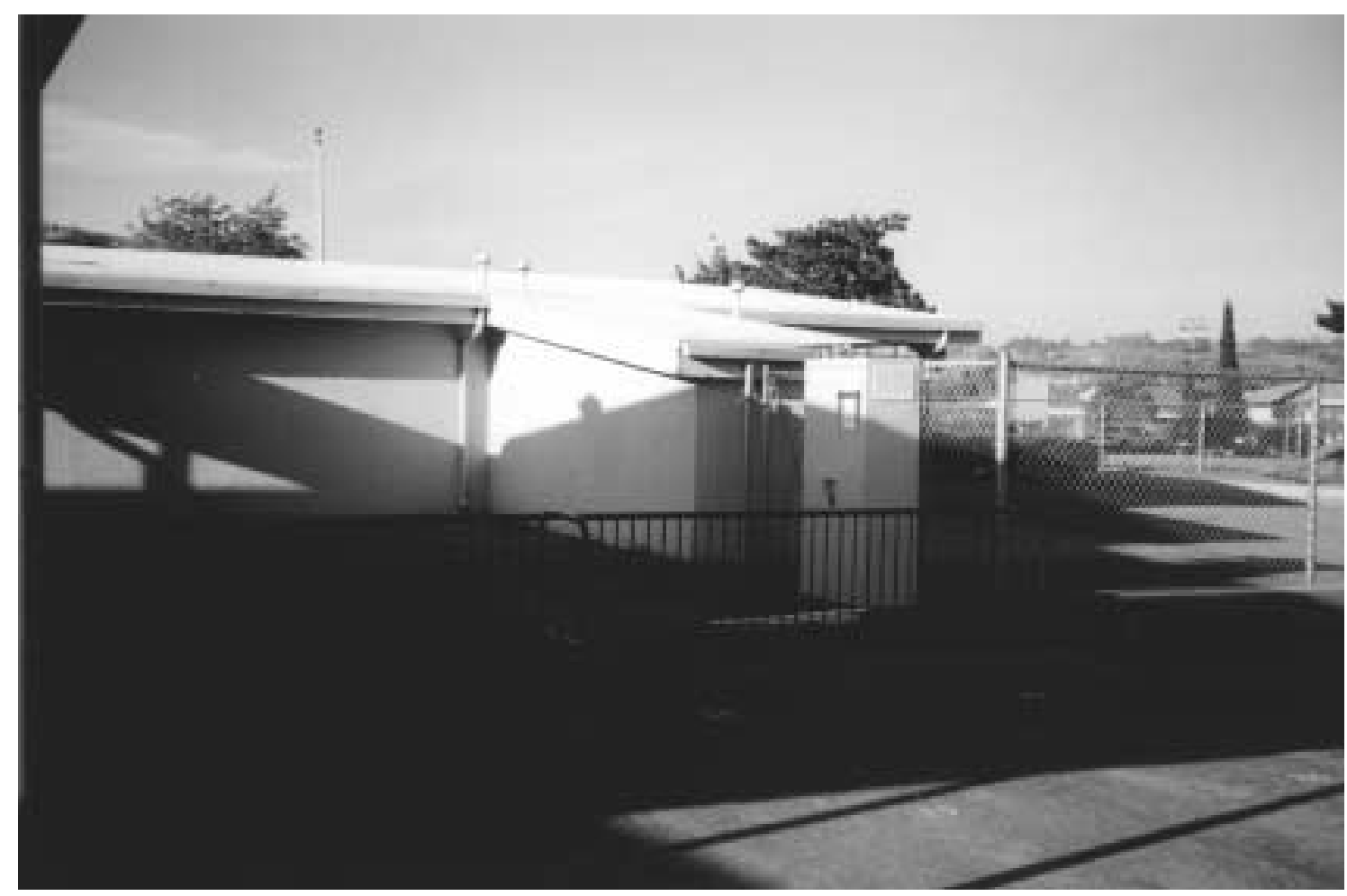

School 5

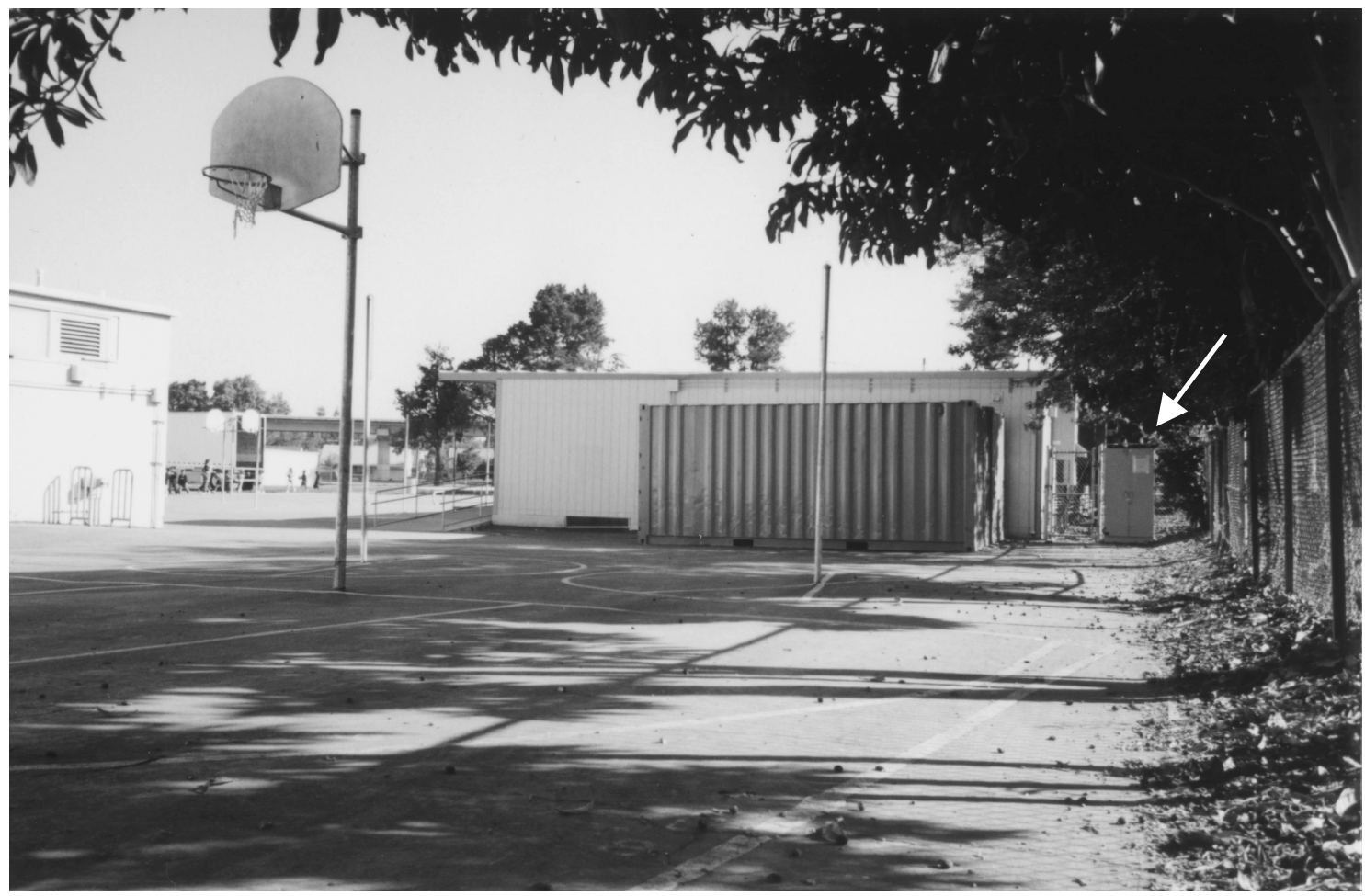

School 6, View 1 


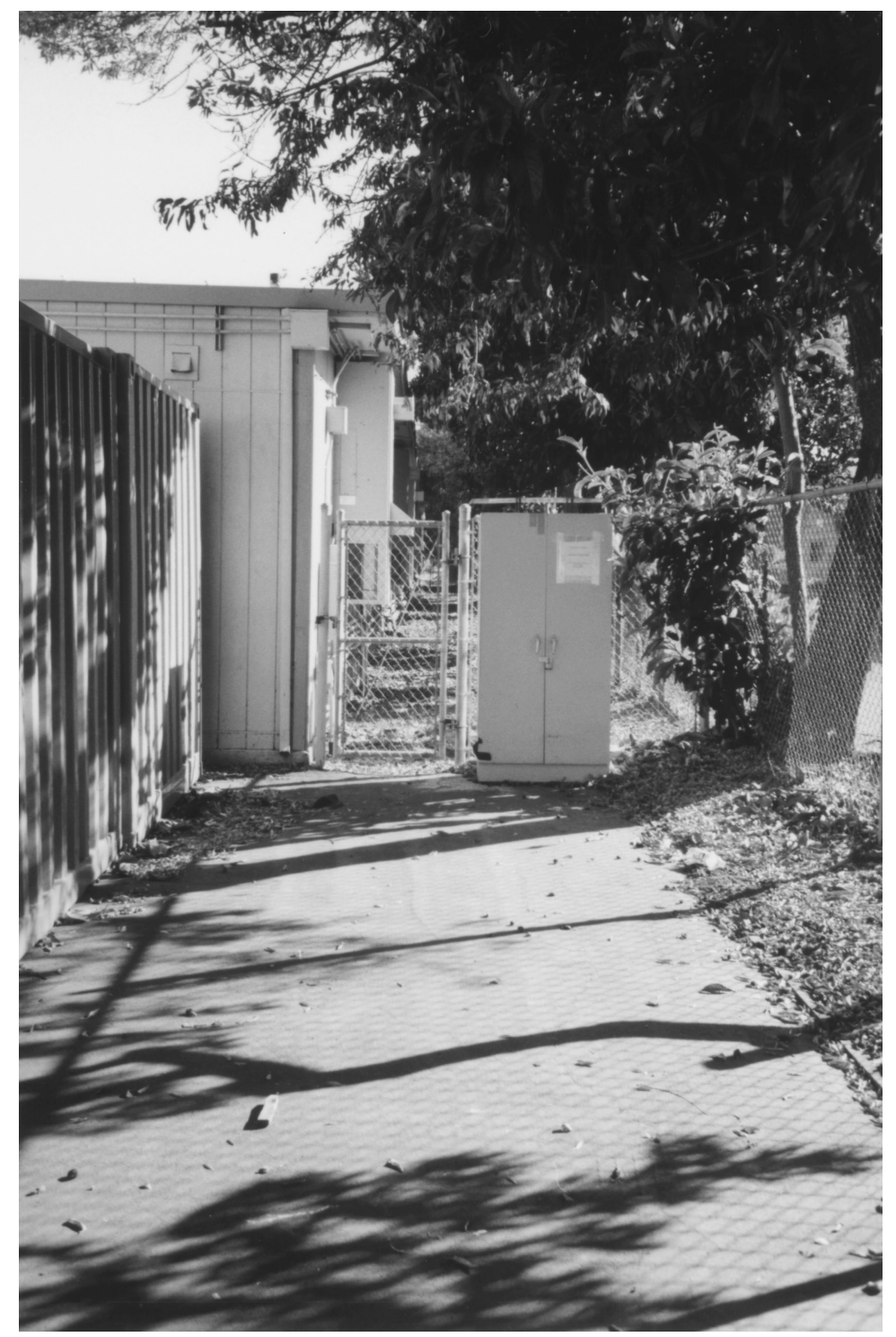

School 6, View 2 


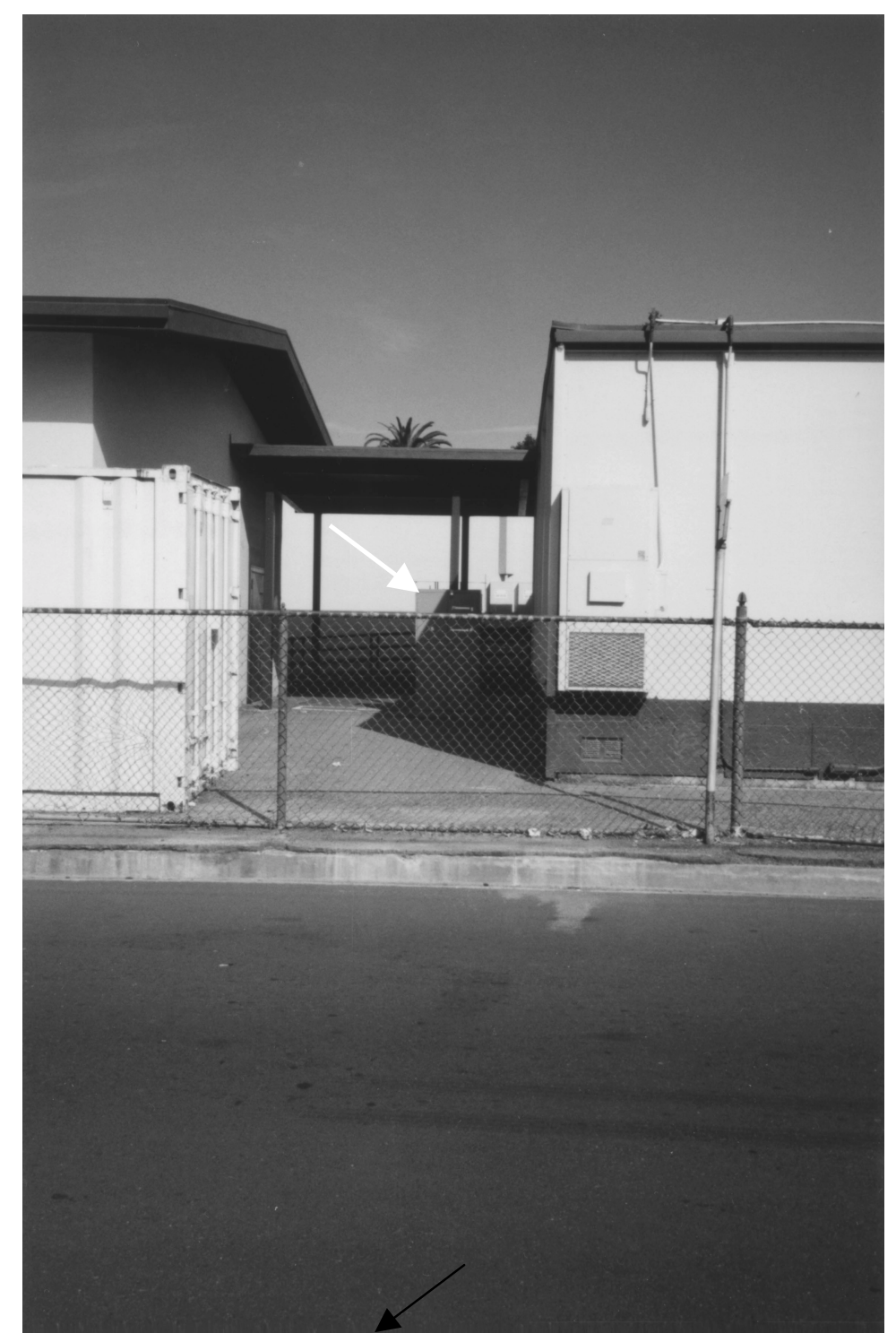

School 7

A-6 


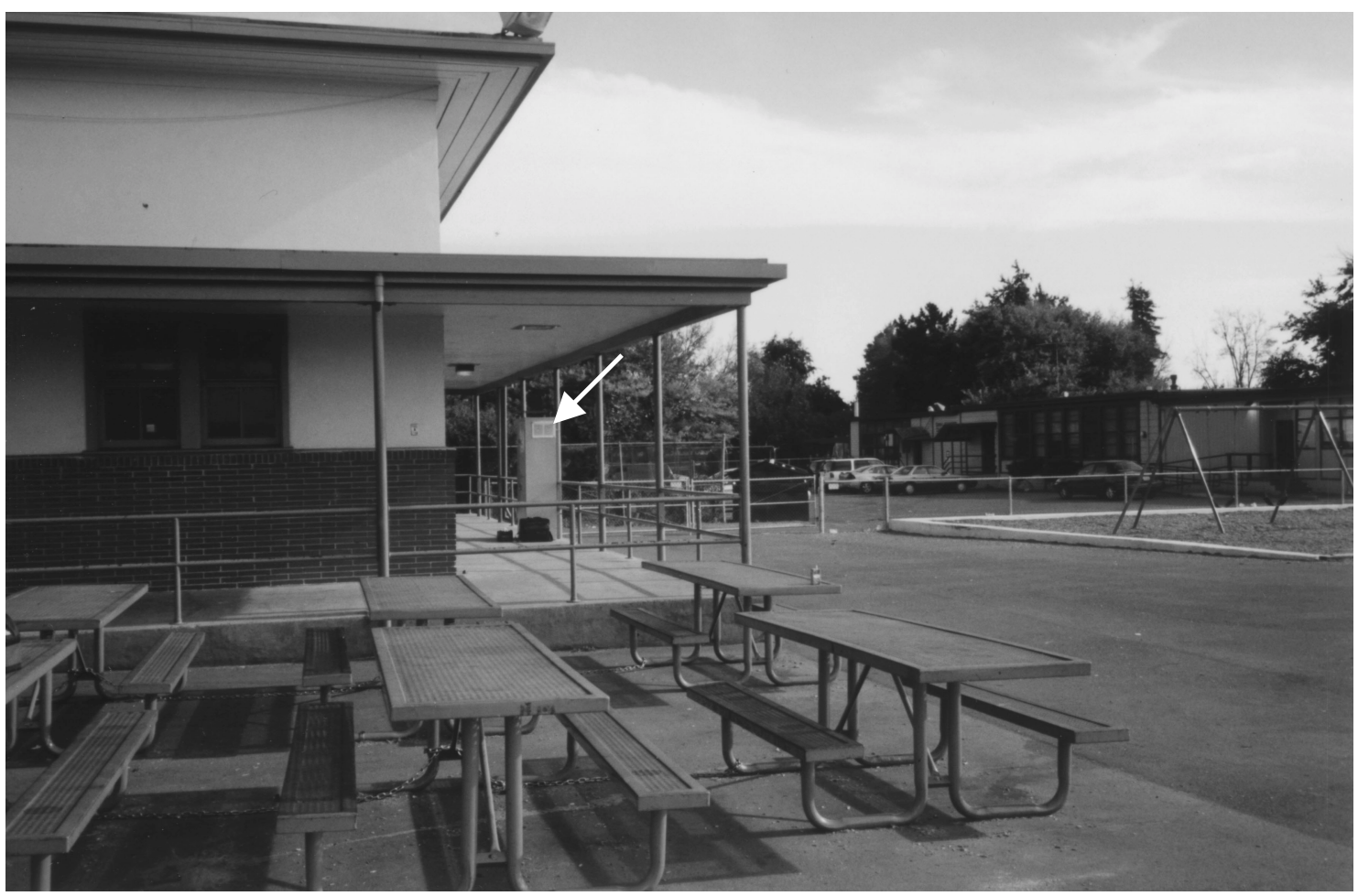

School 8, View 1

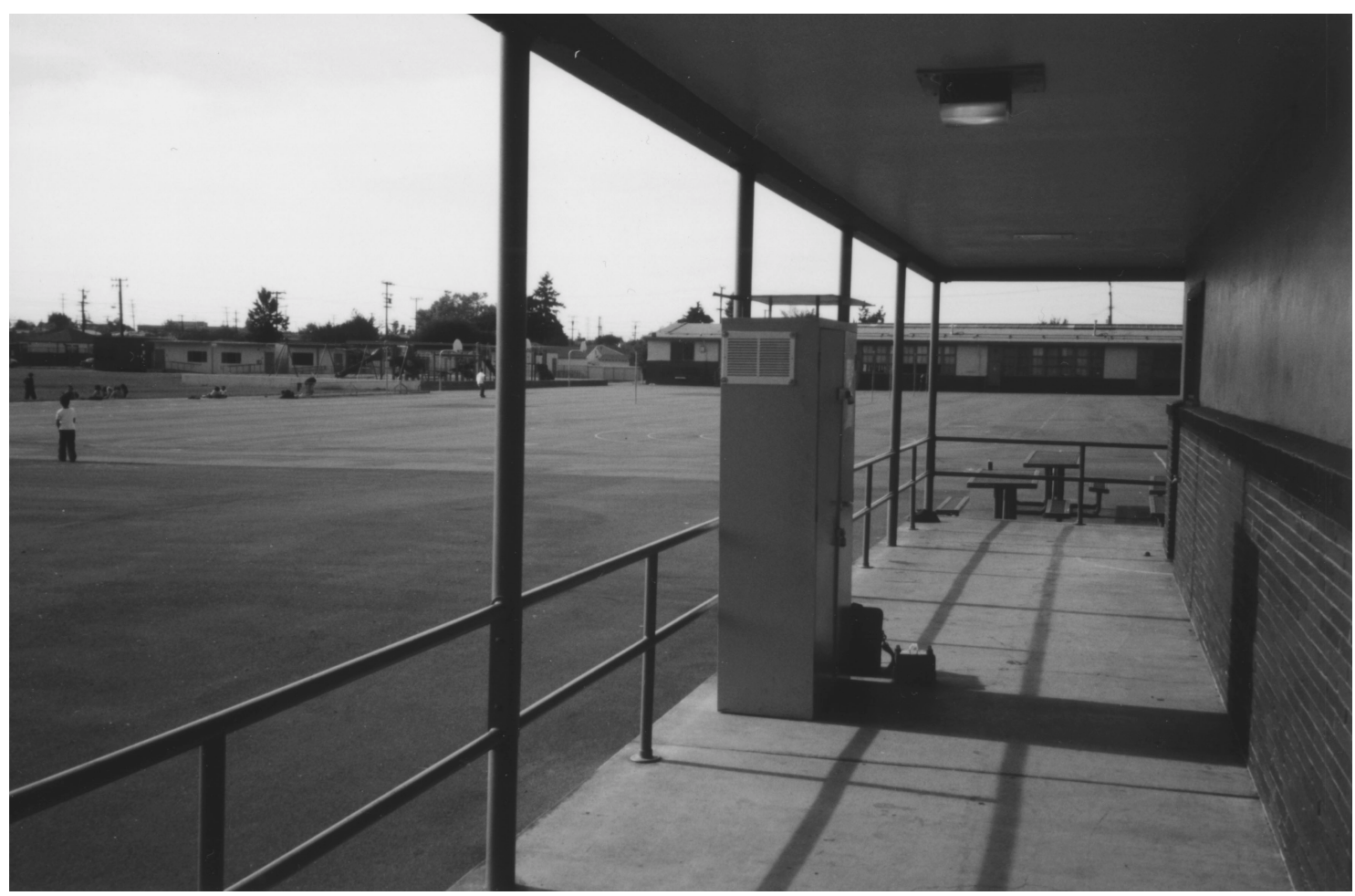

School 8, View 2 


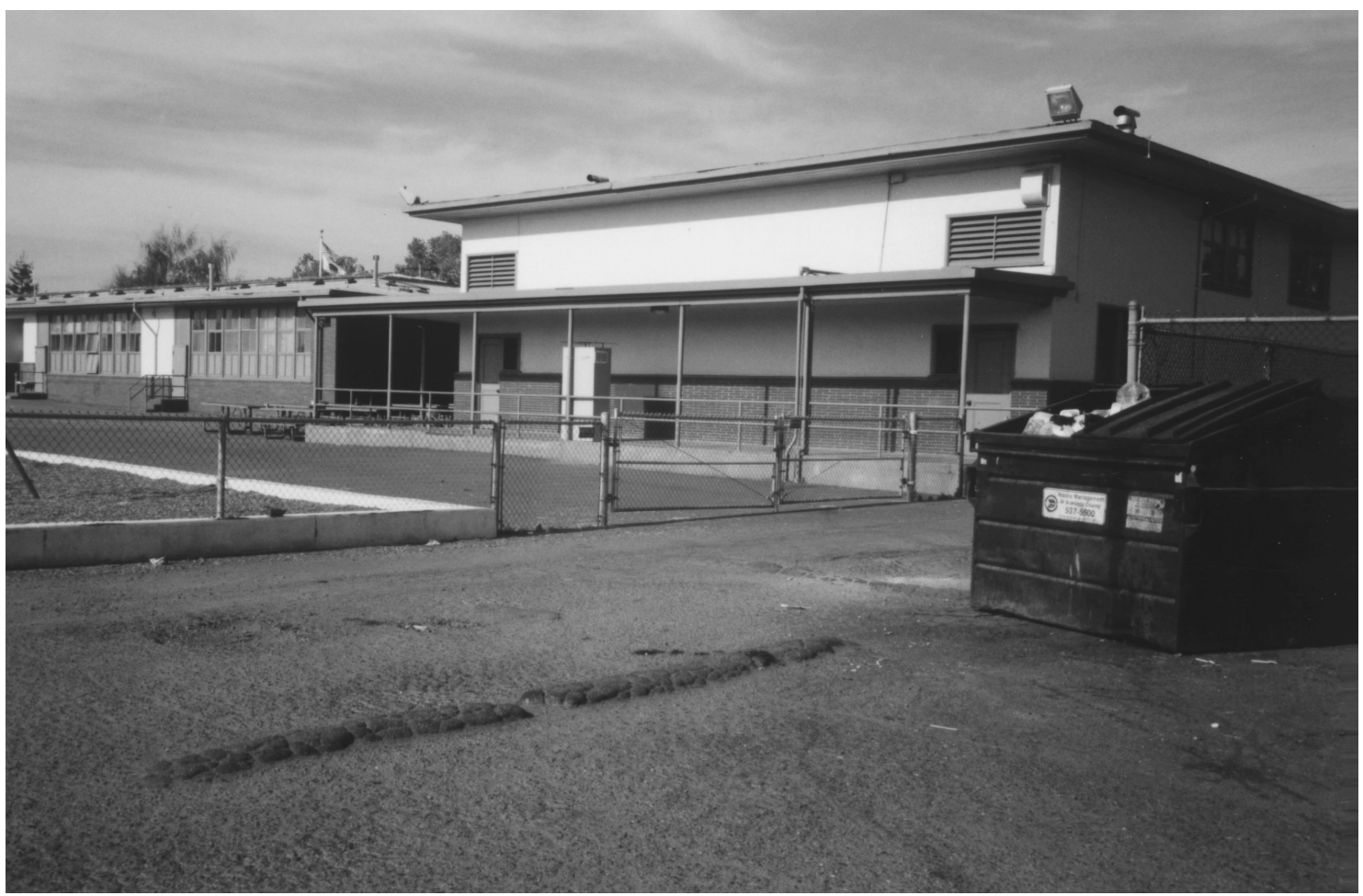

School 8, View 3

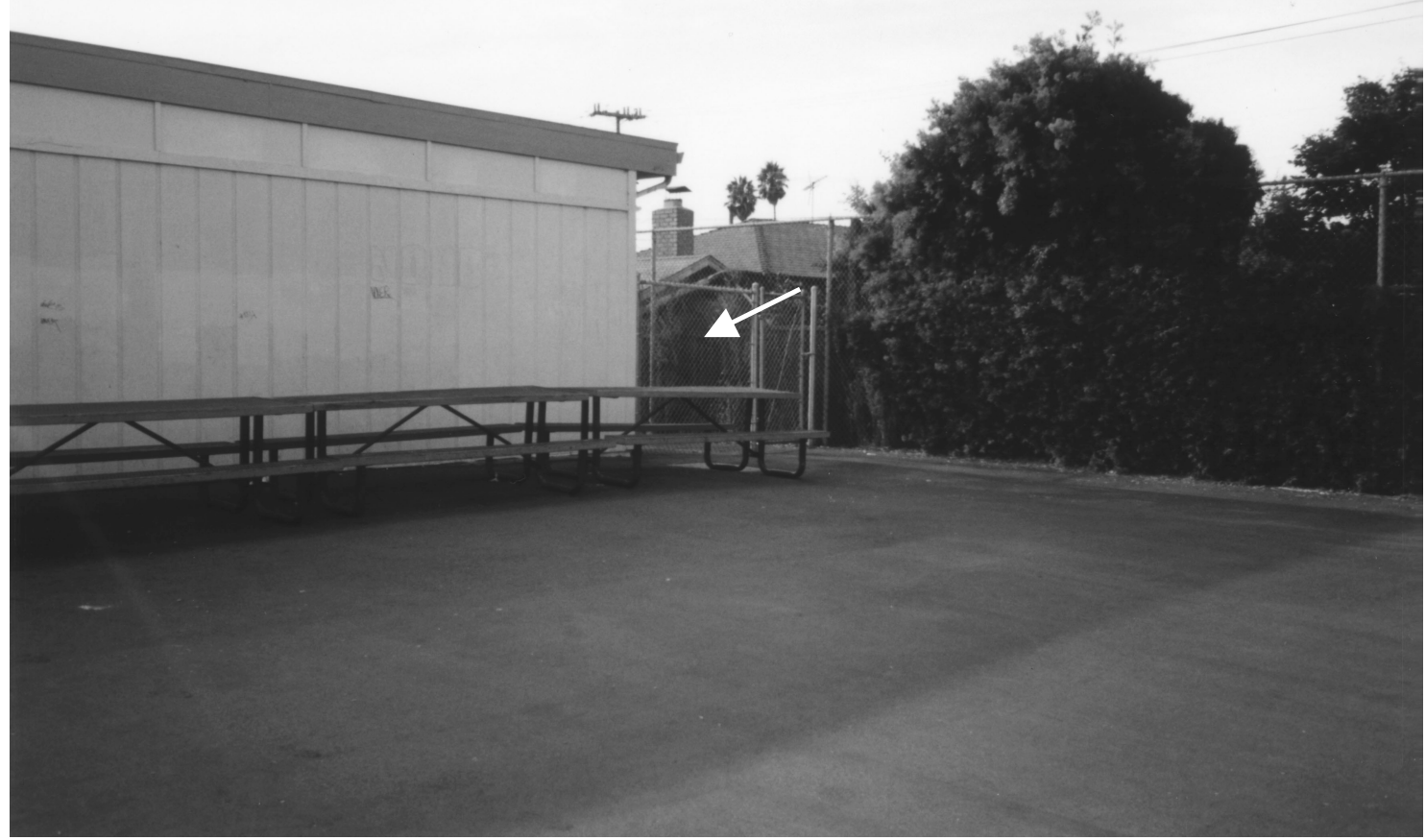

School 9, Monitoring site with equipment housing removed 


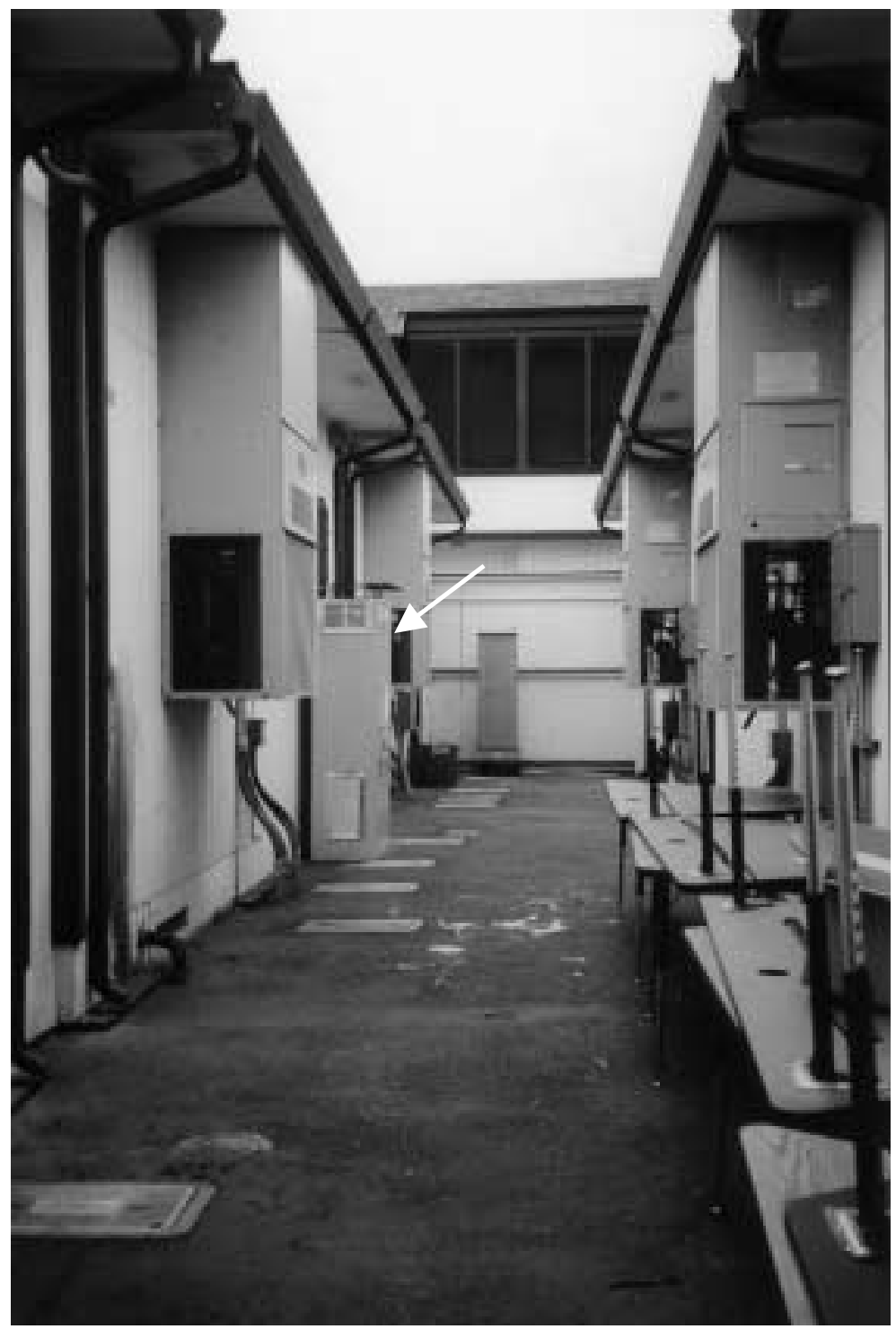

School 10 


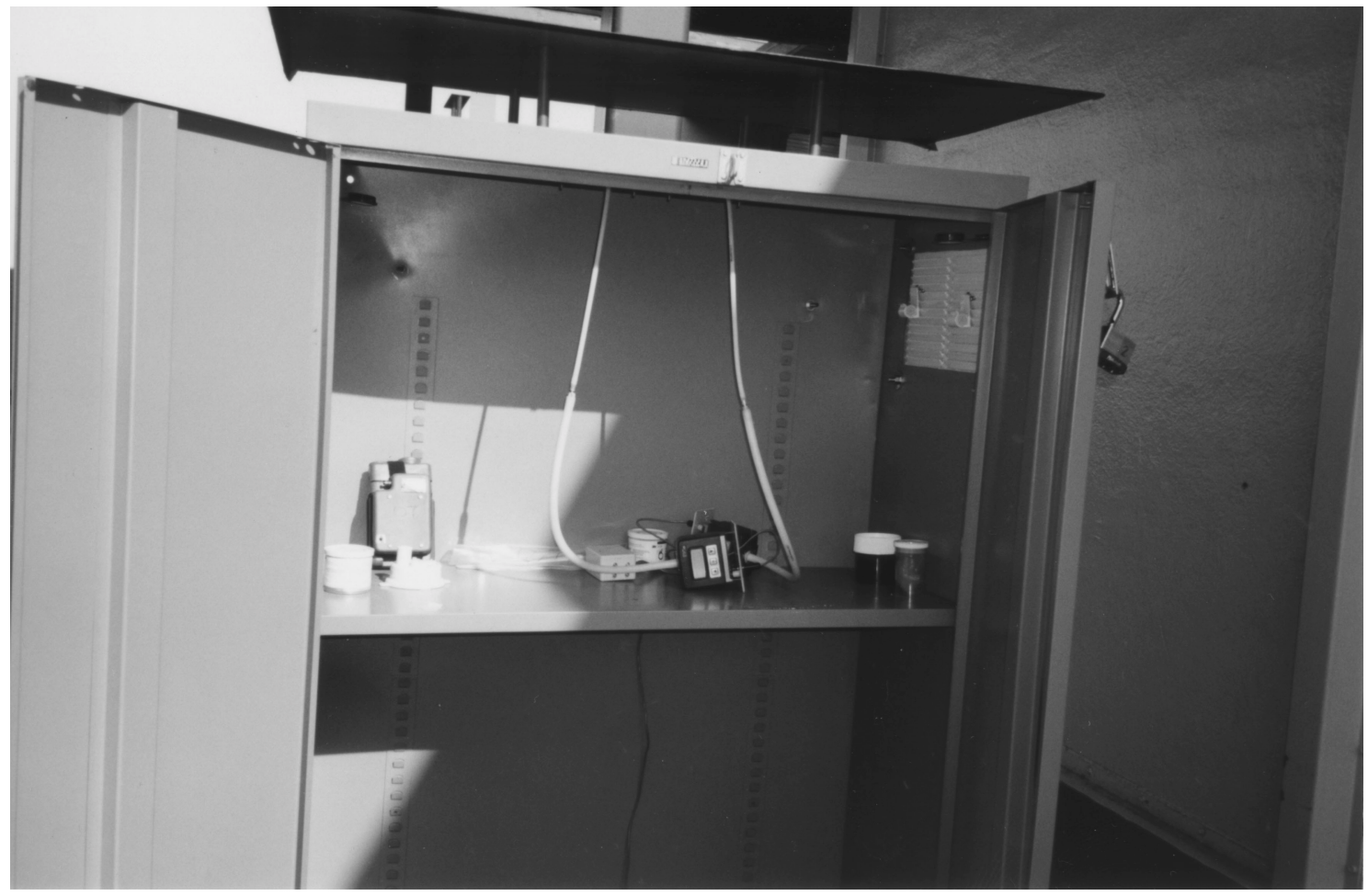

Monitoring equipment and instruments placed in equipment housing; PEMs facing upward, through top of cabinet, under aluminum weather screen. 


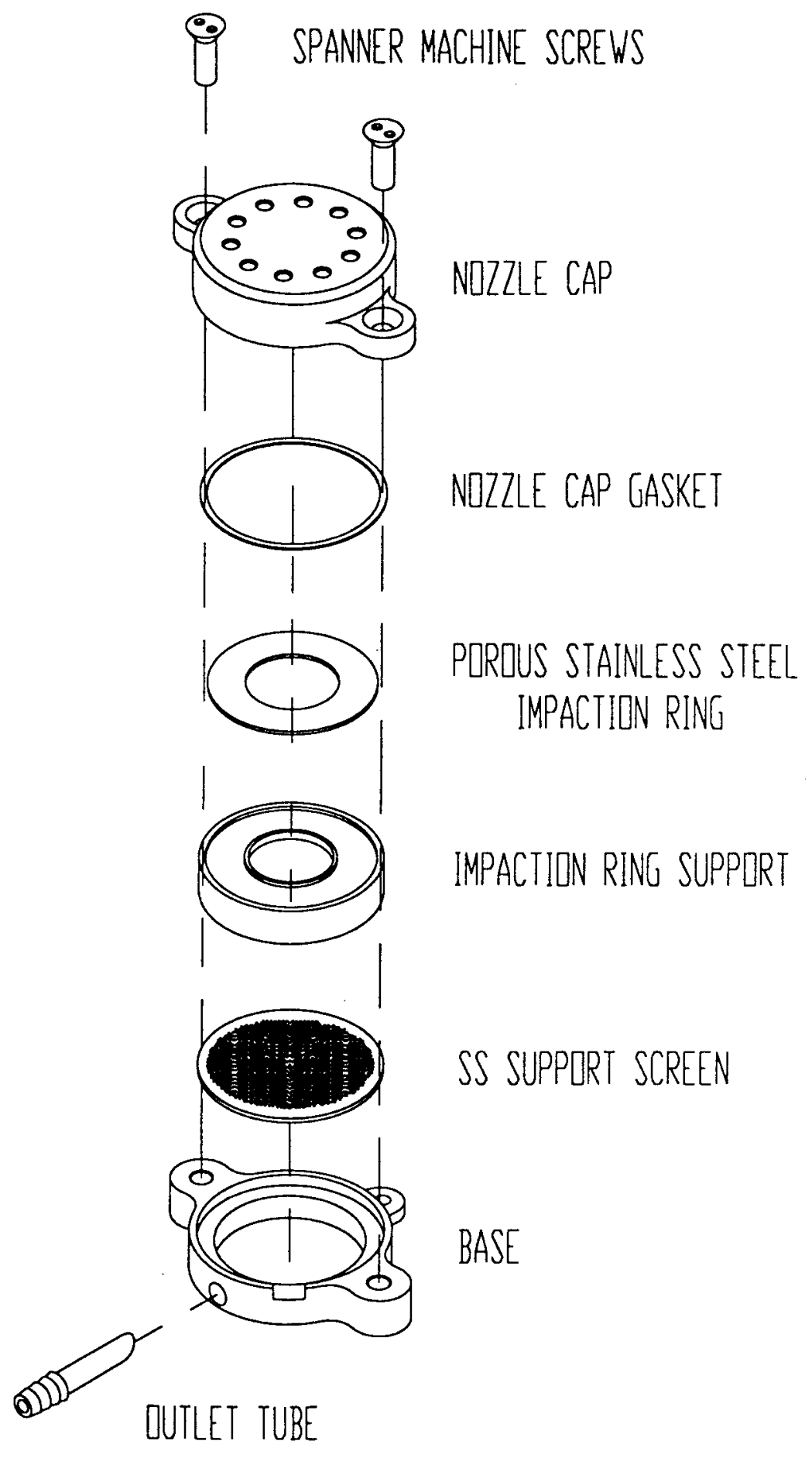

Exploded view of PEM size-selective impactor 


\section{Ogawa Sampler Assembly}

The sampler is comprised of 2 chambers. In each chamber of the sampler, the assembly stack-up is described below. Start at the innermost position with the pad and progress outwards to the diffuser end cap.

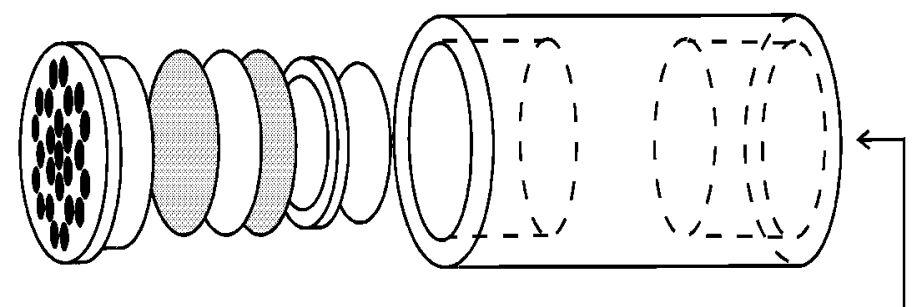

1 Solid Pad

2 Pad Retaining Ring

3 Stainless Screen

4 Coated Collection Filter

5 Stainless Screen

6 Diffuser End Cap

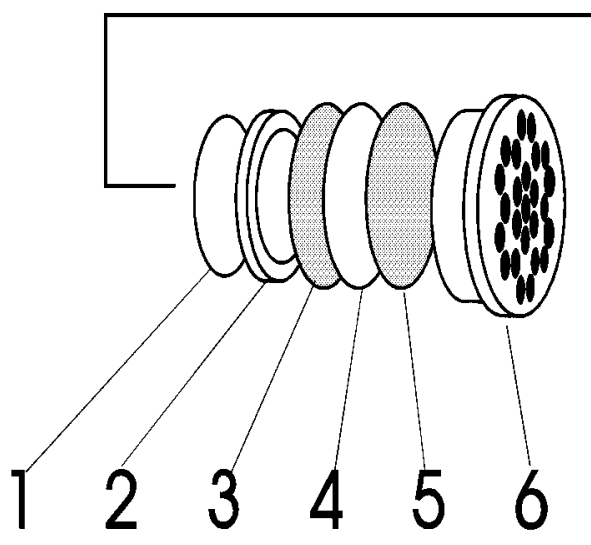




\section{Appendix B. Deployment Records for Carbon Monoxide Instruments and PEM Impactors}

Table B-1. Deployment of carbon monoxide (CO) instruments at schools S1-S10. The instrument number (0-10) used at each school during each week of monitoring is shown.

\begin{tabular}{ccccccccccc}
\hline Week & S1 & S2 & S3 & S4 & S5 & S6 & S7 & S8 & S9 & S10 \\
\hline 1 & 1 & 2 & 3 & 4 & 5 & 6 & 7 & 8 & 9 & N/A $^{\mathbf{1}}$ \\
2 & 1 & 2 & 3 & 4 & 5 & 6 & 7 & 8 & 9 & N/A \\
3 & 1 & 2 & 3 & 4 & 5 & 6 & 7 & 8 & 9 & 10 \\
4 & 1 & 2 & 3 & 4 & 5 & 6 & 7 & 8 & 9 & 10 \\
5 & 1 & 2 & 3 & 4 & 5 & 6 & 0 & 8 & 9 & 10 \\
6 & ---- & --- & --- & --- & --- & --- & --- & --- & --- & --- \\
7 & --- & 6 & 2 & 4 & --- & --- & 0 & 8 & --- & --- \\
$7-$ indoor & --- & 1 & 3 & 5 & --- & --- & 10 & 9 & --- & --- \\
8 & 1 & 6 & 2 & 4 & 5 & 3 & 0 & 8 & 9 & 10 \\
9 & 1 & --- & --- & --- & 5 & 6 & --- & --- & 9 & 10 \\
$9-$ indoor & 2 & --- & --- & --- & 3 & 4 & --- & --- & 0 & 8 \\
10 & 5 & 2 & 3 & 4 & 1 & 6 & 0 & 8 & N/A & 10 \\
$11-12$ & 1 & 2 & 3 & 4 & 5 & 6 & 7 & 8 & 0 & 10 \\
13 & 1 & 2 & 3 & 4 & 5 & 6 & 7 & 8 & 0 & 10 \\
14 & 1 & 2 & 3 & 4 & 5 & 6 & 7 & 8 & 0 & 10 \\
\hline
\end{tabular}

(1) No monitoring at school 10 until week 3.

(2) No CO monitoring was conducted during week 6.

(3) Equipment housing was vandalized. CO instrument 9 was destroyed during week 9. 
Table B-2. Deployment of size-selective PEM impactors for particle sampling at schools S1-S10. The impactor number used at each school during each week of sampling is shown.

\begin{tabular}{|c|c|c|c|c|c|c|c|c|c|c|}
\hline \multicolumn{11}{|c|}{ 2.5- $\mu \mathrm{m}$ PEMs } \\
\hline Week & S1 & S2 & $\mathbf{S 3}$ & S4 & S5 & S6 & S7 & S8 & S9 & S10 \\
\hline 1 & 1 & 2 & 3 & 4 & 5 & 6 & 7 & 8 & 9 & --- \\
\hline 2 & 1 & 2 & 3 & 4 & 5 & 6 & 7 & 8 & 9 & --- \\
\hline 3 & 1 & 2 & 3 & 4 & 5 & 6 & 7 & 8 & 9 & --- \\
\hline 4 & 1 & 2 & 3 & 4 & 5 & 6 & 7 & 8 & 9 & 10 \\
\hline $5-6$ & 1 & 2 & 3 & 4 & 5 & 6 & 7 & 8 & 9 & 10 \\
\hline 7 & --- & 2 & 3 & 4 & --- & --- & 7 & 8 & --- & --- \\
\hline 7-indoor & --- & 1 & 5 & 10 & --- & --- & 9 & 6 & --- & --- \\
\hline 8 & 1 & 2 & 3 & 4 & 5 & 6 & 7 & 8 & 9 & 10 \\
\hline 9 & 1 & --- & --- & --- & 5 & 6 & --- & --- & Stolen & $10 / 21$ \\
\hline 9-in & 2 & --- & --- & --- & 3 & 4 & --- & --- & 7 & 8 \\
\hline 10 & 1 & 2 & 3 & 4 & 5 & 6 & 7 & 8 & --- & 10 \\
\hline $11-12$ & 1 & 2 & 3 & 4 & 5 & 6 & 7 & 8 & 21 & 10 \\
\hline 13 & 1 & 2 & 3 & 4 & 5 & 6 & 7 & 8 & 21 & 10 \\
\hline 14 & 1 & 2 & 3 & 4 & 5 & 6 & 7 & 8 & 21 & 10 \\
\hline \multicolumn{11}{|c|}{ 10- $\mu \mathrm{m}$ PEMs } \\
\hline Week & S1 & S2 & S3 & S4 & S5 & S6 & S7 & S8 & S9 & S10 \\
\hline 1 & 11 & 12 & 13 & 14 & 15 & 16 & 17 & 18 & 19 & --- \\
\hline 2 & 11 & 12 & 13 & 14 & 15 & 16 & 17 & 18 & 19 & --- \\
\hline 3 & 11 & 12 & 13 & 14 & 15 & 16 & 17 & 18 & 19 & --- \\
\hline 4 & 11 & 12 & 13 & 14 & 15 & 16 & 17 & 18 & 19 & 20 \\
\hline $5-6$ & 11 & 12 & 13 & 14 & 15 & 16 & 17 & 18 & 19 & 20 \\
\hline 7 & --- & 12 & 13 & 14 & --- & --- & 17 & 18 & --- & --- \\
\hline 7-indoor & --- & 11 & 15 & 20 & --- & --- & 19 & 16 & --- & --- \\
\hline 8 & 11 & 12 & 13 & 14 & 15 & 16 & 17 & 18 & 19 & 20 \\
\hline 9 & 11 & --- & --- & --- & 15 & 16 & --- & --- & Stolen & $20 / 22$ \\
\hline 9-in & 12 & --- & --- & --- & 13 & 14 & --- & --- & 17 & 18 \\
\hline 10 & 11 & 12 & 13 & 14 & 15 & 16 & 17 & 18 & --- & 20 \\
\hline $11-12$ & 11 & 12 & 13 & 14 & 15 & 16 & 17 & 18 & 22 & 20 \\
\hline 13 & 11 & 12 & 13 & 14 & 15 & 16 & 17 & 18 & 22 & 20 \\
\hline 14 & 11 & 12 & 13 & 14 & 15 & 16 & 17 & 18 & 22 & 20 \\
\hline
\end{tabular}




\section{Appendix C. Plots of Hourly Average Carbon Monoxide (CO) \\ Concentrations at All Schools Over Spring Monitoring Period}

Carbon Monoxide concentrations were monitored at each school with electrochemical

sensor based instruments. Hourly average concentrations at each school are shown in the following plots for all weeks in which monitoring was conducted. 

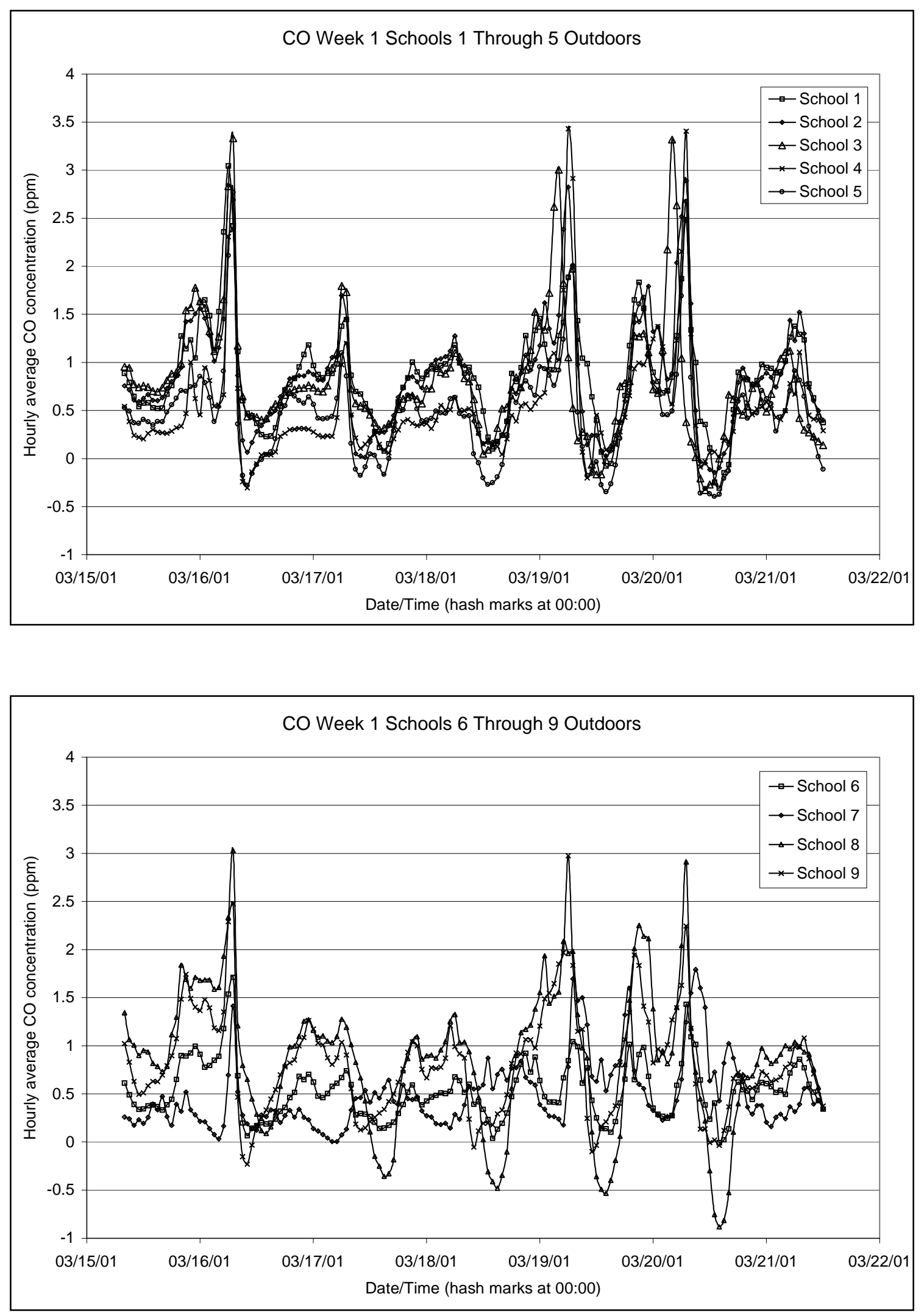

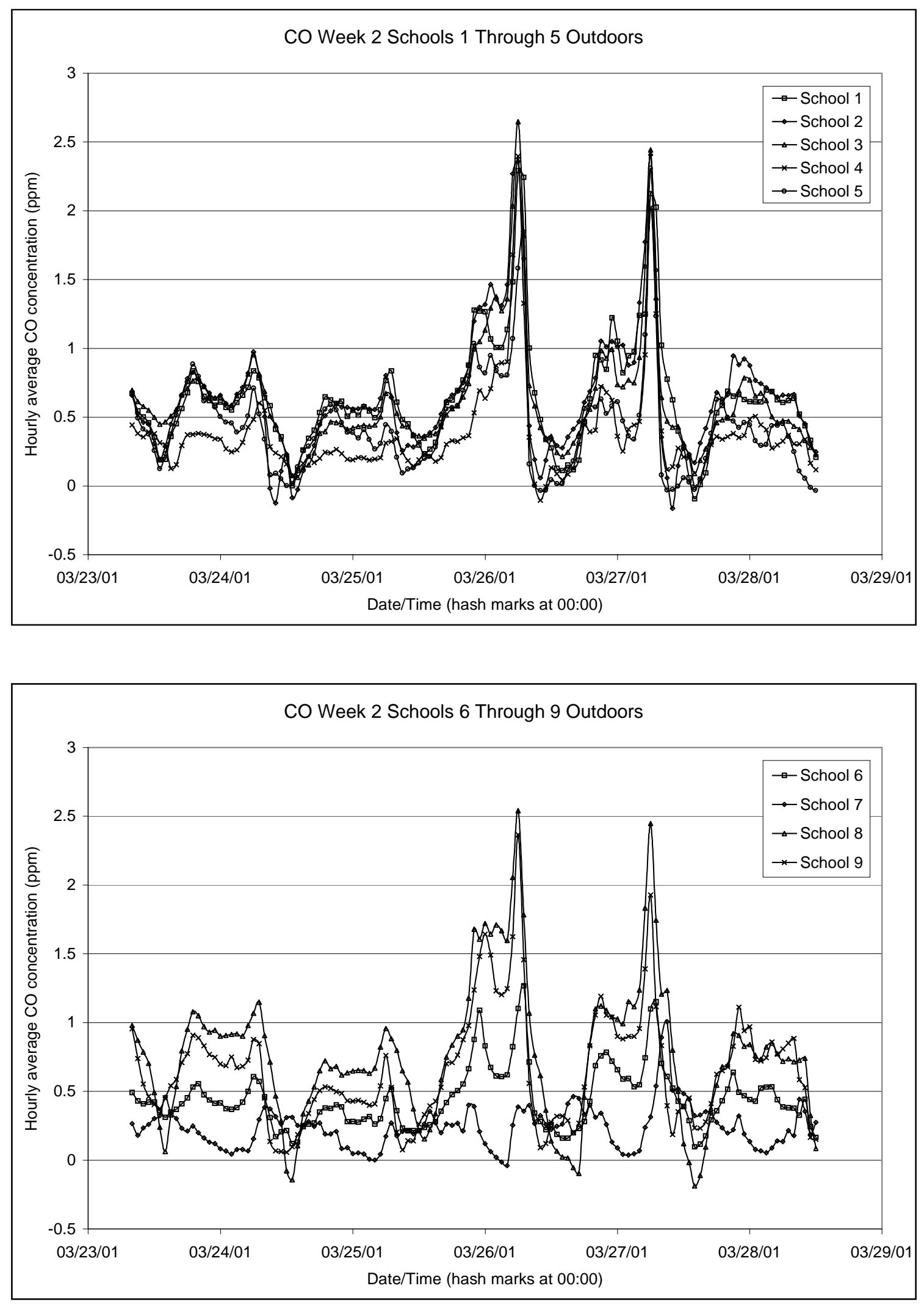

C-3 

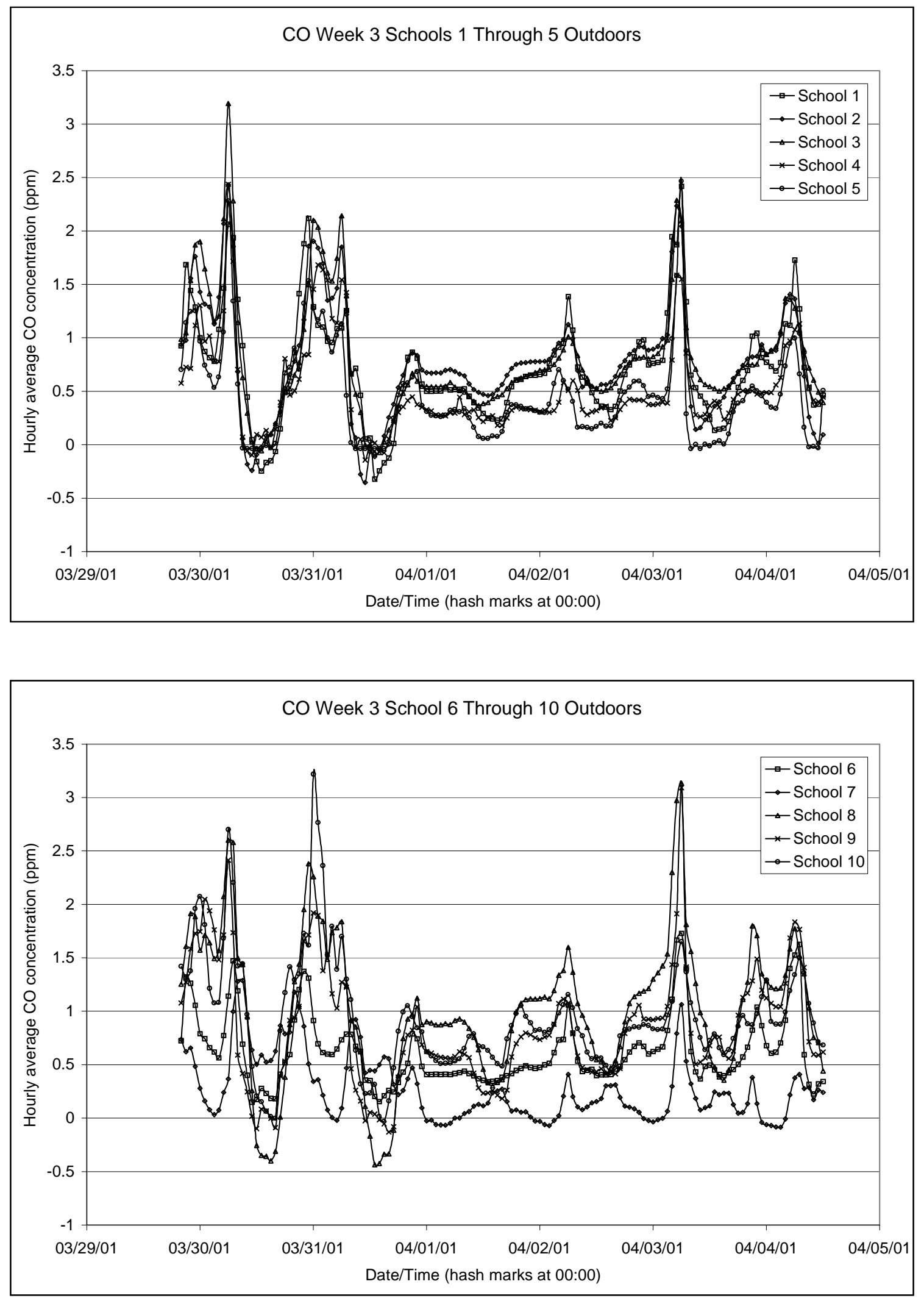

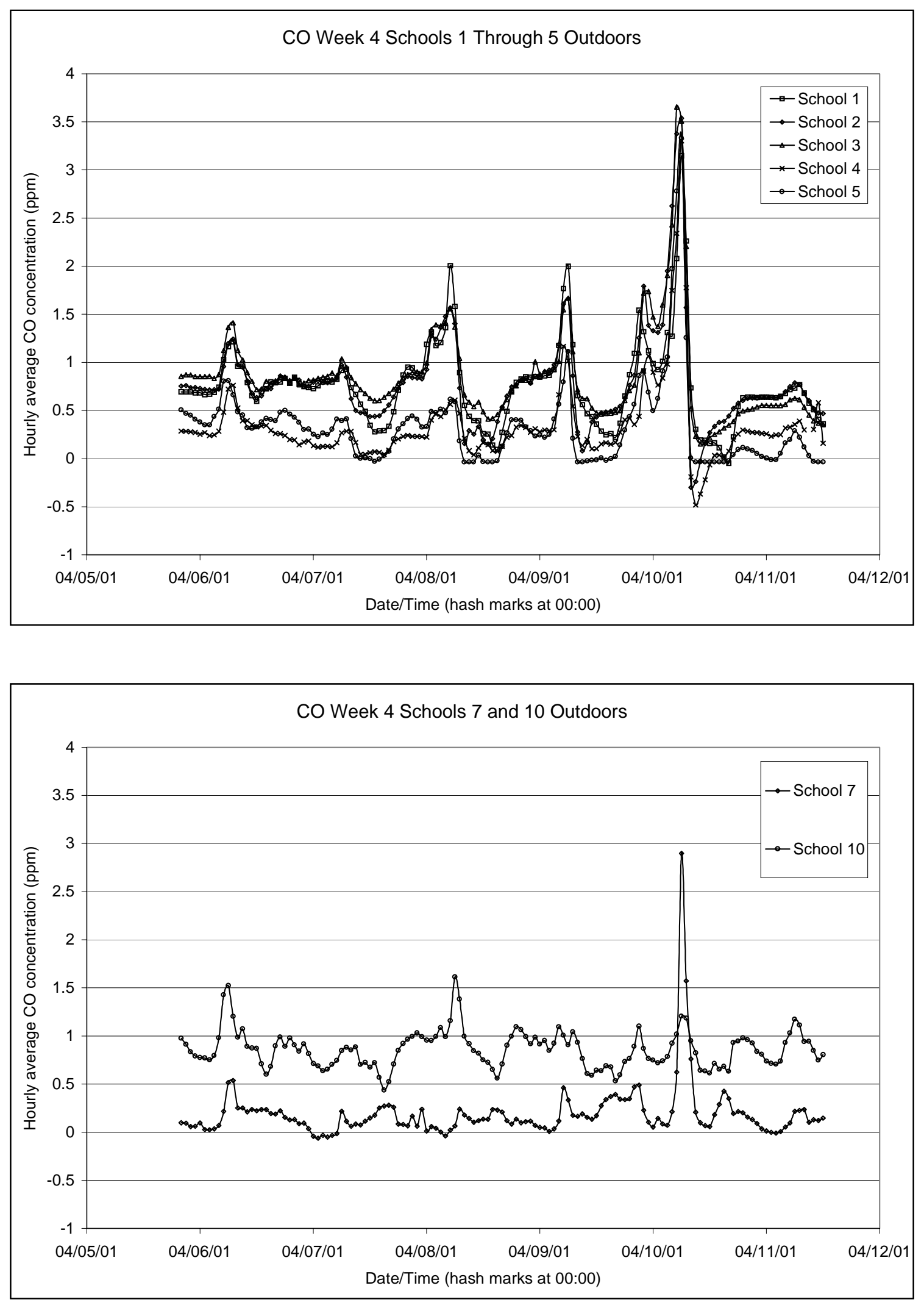

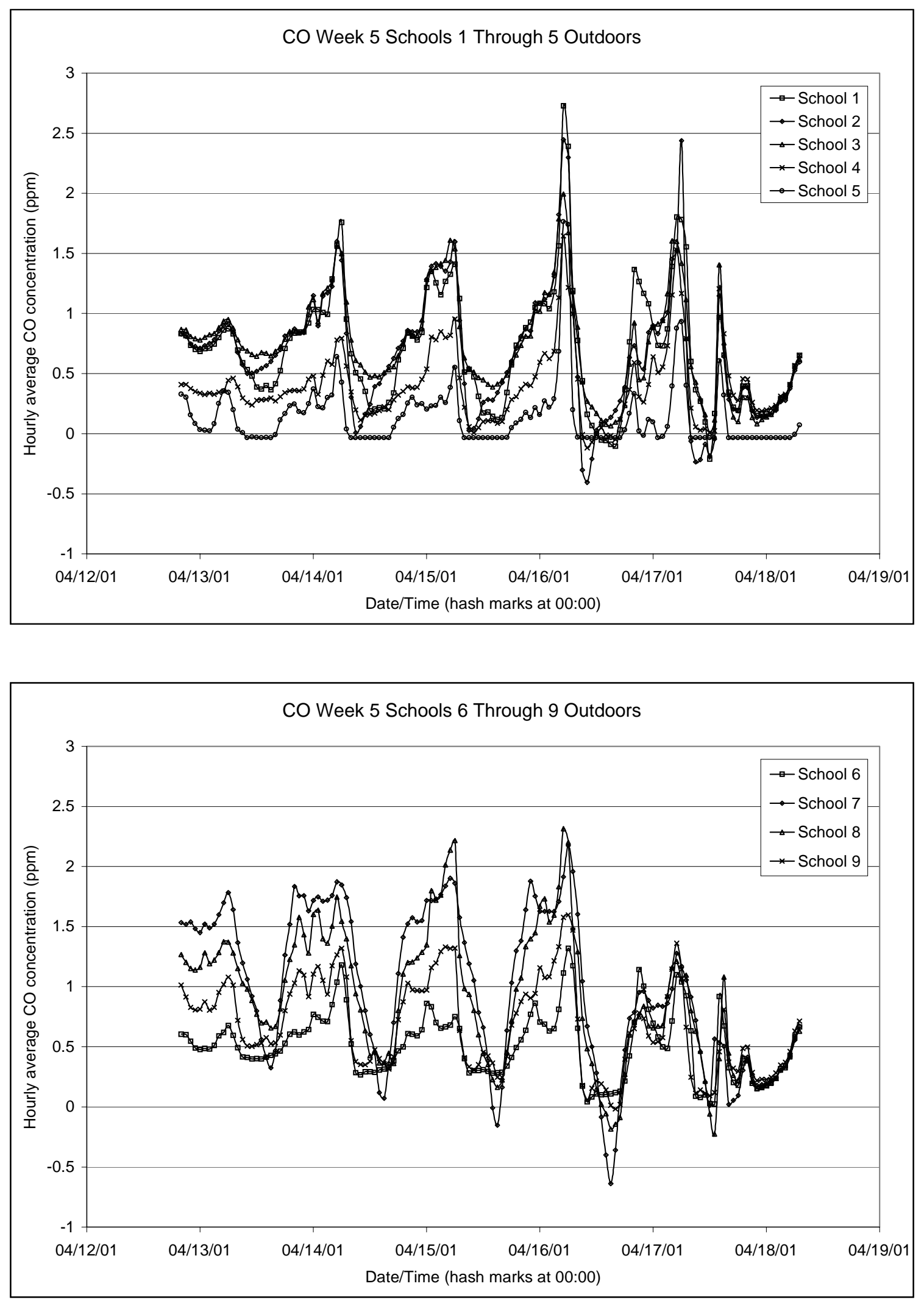

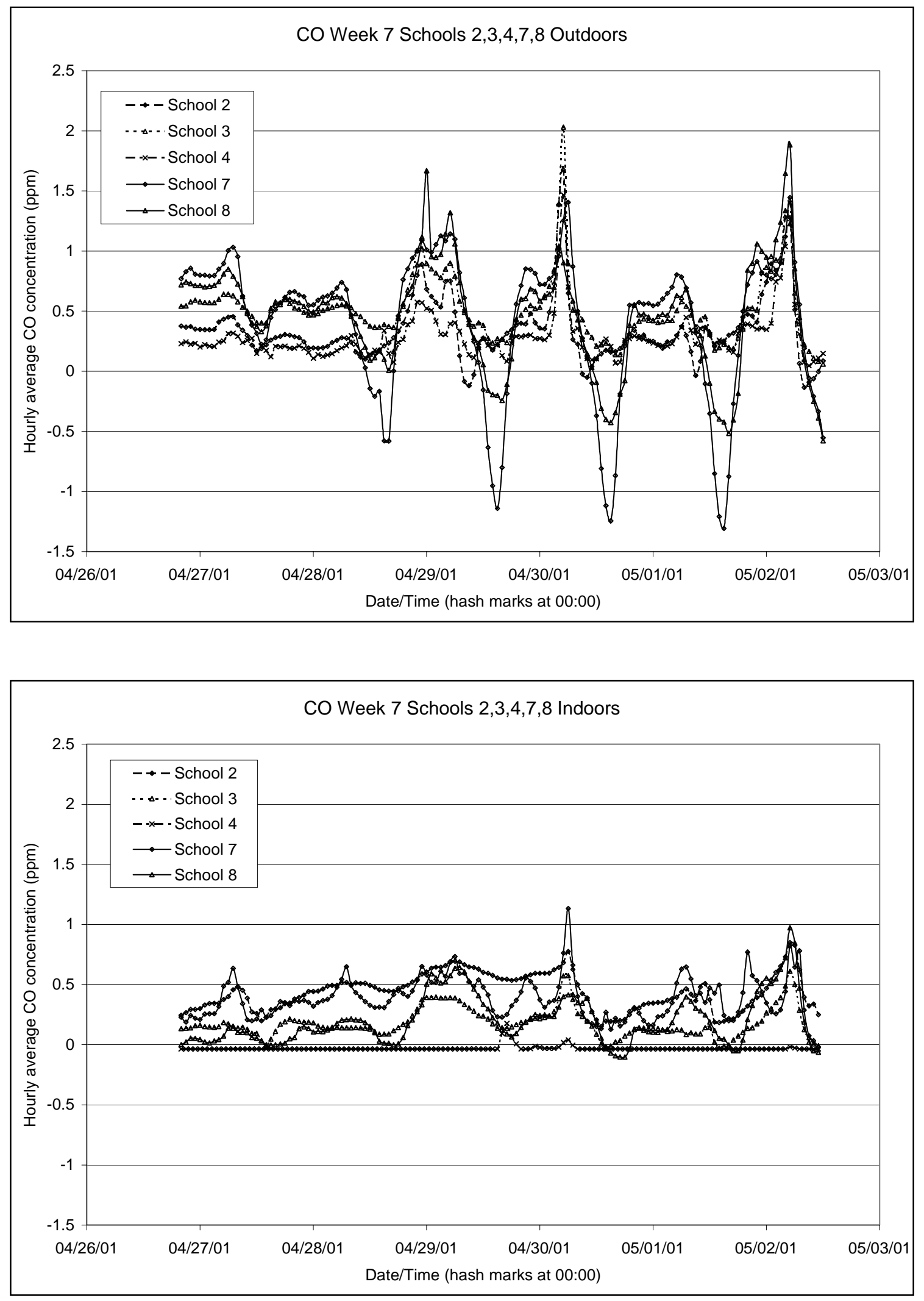

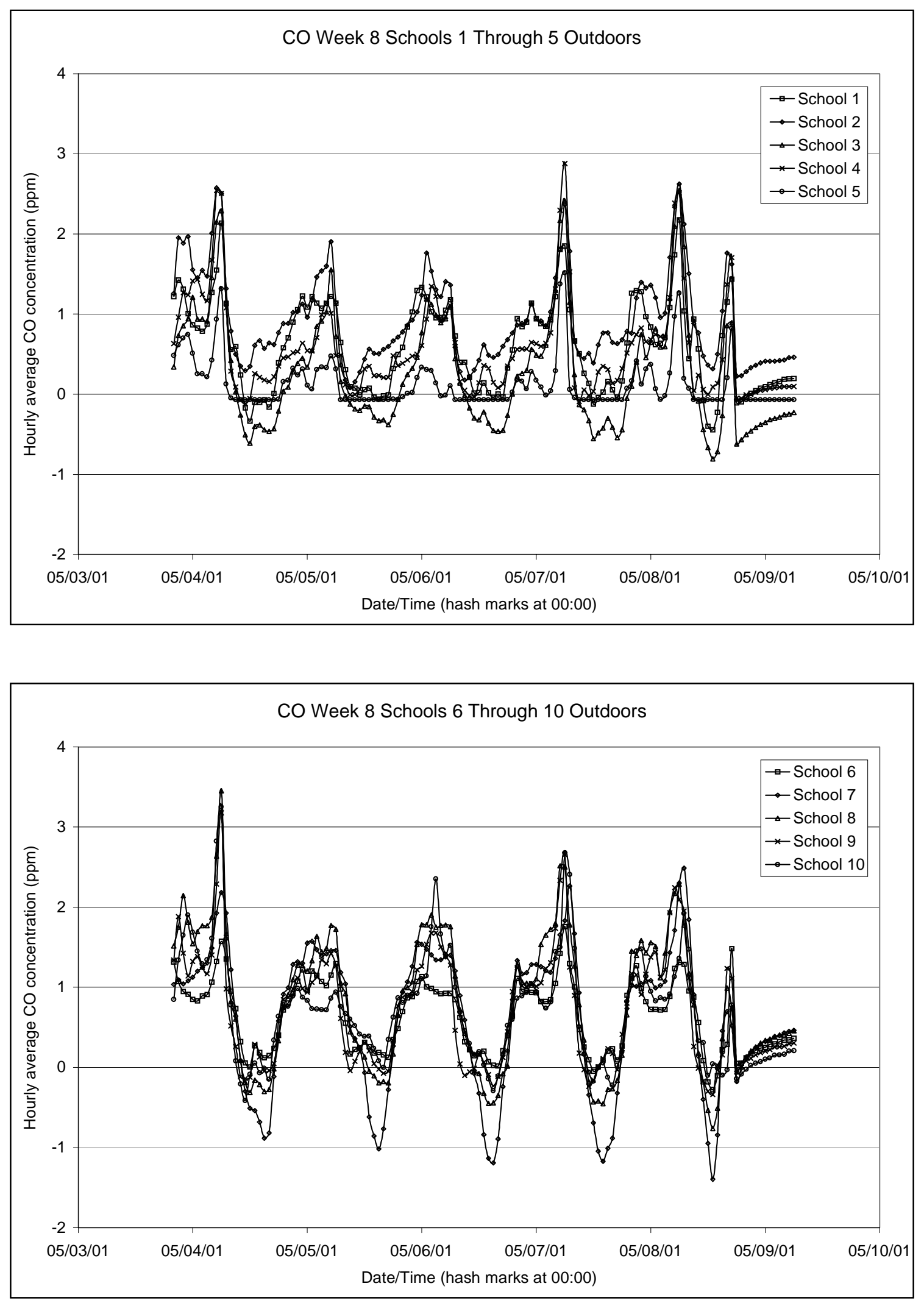

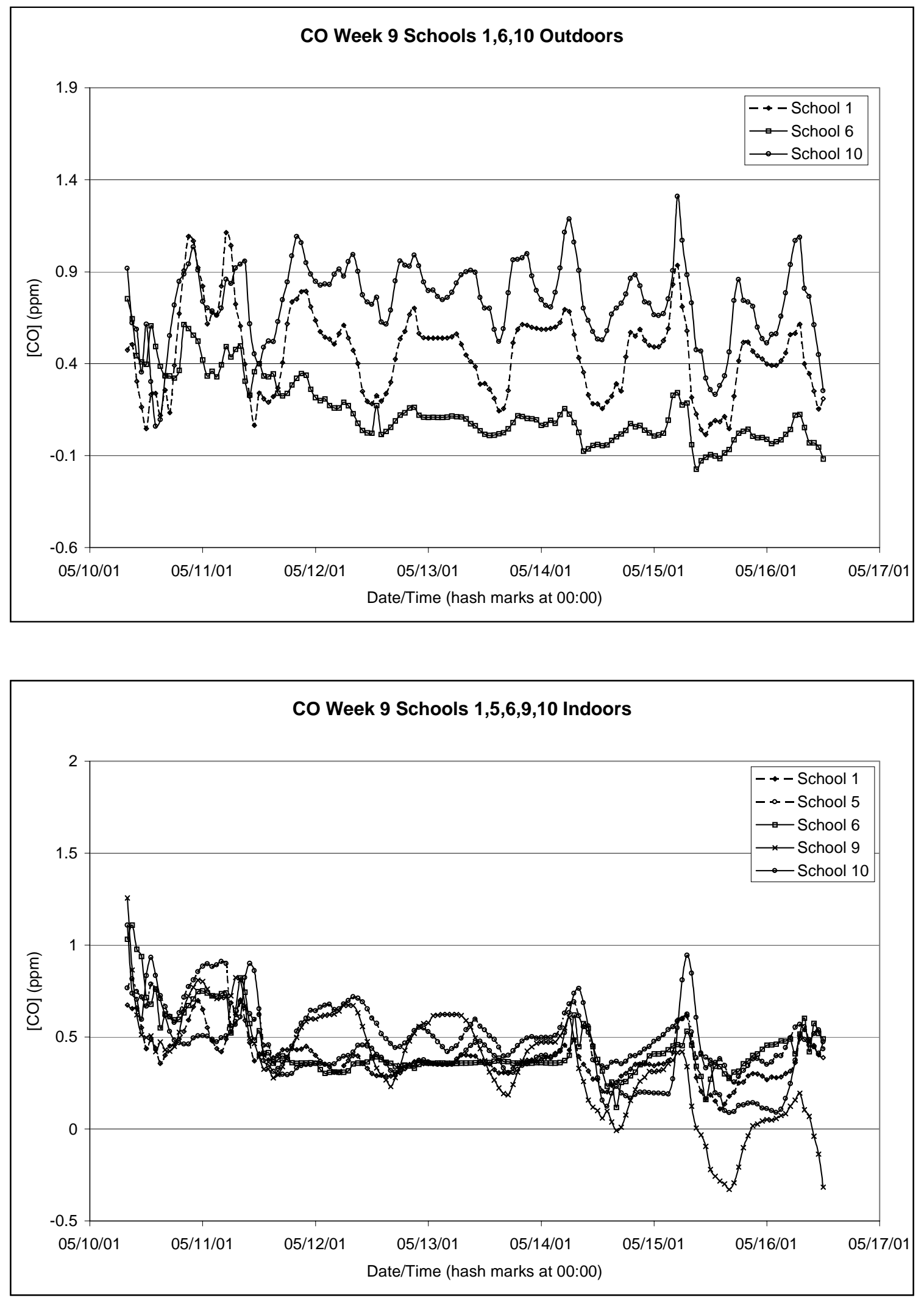

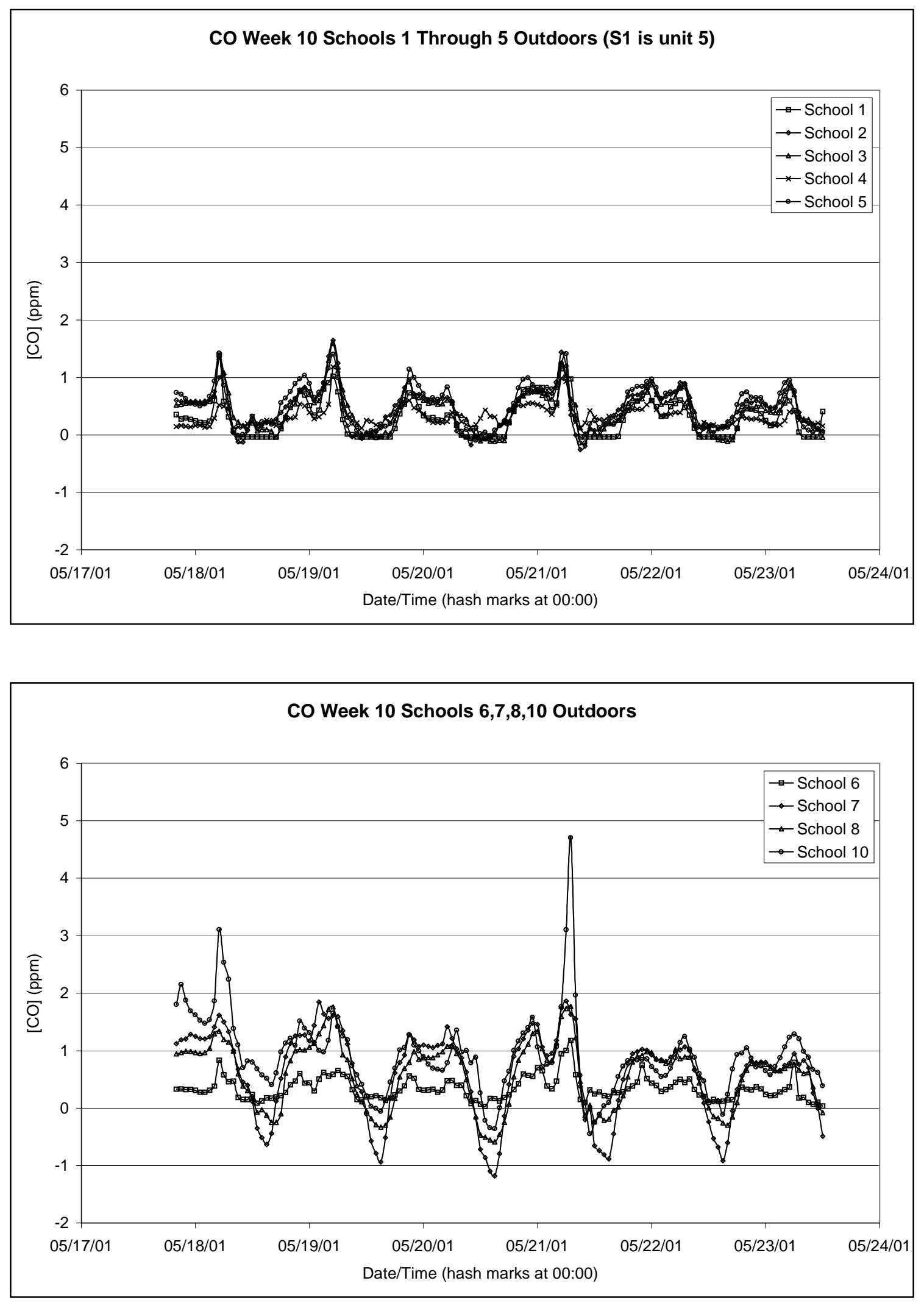

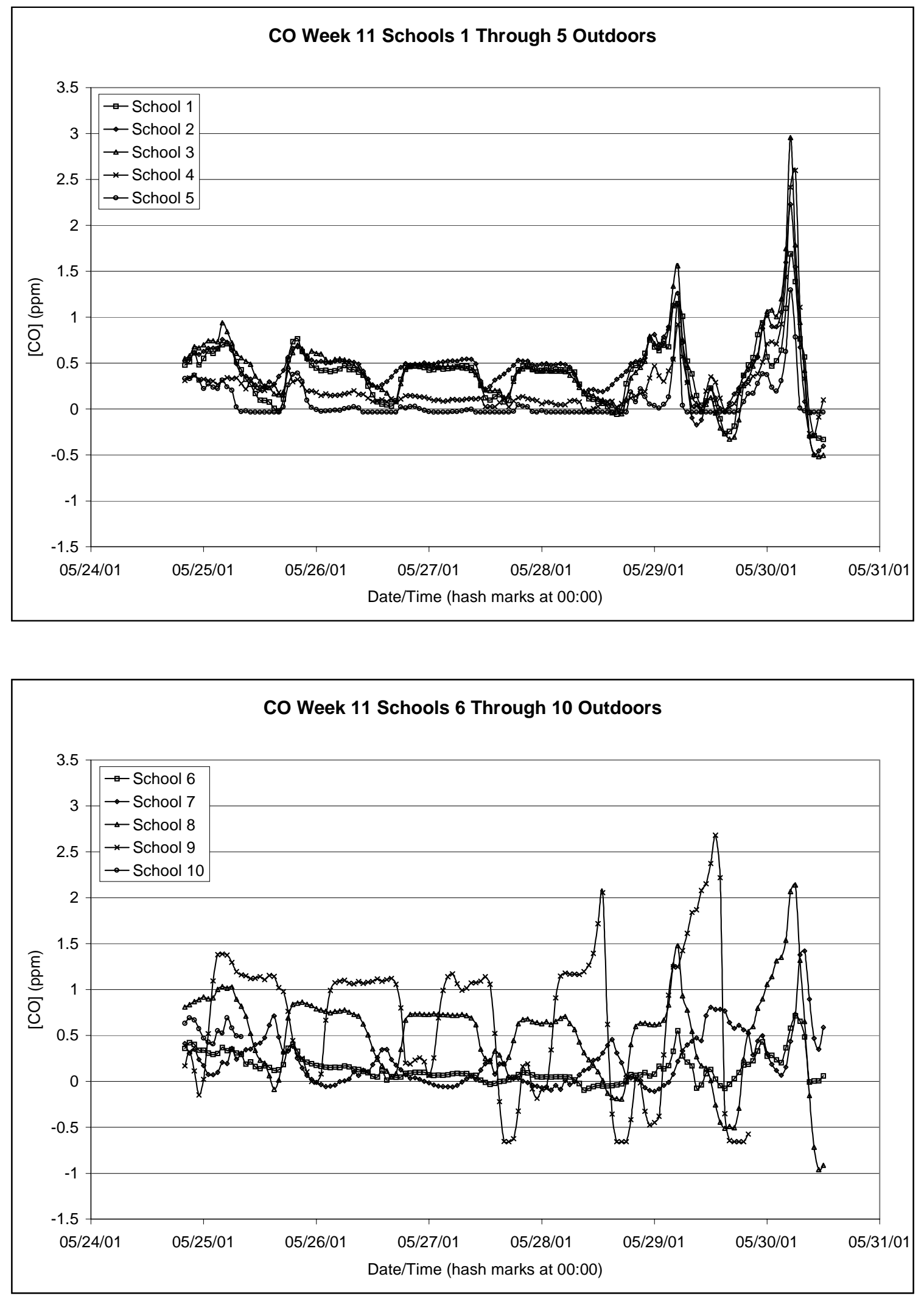

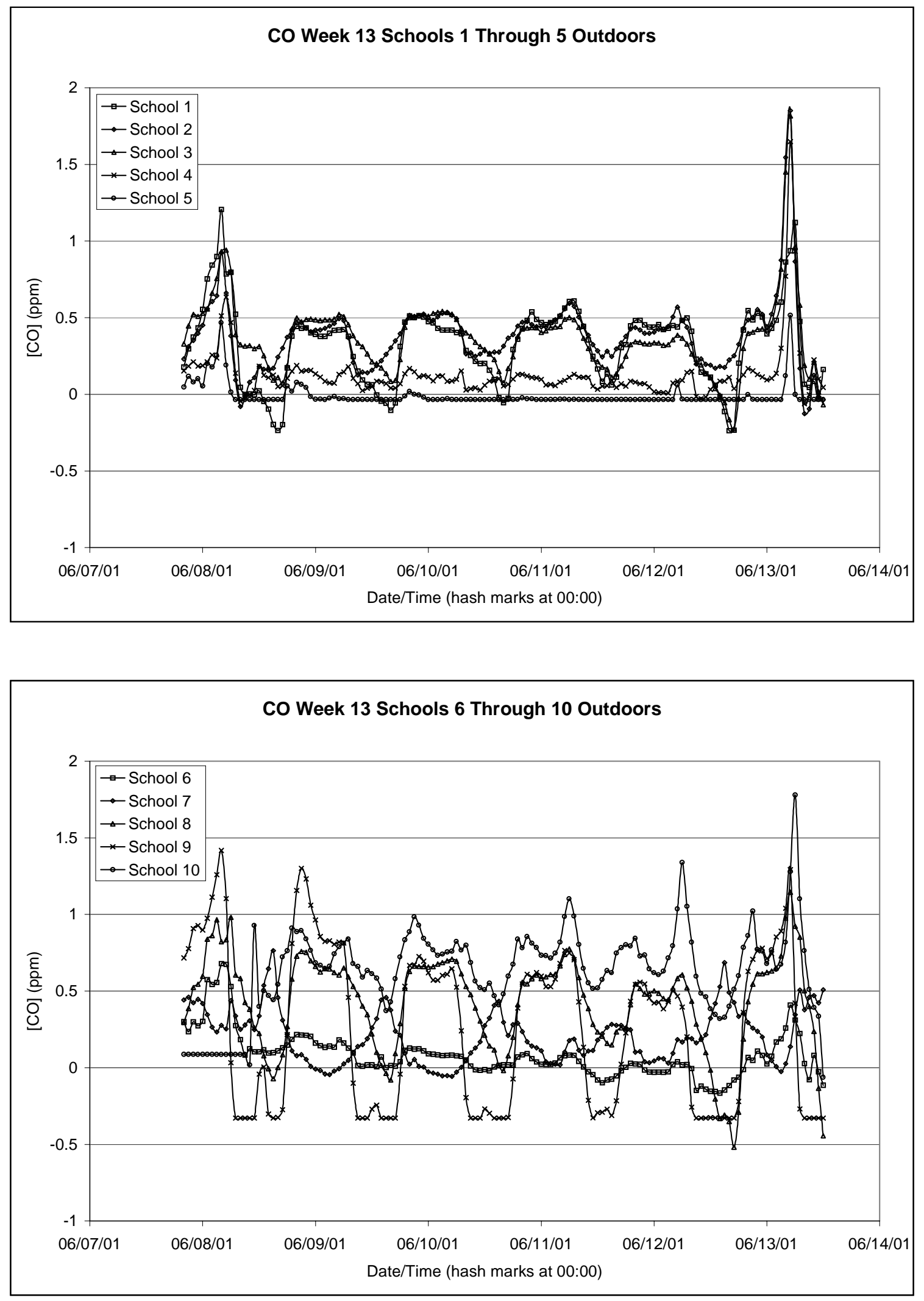

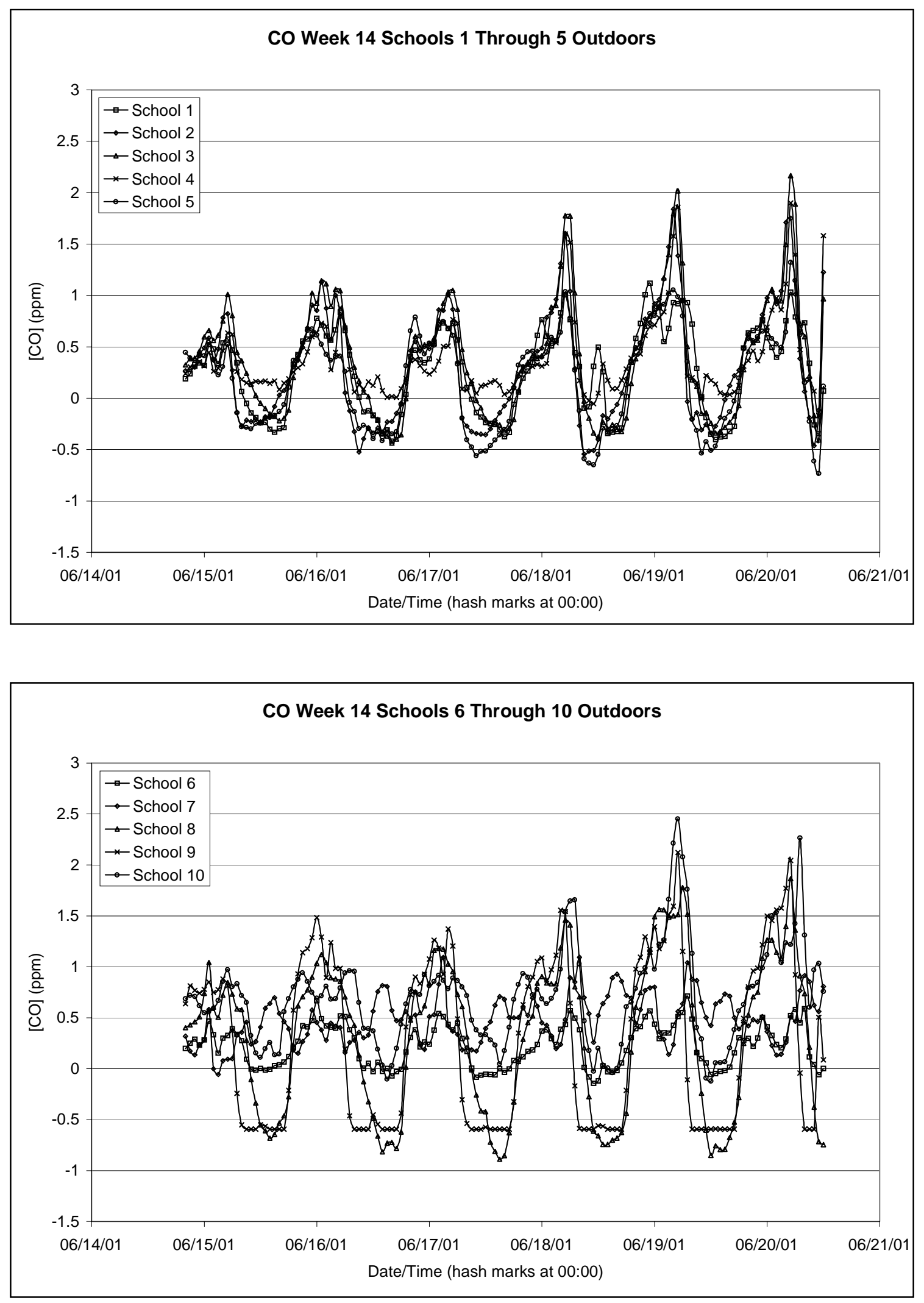
C-14 


\section{Appendix D. Plots of Hourly Average Carbon Monoxide (CO) Concentrations at All Schools Over Fall Monitoring Period}

Carbon Monoxide concentrations were monitored at each school with electrochemical

sensor based instruments. Hourly average concentrations at each school are shown in the following plots for all weeks in which monitoring was conducted. 

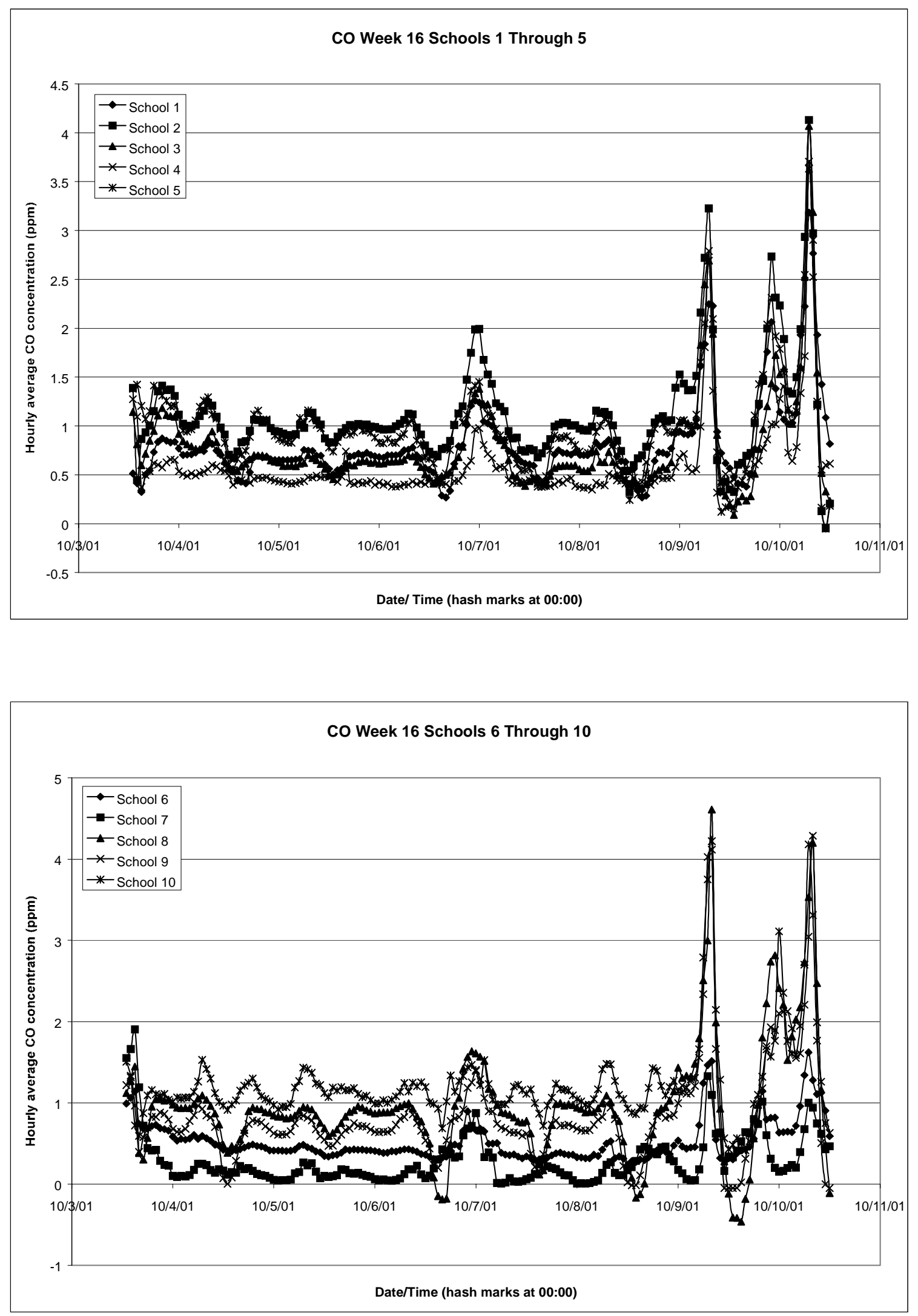

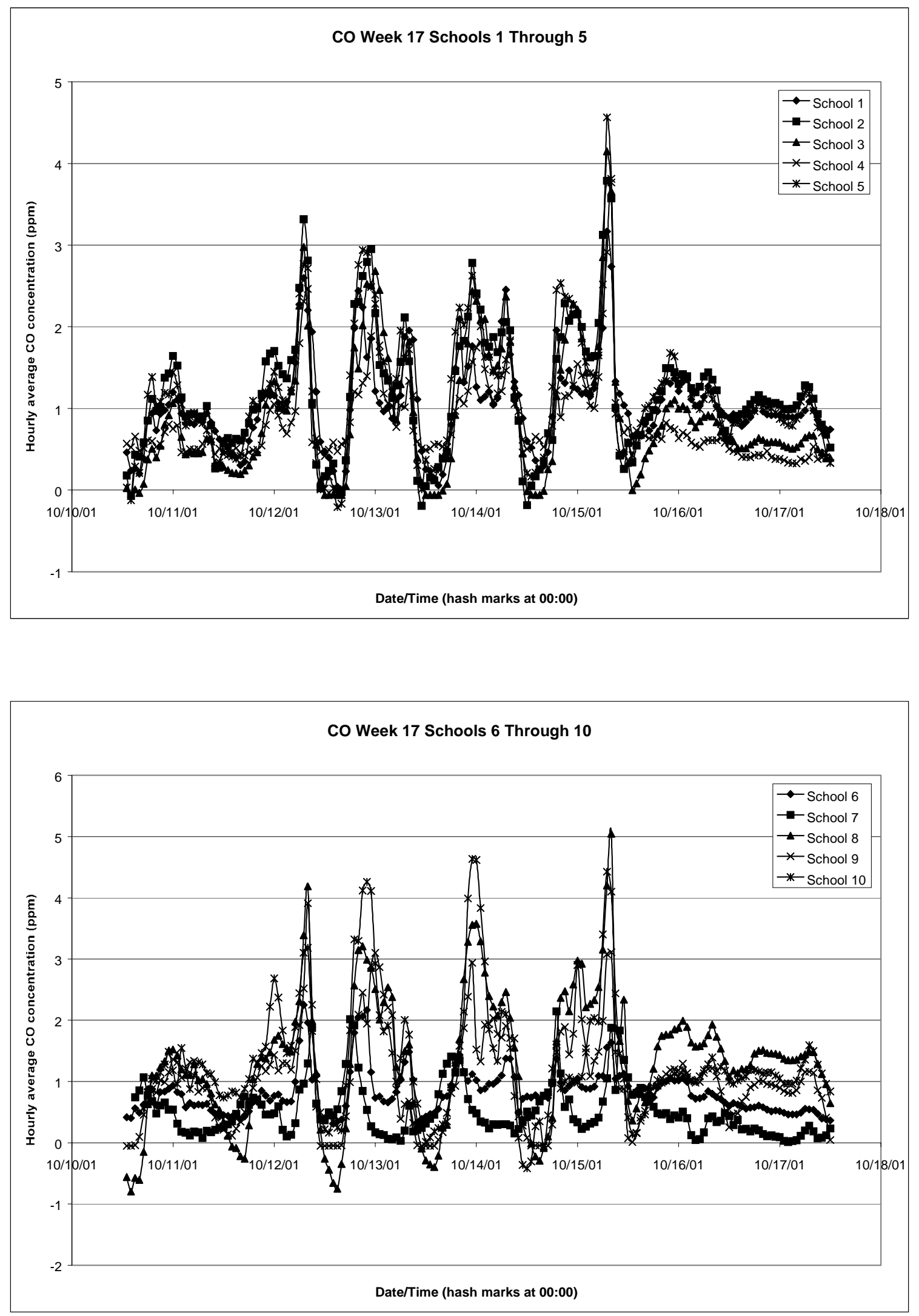

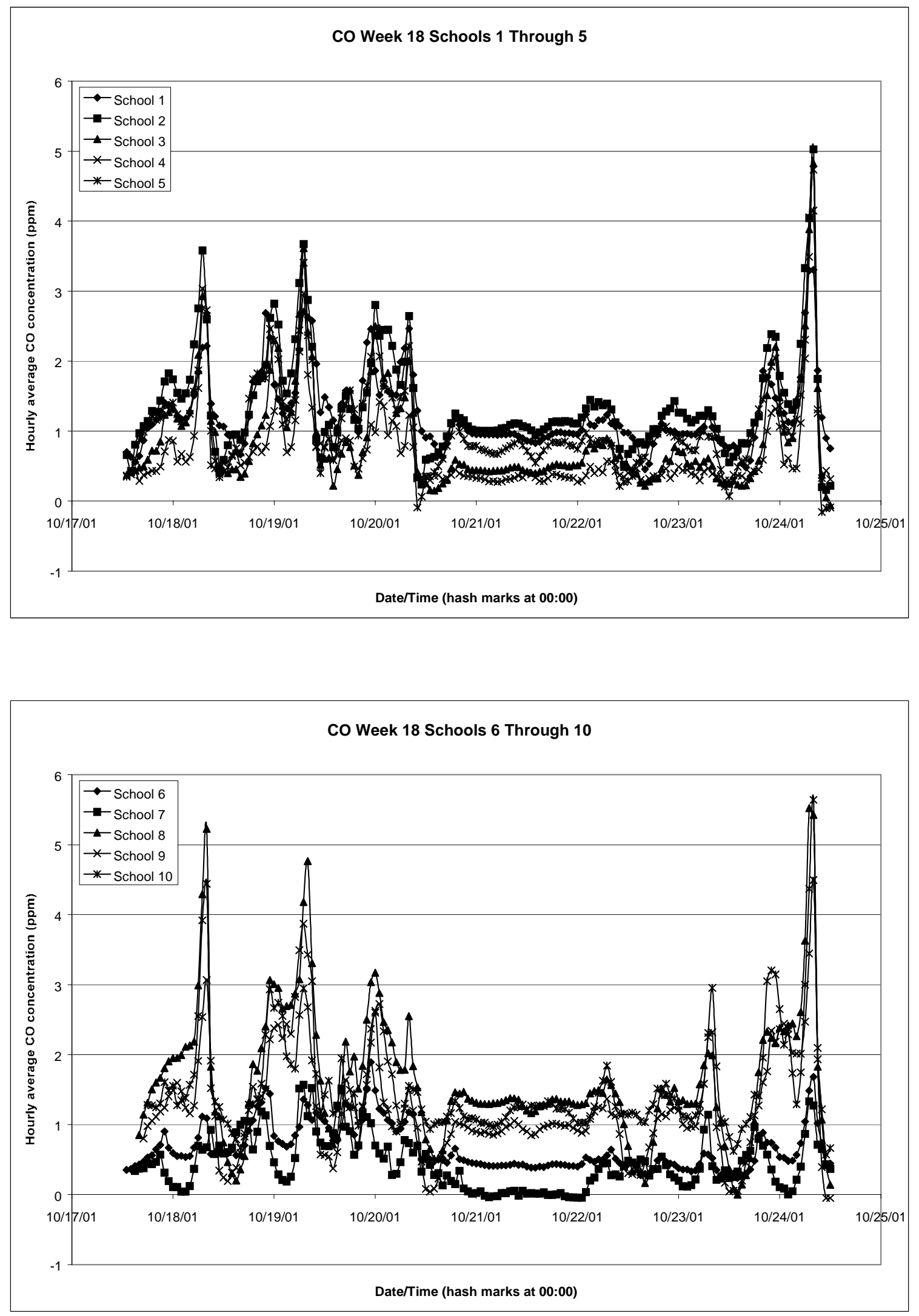

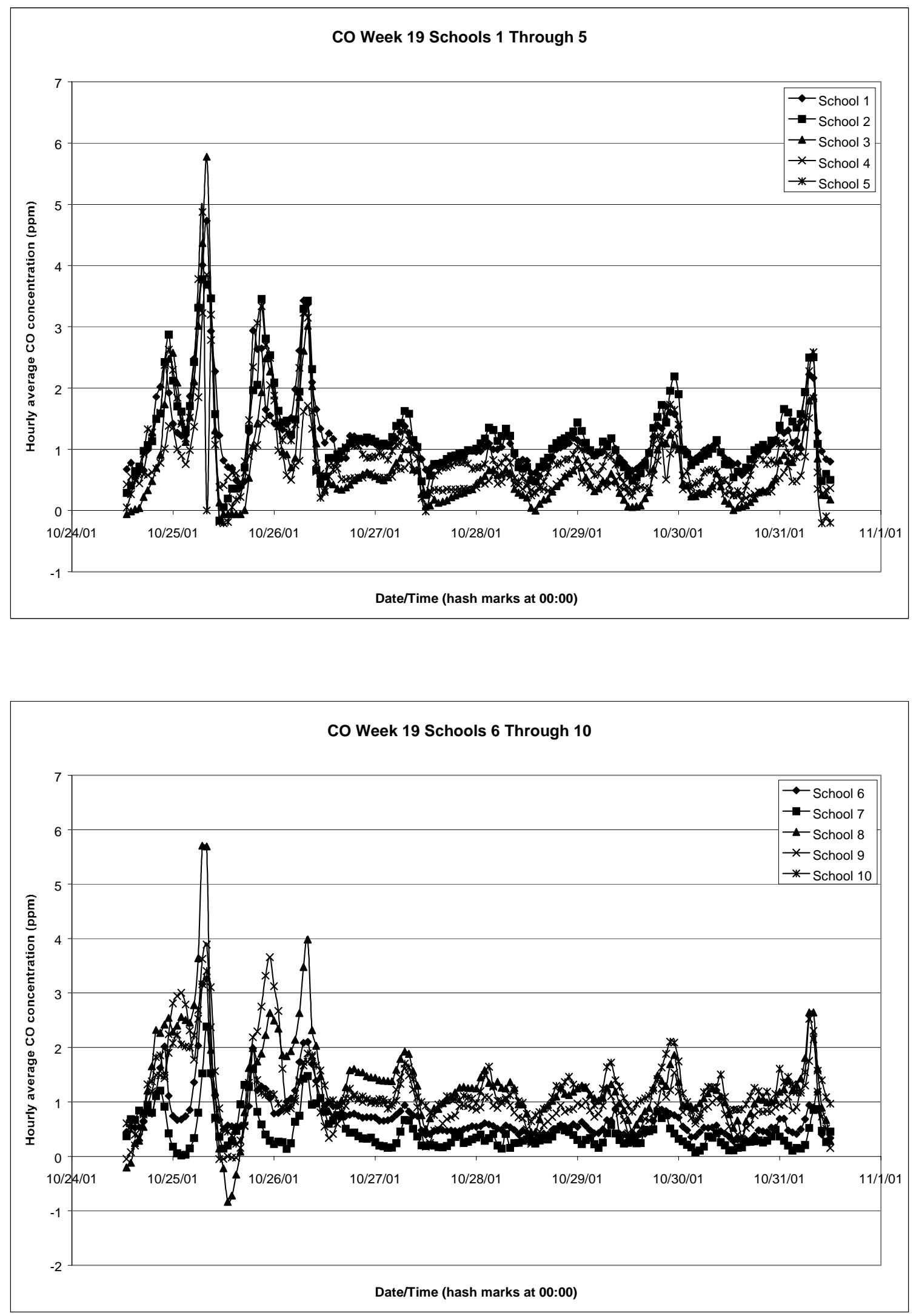

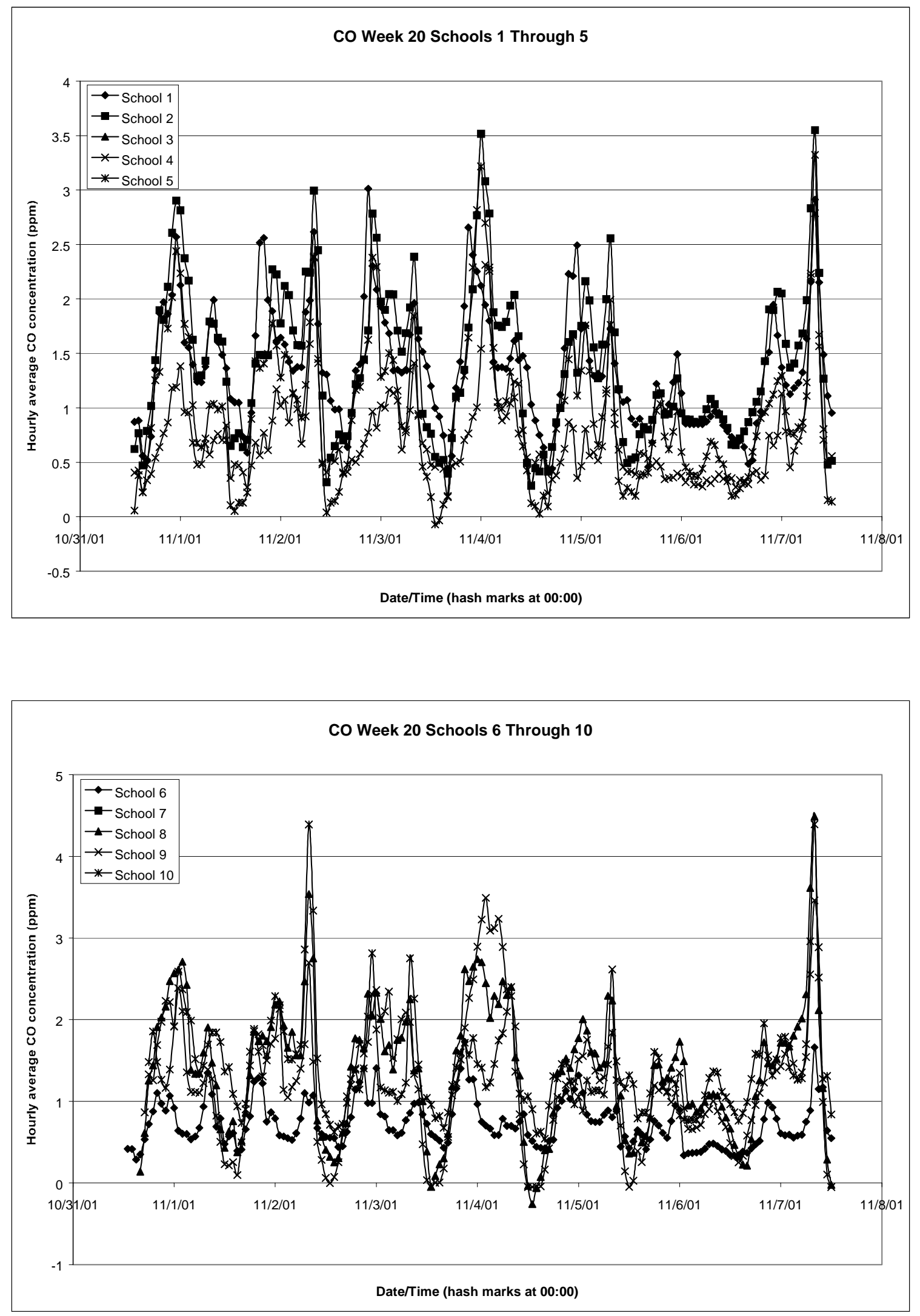

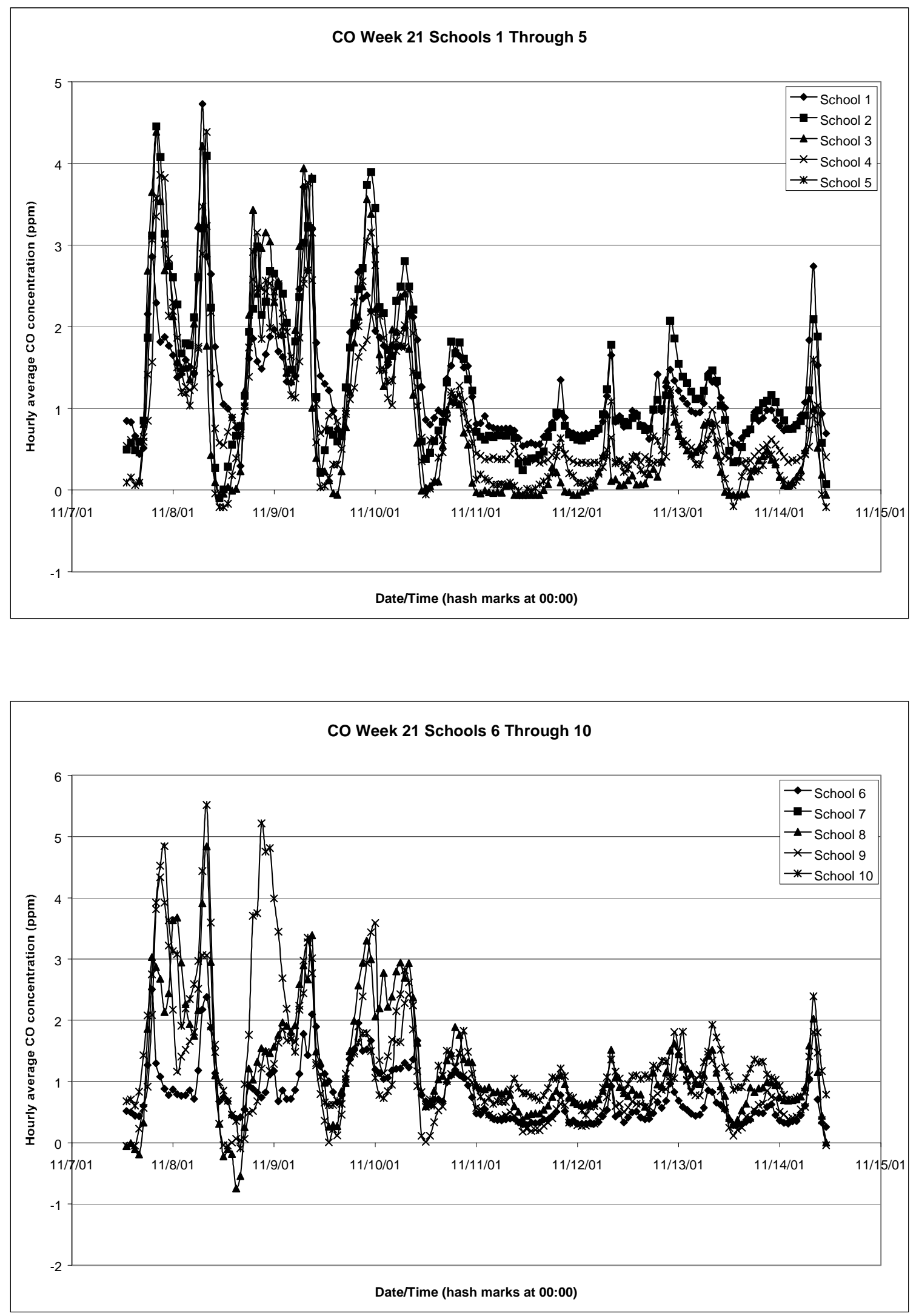

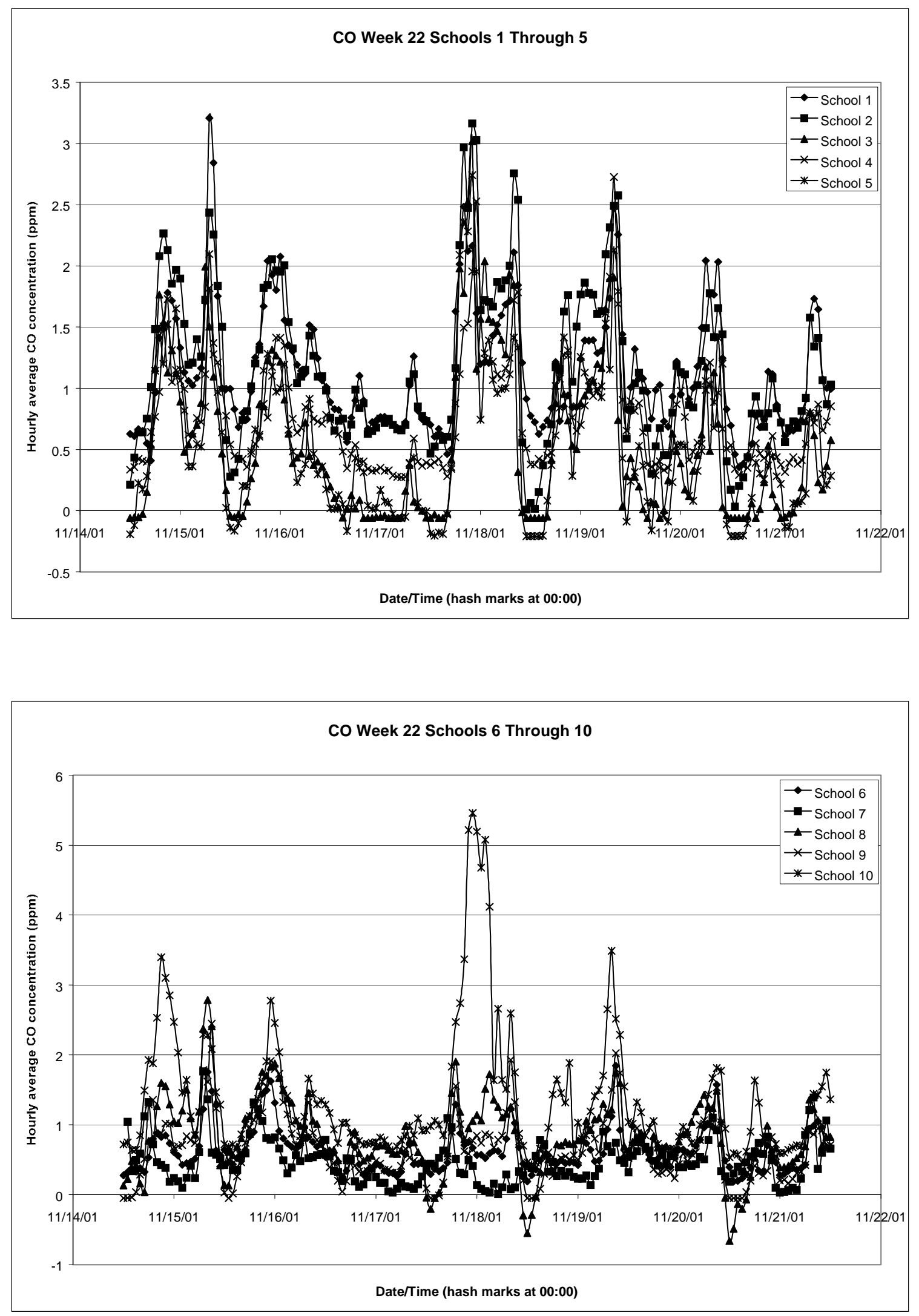